\title{
Mine-to-Mill Optimization of Aggregate Production
}

\author{
Final Report
}

Reporting Period:

6/5/04-9/30/06

Submitted by:

Greg Adel $^{1}$

Toni Kojovic ${ }^{2}$

Darren Thornton ${ }^{2}$

November 2006

\section{DE-FC26-04NT42084}

${ }^{1}$ Department of Mining and Minerals Engineering

Virginia Polytechnic Institute \& State University

Blacksburg, Virginia 24061

${ }^{2}$ JKTech - JKMRC Commercial Division

The University of Queensland

Isles Road

Indooroopilly, Queensland 4068

Australia 


\section{DISCLAIMER}

"This report was prepared as an account of work sponsored by an agency of the United States Government. Neither the United States Government nor any agency thereof, nor any of their employees, makes any warranty, express or implied, or assumes any legal liability or responsibility for the accuracy, completeness, or usefulness of any information, apparatus, product, or process disclosed, or represents that its use would not infringe privately owned rights. Reference herein to any specific commercial product, process, or service by trade name, trademark, manufacturer, or otherwise does not necessarily constitute or imply its endorsement, recommendation, or favoring by the United States Government or any agency thereof. The views and opinions of authors expressed herein do not necessarily state or reflect those of the United States Government or any agency thereof." 


\section{ABSTRACT}

Mine-to-Mill optimization is a total systems approach to the reduction of energy and cost in mining and processing. Developed at the Julius Krutschnitt Mineral Research Centre in Queensland, Australia, the Mine-to-Mill approach attempts to minimize energy consumption through optimization of all steps in the size reduction process. The approach involves sampling and modeling of blasting and processing, followed by computer simulation to optimize the operation and develop alternatives. The most promising alternatives are implemented, and sampling is conducted to quantify benefits. In the current project, the primary objective was to adapt Mine-to-Mill technology to the aggregates industry. The first phase of this work was carried out at the Bealeton Quarry near Fredericksburg, Virginia. The second phase was carried out at the Pittsboro Quarry south of Chapel Hill, North Carolina. Both quarries are operated by Luck Stone Corporation of Richmond, Virginia.

As a result of the work, several conclusions can be drawn from the project which should assist DOE in assessing the applicability of the Mine-to-Mill approach to the aggregates industry.

1. Implementation of MTM guidelines at Pittsboro has resulted in tangible improvements in productivity. It is clear that MTM guidelines represent an energy savings of around $5 \%$ (primary and secondary) and an overall energy savings of $1 \%$. This 1-5\% energy savings is also consistent with simulated results for Bealeton had side-by-side shots used to evaluate the technology been carried out in the same rockmass.

2. Luck Stone clearly runs their operations at a high standard. Hence the percentage improvement realized in this project may represent the lower end of what might be expected overall in the aggregates industry.

3. Variability in ore types across both Bealeton and Pittsboro suggests a 2:1 difference in hardness which contradicts the misconception that quarry rock is homogenous. Therefore, the idea of comparing side-by-side blasts is not viable and long term comparisons stand the best chance of confirming the benefits of optimized blasting.

4. There are clear limitations on how much improvement can be made in the aggregate industry due to the fixed feed size that reports to the tertiary section of a typical aggregate plant. These limitations restrict the MTM approach from exercising significant increases in blasting which would only serve to increase fines and reduce product yield.

5. The key to success at Pittsboro was the development of MTM guidelines for the modified blasting practice in consultation with the drill \& blast crew. Their full buy-in was necessary to implement optimized blasting in a sustained manner.

6. The JKSimBlast and JKSimMet models have proven to be effective tools for examining blasting and processing at Bealeton and Pittsboro. These models should enable Luck Stone to transfer the MTM approach to other sites. 


\section{TABLE OF CONTENTS}

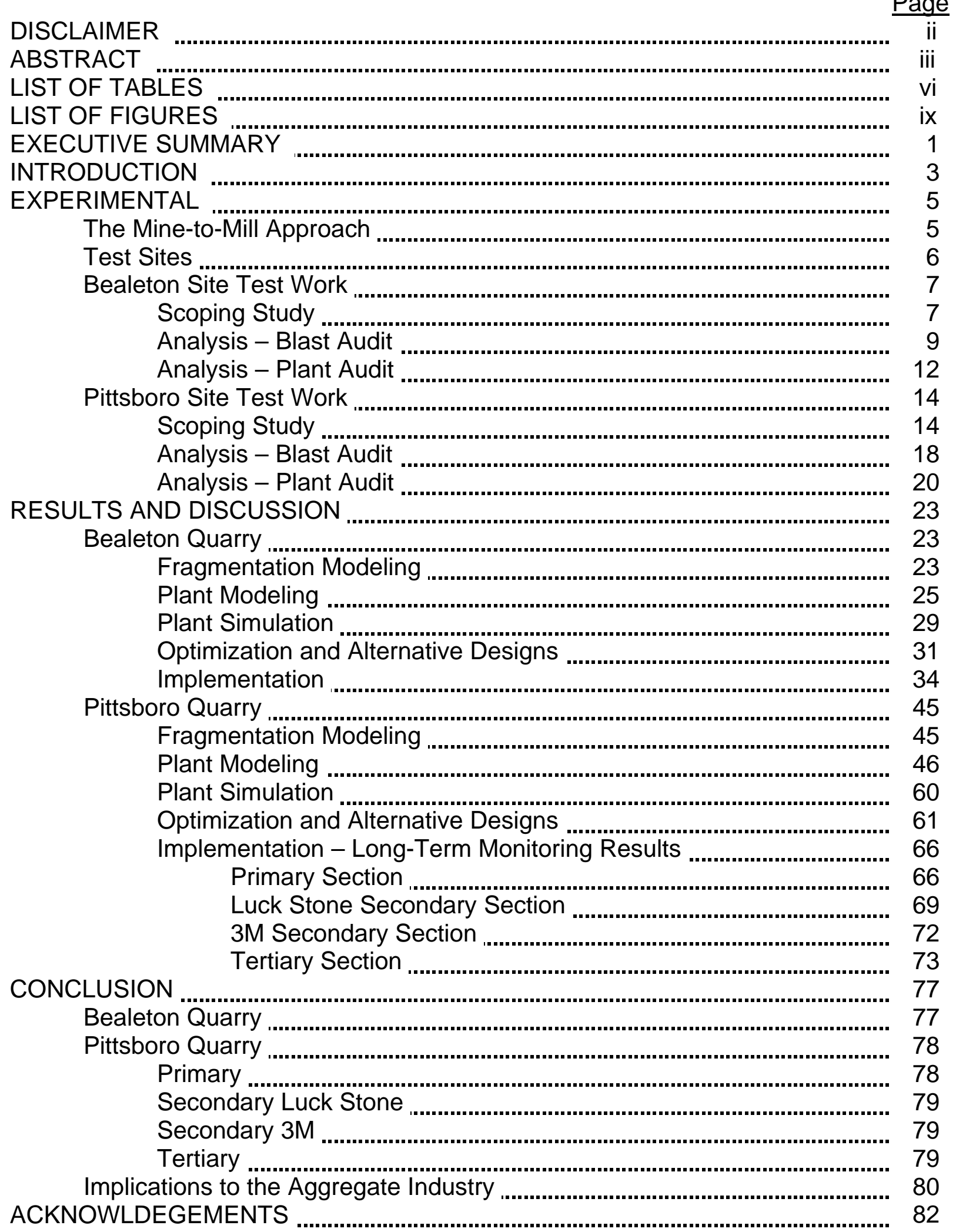




\section{TABLE OF CONTENTS (Continued)}

\begin{tabular}{|c|c|}
\hline \multicolumn{2}{|r|}{$\underline{\text { Page }}$} \\
\hline REFERENCES & 83 \\
\hline DPENDIX I - Summary of JKMRC Drop Weight Breakage Test Results & 85 \\
\hline APPENDIX II - Summary of Crusher Settings and Sampling Details ........ & 94 \\
\hline 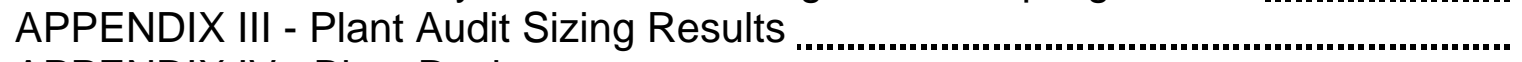 & 97 \\
\hline NDIX IV - Blast Designs ............................. & 152 \\
\hline
\end{tabular}




\section{LIST OF TABLES}

Table 1. Fragmentation Model Input Parameters for Blast 2904.

Page

Table 2. Summary of Impact Breakage Test Results. 25

Table 3. Summary of Crusher Ore Parameters - Bealeton Diabase. 26

a. Appearance Function Data, $\mathrm{t}_{\mathrm{n}}(\%)$,

b. Size Reduction/Specific Comminution Energy, Ecs (kWh/t)

Table 4. Comparison of Audit and Mass Balance Tonnage Rates for Bealeton Secondary Plant - Audit 1 (@ 518 tph).

Table 5. Summary of JKSimMet Crusher Model Parameters. ............................ 28

Table 6. JKSimMet Screen Model Parameters. .................................................... 29

Table 7. Comparison of Measured and Simulated Results

for Audit Baseline Data.

Table 8. Comparison of Blast Design Specifications for the Baseline Blast Design (2904) and the Alternative Blast Design (D1).

Table 9. Comparison between LS and MTM Blast Implementations.

Table 10. Estimated Volume of Rock that could be considered Free-Faced.

Table 11. Comparison of Energy Consumptions between

Luck Stone and MTM.

Table 12. Comparison of Luck Stone and MTM Production Rates.

Table 13. Comparison of Primary Plant Performance (all shot material).

Table 14. Fragmentation Model Input Parameters for Blast 8605.

Table 15. Summary of Ore Breakage Test Results.

Table 16. Summary of Secondary Plant Survey Results.

Table 17. Comparison of Audit and Fitted Tonnage Rates for Pittsboro Secondary Plant - LS Side (Survey 7 @ 463 tph).

Table 18. Comparison of Audit and Fitted Tonnage Rates for Pittsboro Tertiary Plant (Survey $2 @ 135$ tph). 


\section{LIST OF TABLES (Continued)}

Table 19. Summary of JKSimMet Primary Crusher Model Parameters

Page and Operating Conditions.

Table 20. Summary of JKSimMet Secondary Cone Crusher Model Parameters and Operating Conditions.

Table 21. Summary of JKSimMet Tertiary Cone Crusher Model Parameters and Operating Conditions.

Table 22. JKSimMet Screen Model Parameters - Primary.

Table 23. JKSimMet Screen Model Parameters - Secondary. 58

Table 24. JKSimMet Screen Model Parameters - Tertiary. 58

Table 25. JKSimMet Screen Model Parameters - Bivitec Screen. 59

Table 26. Comparison of Energy Consumptions for Pittsboro. 59

Table 27. Proposed Blast Design Guidelines. 63

Table 28. Comparison of Current Practice with Expected Benefits under New Blast Design Guidelines (based on computer simulations).

Table 29. Production Totals for Primary Crushing - Baseline Period.

Table 30. Production Totals for Primary Crushing - MTM Period. 67

Table 31. Production Rates for Primary Crushing - Baseline Period.

Table 32. Production Rates for Primary Crushing - MTM Period. 68

Table 33. Production Totals for LS Secondary Crushing. 70

Table 34. Production Rates for LS Secondary Crushing - Baseline Period. ..... 70

Table 35. Production Rates for LS Secondary Crushing - MTM Period. ........... 70

Table 36. Production Totals for 3M Secondary Crushing. ................................. 72

Table 37. Production Rates for 3M Secondary Crushing - Baseline Period. ..... 72

Table 38. Production Rates for 3M Secondary Crushing - MTM Period. 73 


\section{LIST OF TABLES (Continued)}

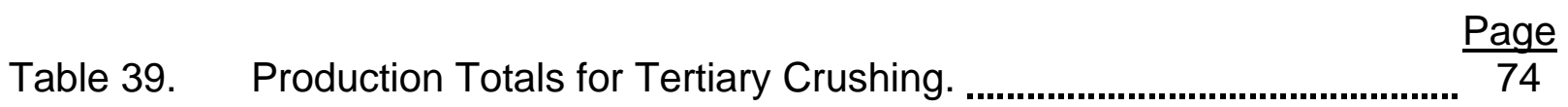

Table 40. Production Rates for Tertiary Crushing - Baseline Period. ................ 74

Table 41. Production Rates for Tertiary Crushing - MTM Period. ...................... 75 


\section{LIST OF FIGURES}

Figure 1. Photograph of the muck pile at the Bealeton Quarry showing large pieces of rock produced during blasting. ..................................... 7

Page

Figure 2. The Bealeton plant flowsheet. .......................................................... 8

Figure 3. Plan of Blast 2904 with surface initiation. .......................................... 10

Figure 4. Easterly view of Blast 2904 with blasted muck pile to the left. ........... 10

Figure 5. Explosive energy distribution in Blast 2904 at mid-bench level. ........ 11

Figure 6. Photograph of Blast 2904 soon after initiation clearly showing oversize blocks in the free face and stemming region.

Figure 7. Bealeton plant sampling layout.

Figure 8. Aerial view of the Pittsboro Quarry showing the areas of andesite mined for $3 \mathrm{M}$. The northwest corner of the quarry is the area being studied in this investigation.

Figure 9. Pittsboro plant flowsheet. .................................................................. 16

Figure 10. Plan of Blast 8605 with surface initiation; inset shows face profile. ... 18

Figure 11. Northerly view of blast 8605. ............................................................ 19

Figure 12. Photograph of blast 8605 soon after initiation clearly showing minimal stemming region and good face movement; second photo shows muckpile.

Figure 13. Pittsboro plant sampling layout. ....................................................... 21

Figure 14. Bealeton ROM size distributions. ....................................................... 24

Figure 15. Comparison of audit and mass balance sizing results for Bealeton secondary plant - audit 1 (@ 518 tph, gap=47.2 mm).

Figure 16. Comparison of mass balance and model predicted sizing results for Bealeton plant audits.

Figure 17. Simulation results for the Bealeton plant, showing key measured and simulated size distributions. 


\section{LIST OF FIGURES (Continued)}

Figure 18. Comparison of alternative blast designs.

Figure 19. LS (0105) and MTM (0305) shots prior to side-by-side testing. 35

Figure 20. Comparison of ROM fragmentation measured by Split for the LS (0105) and MTM (0305) blasts.

Figure 21. Comparison of size distributions estimated by modeling and Split (LS shot - 0105, MTM shot - 0305).

Figure 22. Photograph of the LS blast clearly showing oversize blocks in the free face.

Figure 23. Photograph of the MTM blast clearly showing oversize blocks in the free face and stemming zones.

Figure 24. Liberated blocks in the back wall after the LS blast.

These blocks are in the front face of the MTM blast.

Figure 25. Plan view of the area that could be considered free-faced for the LS (0105) and MTM (0305) shots.

Figure 26. The surface of the LS (left) and MTM (right) muck piles - note the color of the oversize material.

Figure 27. Oversize rocks from the MTM blast that have been set aside.

Figure 28. Effect of rockmass on the size distributions (estimated by modeling).

Figure 29. Pittsboro ROM Fragmentation for Blast 8605, model prediction and Split size analysis.

Figure 30. Example of Pittsboro ore variability; test shot face and C2 sample. ..

Figure 31. Comparison of audit and fitted sizing results for Pittsboro primary plant survey - LS side (@ 1385 tph, gap=146 mm).

Figure 32. Example of LS secondary plant with split flowsheet concept used in mass balancing and model fitting. 


\section{LIST OF FIGURES (Continued)}

Figure 33. Comparison of audit and fitted sizing results for Pittsboro

Page

secondary plant survey 7 - LS side (@ 463 tph, gap=44.5 mm). ..... 50

Figure 34. Representation of the Bivtec screen using 5 screens in series, both top and bottom decks modeled separately.

Figure 35. Comparison of audit and fitted sizing results for Bivitec screen (Survey $7 @ 161$ tph screen feed rate).

Figure 36. Comparison of audit and fitted sizing results for Pittsboro secondary plant survey - 3M side (@ 633 tph, gap=51 mm).

Figure 37. LS tertiary plant with split flowsheet concept used in model fitting. ... 53

Figure 38. Comparison of mass balance and fitted sizing results for Pittsboro tertiary plant (Survey 2 @ 135 tph, gap=22 mm).

Figure 39. JKSimMet baseline flowsheet for Pittsboro 3M plant. ......................... 60

Figure 40. JKSimMet baseline flowsheet for Pittsboro Luck Stone plant. ............ 61

Figure 41. Blast design definitions. ................................................................... 63

Figure 42. Example of surface timing. ............................................................... 65

Figure 43. Comparison of frequency distributions for LS and 3M primary crusher throughput rates.

Figure 44. Comparison of frequency distributions for LS secondary plant throughput rates.

Figure 45. Comparison of frequency distributions for $3 \mathrm{M}$ secondary plant throughput rates.

Figure 46. Comparison of frequency distributions for tertiary plant throughput rates. 


\section{EXECUTIVE SUMMARY}

Mine-to-Mill optimization is a total systems approach to the reduction of energy and cost in mining and processing. Developed at the Julius Krutschnitt Mineral Research Centre in Queensland, Australia, the Mine-to-Mill approach attempts to minimize energy consumption through optimization of all steps in the size reduction process. The approach involves sampling and modeling of blasting and processing, followed by computer simulation to optimize the operation and develop alternatives. The most promising alternatives are implemented, and sampling is conducted to quantify benefits.

In the current project, the primary objective was to adapt Mine-to-Mill technology to the aggregates industry. The first phase of this work was carried out at the Bealeton Quarry near Fredericksburg, Virginia. The second phase was carried out at the Pittsboro Quarry south of Chapel Hill, North Carolina. Both quarries are operated by Luck Stone Corporation of Richmond, Virginia.

In June 2004, a sampling campaign was conducted at the Bealeton Quarry to quantify the performance of the current operation. Based on data collected, blasting and processing operations were modeled. These models were used to simulate the affect of blast design on ROM fragmentation, throughput, energy consumption and final product yields. On the basis of simulations, it was determined that there was scope to reduce energy consumption by $4-5 \%$ through changes in blast design. These changes were implemented and a side-by-side comparison was conducted with one shot following Luck Stone (LS) practice and a second shot following Mine-to-Mill (MTM) recommendations. Both shots were audited to provide a quantitative comparison.

The plant audits suggest the MTM blast yielded a finer primary, secondary and tertiary feed than the corresponding LS shot. The audits further indicate that the MTM material was easier to treat, resulting in higher throughputs and an energy reduction of $11.7 \%$.

Unfortunately, the results obtained from the complete processing of each shot were inconclusive since the MTM shot was much blockier than the LS shot. This resulted in more oversize and a reduction in excavator productivity. Thus, despite the additional energy in the MTM blast, the rockmass properties appear to have mitigated the benefits. Had both shots been implemented in the same rockmass, simulations indicate that the MTM design would have reduced overall energy consumption by $5-6 \%$. In hindsight, it appears the most difficult issue in quantifying the benefits of Mine-to-Mill optimization in an aggregate context might be the method of comparison. Clearly, side-by-side benches are no guarantee of similar rockmass.

In August 2005, blasting and processing operations at the Pittsboro Quarry were audited and modeled. The models were used to investigate a range of blast designs aimed at reducing the amount of oversize while not increasing the percent crusher run. According to simulations, the modified blast designs were expected to increase primary throughput by $15 \%$ and secondary throughput by $6 \%$, with an overall energy reduction of $1 \%$. Tertiary plant performance and product yields were not expected to change. 
Based on lessons learned at the Bealeton Quarry, a 3-month implementation phase was used to evaluate the impact of MTM changes. Monitoring results from April to June, 2006, were analyzed and compared with three months of production data collected prior to the implementation of MTM guidelines (baseline period). Key conclusions from the long-term monitoring analysis are as follows:

- MTM guidelines led to improved productivity in the primary crushing stage, but at higher energy. This suggests the rock fed to the crusher was harder than the baseline material. Based on a comparison of June and December results, which reflect similar rock hardness, MTM production rates were 9\% higher and the MTM approach would have realized a 9\% energy savings had the rock stayed the same.

- The MTM period shows a $6 \%$ improvement in production rate at the secondary crusher. In terms of energy saving, the MTM approach achieved a $2 \%$ reduction.

- At the tertiary stage, the figures suggest the MTM guidelines did not make a significant impact on tertiary throughput. In terms of energy consumption, it also appears the change is negligible.

Several conclusions can be drawn from the project which should assist DOE in assessing the applicability of the Mine-to-Mill approach to the aggregates industry.

7. Implementation of MTM guidelines at Pittsboro has led to tangible improvements in productivity. It is clear that MTM guidelines represent an energy savings of around $5 \%$ (primary and secondary) and an overall energy savings of $1 \%$. This $1-5 \%$ energy savings is also consistent with simulated results for Bealeton had the sideby-side shots been carried out on the same material.

8. Luck Stone clearly runs their operations at a high standard. Hence the percentage improvement realized here may represent the lower end of what might be expected overall in the aggregates industry.

9. Variability in ore types across both Bealeton and Pittsboro suggests a 2:1 difference in hardness which contradicts the misconception that quarry rock is homogenous. Therefore, the idea of comparing side-by-side blasts is not viable and long term comparisons stand the best chance of confirming the benefits of optimized blasting.

10. There are clear limitations on how much improvement can be made in the aggregate industry due to the fixed feed size that reports to the tertiary section. These limitations restrict the MTM approach from exercising significant increases in blasting which would only serve to increase fines and reduce product yield.

11. The key to success at Pittsboro was the development of MTM guidelines for the modified blasting practice in consultation with the drill \& blast crew. Their full buy-in was necessary to implement optimized blasting in a sustained manner.

12. The JKSimBlast and JKSimMet models have proven to be effective tools for examining blasting and processing at Bealeton and Pittsboro. These models should enable Luck Stone to transfer the MTM approach to other sites. 


\section{INTRODUCTION}

The production of a mineral commodity is a two-stage process involving mining to extract the commodity and processing to convert the commodity into a marketable end product. Traditionally, these two stages have been viewed as self-contained entities. In fact, great strides have been made over the years in the stand-alone optimization of each entity. Unfortunately, mining and processing are intimately linked, particularly in the area of particle size reduction. Thus, optimizing each stage separately without considering the total system often misses potential economic benefits and energy savings. This is particularly true in the aggregates industry where the sole objective is to produce crushed stone of various sizes. Since 1998, researchers at the Julius Kruttschnitt Mineral Research Centre (JKMRC) in Queensland, Australia, have been conducting Mine-to-Mill optimization research at operations throughout the world. Mineto-Mill, as the name implies, is the holistic approach to mining and mineral processing. Developed at the JKMRC, it provides a complete fragmentation and size reduction solution to maximize benefit. The entire operation is taken into account, from blasting to comminution, in order to optimize the size reduction process. Mine-to-Mill optimization has been successfully applied in gold, copper, and lead/zinc operations throughout the world producing increases in throughput from $5-18 \%$ and cost reductions in the neighborhood of 10\% (Atasoy et al., 2001; Grundstrom et al., 2001; Hart et al., 2001, Karageorgos et al., 2001, Paley and Kojovic, 2001, Valery et al., 2001).

The aggregates industry appears to be a perfect candidate for Mine-to-Mill optimization since its main focus is particle size reduction through blasting and crushing. The aggregates industry represents the largest segment of the U.S. mining industry accounting for more than two-thirds of the non-fuel minerals produced, and over half of all mined commodities when coal is included (Tepordei, 1999). In fact, 1.65 billion tonnes of crushed stone are produced annually in the U.S., at a value of over $\$ 10$ billion (Tepordei, 2006). Since a typical crushed stone quarry can consume between 1.3-1.8 $\mathrm{kWh} / \mathrm{t}$ (Smith, 2003), over 2.5 billion kWh of electrical energy are consumed per year by crushed stone production. Clearly, if there is a segment of the mining industry where energy saving research can have an impact, it is the aggregates industry.

Unfortunately, this major segment of the U.S. mining industry has been virtually ignored by researchers and funding agencies. Furthermore, Mine-to-Mill optimization has yet to be applied to the aggregates industry. The aggregates industry presents a unique challenge in that, unlike the metal mining industry, its goal is particle size control as opposed to particle size reduction. Whereas increased particle size reduction during blasting may be a benefit in the metal mining industry, it may actually be a detriment in the aggregates industry if the increased blasting energy results in the creation of fine particles that cannot be marketed. Thus, additional research is needed in order to translate the Mine-to-Mill approach to the aggregates industry.

The purpose of this project was to adapt the Australian Mine-to-Mill optimization technology to the U.S. aggregates industry. The project was carried out over 28 months by a team consisting of (i) Virginia Tech - project manager and prime contractor, (ii) 
Contract Support Services/JKTech representing JKMRC - subcontractor and provider of mine-to-mill expertise, (iii) Luck Stone - the 12th largest U.S. crushed stone producer providing locations for the test work, (iv) Austin Powder - providing support on blasting, and (v) Mellott Enterprises, Inc. - representing major equipment manufacturers and providing support on crushing and screening. The work was conducted at two Luck Stone quarries, the Bealeton Quarry near Fredericksburg, Virginia, and the Pittsboro Quarry, near Chapel Hill, North Carolina.

This report serves to summarize the mine-to-mill approach, results obtained, and conclusions drawn during this 28 month effort. 


\section{EXPERIMENTAL}

\section{The Mine-to-Mill Approach}

Mining and processing operations involve a variety of steps, each with their own attributes and requirements for efficiency. However, in some cases the conditions required to optimize any one of these steps may be counterproductive for the achievement of optimization in another. For example, at a crushed stone operation, increased blasting may make materials handling easier, but the excess fines generated may make subsequent particle size control at the crushing stage difficult. An approach is therefore warranted in which conditions for each step are varied so as to achieve global optimization.

Initially in the mine-to-mill scheme, the critical steps in the mining and processing route are identified after which they are modeled. Effective control is then possible by:

- characterization of appropriate in-situ ore properties,

- modeling and simulation of the performance of each step,

- simulation of the conditions to achieve overall optimum performance,

- implementation of a strategy to achieve optimum performance, and

- tracking and measurement of the ore and its properties throughout the various processes.

Clearly, the number of steps, their complexity, and interactions make trial-and-error attempts at achieving global optimization difficult and expensive. However, modeling and simulation offer a rapid, cost-effective route to a successful outcome. Over the years, researchers at the JKMRC have developed considerable expertise in the analysis and modeling of mining and processing operations, and the application of these models to mine-to-mill optimization. In fact, the term Mine-to-Mill ${ }^{\circledR}$ is a registered trademark of JKTech, the commercial arm of the JKMRC, and researchers at JKTech are recognized experts in this technology.

The main tools used in mine-to-mill optimization include two computer programs developed at the JKMRC and marketed by JKTech, JKSimBlast and JKSimMet (Higgins, 1998; Napier-Munn et al., 1999). JKSimBlast is a general-purpose blasting simulation package that includes CAD-like tools to create a complete blast design (holes, decks, and timing) with on-screen detonation simulation to check expected performance. Blasts can be analyzed and evaluated for energy, scatter, vibration, fragmentation, damage, and cost.

JKSimMet is a general-purpose mineral processing plant simulation package for the simulation and analysis of comminution and classification circuits. It allows the user to take raw plant data, construct a flowsheet of the process to be simulated, assign characteristics to the various process units and flows, and simulate the flows and size distributions. 
A typical mine-to-mill optimization effort includes four steps: (i) scoping study, (ii) analysis, (iii) optimization, and (iv) implementation. The scoping study consists of a site visit to review current mining and processing practices and discover possible areas for improvement. The analysis step involves a detailed survey of all aspects of a mining operation from blasting to crushing and screening. Rock domains are identified and rock mass characteristics are determined. Samples are collected around all crushers and screens under a variety of operating conditions in order to obtain information for use in the JKSimBlast and JKSimMet models. The data collected from the analysis step are used in the optimization step in conjunction with the JKSimBlast and JKSimMet computer packages to optimize the mine and plant operating strategies. Finally, the most promising operating strategies identified from the optimization step are used in the implementation step to improve the total system performance. Once again, a detailed analysis is an integral part of this final step in order to quantify any improvements made in the overall throughput, cost, or energy utilization of the operation. Throughout the mine-to-mill process, training and technology transfer are critical in order for benefits to be sustained at the operation being studied, as well as transferred to other operations within the company.

\section{Test Sites}

The test sites for this project were provided by Luck Stone. Luck Stone, the 12th largest producer of crushed stone and the largest privately owned and family-run construction aggregate company in the country, is headquartered in Richmond, Virginia. The company currently has 16 operating production facilities where aggregate is mined and crushed throughout Virginia and North Carolina, and is a major supplier of crushed stone for the highly populated Northern Virginia and Washington, D.C. areas.

The two test sites provided by Luck Stone include the Bealeton, Virginia plant and the Pittsboro, North Carolina plant. The Bealeton plant is located on Route 17 in Fauquier County, Virginia, about $32 \mathrm{~km}$ northwest of Fredericksburg. Luck Stone started this plant in 1988 to serve the growing area on the fringes of Northern Virginia. Bealeton mines a type of rock known as traprock by miners or diabase by geologists - a dense, igneous rock with a greenish-black to bluish-black color. This site currently produces over one million tonnes of crushed stone products per year.

The Pittsboro, North Carolina plant is located off of route 15, south of Chapel Hill. With the $3 \mathrm{M}$ Corporation as a major customer on site, this plant began to market material for the public market in April of 2002, and will grow its presence over the next few years. Pittsboro mines a green-colored andesite utilized on site by $3 \mathrm{M}$ for the production of roofing shingle granules. The plant also blends volcanic tuffs with other volcanic types for aggregate use. The two types of rock processed at this site provided a unique opportunity to look at the effect of rock type on the mine-to-mill optimization procedure. Pittsboro produces about 1.6 million tonnes of crushed stone products per year. 


\section{Bealeton Site Test Work}

Scoping Study: The project began in June 2004. The initial plan was to carry out test work at both sites simultaneously; however, changes in the mining plan at the Pittsboro site made it necessary to focus the first phase of the project on the Bealeton site.

Test work at the Bealeton site began with a scoping study to evaluate current practices and potential areas for improvement. During this study, it was noted that the rock at the pit face was highly jointed and fractured. As a result, large pieces of rock were often found to be ejected from the face during blasting as shown in Figure 1 . Since these pieces were generally too big for the primary crusher, they were physically moved out of the way and broken individually with a hydraulic rock breaker. The resulting rehandling of the rock and subsequent loss of production were of some concern to Luck Stone management and presented a potential area for improvement. The remaining feed to the primary crusher was also noted to be quite large for the equipment used which tended to limit the throughput. Thus, reducing the size of the material presented to the primary crusher was viewed as a potential benefit for this particular operation.

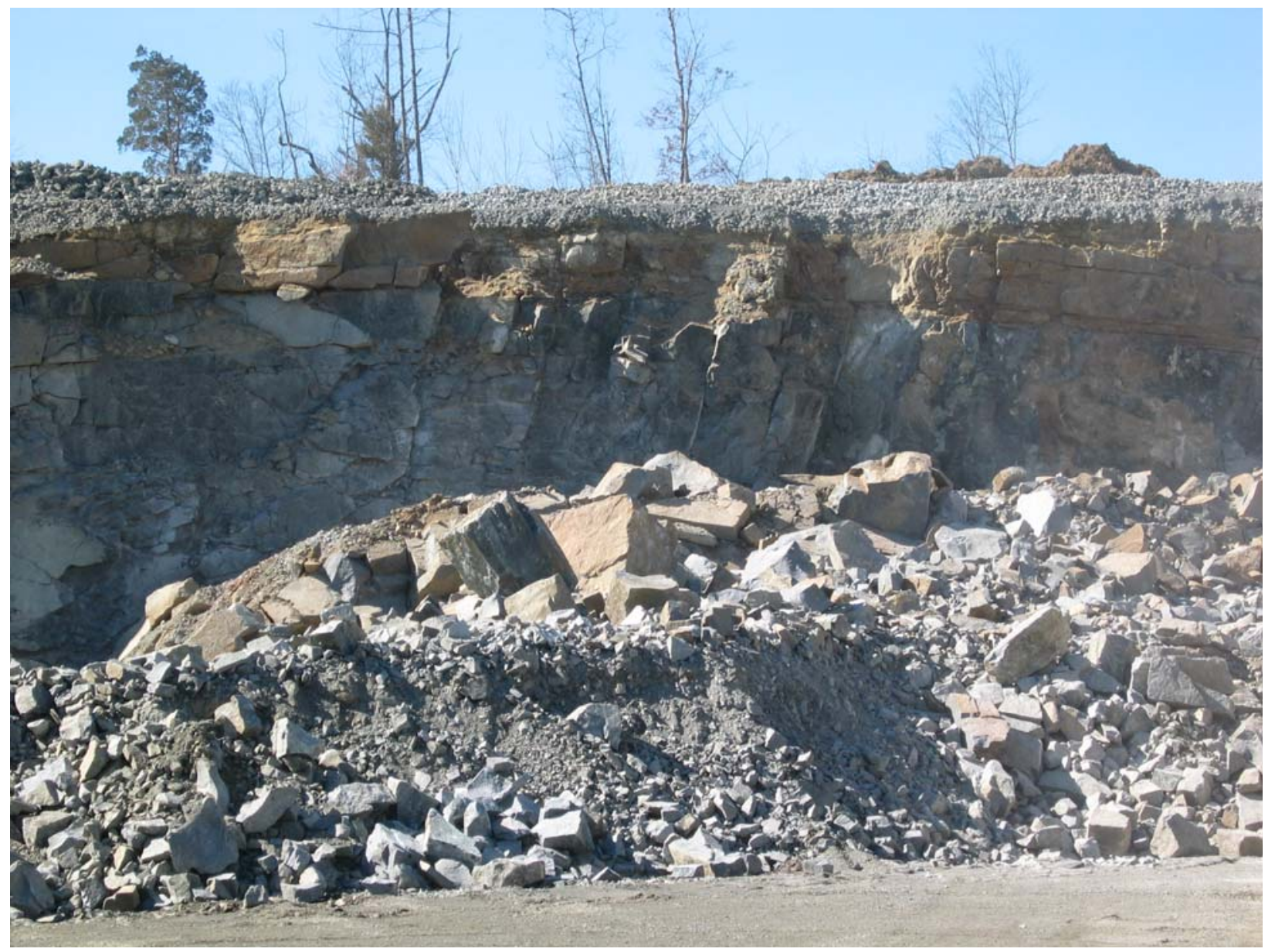

Figure 1. Photograph of the muck pile at the Bealeton Quarry showing large pieces of rock produced during blasting. 
The flowsheet for the Bealeton plant is shown in Figure 2. As shown, the plant is divided into three sections (primary, secondary, and tertiary) which can operate independently of each other. Mined ore is dumped directly from an excavator into the hopper/grizzly feeder of an in-pit primary jaw crusher. The grizzly oversize reports to the jaw crusher. The grizzly undersize and crushed ore report to a conveyor belt ahead of a series of linked belts that transport the material from the pit to the secondary plant surge pile.

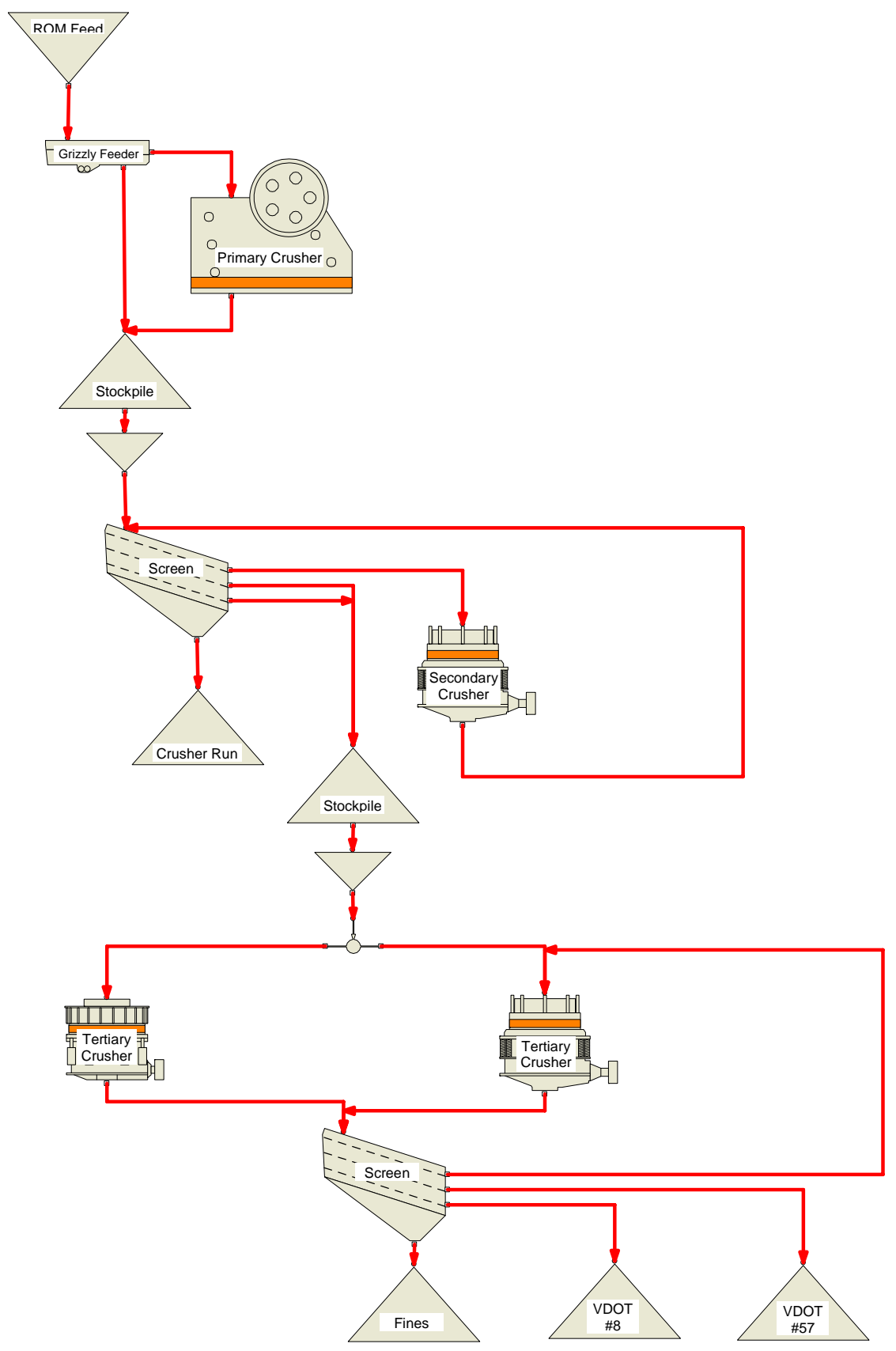

Figure 2. The Bealeton plant flowsheet. 
The secondary plant is fed by four apron feeders, the combined feed reporting to an inclined triple deck vibrating screen. The purpose of the screen is to reject the material too coarse for the tertiary plant, and also remove the $-25 \mathrm{~mm}$ material known as crusher run. The nominal $90 \mathrm{~mm}$ top deck oversize material reports to a feed bin ahead of the secondary cone crusher. The $63 \mathrm{~mm}$ middle deck acts to protect the nominal $30 \mathrm{~mm}$ bottom deck wire mesh screen. The crusher product recycles back to the top deck screen. The bottom and middle deck oversize reports to the tertiary plant surge pile. Since the crusher is oversized and the screen is undersized for the duty, the plant tends to cycle, during which the crusher feeder stops every few minutes to allow oversize material to fill the bin. The load on the screen when the crusher is receiving feed is higher than the screen can handle, resulting in fine rocks misreporting to the crusher feed bin. This stop-start operation consequently results in additional wear on the crusher and reduced efficiency in screening. The plant is controlled using a strategy that looks at the feedrate set-point plus the crusher amps, feed bin level, and crusher bowl level.

The tertiary plant is fed by five apron feeders, the combined feed reporting to a feed tank at the end of a variable speed belt. At the base of the tank are two vibrating feeders that feed two tertiary cone crushers. The combined crusher product reports to an inclined triple deck vibrating screen. The $25 \mathrm{~mm}$ top deck oversize recycles back to the feed tank, and by virtue of the tank design, is predominantly fed to one of the tertiary crushers. Similarly the new feed tends to report primarily to the other tertiary crusher. The products from the screen are: \#57 - middle deck $12.7 \mathrm{~mm}$ oversize; \#8 - bottom deck $6.5 \mathrm{~mm}$ oversize; and $\# 10$ - bottom deck undersize. The products report to stackers which can blend the products onto stockpiles as required. The plant is controlled using a strategy that looks at crusher amps and bowl levels, and feed tank level. The feedrate to the plant is allowed to vary to maintain the amp and level setpoints.

During the scoping study, belt speed measurements were taken at all sampling points throughout the plant, and estimates of belt loads were used to determine the length of belt that would be required to provide a sufficient sample size. Crusher sets were also determined using lead weights lowered into the crushing chambers.

Analysis - Blast Audit: In order to collect data to calibrate the blasting and comminution models, it is necessary to carefully monitor all relevant aspects of a blast. On June 16, 2004, blast 2904, a standard Bealeton pattern, was used for this purpose. The pattern was nominally a square $4.5 \mathrm{~m} \times 4.2 \mathrm{~m}$ (burden $\mathrm{x}$ spacing) with $4.3 \mathrm{~m}$ of stemming in a $12 \mathrm{~m}$ bench. It was initiated in a V-configuration with $25 \mathrm{~ms}$ delays along the control line and $67 \mathrm{~ms}$ on the echelon. Figure 3 is a plan view of the pattern generated using JKSimBlast. The western face of the blast is completely clean while there is a blasted muck pile to the north (Figure 4). 


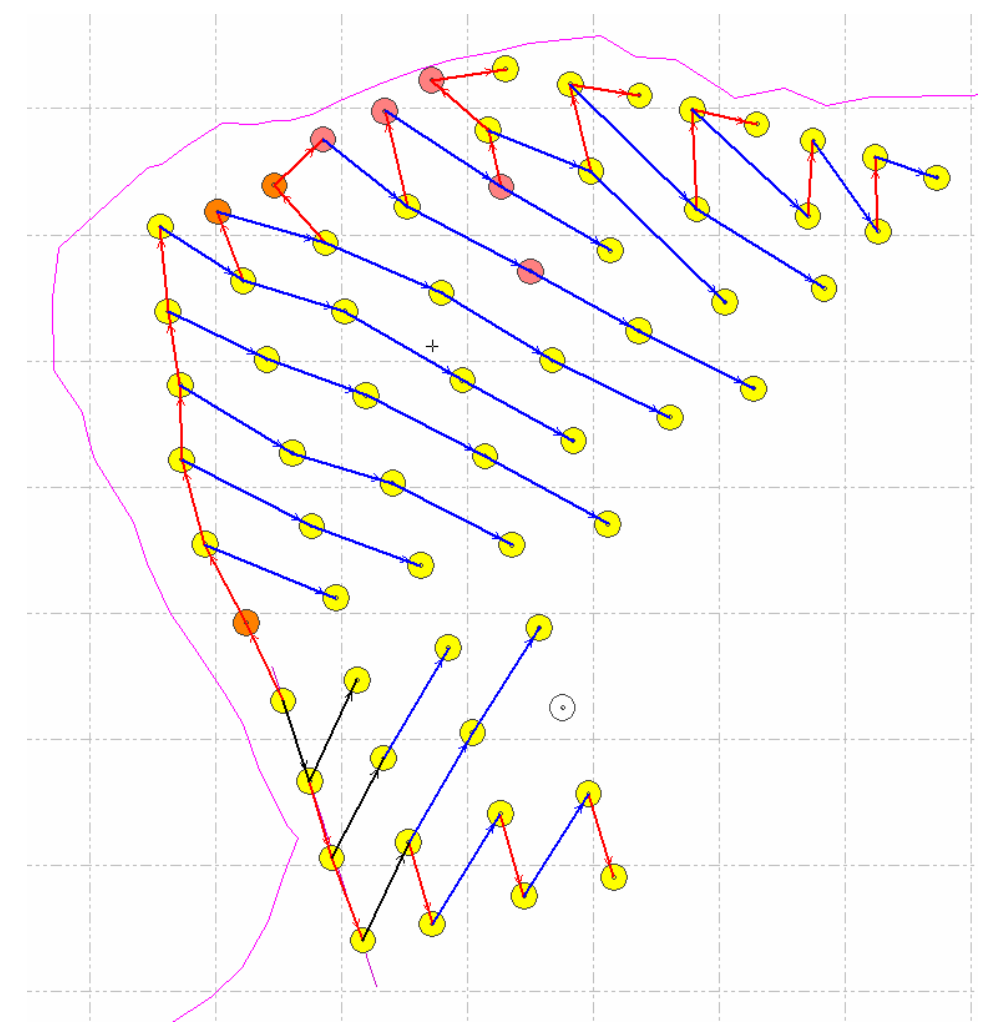

Figure 3. Plan of Blast 2904 with surface initiation.

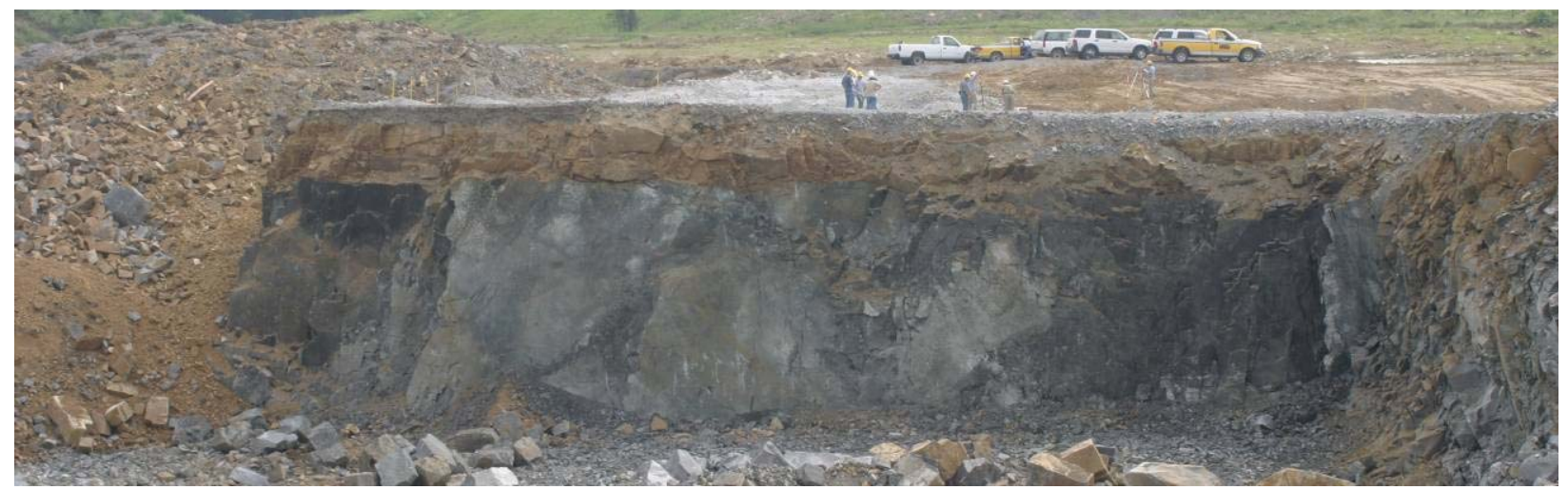

Figure 4. Easterly view of Blast 2904 with blasted muck pile to the left.

It is important that the input parameters of the blast fragmentation model correspond with the actual blast parameters that were implemented. The following list summarizes the data that were collected for this blast.

- All hole collars and crest lines were surveyed to determine actual burden and spacing.

- Hole depths, charge lengths for each product, and stemming lengths were obtained from detailed loading sheets.

- Face profiling was used to determine face burden. 
- Velocity of detonation (VOD) was recorded for selected holes.

- Every hole was bore tracked to quantify the deviation from vertical.

- Fracture frequency of two faces adjacent to the blast was measured to estimate in situ rockmass structure.

- Intact rock properties were obtained from measurements previously performed at Virginia Tech.

To achieve consistent fragmentation in a homogeneous rockmass, the explosive's energy must be distributed as evenly as possible and the characteristics of the pattern will determine this. There are two regions of a blast where the energy is typically different from the body of the blast for practical reasons - free faces and the top of the bench (stemming zone). Figure 5 shows the energy distribution on a plane at approximately the mid-bench level (below the stemming).

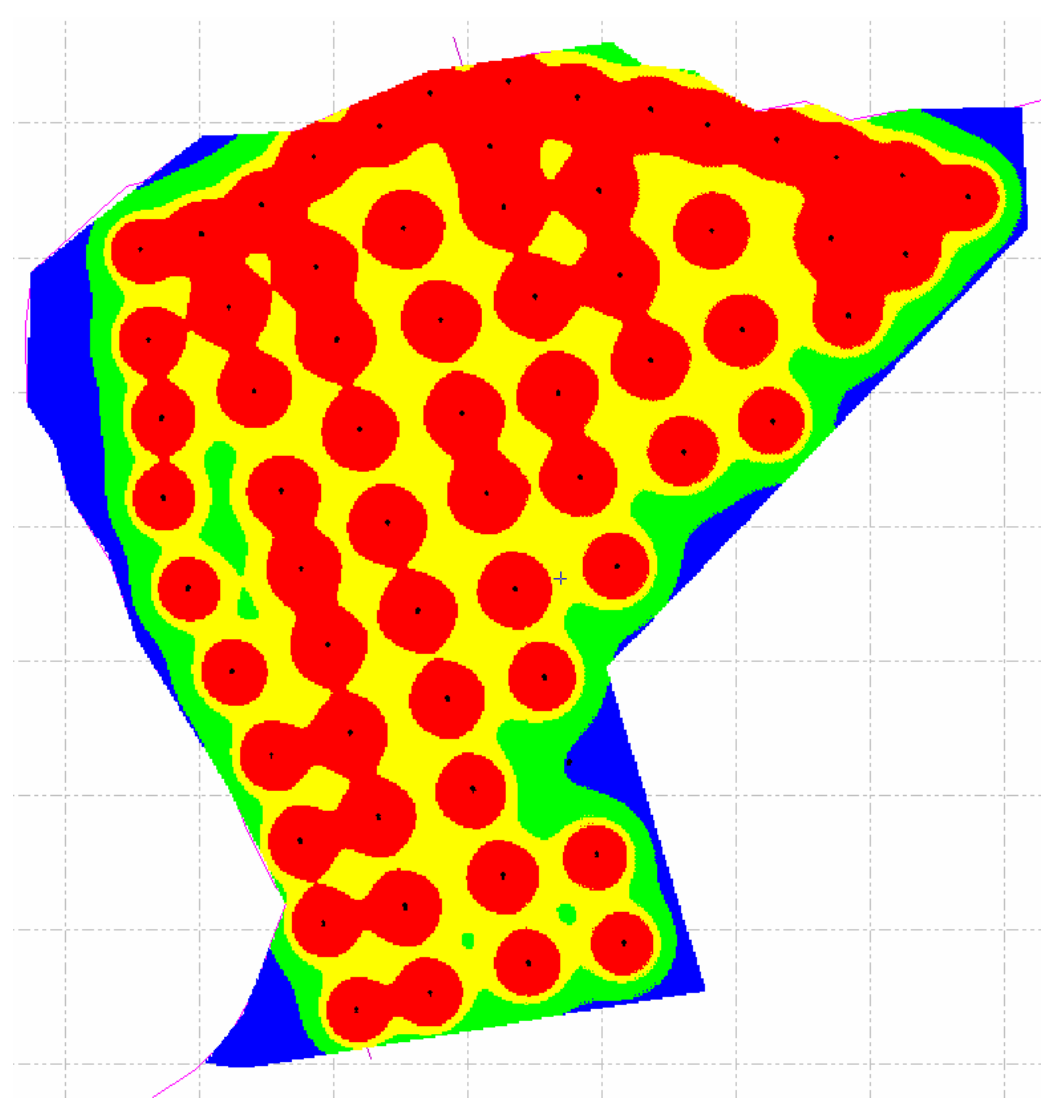

Figure 5. Explosive energy distribution in Blast 2904 at mid-bench level.

The distribution is reasonably uniform, especially through the body of the blast with some exceptions as follows:

- A hole near the southeast corner collapsed and could not be loaded. The reduction in the energy level in this region is clearly evident. 
- The relatively large face burden in the northwest corner results in lower energy levels in the rockmass.

- The in-fill holes along the northern buffered face increases the energy along this edge.

Fragmentation is expected to be coarser in regions where the energy is low compared with regions where it is higher which is why fragmentation is coarser in the stemming region. Fragmentation from a free face is typically coarse because the in situ blocks are less constrained and therefore less likely to break. For example, there is likely to be more oversize blocks from the northwest corner due to the large face burden combined with the free face conditions. Some of these effects can be seen in Figure 6.

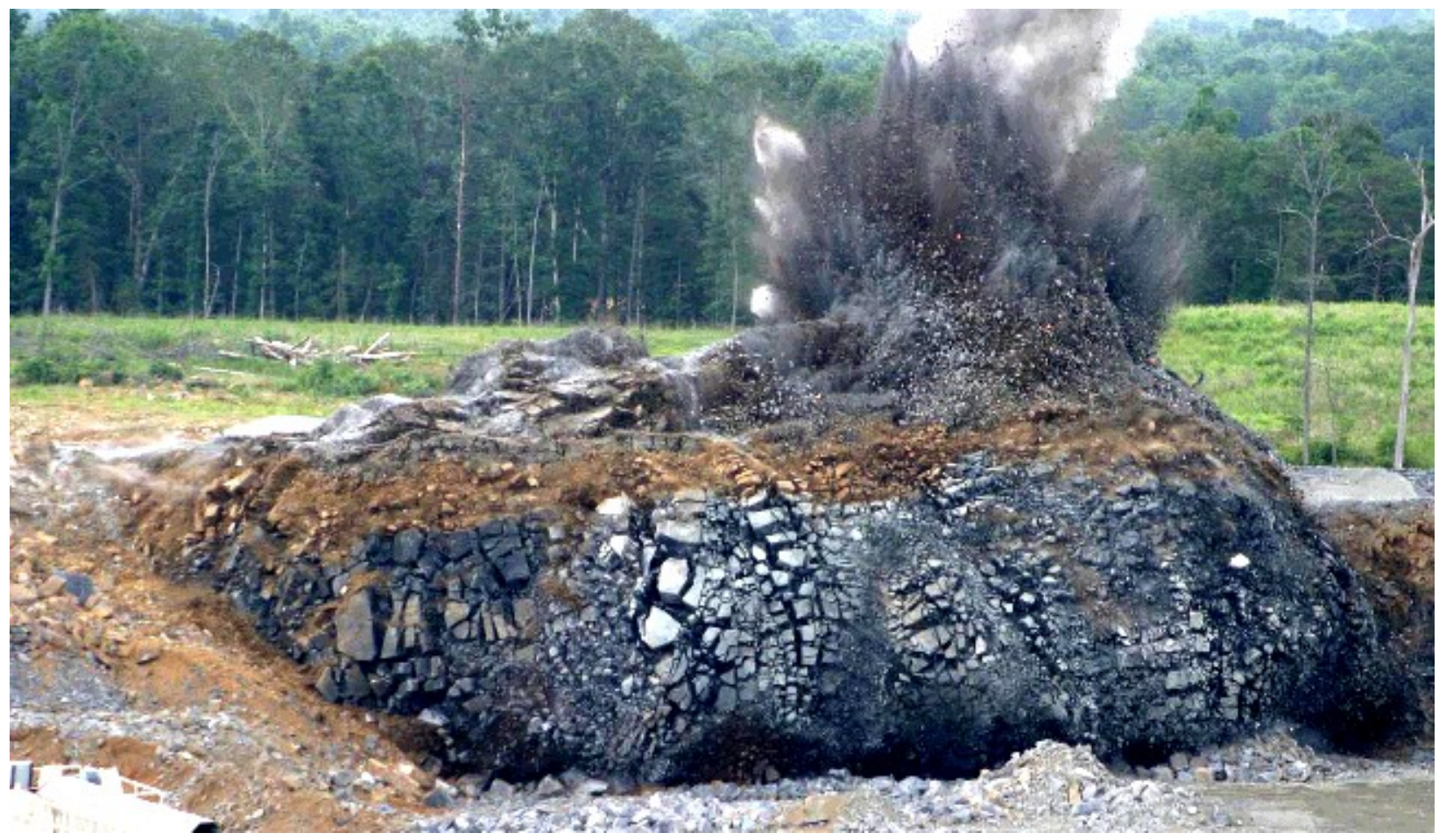

Figure 6. Photograph of Blast 2904 soon after initiation clearly showing oversize blocks in the free face and stemming region.

Analysis - Plant Audit: The plant audits were carried out in sequence, starting with the primary section. Once the excavator had progressed well into the shot, the C29 belt sample was collected. After sufficient material from the audit shot was crushed and stockpiled, the team moved to the secondary plant. Similarly, the tertiary audits were run after sufficient material was processed through the secondary plant. Figure 7 shows the plant layout with the belt sample points indicated. 


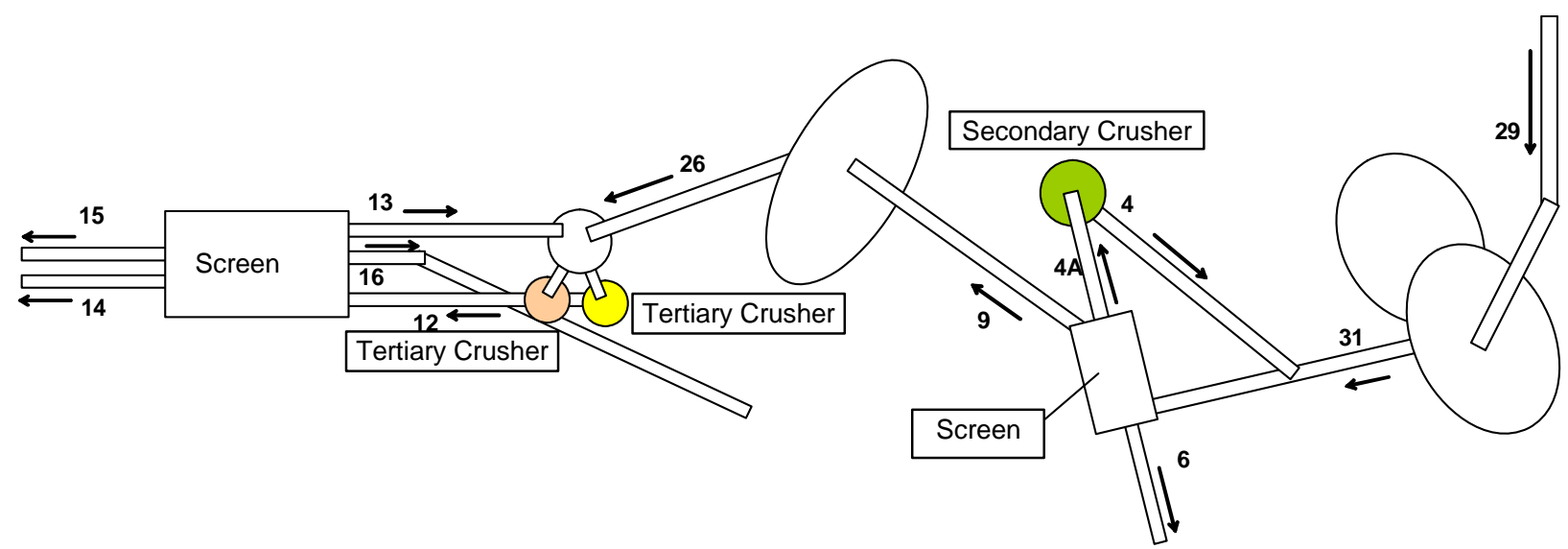

Figure 7. Bealeton plant sampling layout.

The primary crusher sample was conducted in open circuit mode, at the typical closed side setting (CSS) of $114 \mathrm{~mm}$. Both the secondary and tertiary surveys were conducted in closed circuit mode, as close as possible to steady-state, at three CSS settings. As noted, the cyclic nature of the secondary plant forced the sampling to take place around half way through a typical cycle. Hence the loads on the belts were not expected to be stable. The tertiary plant was much more stable so it was possible to run the plant in near steady-state conditions before each survey. The strategy was to calibrate the performance of the individual unit operations accurately enough to allow a full circuit simulation at any combination of feedrate and crusher settings likely to be present in the plant. Changes in ROM feed sizing could then be investigated independently.

The experimental procedure consisted of:

1. The primary crusher product was sampled first, at the prevailing feedrate at the time of sampling. Almost $15 \mathrm{~m}$ of sample was removed from the C29 belt, both coarse rock $(>75 \mathrm{~mm})$ and fines. The coarse rock was processed on site using a set of square frames, sized from $75 \mathrm{~mm}$ to $212 \mathrm{~mm}$. The fines sample was placed into a barrel and returned to Virginia Tech for detailed sizing down to 75 microns. The crusher gap was measured by Luck Stone staff before the crusher was started that same morning.

2. For the secondary plant, three crusher gaps were tested, the normal setting ( 47.2 $\mathrm{mm})$ plus a finer setting $(39.9 \mathrm{~mm})$ and a coarser setting $(53.3 \mathrm{~mm})$. In each case the top deck oversize (C4A), crusher product (C4), tertiary plant feed (C9) and crusher run (C6) were sampled. The crusher gaps were measured using both lead balls and 'Reynolds' foil balls provided by the operators in each plant.

3. The tertiary plant audits examined four crusher gap settings on the Omnicone $(47.2 \mathrm{~mm}, 39.9 \mathrm{~mm}, 53.3 \mathrm{~mm}$, and $19.6 \mathrm{~mm}$ ) and one setting on the Symons $(10.9 \mathrm{~mm})$. Since the Symons crusher required maintenance, it could not be run for long, limiting the test program to just one audit with both crushers online. For each Omnicone setting, the plant feed (C26) and all the product belt samples 
(C12, C13, C14, C15 and C16) were collected. The speed of the feed belt was measured just prior to the plant being stopped for sampling. In the fourth audit when both crushers were running, one feed grab sample was taken for each crusher. The Symons product was sampled independently by stopping the feed to the Omnicone. The crusher gaps were measured using both lead and 'Reynolds' wrap foil balls.

All the conveyor belt speeds were measured prior to sampling. Belt cut lengths were selected on the basis of statistical considerations, considering the size of rocks on each belt, the load, and conveyor speed. The belt samples from the secondary and tertiary audits was placed into barrels and buckets and returned to Virginia Tech for detailed sizing down to 75 microns. Samples from the audits were also retained for JKMRC drop-weight breakage tests. Appendix 2 gives a summary of the crusher settings and samples collected during the audits, while Appendix 3 gives full size analyses of the samples collected.

\section{Pittsboro Site Test Work}

Scoping Study: Test work at the Pittsboro site began with a scoping study in March 2005 to evaluate current practices and potential areas for improvement. An aerial view of the quarry is shown in Figure 8. As shown, the areas marked "3M Andesite" are mined, crushed to below $90 \mathrm{~mm}$, and sent to $3 \mathrm{M}$ for their on-site roofing granule manufacturing process. All other rock is processed by Luck Stone and sold on the commercial market.

The Mine-to-Mill optimization study at the Pittsboro Quarry was focused primarily on the Luck Stone part of the operation. Luck Stone is currently moving into an area in the northwest corner of the quarry that contains a basalt-type rock. They expect to be mining this material for several years and hope to ultimately access some additional andesite for use by $3 \mathrm{M}$.

Blasting at the Pittsboro Quarry is normally carried out using a $5.5 \mathrm{~m} \times 4.3 \mathrm{~m}$ pattern (burden $x$ spacing) although a $4.6 \mathrm{~m} \times 4.6 \mathrm{~m}$ pattern is used on harder materials. These patterns are typically used on $21 \mathrm{~m}$ benches with $4.8 \mathrm{~m}$ of stemming and a hole diameter of $165 \mathrm{~mm}$. Blasting is typically conducted 3 times per week with a typical shot of 30,000 tonnes at a powder factor of $0.35 \mathrm{~kg} / \mathrm{t}$. As compared to the Bealeton quarry, oversize material is generally not an issue at Pittsboro (less than $2 \%$ of a typical shot) with the hydraulic rock breaker being required less than 0.5 hour per day.

Figure 9 gives a schematic of the Pittsboro plant layout and material flow. The Pittsboro plant currently produces around 1.6 million tonnes of crushed stone products per year, of which two-thirds represents $3 \mathrm{M}$ material. Three main rock types are present including andesite, which is fed to the $3 \mathrm{M}$ plant, and dacite tuffs and basalt which are fed to the Luck Stone plant. A significant portion of the ore body is massive, particularly in the lower lifts. In the upper lift the rock can be highly structured. Andesite tends to be found in the massive zones. 


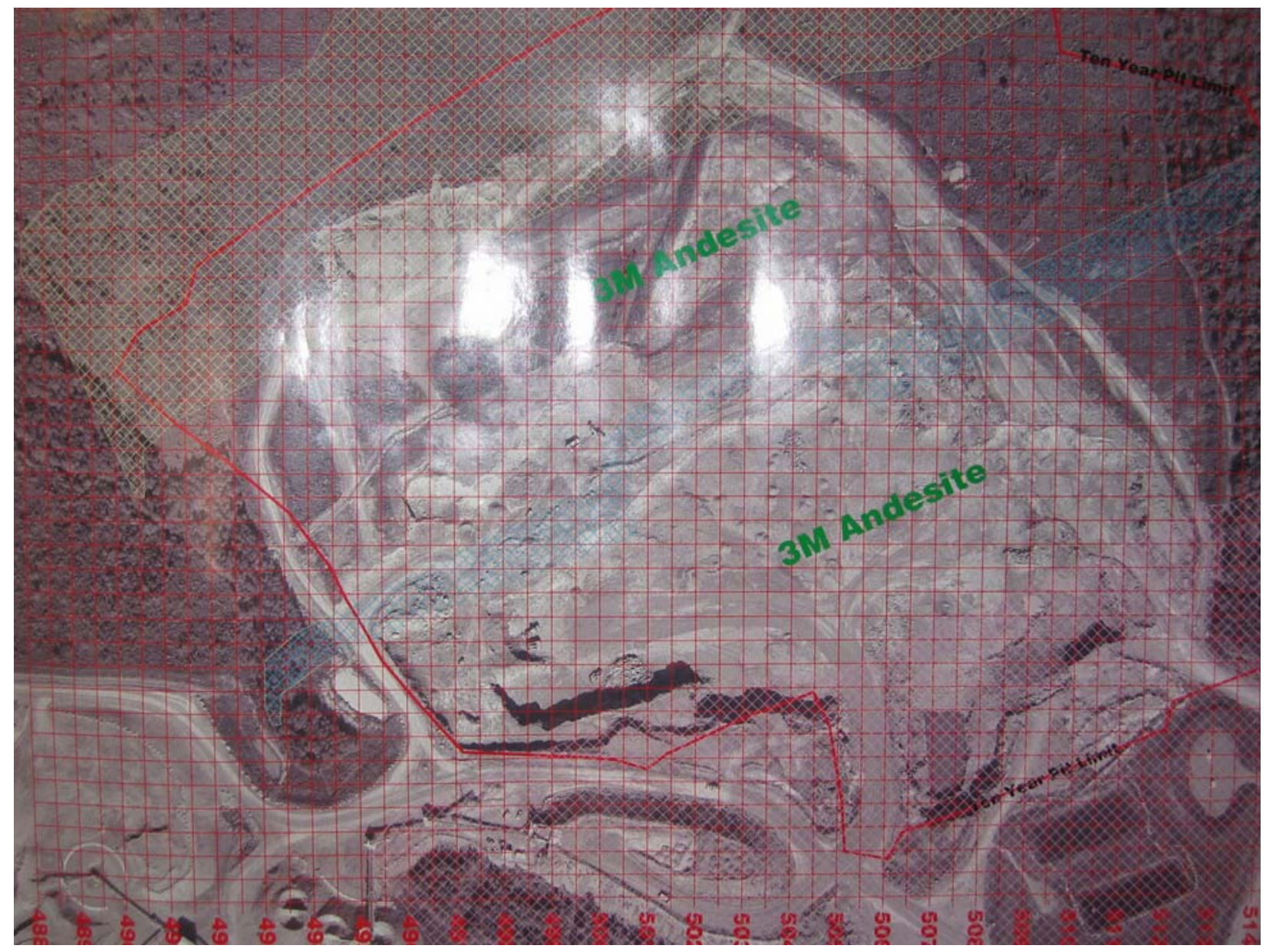

Figure 8. Aerial view of the Pittsboro Quarry showing the areas of andesite mined for $3 \mathrm{M}$. The northwest corner of the quarry is the area being studied in this investigation.

Mine haulage equipment consists of three trucks and two loaders. The mine also has a $165 \mathrm{~mm}$ diameter blasthole drill. Excavated ore is trucked to the primary crusher. The grizzly oversize reports to the primary jaw crusher, which has a capacity of approximately $475 \mathrm{tph}$ at the typical $146 \mathrm{~mm}$ closed side setting. The grizzly has a 165 $\mathrm{mm}$ opening at the end of the tapered bars. Grizzly undersize and crushed ore report to a conveyor belt ahead of a rip-rap screen fitted with 230 and $280 \mathrm{~mm}$ holes. The rip-rap screen removes the slabby oversize that typically has a thickness just under the primary crusher gap, but can be 280 to $600 \mathrm{~mm}$ in length and width. Unless removed, this oversize can bridge the feeders and secondary crushers downstream. The rip-rap undersize material reports to a stacker that can place the crushed ore into one of three secondary plant surge piles. Pile $A$ is designated for $3 \mathrm{M}$ only, B can feed either $3 \mathrm{M}$ or Luck Stone (LS), and C is for Luck Stone (LS) only. A sensor, installed as part of this study, automatically tracks the stacker position and thereby quantifies the operation of the primary crusher on both $3 \mathrm{M}$ and LS rock types. The secondary piles each have over 6,000 tonnes of live surge capacity. 


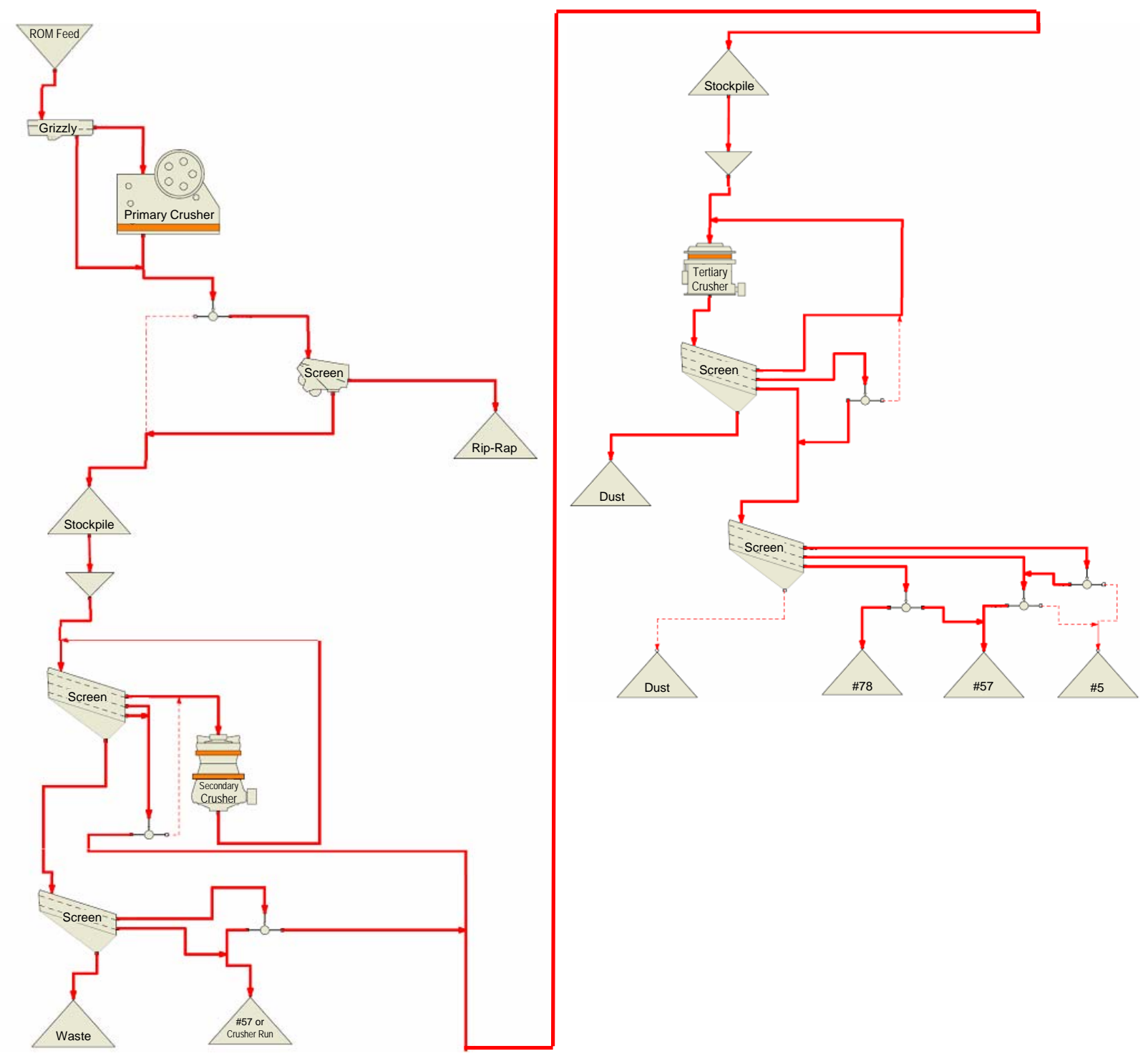

Figure 9. Pittsboro plant flowsheet.

The LS secondary plant is fed by two apron feeders, the combined feed reporting to an inclined triple-deck vibrating screen. The purpose of the screen is to reject the material too coarse for the tertiary plant, and also remove the $-38 \mathrm{~mm}$ material, which contains all the weathered material, known as base or crusher run. Due to problems in meeting North Carolina specifications on the plasticity of this product, Luck Stone has upgraded the secondary plant which now includes a Bivitec screen to remove the clayey fines from the base. The apertures on the top deck of the Bivitec are nominally $19 \mathrm{~mm}$, whereas the bottom deck has apertures ranging from 3 to $6.5 \mathrm{~mm}$. Since the capacity of the Bivitec screen is limited to around $450 \mathrm{tph}$, there is a provision to by-pass the screen. The nominal $90 \mathrm{~mm}$ top deck oversize material reports to a feed bin ahead of a cone crusher. The $63 \mathrm{~mm}$ middle deck acts to reduce the load on the nominal $38 \mathrm{~mm}$ bottom rubber deck screen. The crusher product recycles back to the top deck screen. The bottom and middle deck oversize reports to the tertiary plant surge pile. 
The Bivitec top deck has 9 blend gates which allow Luck Stone to tune the grading on the base product to meet the unusual North Carolina regulation that controls both the fines and coarseness (ie. $94 \%-25 \mathrm{~mm}$ and $3-6 \%+25 \mathrm{~mm}$ ). The remaining fraction of the top deck is conveyed to the tertiary plant feed belt. Since the feed to the secondary plant is typically limited to 540 tph and the coarseness of the feed is quite variable, the plant tends to cycle during which the crusher feeder stops every few minutes to allow oversize material to fill the bin. This stop-start operation consequently results in additional wear on the crusher and reduced efficiency in screening. The plant is controlled using a strategy that looks at the feed rate set-point plus the crusher amps, feed bin level and crusher bowl level.

The tertiary plant is fed by four apron feeders, the combined feed reporting to a cone crusher on a variable speed belt. The crusher is also fed by the recycled top deck screen oversize. The crusher product reports to an inclined triple-deck vibrating screen. The screen apertures are configured on the basis of the production setup (i.e., only products \#57 and \#78). During the March 2005 scoping study, the following apertures were used:

Top Deck - $\quad 40 \%$ rubber (22 $\mathrm{mm}$ openings) and $60 \%$ wire (22 $\mathrm{mm}$ openings) Middle Deck - $\quad 60 \%$ rubber (12.7 mm openings) and $40 \%$ wire (12.7 $\mathrm{mm}$ openings) Bottom Deck - $\quad 100 \%$ rubber with a combination of $5 / 5 / 3.5 / 5 / 5 \mathrm{~mm}$ openings

The middle and bottom deck oversize is fed to an inclined triple-deck tertiary wash vibrating screen. The bottom deck undersize is the dust. The plant is controlled using a strategy that looks at crusher amps and bowl levels, and feed tank level. The feedrate to the plant is allowed to vary to maintain the amp and levels set-points.

The wash screen has blend gates on all three decks, allowing four setups to be configured depending on the target products. During the August audits, only \#78 and \#57 products were produced. These two products report to stackers; while the \#5 product, which is not typically produced, reports directly to its own stockpile. The following apertures were in place during the audits:

Top Deck - $\quad 50 \%$ rubber (22 $\mathrm{mm}$ openings) and $50 \%$ wire (22 $\mathrm{mm}$ openings) Middle Deck - $\quad 100 \%$ polyurethane (12.7 mm openings)

Bottom Deck - $\quad 100 \%$ polyurethane (0.5 $\mathrm{mm}$ openings)

The bottom deck screen undersize reports to the fines sump/launder collection system, which then pumps the washed fines to a settling pond.

Just as in the case of the Bealeton scoping study, belt speed measurements were taken at all sampling points throughout the plant, and estimates of belt loads were used to determine the length of belt that would be required to provide a sufficient sample size. Crusher sets were also determined using lead weights lowered into the crushing chambers. 
Analysis - Blast Audit: In order to collect data to calibrate the blasting and comminution models, it is necessary to carefully monitor all relevant aspects of a blast. On August 10,2005 , blast 8605 , was used for this purpose. The pattern was nominally $5.5 \mathrm{~m} \times 4.3 \mathrm{~m}$ (toe burden $\times$ spacing) with $4.8 \mathrm{~m}$ of stemming in a $21 \mathrm{~m}$ bench. Drill holes were angled to protect the back wall, which means the burden and spacing were referenced to the toe, not the collar. Figure 10 is a plan view of the pattern generated using JKSimBlast. The face of the blast was completely clean (Figure 11).

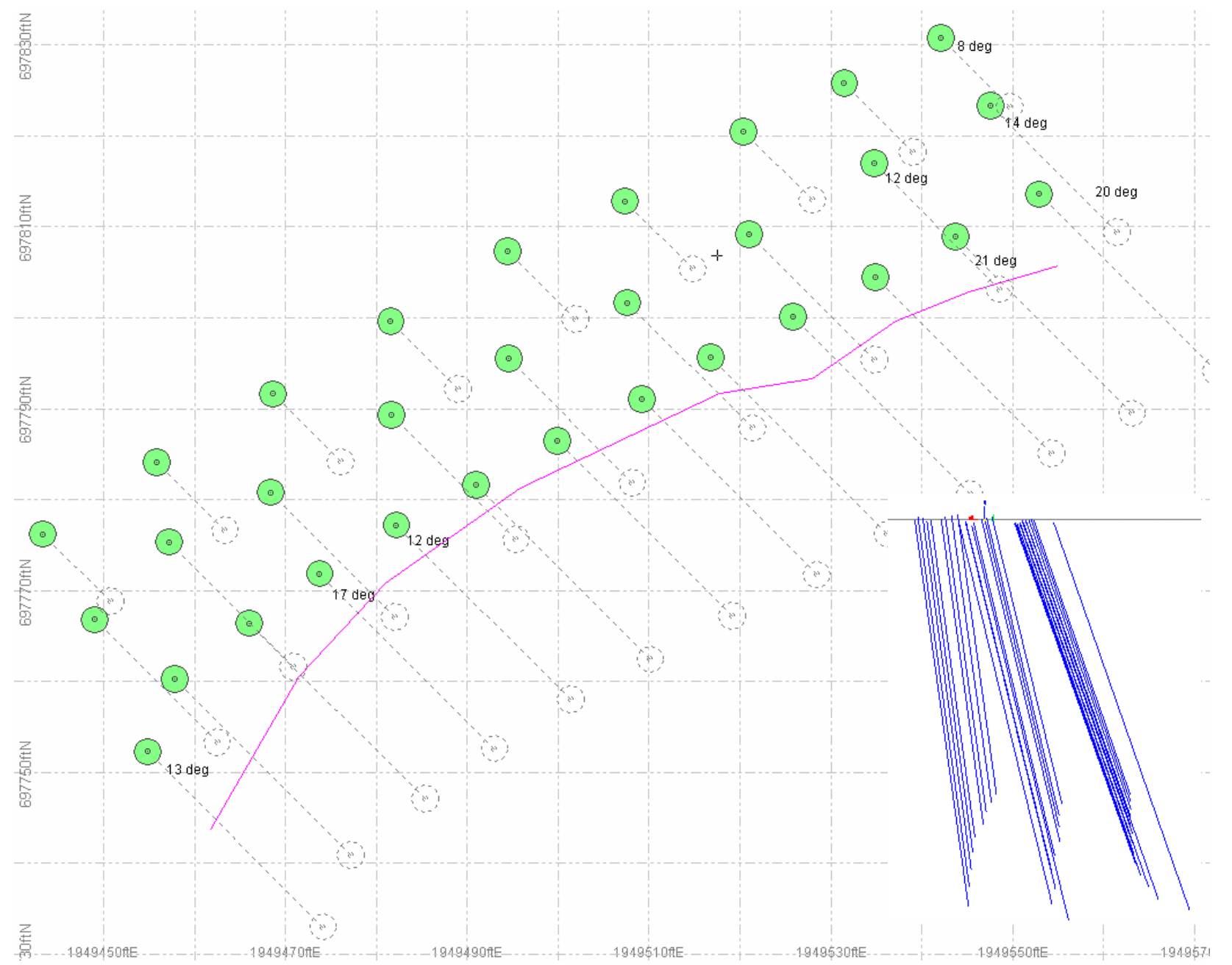

Figure 10. Plan of Blast 8605 with surface initiation; inset shows face profile.

An overview of the blasting practice and implementation in shot 8605 found the actual design to be somewhat tighter than planned $(4.3 \times 3.8 \mathrm{~m}$ at mid bench). This smaller spacing coupled with the highly energetic emulsion of HydroMite 4400 , necessary in the wet holes, resulted in very fine fragmentation in what appeared to be fractured weak rock (see Figure 12). Samples from the $\mathrm{C} 2$ belt revealed rocks with a variable strength from 20 to $200 \mathrm{MPa}$, supporting this initial assessment. The throughputs observed on the 8605 shot material were significantly higher than the typical daily average in the 
plant, attesting to the unusual nature of this material. The muckpile was free of any oversize, with the exception of one large rock that fell out of the adjoining face.

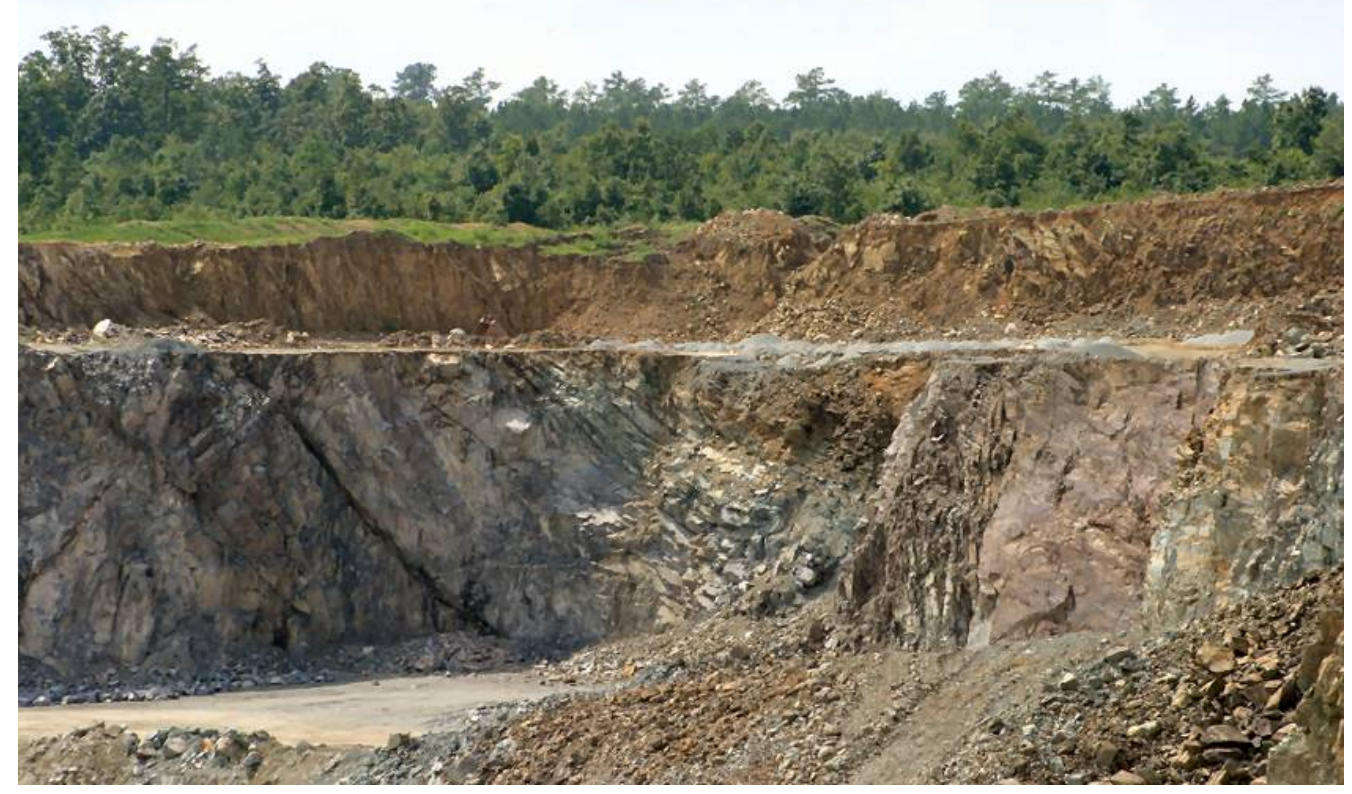

Figure 11. Northerly view of blast 8605.

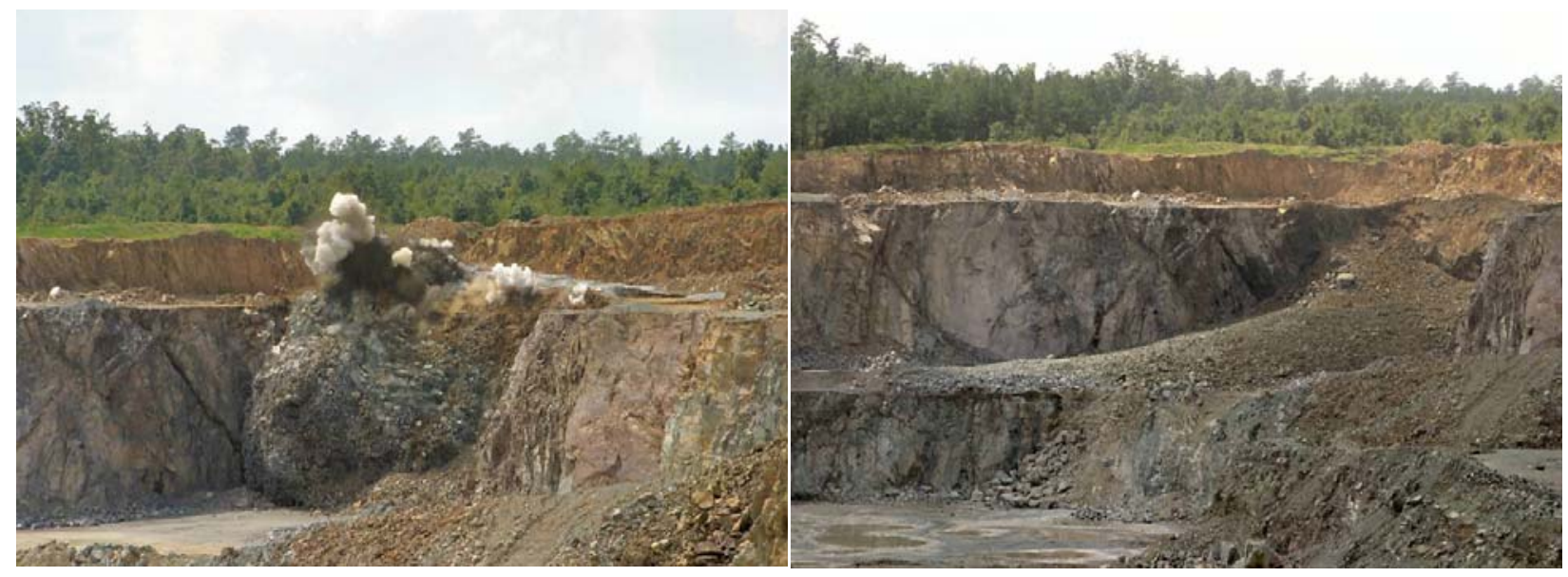

Figure 12. Photograph of blast 8605 soon after initiation clearly showing minimal stemming region and good face movement; second photo shows muckpile.

Once again, the same blasting data as collected at the Bealeton site were collected at the Pittsboro site (see pp. 9 and 10 of this report). 
Analysis - Plant Audit: The aim of the plant audit was to calibrate the JKMRC blast and process plant models based on current practices at Pittsboro. These models would then be used in a simulation study to explore potential new blast design(s) and possibly, operating strategies in the plant.

Since a significant proportion of the mining and processing at Pittsboro is dedicated to $3 \mathrm{M}$, it was decided that the audits should include both 3M and LS rock types. To this end, the primary and secondary audits included one survey with $3 \mathrm{M}$ feed material. After sufficient material from the test shot was crushed and stockpiled, the team moved to the LS secondary plant.

The jaw crusher feed size distribution was determined using the Split image analysis on trucks sent to the crusher ahead of each survey. The last truck dumped into the grizzly feeder before the C2 belt was stopped for sampling was assumed to represent the feed to the crusher.

An estimate of the Rip-Rap oversize was made from hand measurements of the dimensions for 10 pieces of rock. The flowrate was estimated by counting the number of pieces that discharged to the stockpile over a 5 minute period.

As far as the secondary plant, its operation post the upgrade and installation of the Bivitec screen was still under investigation by the operations staff when the mine-to-mill team arrived at site. The configuration of the screen apertures on the Bivitec screen was recognized as one of the key operating variables and several adjustments had been made to better distribute the load between the top and bottom decks. It was also clear that the maximum feedrate to the screen was limited to around $450 \mathrm{tph}$, which meant that surveys on fine feeds like that expected from the test shot (8605) would require the Bivitec to be by-passed at feedrates in excess of $450 \mathrm{tph}$. The only way to test the plant on coarser feed from the test shot material was to wait for the stockpile to run down, when the fines would be depleted. Hence the audit plan for the secondary plant required 7 surveys to quantify the effects of feed size (stockpile level), feedrate and crusher gap. The tertiary audits were run after sufficient material was processed through the secondary plant. Figure 13 shows the plant layout with the belt sample points indicated by red circles.

The primary crusher survey was conducted in open circuit mode, at the typical closed side setting (CSS) of $146 \mathrm{~mm}$ and $181 \mathrm{~mm}$ open side setting (OSS). Both the secondary and tertiary surveys were conducted in closed circuit mode, as close as possible to steady-state, at nominal CSS settings (secondary - 51, 44 and $38 \mathrm{~mm}$; tertiary $-28,22$ and $19 \mathrm{~mm}$ ). As noted, the cyclic nature of the secondary plant forced the sampling to take place about half way through a typical cycle for five of the seven surveys. Hence the loads on the belts in these surveys were not expected to be stable. The two surveys in which the plant was almost at steady-state had by far the coarsest feed. The tertiary plant was much more stable so it was possible to run the plant in near steady-state conditions before each survey. Once the performance of the individual unit 
operations was calibrated, changes in ROM feed sizing could then be investigated independently at any combination of feedrate and crusher settings.

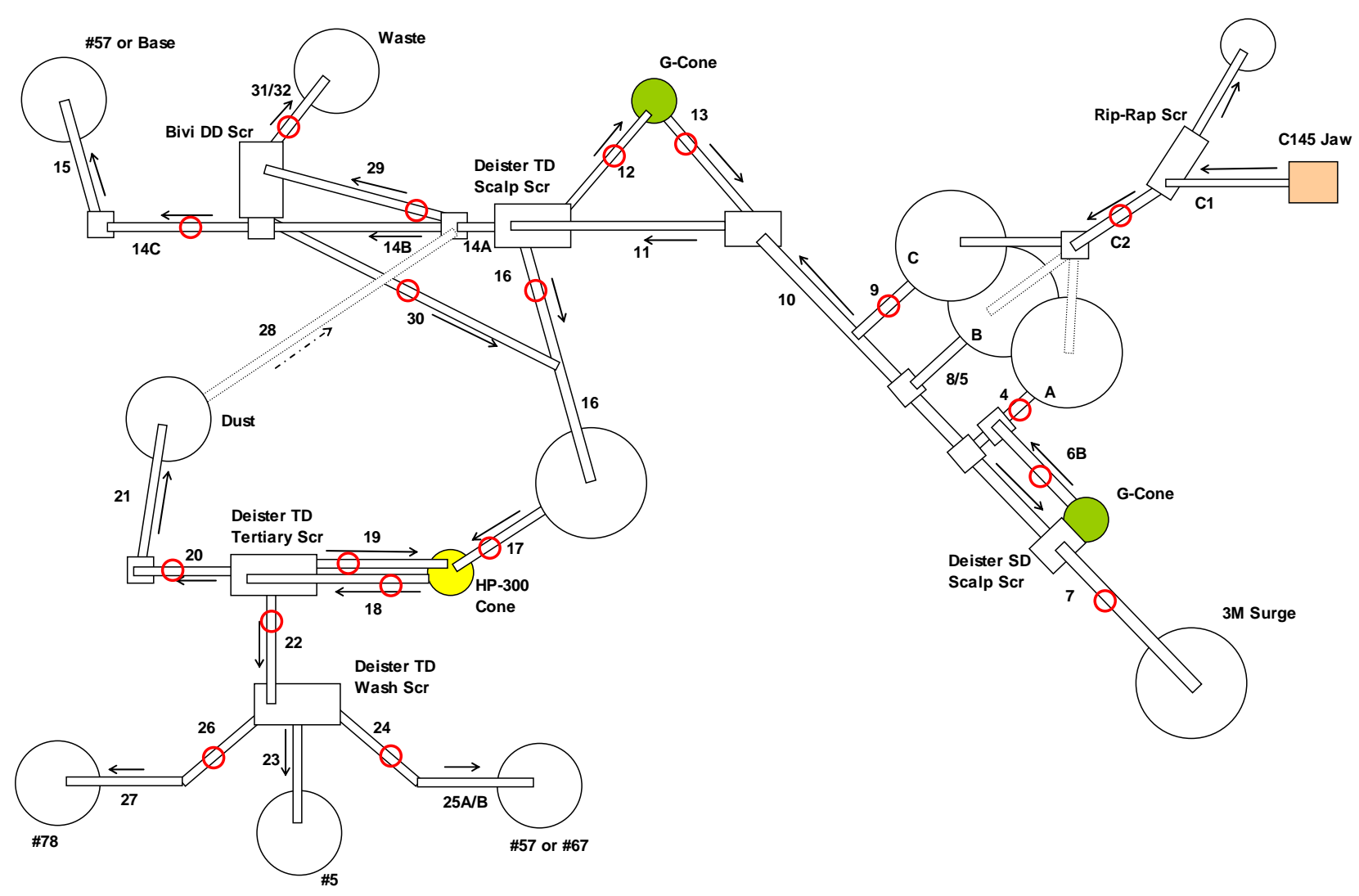

Figure 13. Pittsboro plant sampling layout.

The experimental procedure consisted of:

1. The primary crusher product was sampled first at the prevailing feedrate at the time of sampling (approximately $900 \mathrm{tph}$ for the $3 \mathrm{M}$ andesite and 1400 tph for the Luck Stone basalt). Approximately $11 \mathrm{~m}$ of material was removed from the $\mathrm{C} 2$ belt for the 3M sample, both coarse rock $(>75 \mathrm{~mm})$ and fines, and approximately $8.5 \mathrm{~m}$ of material was removed for the Luck Stone sample. The coarse rock was processed on site using a set of square frames, sized from $75 \mathrm{~mm}$ to $212 \mathrm{~mm}$. The fines samples were placed into barrels and returned to Virginia Tech for detailed sizing down to 75 microns. The crusher gap was measured by Luck Stone staff before the crusher was started that same morning.

2. For the LS secondary plant audits, the aim was to test the effect of feed coarseness, gap and crusher load. The normal setting $(44 \mathrm{~mm})$ was tested at a 450 tph feedrate setpoint, considered by the plant operators to be appropriate for the fine feed size conditions (high stockpile) and Bivitec limit. The feedrate was then increased to 590 tph, which was considered too high a load for the Bivitec, considering the fines level in the feed. Three settings were tested; 44, 51 and 38 
$\mathrm{mm}$. The plant was then allowed to run overnight to bring the pile down and thereby coarsen the feed. The next morning the plant was surveyed at 540 tph and the normal gap setting, with a low stockpile level expected to provide a much coarser feed. The gap was then increased and another survey at the 590 tph throughput was carried out. The final survey was conducted at $450 \mathrm{tph}$, low stockpile and normal gap setting, with the Bivitec online. To simplify the survey analysis, no dust material was returned via belt C28. The crusher gaps were measured using lead balls before each survey.

3. Only one survey was conducted on the $3 \mathrm{M}$ secondary, at the normal setting of 51 $\mathrm{mm}$ and feedrate of $635 \mathrm{tph}$. The single deck screen aperture was $100 \mathrm{~mm}$. The survey consisted of plant feed (C4), crusher product (C6B) and final product (C7).

4. Three audits were carried out on the LS tertiary section. The CSS settings used were 28, 22 and $19 \mathrm{~mm}$. The approach was to test the plant performance at each setting with the plant in automatic control on amps and crusher feed level. Hence the feedrate varied since the controller attempted to keep the crusher choke fed. For each audit, the plant feed (C17) and all product belt samples (C18, C19, C20, C22, C24 and C26) were collected. The wash screen bottom deck undersize was not sampled.

Throughout the plant audit phase, all the conveyor belt speeds were measured prior to sampling. Belt cut lengths were selected on the basis of statistical requirements, considering the size of rocks on each belt, the load and conveyor speed. The belt samples from the secondary and tertiary audits were placed into barrels and buckets and returned to Virginia Tech for detailed sizing, down to 75 microns. The coarse rock from the secondary surveys (C9 and C12 in the LS plant, and C4 in the 3M plant) were processed on site using a set of square frames, sized from $75 \mathrm{~mm}$ to $212 \mathrm{~mm}$. Appendix 2 gives a summary of the crusher settings and samples collected during the audits, while Appendix 3 gives full size analyses of the samples collected. 


\section{RESULTS AND DISCUSSION}

\section{Bealeton Quarry}

Fragmentation Modeling: Thirty years ago Kuznetsov published a model that predicted the mean fragment size from a blast and so enabled engineers to control fragmentation. This model was later improved by Cunningham (1983; 1986) and Lilly (1986) such that the entire fragment size distribution from a blast could be predicted. At that time, coarse fragmentation was still the main focus for the majority of mining engineers and the so-called Kuz-Ram model gained wide acceptance. Mining engineers began to appreciate the importance of fines with the acceptance of the mineto-mill philosophy in the last decade or so. Research at the JKMRC and elsewhere has demonstrated that the Kuz-Ram model underestimates the fines in the ROM size distribution (Kojovic et al.1995, Comeau 1996, Kanchibotla et al, 1999). Since the fine end of the curve has a direct impact on critical downstream processes, it is important to be able to accurately predict blast-induced fines so they can be controlled. The Crush Zone Model (CZM) (Kanchibotla et al, 1999), used in this project, employs a semimechanistic approach to calculate the volume of crushed material around each blast hole, while the Kuz-Ram model - or a modification of it - continues to be used for the coarse end of the fragmentation product.

Analysis of the data collected during blast monitoring and assessment of blast 2904 resulted in the following input parameters for the blast fragmentation model (Table 1).

\section{Table 1. Fragmentation Model Input Parameters for Blast 2904.}

\begin{tabular}{|c|c|c|}
\hline \multicolumn{3}{|l|}{ PATTERN } \\
\hline Bench Height $(\mathrm{m})$ & \multicolumn{2}{|l|}{11.6} \\
\hline Burden $(\mathrm{m})$ & \multicolumn{2}{|l|}{4.5} \\
\hline Spacing $(\mathrm{m})$ & \multicolumn{2}{|l|}{4.2} \\
\hline Hole Diameter $(\mathrm{mm})$ & \multicolumn{2}{|l|}{165} \\
\hline Hole Depth $(\mathrm{m})$ & \multicolumn{2}{|l|}{12.5} \\
\hline Sub-drill $(m)$ & \multicolumn{2}{|l|}{0.9} \\
\hline Stemming Height $(\mathrm{m})$ & \multicolumn{2}{|l|}{4.3} \\
\hline \multicolumn{3}{|l|}{ ROCKMASS } \\
\hline Rock Type & \multicolumn{2}{|l|}{ Diabase } \\
\hline Specific Gravity & \multicolumn{2}{|l|}{2.973} \\
\hline Young's Modulus (GPa) & \multicolumn{2}{|l|}{67} \\
\hline $\operatorname{UCS}(\mathrm{MPa})$ & \multicolumn{2}{|l|}{245} \\
\hline Mean Block Size $(\mathrm{m})$ & \multicolumn{2}{|l|}{0.4} \\
\hline \multicolumn{3}{|l|}{ EXPLOSIVES } \\
\hline & $1^{\text {st }} \operatorname{Deck}(\mathrm{s})$ & $2^{\text {nd }} \operatorname{Deck}(s)$ \\
\hline Type & HEET 30 & ANFO \\
\hline Length $(\mathrm{m})$ & 6.4 & 1.8 \\
\hline Mass $(\mathrm{kg})$ & 167.0 & 32.7 \\
\hline Specific Gravity & 1.22 & 0.85 \\
\hline $\operatorname{VOD}(\mathrm{m} / \mathrm{s})$ & 4800 & 3962 \\
\hline & & \\
\hline
\end{tabular}


The blast design, provided by Luck Stone, was used together with the rock characteristics to predict the ROM size distribution in the muck pile. The resultant size distribution is shown in Figure 14, together with the size distribution determined from digital image analysis of the grizzly oversize, and the size distribution obtained by sampling the primary crusher product belt (grizzly undersize + jaw crusher product). The primary crusher product belt sample has been included in this plot since it should reflect the fines $(<10 \mathrm{~mm})$ in the muck pile, assuming the sample is representative of the full shot. The image analysis sizing shows minimal fines as expected, since the images represent the grizzly oversize. Also, the ROM sample from image analysis is somewhat finer in the coarse end than the ROM expected from the full shot. The ROM shows around $6 \%$ less than $6.3 \mathrm{~mm}$, and $13.5 \%$ less than $25 \mathrm{~mm}$. The slightly higher fines content in the primary crusher product sample is believed to be due to the weathered cap rock (see Figure 4) in the blast that was not considered in the blast modeling. However these fines would all report to the crusher run pile in the secondary plant, so the discrepancy in the ROM prediction was not considered serious in terms of the impact on the downstream plant simulations.

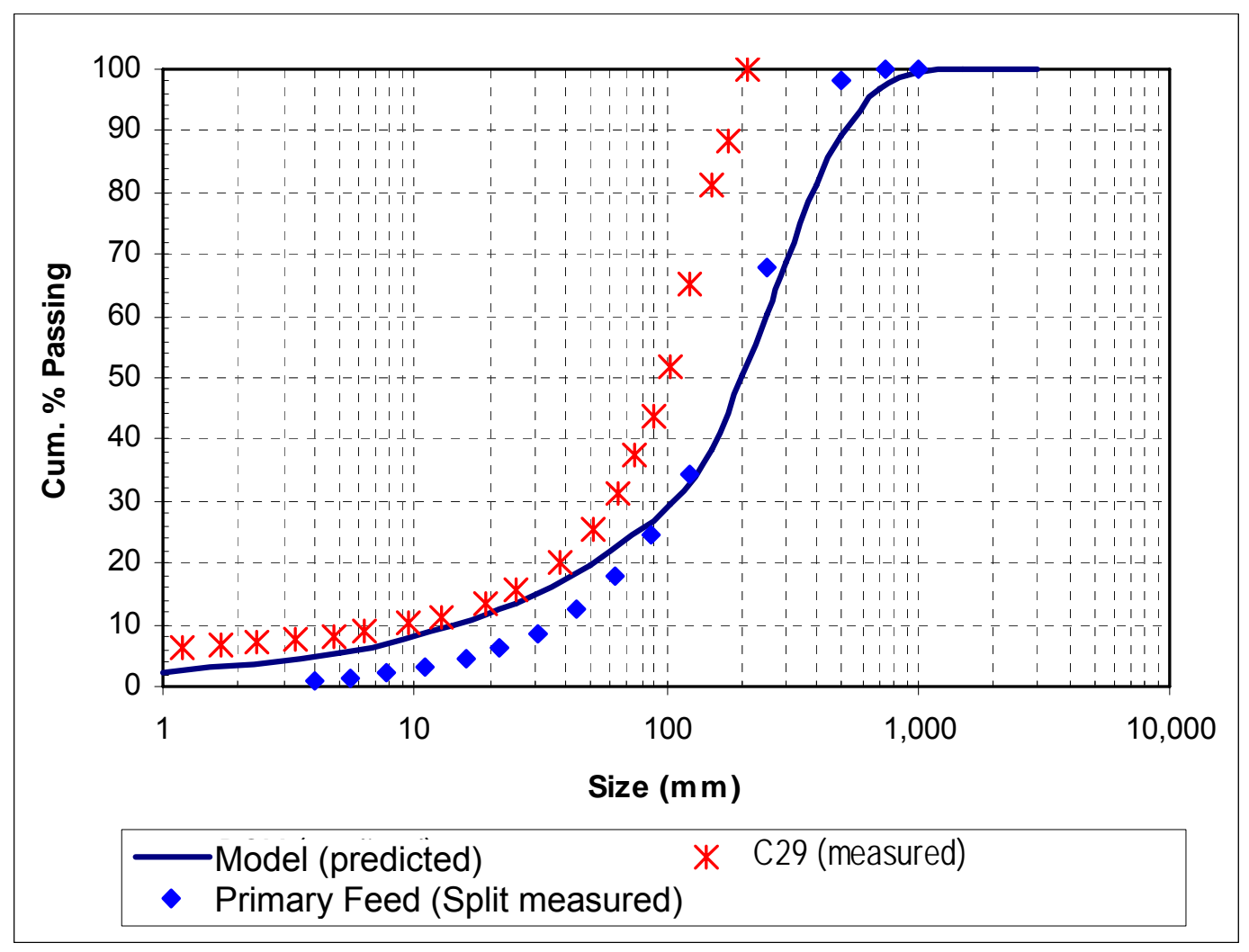

Figure 14. Bealeton ROM size distributions. 
Plant Modeling: Modeling of the plant operation at the Bealeton Quarry was a three stage process that involved determining the breakage characteristics of the ore, mass balancing the samples collected during the plant audit, and fitting the breakage data and mass-balanced sample data to the model equations contained in JKSimMet. The details of this procedure can be found in Napier-Munn et al., 1999.

Impact breakage tests were performed on selected samples of the Bealeton ore to characterize the breakage behavior of the rock. The data obtained from these tests were used in conjunction with the equation:

$$
t_{10}=A\left[1-e^{(-b . E c s)}\right]
$$

which relates the breakage behavior of the ore to the specific comminution energy. In the above equation, $t_{10}$ represents the percent of material in the product from the impact breakage test that is finer than one tenth of the original rock size prior to breakage. Ecs represents the specific comminution energy $(\mathrm{kWh} / \mathrm{t})$ determined from the mass of the weight and the height from which it is dropped when the impact breakage test is performed, and ' $A$ ' and ' $b$ ' are model parameters which are fitted to the experimental data. In general, parameter ' $A$ ' represents the maximum level of breakage for a particular ore type and parameter ' $b$ ' is related to the hardness of the ore with lower values indicating a harder ore. As there is some interaction between ' $A$ ' and ' $b$ ' in the impact breakage equation, the product $A^{*} b$ is generally used for comparison since it is better defined. The results of the impact breakage tests are summarized in Table 2, which shows the average parameters $A$ and $b$ for the diabase. For the Bealeton sample tested, the $A^{*} b$ result indicates that this diabase ore is very hard.

Table 2. Summary of Impact Breakage Test Results.

\begin{tabular}{|c|c|}
\hline Parameter & Diabase \\
\hline $\mathrm{A}$ & 86.1 \\
$\mathrm{~B}$ & 0.36 \\
$\mathrm{~A}^{*} \mathrm{~b}$ & 31.0 \\
\hline
\end{tabular}

The crusher model ore parameters are represented by two data sets as shown in Table 3. The first data set is an appearance function which relates the degree of breakage, $\mathrm{t}_{10}$, to the remainder of the size distribution (Table $3 a$ ). The second data set relates the size-specific energy required to achieve a set degree of breakage (Table $3 b$ ).

Once the breakage characteristics of the ore were determined, the secondary and tertiary audit data had to be mass balanced to provide consistent information around the screens. The belt cuts and conveyor speeds provided initial estimates of the tonnage rates on each belt just prior to the plant being crash stopped, and weightometers on the main plant feed conveyors were assumed to be correct. Since the belt cuts were sized to be statistically large enough for each product (Gy, 1976), the resulting sizing data from each sample were considered to be representative. 
Table 3. Summary of Crusher Ore Parameters - Bealeton Diabase.

(a) Appearance Function Data, $t_{n}(\%)$

\begin{tabular}{|c|c|c|c|c|c|}
\hline $\mathrm{t} 10(\%)$ & $\mathrm{t} 75$ & $\mathrm{t} 50$ & $\mathrm{t} 25$ & $\mathrm{t} 4$ & $\mathrm{t} 2$ \\
\hline 10 & 3.00 & 3.60 & 5.30 & 23.50 & 53.30 \\
20 & 6.00 & 7.40 & 10.80 & 44.80 & 82.90 \\
30 & 9.20 & 11.40 & 16.50 & 63.20 & 95.70 \\
\hline
\end{tabular}

(b) Size Reduction/Specific Comminution Energy, Ecs (kWh/t)

\begin{tabular}{|l|c|c|c|}
\hline & \multicolumn{3}{|c|}{ Initial Particle Size $(\mathrm{mm})$} \\
$\mathrm{t} 10(\%)$ & 14.5 & 28.9 & 41.1 \\
\hline 10 & 0.39 & 0.34 & 0.27 \\
20 & 0.84 & 0.71 & 0.58 \\
30 & 1.34 & 1.14 & 0.93 \\
\hline
\end{tabular}

The secondary plant data showed the most variation from the belt cut tonnage rates. This was not surprising considering the cyclic nature of that plant. Consequently, the mass balance relied on the secondary feed belt weightometer for plant feedrate and sizings. Figure 15 is an example of the balanced and experimental sizings, showing a close agreement. The flows in the plant are summarized in Table 4.

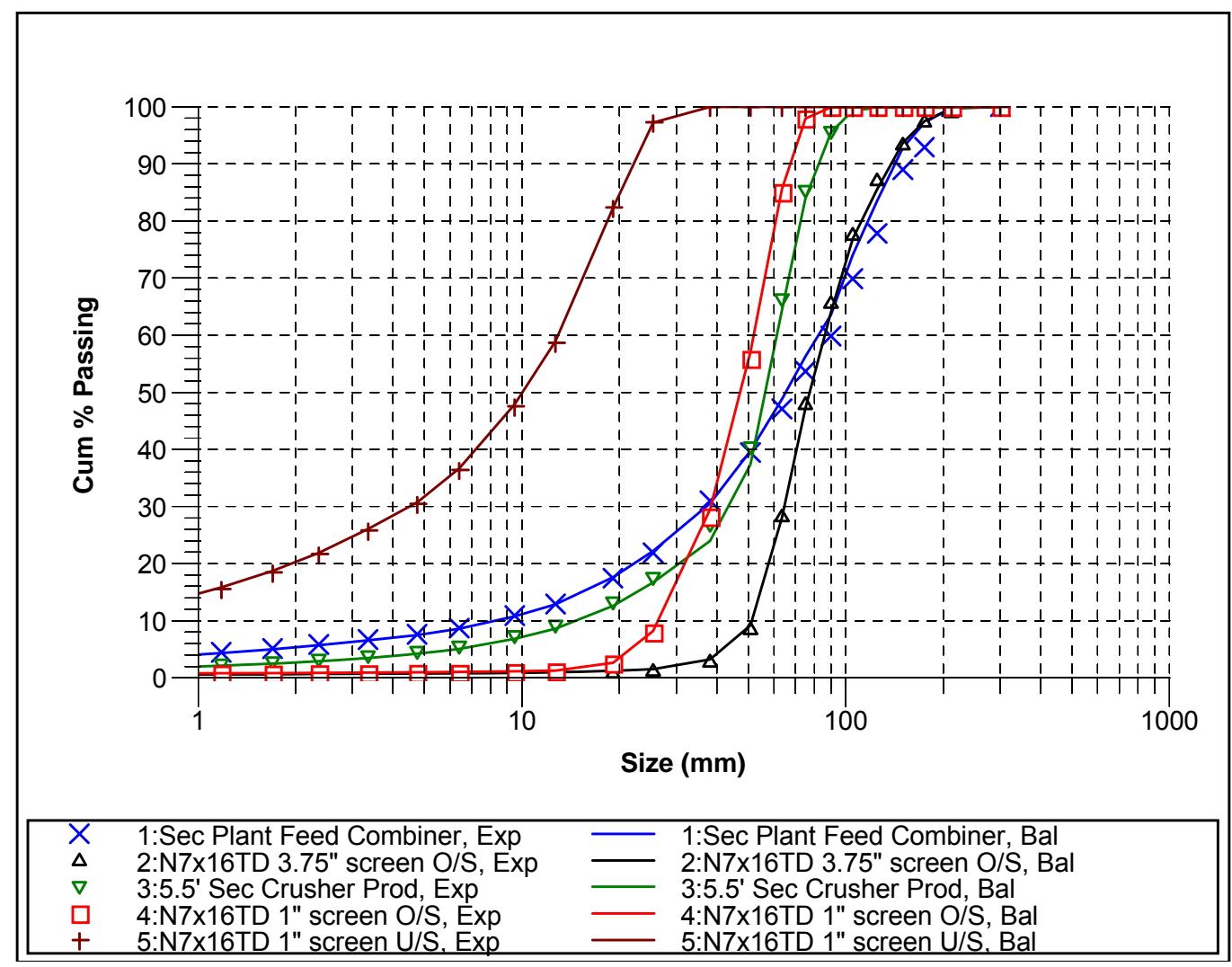

Figure 15. Comparison of audit and mass balance sizing results for Bealeton secondary plant - audit 1 (@ 518 tph, gap=47.2 mm). 
Table 4. Comparison of Audit and Mass Balance Tonnage Rates for Bealeton Secondary Plant - Audit 1 (@ 518 tph).

\begin{tabular}{|l|c|c|}
\hline \multirow{2}{*}{$\begin{array}{l}\text { Circuit } \\
\text { Stream }\end{array}$} & \multicolumn{2}{|c|}{ Flowrate (tph) } \\
\cline { 2 - 3 } Sec. Plant Feed (C31) & Measured & Balanced \\
Sec. Crusher Feed (C4A) & 518 & 516 \\
Sec. Crusher Product (C4) & 519 & 596 \\
Tertiary Feed (25 mm o/s, C9) & 449 & 596 \\
Crusher Run (25 mm u/s, C6) & 163 & 333 \\
\hline
\end{tabular}

The tertiary plant data balanced well since the plant was close to steady-state prior to each crash stop. Overall the mass balanced data were very consistent with experimental results and very suitable for modeling.

Once the breakage characteristics of the ore had been determined and the data acquired through the plant audit had been mass balanced, this information was used in conjunction with the JKSimMet program to create the mathematical representation of the Bealeton plant.

The Anderson/Whiten crusher model (Napier-Munn et al, 1999) was used to model the Bealeton crushers, based on the settings and ore breakage characteristics obtained from drop-weight test on the diabase samples. For conventional reciprocating crushers such as jaw, gyratory and cone units these characteristics are represented by 3 parameters $\left(K_{1}, K_{2}\right.$ and $\left.t_{10}\right)$. These ideally are equal to the closed side setting (CSS), open side setting (OSS), and the degree of size reduction that the rock undergoes each time the crusher completes a cycle in its operation respectively. In practice factors such as liner design, wear, and the shape of the product influence the actual values of these parameters. Studies at the JKMRC have shown that the parameter $t_{10}$ is a function of gap and feed coarseness, with the average degree of breakage per cycle of crushing decreasing as the feed becomes coarser at the same gap. Larger gaps reduce the effective $t_{10}$, while coarser feeds get nipped higher in the chamber, thereby undergoing more breakage steps in each crushing cycle, at an effectively lower $t_{10}$. The JKSimMet crusher model provides a good prediction of size reduction performance and power draw, but does not include ultimate throughput capacity at each setting. Equipment manufacturers were consulted to determine the expected capacity for each unit, and given ore bulk density.

Table 5 lists the parameters for the baseline audits at Bealeton. In the case of the primary crusher, the predicted ROM size distribution was assumed to be the crusher feed.

The primary crusher parameter $\mathrm{K}_{2}$ is unusually high and, assuming the predicted ROM feed size distribution is valid, suggests the crusher is allowing large thin rocks to pass into the product, without being broken. This is a common aspect of jaw crushers 
treating materials that fracture into 'slabby' pieces. The low $t_{10}$ value reflects a coarse feed that undergoes multiple small breakage steps before it can pass through the crusher. The secondary and tertiary crusher parameters are consistent with cone crusher behavior. The relatively low $t_{10}$ values across the stages suggest the machines are very suitable for the aggregate industry that seeks to create minimal fines in the production of closely sized crushed products. High $\mathrm{t}_{10}$ machines would be undesirable since they tend to generate more fines at the same reduction ratio.

Table 5. Summary of JKSimMet Crusher Model Parameters.

\begin{tabular}{|l|c|c|c|c|}
\hline Parameter & $\begin{array}{c}\text { Primary Jaw } \\
\text { Crusher }\end{array}$ & $\begin{array}{c}\text { Secondary Cone } \\
\text { Crusher }\end{array}$ & $\begin{array}{c}\text { Tertiary Cone } \\
\text { Crusher (Omnicone) }\end{array}$ & $\begin{array}{c}\text { Tertiary Cone } \\
\text { Crusher (Symons) }\end{array}$ \\
\hline Base Case & $\begin{array}{c}\text { CSS }=114 \mathrm{~mm} \\
\text { Throw }=42 \mathrm{~mm}\end{array}$ & CSS $=47.2 \mathrm{~mm}$ & CSS $=19.3 \mathrm{~mm}$ & CSS $=10.9 \mathrm{~mm}$ \\
\hline $\mathrm{K}_{1}$ & 114 & 63.0 & 23.0 & 15.2 \\
\hline $\mathrm{K}_{2}$ & 243 & 142.0 & 37.3 & 32.3 \\
\hline $\mathrm{t}_{10}$ & 1.36 & 12.2 & 13.5 & 7.8 \\
\hline
\end{tabular}

Having successfully fitted the models using the secondary and tertiary audits, statistical analysis of the relationships between the parameters and operating conditions was carried out. A dependency of the crusher parameters $\mathrm{K}_{1}, \mathrm{~K}_{2}$ and $\mathrm{t}_{10}$ on gap, throughput and feed coarseness was established. These relationships had the form:

$$
\text { CrusherParameter }=\mathrm{a}+\mathrm{b} \times \mathrm{CSS}+\mathrm{c} \times \mathrm{TPH}+\mathrm{d} \times \mathrm{F} 80
$$

where $a, b, c$ and $d$ are the regression coefficients in each parametric relationship. These relationships were used in JKSimMet to allow simulations to take into account changes in gap and/or crusher operating conditions.

The top, middle and bottom decks of the Bealeton vibrating screens were modeled using a simple efficiency curve which is described by three parameters (Napier-Munn et al, 1999):

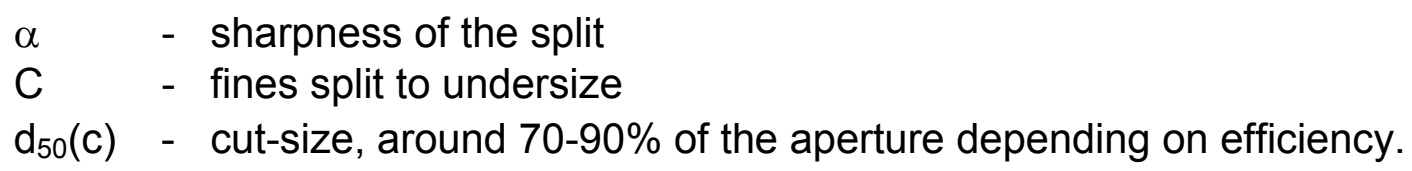

Information from the Bealeton scalp and product screens collected in the audits were used to derive simple relations between the screen load $(\mathrm{tph} / \mathrm{screen} / \mathrm{m})$ and the efficiency curve parameters. Table 6 lists the parameters for the baseline audits at Bealeton. In the case of the tertiary screen, the parameters reflect the normal plant throughput ( $315 \mathrm{tph})$. 
Table 6. JKSimMet Screen Model Parameters.

\begin{tabular}{|l|c|c|c|c|c|c|}
\hline Screen & Primary & \multicolumn{2}{|c|}{ Secondary } & \multicolumn{3}{c|}{ Tertiary } \\
\hline Parameter & Grizzly & TD & BD & TD & MD & BD \\
\hline$\alpha$ & 7.2 & 5.8 & 8.2 & 7.9 & 7.7 & 8.5 \\
\hline C & 99.9 & 98.1 & 97.1 & 99.2 & 96.2 & 97.0 \\
\hline $\begin{array}{c}d_{50}(c) \\
m m\end{array}$ & 126.2 & 60.4 & 23.4 & 18.5 & 9.36 & 4.21 \\
\hline
\end{tabular}

The screen parameters reflect the apertures and nature of the operation of the different screens. For example, the secondary screen top deck shows a relatively low sharpness of separation $(\alpha)$ for a coarse aperture screen. This reflects the inefficiency of that deck at the typical loads it treats.

A statistical analysis of the relationship between screen parameters and operating conditions was carried out for each deck, and a dependency of screen parameters $\alpha, C$, and $d_{50}(c)$ on throughput and percent passing nominal screen aperture was established. In the case of the tertiary screen top deck, which has a $25.4 \mathrm{~mm}$ nominal aperture, the relationship is of the form:

$$
\text { ScreenParameter }=p+q \times T P H+r \times \%-25.4 \mathrm{~mm}
$$

where $p, q$ and $r$ are regression coefficients. Relationships of this type were used to update parameters in JKSimMet to allow simulations to take into account changes in screen operating conditions, particularly screen load.

Figure 16 illustrates the agreement between model predicted and mass balanced data for the primary, secondary and tertiary plant audits. Overall the JKSimMet models describe the measured performance of the plants very well, and therefore can be used in the Mine-to-Mill simulation study with reasonable confidence.

Plant Simulation: Having determined the model parameters for each unit in the circuit and the influence of crusher gap and operating conditions on the parameters, the next step was to simulate the steady-state behavior of the full circuit. One of the remaining features of the tertiary plant that required special attention was feed segregation in the tertiary feed tank. As noted previously, when both crushers are online, the new feed tends to report to the Omnicone, while the screen top deck oversize reports predominantly to the Symons. To represent this in JKSimMet, two splitters were introduced, each having a parameter that could be set to mimic the mass fraction that reports to each crusher. Based on the data from the last tertiary plant audit, a near perfect segregation of the two streams feeding the tank was observed. 

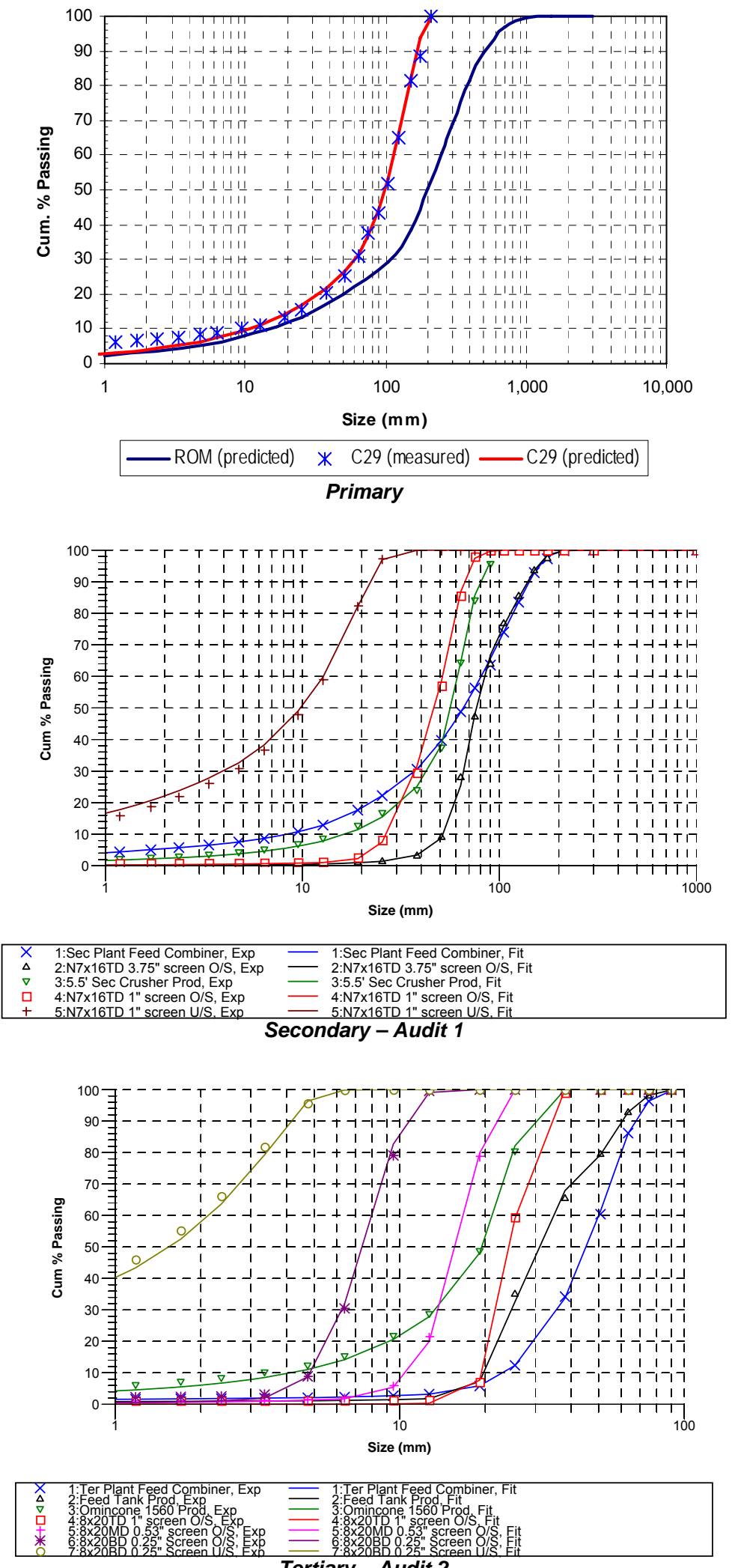

Figure 16. Comparison of mass balance and model predicted sizing results for Bealeton plant audits. 
Based on the fitted crusher, screen and tertiary feed tank model parameters and ore breakage data, a simulation model of the Bealeton circuit was developed in JKSimMet. The objective was to compare the simulated plant production figures with those achieved during the plant audits and test shot monitoring.

As shown in Table 7, the agreement between the simulated and measured data is reasonably close. The simulated results are those obtained from predicting plant performance under 'typical' steady-state conditions at nominal plant throughputs, while the plant data show the range of values obtained from the control system during the course of the test shot. In addition, the simulated size distributions are very close to the audit data, as shown in Figure 17, indicating again that the simulation models adequately describe the behavior of the plant.

Table 7. Comparison of Measured and Simulated Results for Audit Baseline Data.

\begin{tabular}{|l|c|c|c|c|}
\hline \multirow{2}{*}{\multicolumn{1}{|c|}{ Stream }} & \multicolumn{2}{c|}{ Flowrate (tph) } & \multicolumn{2}{c|}{ P80 (mm) } \\
\cline { 2 - 5 } & Measured & Simulated & Measured & Simulated \\
\hline Primary Crusher Product & $451-668$ & 541 & 148 & 143 \\
\hline Secondary Plant Feed & $516-693$ & 541 & $101-117$ & 143 \\
\hline Secondary Crusher Feed & $374-596$ & 557 & $111-130$ & 142 \\
\hline Secondary Crusher Product & $374-596$ & 557 & $63-79$ & 61 \\
\hline Secondary Screen +30 mm & $334-378$ & 355 & $57-61$ & 56 \\
\hline Secondary Screen -30 mm & $183-316$ & 186 & $15.6-18.3$ & 17.9 \\
\hline Tertiary Plant Feed & $159-315$ & 315 & $58-60$ & 56 \\
\hline Omnicone Product & $297-360$ & 311 & $23.2-27.2$ & 24.7 \\
\hline Symons Product & 201 & 185 & 18.5 & 19.1 \\
\hline Tertiary Screen +25 mm & $121-265$ & 182 & $28.6-30.8$ & 27.9 \\
\hline Tertiary Screen +13.5 mm & $99-173$ & 185 & $17.1-19.4$ & 17.5 \\
\hline Tertiary Screen +6.4 mm & $30-68$ & 72 & $9.1-9.6$ & 8.9 \\
\hline Tertiary Screen $-6.4 \mathrm{~mm}$ & $30-75$ & 58 & $3.1-3.3$ & 3.2 \\
\hline
\end{tabular}

Optimization and Alternative Designs: Having successfully modeled the baseline conditions, including the blast fragmentation and plant response, the next phase was to investigate ways of reducing the energy consumption through alternative blast designs. There were several constraints that had to be considered when changing the existing design. These included:

1. The proximity of the in-pit crusher to the face may necessitate limiting the amount of explosive energy in the blast to minimize the risk of damage from flyrock.

2. The structure of the rockmass of the upper benches is such that oversize blocks are readily formed and can be difficult to break in certain regions of the blast volume. The fragmentation model is a single-hole empirical model that is reasonably accurate for the body of the blast but has no mechanism for 
predicting blocks that "fall out" of the free face. Therefore, changes to the pattern for Mine-to-Mill objectives may have limited impact on the quantity of oversize rocks in certain regions of the blast.

3. The loader and primary crusher productivity are affected by the amount of oversize rocks, since these rocks cannot be fed directly to the primary crusher. Large rocks that "fall out" of the free face may limit other gains made by the Mine-to-Mill optimization.

4. The amount of fines that are created in the blast should be kept to a minimum to maximize the yield to the tertiary plant.

5. Drill holes are currently $165 \mathrm{~mm}$ in diameter. It may be possible for Luck Stone to use 178,190 and $203 \mathrm{~mm}$ holes, if required.

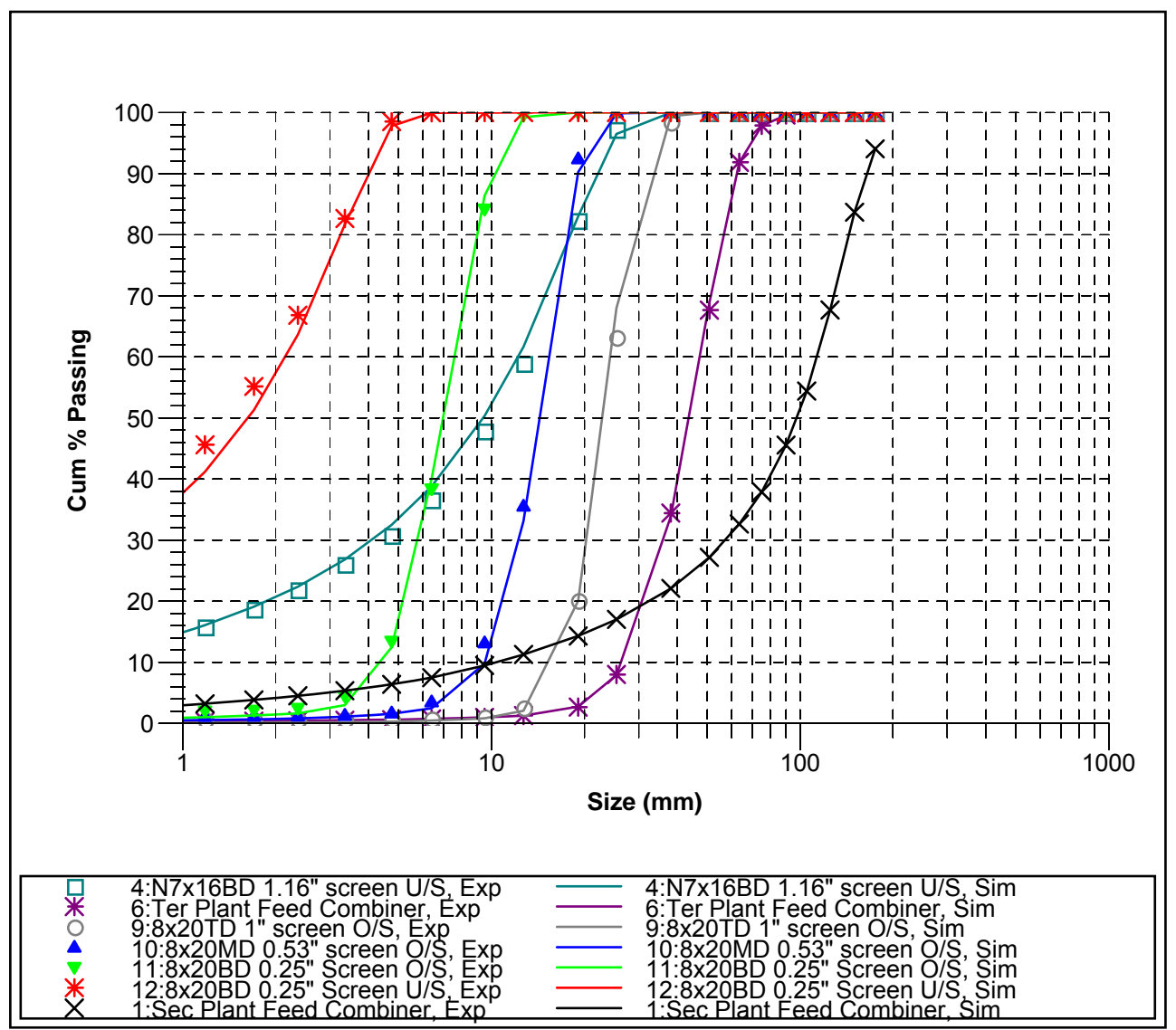

Figure 17. Simulation results for the Bealeton plant, showing key measured and simulated size distributions.

The above issues suggest that the ideal design should aim to reduce oversize while limiting the production of fines and minimizing the risk of damage to the primary crusher. This new design should allow Luck Stone to increase production through the primary and secondary plants, thereby reducing the power and man-hours required to treat the 
annual production target. To this end several alternative blast designs were evaluated using JKSimBlast. The resulting ROM fragmentation from each design was used to run the JKSimMet model of the Bealeton plant to quantify the impact on production in terms of throughput, energy consumption, fines generation and product yields. The key criteria considered in the evaluation were:

1. Drill and blast cost per ton of rock blasted, relative to base design

2. Reduction in energy consumption, $\%$

3. Increase in primary crusher throughput, $\%$

Figure 18 summarizes the effect of the six alternative designs investigated.

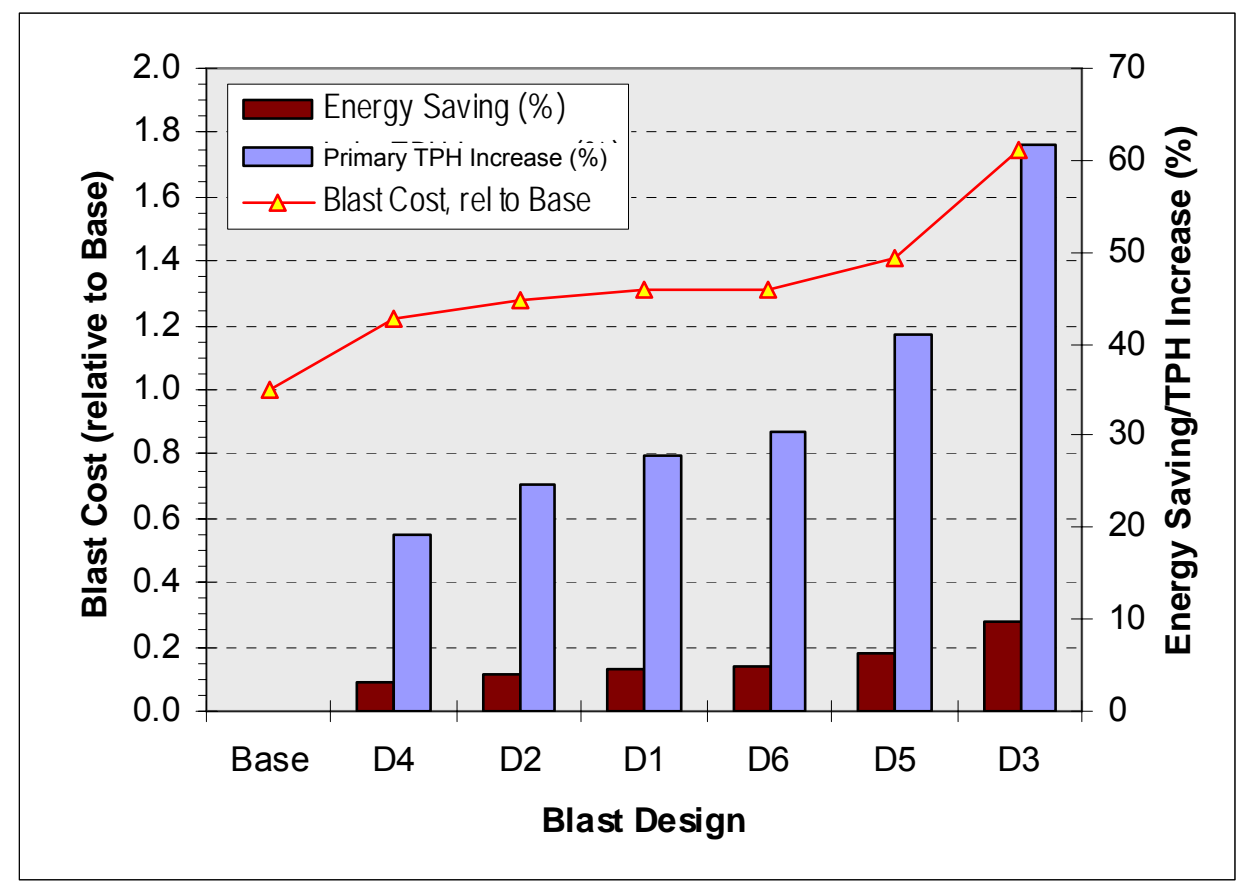

Figure 18. Comparison of alternative blast designs.

The simulations suggest that a $30 \%$ increase in blasting costs (energy) should allow the primary crusher throughput to be increased by around $27 \%$, by virtue of the finer fragmentation in the muck pile. This assumes the oversize rocks, still expected to be present in the muck pile, will not hamper the excavator digging rates. The percent oversize is expected to reduce, but cannot be eliminated in one blast design change since the burden shows damage from the previous blasts and is highly jointed. The resulting energy savings across the full plant is expected to be around $4-5 \%$. Higher production rates are expected from designs D5 and D3, but the risk of damage to the primary crusher may be too high. Overall, blast design D1 appears to be a significant change from current practice, with the greatest benefit for the least risk to the operation. This design introduces a staggered pattern, with a reduced burden and spacing, resulting in a $30 \%$ increase in blasting energy. Table 8 summarizes the design specifications for both the baseline and D1 blast designs. 
Table 8. Comparison of Blast Design Specifications for the Baseline Blast Design (2904) and the Alternative Blast Design (D1).

\begin{tabular}{|c|c|c|c|c|}
\hline PATTERN & \multicolumn{2}{|c|}{ Blast 2904} & \multicolumn{2}{|c|}{ Design 1} \\
\hline Bench Height (m) & \multirow{2}{*}{\multicolumn{2}{|c|}{$\begin{array}{l}11.6 \\
4.5\end{array}$}} & \multicolumn{2}{|c|}{$\begin{array}{c}11.6 \\
3 ?\end{array}$} \\
\hline Burden (m) & & & & \\
\hline Spacing (m) & \multicolumn{2}{|c|}{4.2} & \multicolumn{2}{|c|}{3.7} \\
\hline Hole Diameter (mm) & \multicolumn{2}{|c|}{165} & \multicolumn{2}{|c|}{165} \\
\hline Hole Depth (m) & \multicolumn{2}{|c|}{12.5} & \multicolumn{2}{|c|}{12.2} \\
\hline Sub-drill (m) & \multicolumn{2}{|c|}{0.9} & \multicolumn{2}{|c|}{0.6} \\
\hline Stemming Height (m) & \multicolumn{2}{|c|}{4.3} & \multicolumn{2}{|c|}{4.3} \\
\hline Staggered & \multicolumn{2}{|c|}{ No } & \multicolumn{2}{|c|}{ Yes, equilateral } \\
\hline ROCKMASS & & \\
\hline Rock Type & & & \multicolumn{2}{|c|}{ Diabase } \\
\hline Specific Gravity & \multicolumn{2}{|c|}{$\begin{array}{c}\text { Diabase } \\
2.973\end{array}$} & \multirow{2}{*}{\multicolumn{2}{|c|}{$\begin{array}{c}2.973 \\
67\end{array}$}} \\
\hline Young's Modulus (GPa) & \multicolumn{2}{|c|}{67} & & \\
\hline UCS (MPa) & \multicolumn{2}{|c|}{245} & \multicolumn{2}{|c|}{245} \\
\hline Mean Block Size (m) & \multicolumn{2}{|c|}{0.4} & \multicolumn{2}{|c|}{0.4} \\
\hline EXPLOSIVES & $1^{\text {st }} \operatorname{Deck}(\mathrm{s})$ & $2^{\text {nd }} \operatorname{Deck}(s)$ & $1^{\text {st }} \operatorname{Deck}(s)$ & $2^{\text {nd }} \operatorname{Deck}(s)$ \\
\hline Type & HEET 30 & ANFO & HEET 30 & ANFO \\
\hline Length (m) & 6.4 & 1.8 & 3.0 & 4.9 \\
\hline Mass (kg) & 167.0 & 32.7 & 78.5 & 89.0 \\
\hline Specific Gravity & 1.22 & 0.85 & 1.22 & 0.85 \\
\hline $\operatorname{VOD}(\mathrm{m} / \mathrm{s})$ & 4800 & 3962 & 4800 & 3962 \\
\hline RWS & 95 & 100 & 95 & 100 \\
\hline Powder Factor (kg/t) & \multicolumn{2}{|c|}{0.30} & \multicolumn{2}{|c|}{0.41} \\
\hline
\end{tabular}

Overall, the simulations suggest that energy savings should be realized in the primary and secondary plants, due to the finer blast fragmentation. The savings expected in the tertiary plant are marginal because the feed is essentially the $25 \times 90 \mathrm{~mm}$ fraction produced by the secondary plant. The relative size distribution of this fraction varies little in the simulations; hence the impact on the tertiary plant is small. However, since the feed to the secondary plant is finer, there may be scope for Luck Stone to reduce the aperture of the lower deck to maintain or increase the yield to the tertiary plant. The resulting feed to the tertiary plant would then be marginally finer, which should allow Luck Stone to increase the yield of \#57 and \#8 products.

Implementation: In November 2004, side-by-side tests were conducted at the Bealeton Quarry to implement changes suggested by the Mine-to-Mill models and to generate data for a quantitative comparison of current practice vs. recommended practice. The Luck Stone shot (LS-0105) contained approximately $7,000 \mathrm{~m}^{3}$ of material while the Mine-to-Mill shot (MTM-0305) contained approximately $10,000 \mathrm{~m}^{3}$ of material. The approximate location of the two shots can be seen in Figure 19. 
Figure 19. LS (0105) and MTM (0305) shots prior to side-by-side testing.

Table 9 summarizes the patterns as implemented. There are a couple of significant differences between the implemented patterns and the original design (Table 8). The bench height is 0.3 meters lower for the LS blast which had an affect on the sub-drill. There was more ANFO used in the LS blast and less than designed in the MTM blast which indicates that there was a lot more water in the MTM blast. This change in explosive loading was a major contributor to the much greater increase in powder factor than planned, $75 \%$ compared to $34 \%$. The net result was that the LS blast should have been coarser than the original baseline case, and the MTM blast should have been finer than predicted for D1. However, as it turned out, this was not the case.

Table 9. Comparison between LS and MTM Blast Implementations.

\begin{tabular}{|c|c|c|c|c|}
\hline PATTERN & \multicolumn{2}{|c|}{ LS Blast } & \multicolumn{2}{|c|}{ MTM Blast } \\
\hline Bench Height $(\mathrm{m})$ & \multicolumn{2}{|c|}{11.0} & \multicolumn{2}{|c|}{11.3} \\
\hline Burden $(\mathrm{m})$ & \multicolumn{2}{|c|}{4.2} & \multicolumn{2}{|c|}{3.2} \\
\hline Spacing (m) & \multicolumn{2}{|c|}{4.1} & \multicolumn{2}{|c|}{3.7} \\
\hline Hole Diameter $(\mathrm{mm})$ & \multicolumn{2}{|c|}{165} & \multicolumn{2}{|c|}{165} \\
\hline Hole Depth $(\mathrm{m})$ & \multicolumn{2}{|c|}{11.3} & \multicolumn{2}{|c|}{11.9} \\
\hline Sub-drill (m) & \multicolumn{2}{|c|}{0.3} & \multicolumn{2}{|c|}{0.6} \\
\hline Stemming Height (m) & \multicolumn{2}{|c|}{4.3} & \multicolumn{2}{|c|}{4.3} \\
\hline Staggered & \multicolumn{2}{|c|}{ No } & \multicolumn{2}{|c|}{ Yes, equilateral } \\
\hline \multicolumn{5}{|l|}{ ROCKMASS } \\
\hline Rock Type & \multicolumn{2}{|c|}{ Diabase } & \multicolumn{2}{|c|}{ Diabase } \\
\hline Specific Gravity & \multicolumn{2}{|c|}{2.973} & \multicolumn{2}{|c|}{2.973} \\
\hline Young's Modulus (GPa) & \multicolumn{2}{|c|}{67} & \multicolumn{2}{|c|}{67} \\
\hline UCS (MPa) & \multicolumn{2}{|c|}{245} & \multicolumn{2}{|c|}{245} \\
\hline Mean Block Size (m) & \multicolumn{2}{|c|}{0.4} & \multicolumn{2}{|c|}{0.4} \\
\hline EXPLOSIVES & $1^{\text {st }} \operatorname{Deck}(s)$ & $2^{\text {nd }} \operatorname{Deck}(s)$ & $1^{\text {st }} \operatorname{Deck}(s)$ & $2^{\text {nd }} \operatorname{Deck}(\mathrm{s})$ \\
\hline Type & HEET 30 & ANFO & HEET 30 & ANFO \\
\hline Length $(\mathrm{m})$ & 2.7 & 4.3 & 5.8 & 1.8 \\
\hline Mass $(\mathrm{kg})$ & 70 & 78 & 151 & 33 \\
\hline Specific Gravity & 1.22 & 0.85 & 1.22 & 0.85 \\
\hline $\operatorname{VOD}(\mathrm{m} / \mathrm{s})$ & 4800 & 3962 & 4800 & 3962 \\
\hline RWS & 95 & 100 & 95 & 100 \\
\hline Powder Factor (kg/t) & \multicolumn{2}{|c|}{0.26} & \multicolumn{2}{|c|}{0.47} \\
\hline
\end{tabular}


Figure 20 represents the size distributions of the material fed to the primary crusher during side-by-side testing. The distributions were estimated by photographing full excavator buckets and analyzing these photographs with the Split image analysis system. Since oversize rocks are set aside for secondary breakage and not fed directly to the primary crusher, the actual top size of the muck pile is much greater than indicated here (approx. $1.8 \mathrm{~m}$ ). It is evident from these results that there is a large variation in fragmentation within the MTM muck pile (and probably within the LS muck pile). The material that was excavated on the afternoon of November 9 was much finer than the material excavated the following morning. While the MTM muck pile was visibly finer and excavator cycle times were shorter for the periods observed, there were still some very large rocks within the MTM muck pile that affected the overall excavation productivity.

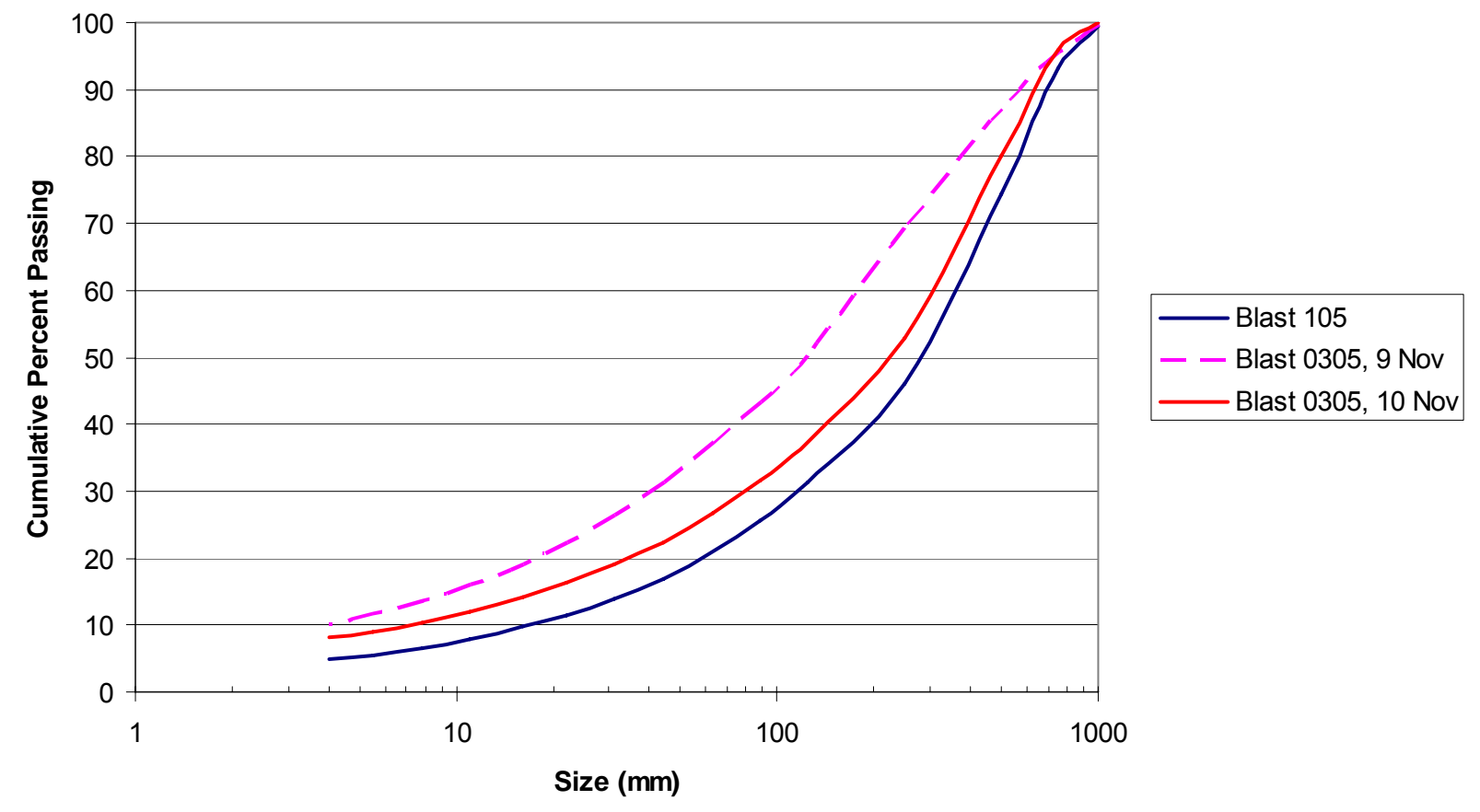

Figure 20. Comparison of ROM fragmentation measured by Split for the LS (0105) and MTM (0305) blasts.

The actual blast data from Table 9 were used in conjunction with the JKSimBlast rockmass model to predict the ROM distributions for both the LS and the MTM shots. Figure 21 shows a comparison of these predicted distributions with the Split image analysis data from Figure 20. As shown, there is a close match at the fine end of the distribution but a poor match at the coarse end, particularly for the MTM blast. Since the Split results do not include the oversize rocks whereas the model predicts the full size distribution, the comparison of the ROM size distributions at the coarse end is even worse than shown in Figure 21. The discrepancy between the Split size analysis data and the model predictions seems to suggest that there was a change in the rockmass properties between the time of the initial audit and the time of the side-by-side testing. Furthermore, the data also seem to indicate that there was a significant difference in the rockmass properties for the two shots compared in the side-by-side testing 


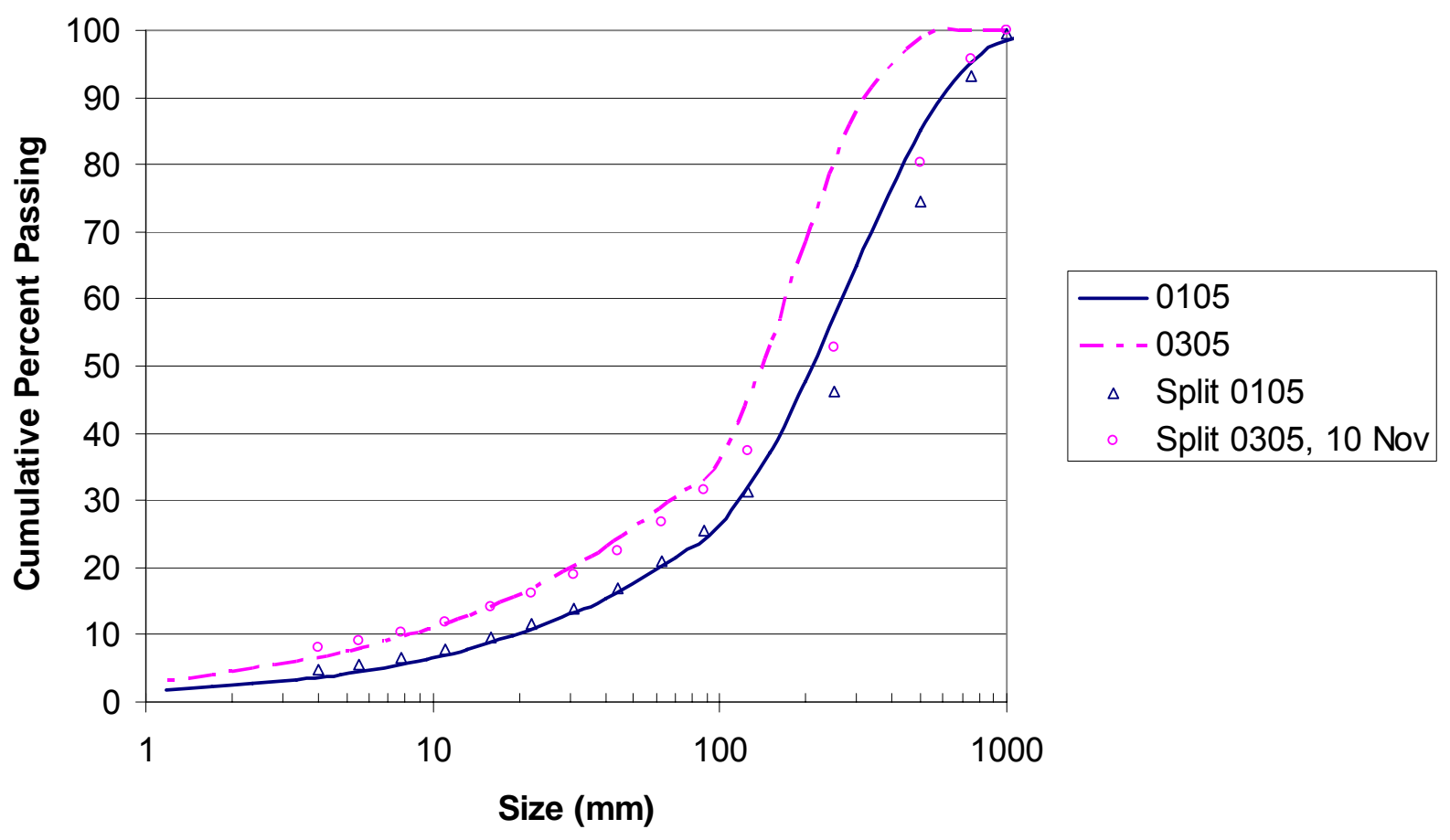

Figure 21. Comparison of size distributions estimated by modeling and Split (LS shot - 0105, MTM shot - 0305).

While it is difficult to quantify the hypotheses that changes in rockmass properties resulted in less improvement than expected with the modified blast design, there are several facts that seem to support this contention.

1. The JKMRC fragmentation model is typically accurate at predicting coarse fragmentation.

2. Split is typically accurate at measuring the coarse end of the distribution; however, it cannot measure what it cannot see - fines and oversize. Fines are estimated by a built-in algorithm, but the oversize, absent from the excavator bucket, is excluded.

3. Past experience indicates that any discrepancies between Split and modeled ROM are typically in the fine end.

4. Coarse fragmentation is dominated by the rockmass structure and whether the explosive energy can break in-situ blocks.

5. Less breakage occurs adjacent to a free face where a block can move instead of break. The front row burden and the stemming zone will have coarser fragmentation than the lower-middle zone of the blast.

6. The practice of reducing the front row charge and increasing face burdens is commendable for safety and damage control but will result in more oversize. 
7. The powder factor of the MTM blast was $75 \%$ greater than the LS blast; however, the measured change in coarse fragmentation is modest by comparison. Though the Split size analyses are consistent with the change in powder factor at the fine end, the measured size analyses from the primary crusher product samples show little change. This suggests the intact rock hardness in the MTM shot was potentially higher than for the LS shot.

8. The Virginia Tech laboratory tests on Bealeton rock samples indicate a significant variation in the UCS of the diabase. The average was found to be 245 $\mathrm{MPa}$, with $95 \%$ confidence limits of 125 to $365 \mathrm{MPa}$.

9. The oversize rocks from the LS blast took 21 hours to break compared with 66 hours for the oversize from the MTM blast.

10. The blasts were of different shape and volume with the MTM blast being $40 \%$ larger than the LS blast.

11. There is more weathered cap-rock in the LS blast than in the MTM blast.

Figures 22 and 23 are photographs of the LS and MTM blasts respectively after all holes have initiated. The containment of energy is similar for both blasts and the amount of cratering and flyrock is typical. In fact, considering the increased energy in the MTM blast, the containment is very good. There are many oversize blocks evident in the faces of both blasts. The rockmass in the free face is conditioned by the neighboring blast such that the in-situ blocks are loosened and more likely to be pushed out of the face rather than fractured. Figure 24 clearly shows large liberated blocks after the LS blast in what will be the north-west corner of the MTM blast. The large block to the right is estimated to be $2-2.5$ meters high.

The JKMRC fragmentation model is a single-hole, semi-empirical model that does not directly account for free face fragmentation. Therefore if the modeled blast is different than a "typical" blast, the model will be inaccurate. The fact that the face holes are over-burdened and under-charged at Bealeton to protect in-pit equipment could account for some of the oversize but does not explain why the MTM blast had more oversize than the LS blast.

Since the LS blast was smaller than the MTM blast, one would expect the total volume of oversize rock to be greater for the larger blast. Figure 25 is a plan view of both blasts showing the regions of each blast adjacent to free faces. The stemming zone at the top of each blast is also a free face. It is by no means suggested that all material in these zones ends up as oversize but for the sake of this exercise, the volume of oversize is assumed to be proportional to this volume. A summary of the simple calculation is presented in Table 10. 


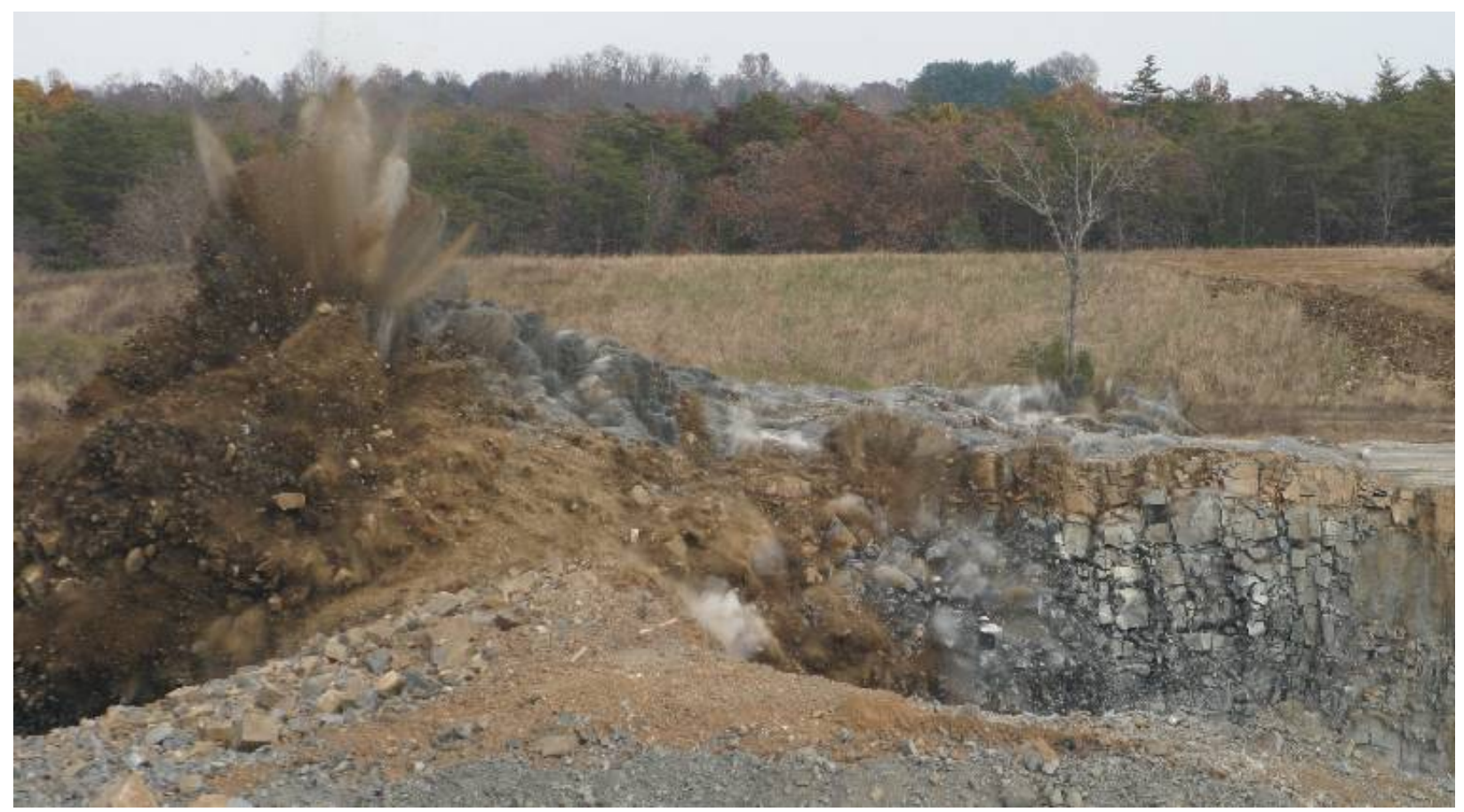

Figure 22. Photograph of the LS blast clearly showing oversize blocks in the free face.

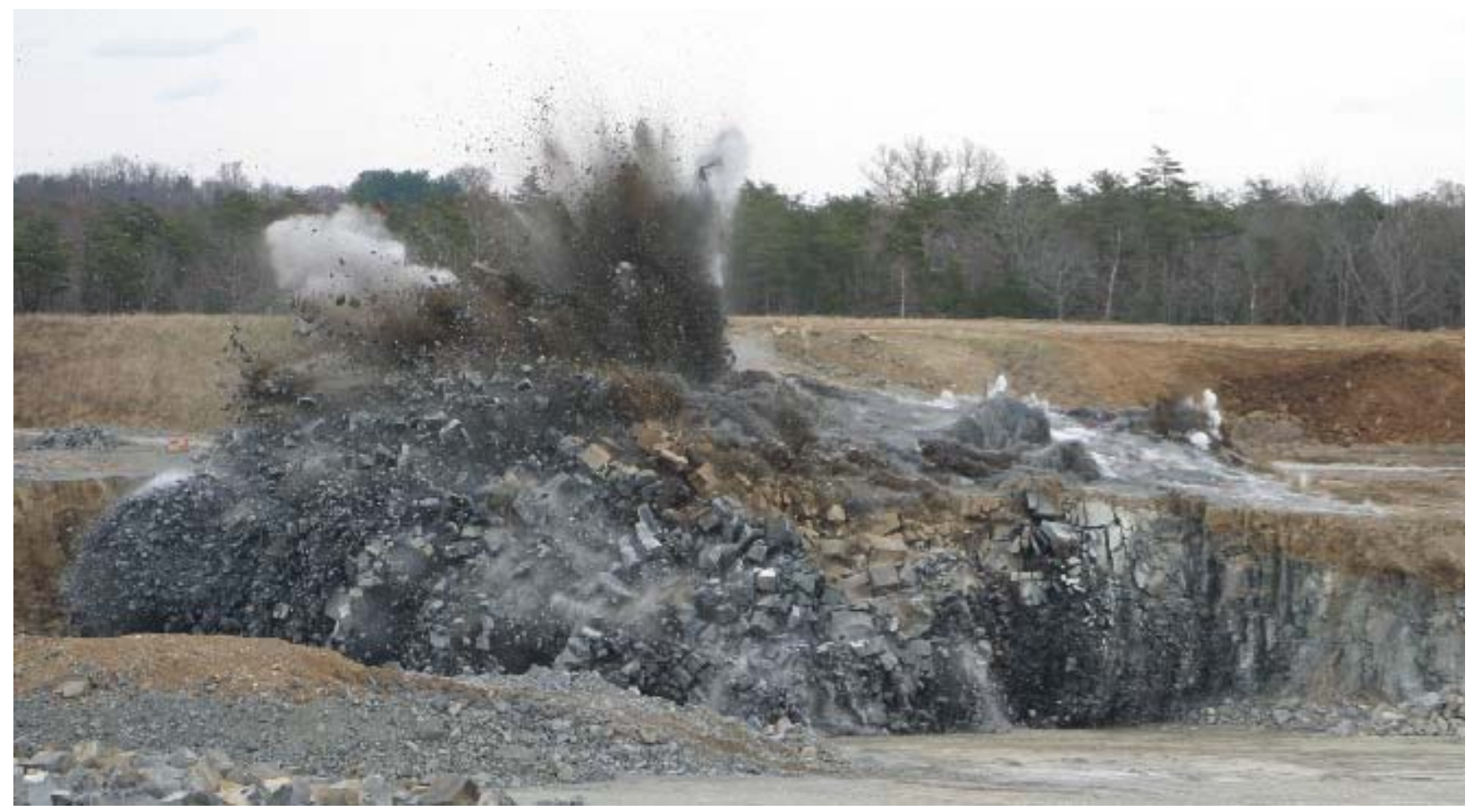

Figure 23. Photograph of the MTM blast clearly showing oversize blocks in the free face and stemming zones. 


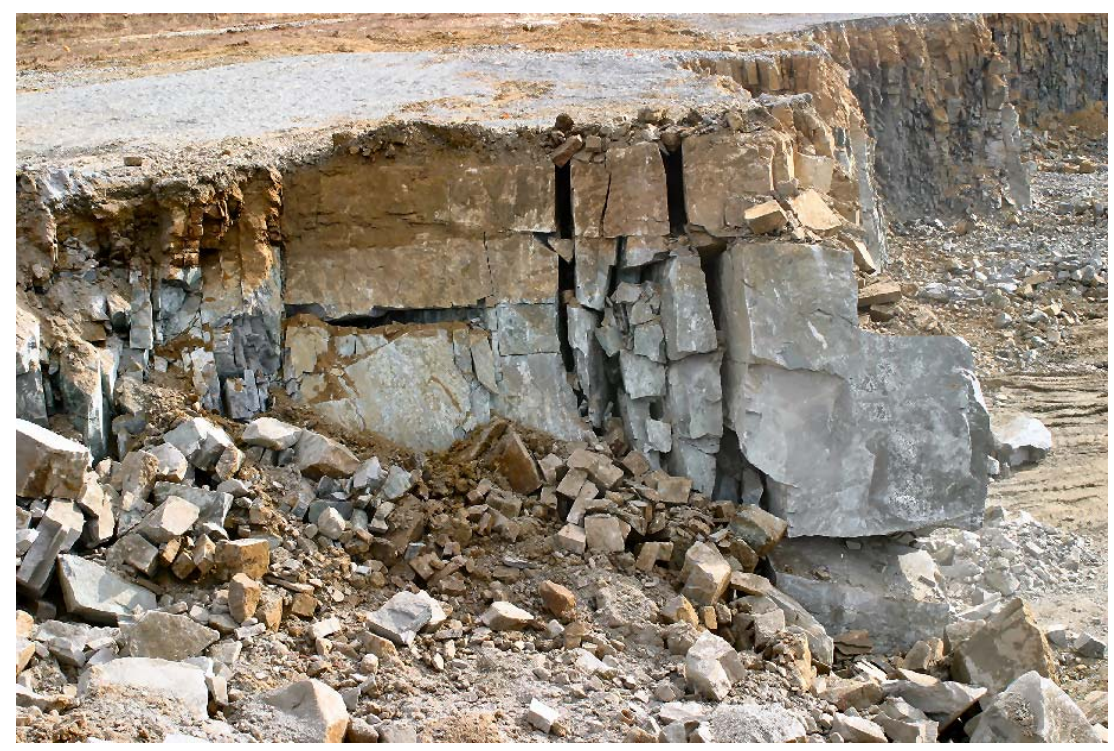

Figure 24. Liberated blocks in the back wall after the LS blast. These blocks are in the front face of the MTM blast.

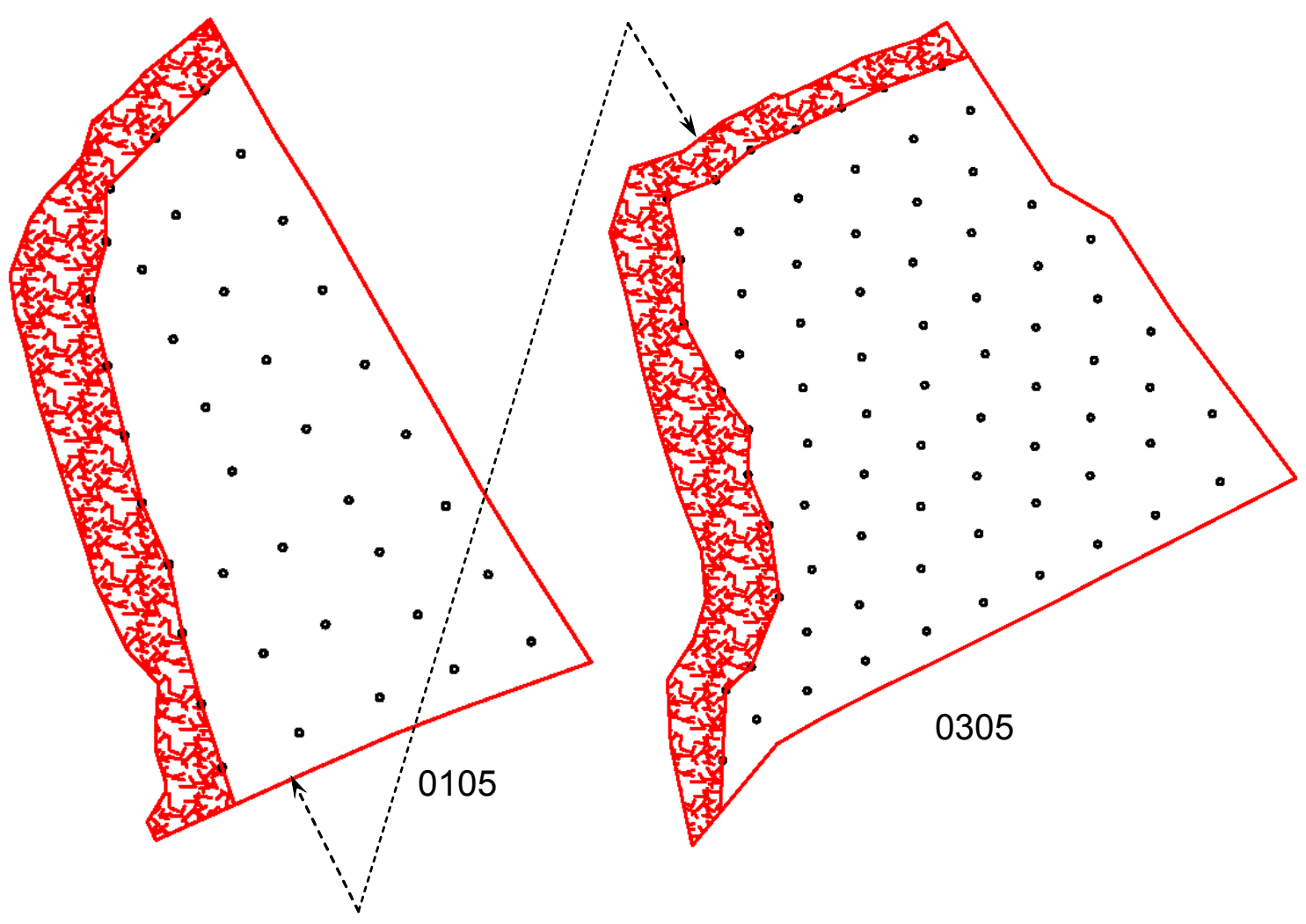

Figure 25. Plan view of the area that could be considered free-faced for the LS (0105) and MTM (0305) shots. 
Table 10. Estimated Volume of Rock that could be considered Free-Faced.

\begin{tabular}{|l|c|c|c|c|}
\cline { 2 - 5 } \multicolumn{1}{c|}{} & \multicolumn{2}{c|}{ LS Blast } & \multicolumn{2}{c|}{ MTM Blast } \\
\cline { 2 - 5 } \multicolumn{1}{c|}{} & Volume $\left(\mathrm{m}^{3}\right)$ & $\%$ of Total & Volume $\left(\mathrm{m}^{3}\right)$ & $\%$ of Total \\
\hline Free Face & 1585 & $22 \%$ & 1812 & $18 \%$ \\
\hline Stemming Zone & 2854 & $40 \%$ & 4009 & $40 \%$ \\
\hline TOTALS & 4439 & $63 \%$ & 5821 & $59 \%$ \\
\hline Time to Break $(\mathrm{hrs})$ & 21 & & 66 & \\
\hline Breakage Rate $\left(\mathrm{m}^{3} / \mathrm{hr}\right)$ & $\mathbf{2 1 1}$ & & $\mathbf{8 8}$ & \\
\hline
\end{tabular}

As shown, both blasts have about $60 \%$ of their total volume within this hypothetical freeface zone but by virtue of its greater volume, the MTM blast has $5800 \mathrm{~m}^{3}$ compared with $4400 \mathrm{~m}^{3}$ for the LS blast. Clearly, the $200 \%$ increase in the time required to break the oversize from the MTM blast is not consistent with the 30\% increase in the oversize volume. It is apparent that the MTM oversize was more difficult to break. Perhaps the rocks were larger and required more strikes or perhaps the rocks were harder. There is no data to quantify the breakage mechanism but photographs clearly show a difference between the two blasts. The LS muck pile was littered with large weathered cap-rock (Figure 26, left) whereas most of the oversize in the MTM muck pile was fresh diabase (Figure 26, right). On the whole, the LS blast oversize was visibly smaller than the oversize from the MTM blast (Figure 27).

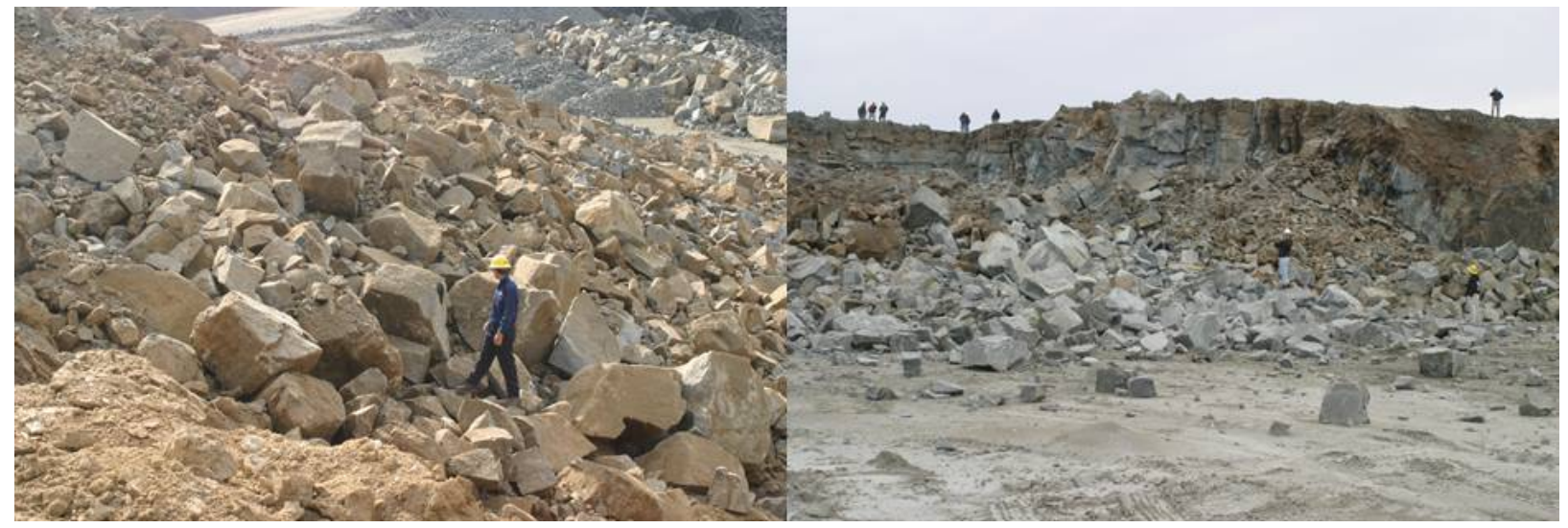

Figure 26. The surface of the LS (left) and MTM (right) muck piles - note the color of the oversize material.

The results to date all point at the rockmass being responsible for the coarser than expected fragmentation. The biggest unknown for any blast is generally the rockmass and the preceding discussion provides evidence that the overall rockmass for the MTM blast was much blockier and harder than the adjacent LS blast. Although the actual rockmass parameters for the side-by-side comparison test are unknown, it is possible to use JKSimBlast to back-calculate the parameters that would be required to match the experimental ROM size distributions. Using this approach, the LS blast only required a modest change, increasing the in-situ block size from $0.4 \mathrm{~m}$ to $0.6-0.7 \mathrm{~m}$. In contrast, 
the MTM blast required large changes to get close to the measured ROM at the coarse end. The in-situ block size increased from 0.4 to $1.5 \mathrm{~m}$ and the UCS increased from 245 to $350 \mathrm{MPa}$ (recall that the upper 95\% confidence limit for the Bealeton diabase is $365 \mathrm{MPa})$.

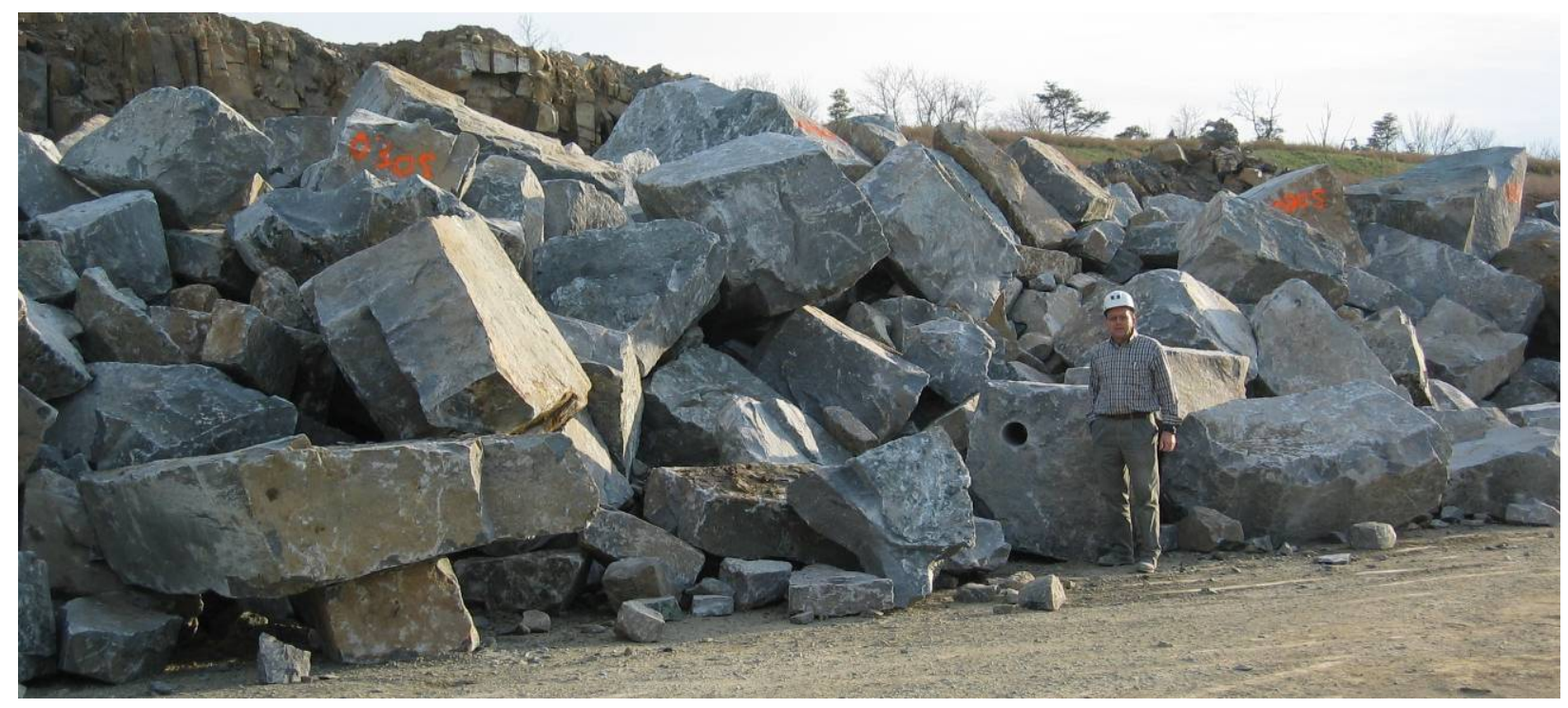

Figure 27. Oversize rocks from the MTM blast that have been set aside.

So while the benefits from the MTM blast compared with the LS blast were inconclusive, the model can be used to postulate the outcome if the LS blast pattern had been used in the MTM rockmass. To address this question, the model for the LS blast was re-run with the mean in-situ bock size increased from 0.4 to $1.5 \mathrm{~m}$, and the UCS increased from 245 to $350 \mathrm{MPa}$. Figure 28 compares the fragmentation model predictions.
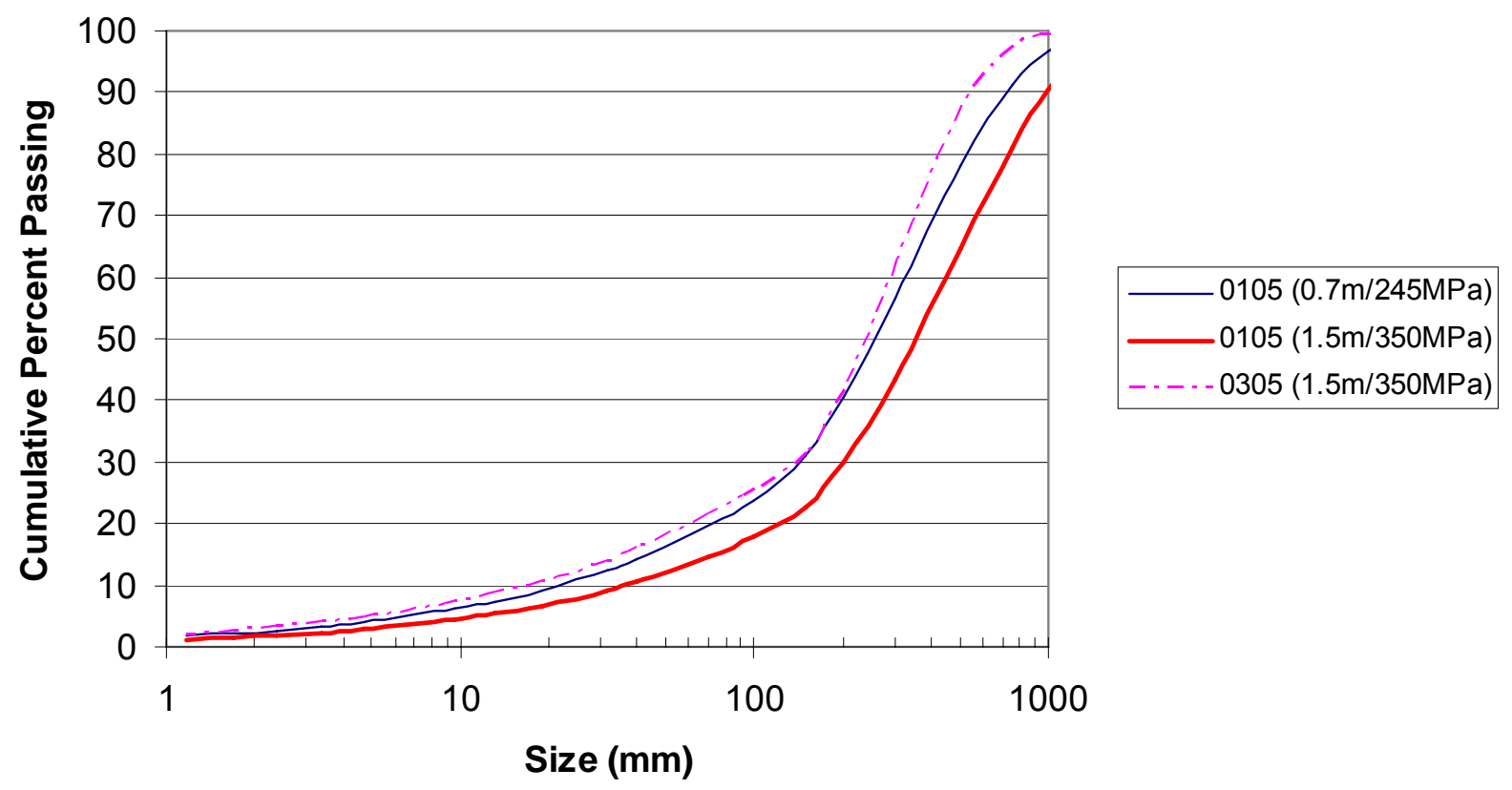

Figure 28. Effect of rockmass on the size distributions (estimated by modeling). 
The results suggest that had the LS blast design been applied to the rockmass encountered in the MTM shot, the fragmentation would have been markedly coarser than achieved with the MTM design. The impact of this change was simulated using the latest model of the Bealeton plant to quantify the change in energy consumption expected with the coarser fragmentation. The simulation results indicate a $5-6 \%$ increase in energy consumption with the LS design over that expected with the MTM design.

It is interesting to note that the plant audit data, which represents a snapshot of the plant performance in the absence of production slowdowns due to oversize rock, indicates a significant reduction in the energy consumption using the MTM design (Table 11).

Table 11. Comparison of Energy Consumptions between Luck Stone and MTM.

\begin{tabular}{|l|c|c|c|}
\hline Crusher Stage & Luck Stone & MTM & Difference \\
\hline Primary kWh/t & 0.35 & 0.29 & $17.1 \%$ \\
\hline Secondary kWh/t & 0.26 & 0.24 & $7.7 \%$ \\
\hline Tertiary kWh/t & 1.17 & 1.05 & $10.3 \%$ \\
\hline TOTAL kWh/t & 1.77 & 1.57 & $11.7 \%$ \\
\hline
\end{tabular}

The audit results suggest that the MTM blast design allowed the Bealeton plant to save around $11.7 \%$ in energy consumed per tonne of rock fed to the plant, without any significant impact on product yields or their size distributions. This is consistent with the original DOE project objective of $5-10 \%$ savings.

Unfortunately, the overall production figures, which include the time associated with the handling of oversize rock, do not support the plant audit results. Table 12 summarizes the overall production rates on the feed material from the two shots.

Table 12. Comparison of Luck Stone and MTM Production Rates.

\begin{tabular}{|l|c|c|c|c|}
\hline \multirow{2}{*}{ Circuit } & \multicolumn{2}{|c|}{ Luck Stone } & \multicolumn{2}{c|}{ MTM } \\
\cline { 2 - 5 } & Tonnes & MTPH & Tonnes & MTPH \\
\hline Primary & 19169 & 645 & 27553 & 610 \\
Secondary & 18516 & 578 & 27004 & 560 \\
Tertiary & 9523 & 283 & 13066 & $225^{\star}$ \\
\hline
\end{tabular}

The overall production rates are not consistent with the plant audits, for several reasons:

1. The larger oversize in the MTM shot resulted in a decrease in overall productivity at the primary crusher. 
2. When finer material was present in the MTM shot, the operators may not have recognized the potential to run the plant at more optimum settings.

3. A tertiary crusher re-line during the processing of the MTM material forced the plant to run with only one tertiary crusher.

Likewise, the total energy consumption figures for the primary crusher are not consistent with the plant audit and appear to support the contention that there was a significant difference in the rockmass associated with each shot. Table 13 is a summary of data collected from the operating logs on the primary product belt weightometer and primary crusher fuel consumption over the duration of both shots. While the MTM shot was larger than the LS shot by $44 \%$, it required $73 \%$ more fuel. This would tend to support the contention that the rockmass in the MTM shot was blockier, had less weathered material, and resulted in more coarse product and oversize than the LS shot, despite the fact that there seemed to be more fines in the body of the shot.

Table 13. Comparison of Primary Plant Performance (all shot material).

\begin{tabular}{|c|c|c|}
\hline Shot & LS & MTM \\
\hline Tonnes & 19169 & 27553 \\
Hours (crushing) & 29.7 & 45.2 \\
\hline Ave MTPH & 645 & 610 \\
Primary Fuel (gals) & 576 & 997 \\
kWh & 7407 & 12821 \\
kWh/t & 0.39 & 0.47 \\
\hline
\end{tabular}

Hence it appears that differences in rockmass conditions between the LS and MTM benches mitigated the expected benefits from the MTM design. Had the MTM design been applied to the first blast, and the LS design to the second blast, the resulting fragmentation would have been markedly different. In terms of experimentation, one hopes to control the disturbances as much as possible. It appears in the Bealeton case, the rockmass was not as consistent as expected by the project team. In hindsight, there may be merit in evaluating the effect of the MTM implementation over a longer period from which operating data on throughput and energy can be compared with the production data under the previous blasting practice. This should smooth out any short term fluctuations which the site might experience in applying the new blast design over an extended period, say three to six months. As a result of this experience at Bealeton, the long-term monitoring approach was implemented in the second phase of this work at the Pittsboro Quarry. 


\section{Pittsboro Quarry}

Fragmentation Modeling: Analysis of the data collected during the blast monitoring and assessment of blast 8605 at the Pittsboro test site resulted in the following input parameters for the JKMRC blast fragmentation model (Table 14).

Table 14. Fragmentation Model Input Parameters for Blast 8605.

\begin{tabular}{|l|l|}
\hline PATTERN & \\
\hline Bench Height $(\mathrm{m})$ & 21 \\
\hline Burden $(\mathrm{m})$ & 4.3 \\
\hline Spacing $(\mathrm{m})$ & 3.8 \\
\hline Hole Diameter $(\mathrm{mm})$ & 165 \\
\hline Hole Depth $(\mathrm{m})$ & 22 \\
\hline Sub-drill $(\mathrm{m})$ & 1.0 \\
\hline Stemming Height $(\mathrm{m})$ & 4.8 \\
\hline ROCKMASS & \\
\hline Rock Type & Basalt \\
\hline Specific Gravity & 2.79 \\
\hline Young's Modulus $(\mathrm{GPa})$ & 67 \\
\hline UCS $(\mathrm{MPa})$ & 200 \\
\hline Mean Block Size $(\mathrm{m})$ & 0.3 \\
\hline EXPLOSIVES & \\
\hline Type & HydroMite 4400 \\
\hline Length $(\mathrm{m})$ & 17.3 \\
\hline Mass $(\mathrm{kg})$ & 452 \\
\hline Specific Gravity & 1.22 \\
\hline VOD $(\mathrm{m} / \mathrm{s})$ & 5500 \\
\hline RWS & 95 \\
\hline Powder Factor $\left(\mathrm{kg} / \mathrm{m}^{3}\right)$ & 1.31 \\
\hline Powder Factor $(\mathrm{kg} / \mathrm{t})$ & 0.45 \\
\hline
\end{tabular}

The model-predicted size distribution for shot 8605 (solid line) is shown in Figure 29, together with the Split measured primary crusher feed as determined from 10 images of different truck loads heading up to the crusher pad. The C2 sample has been included in the chart since it should reflect the fines $(<10 \mathrm{~mm})$ in the muckpile, assuming the sample is representative of the full shot. The ROM size distribution shows around $13.7 \%$ less than $6.3 \mathrm{~mm}$, and $34 \%$ less than $38 \mathrm{~mm}$. 


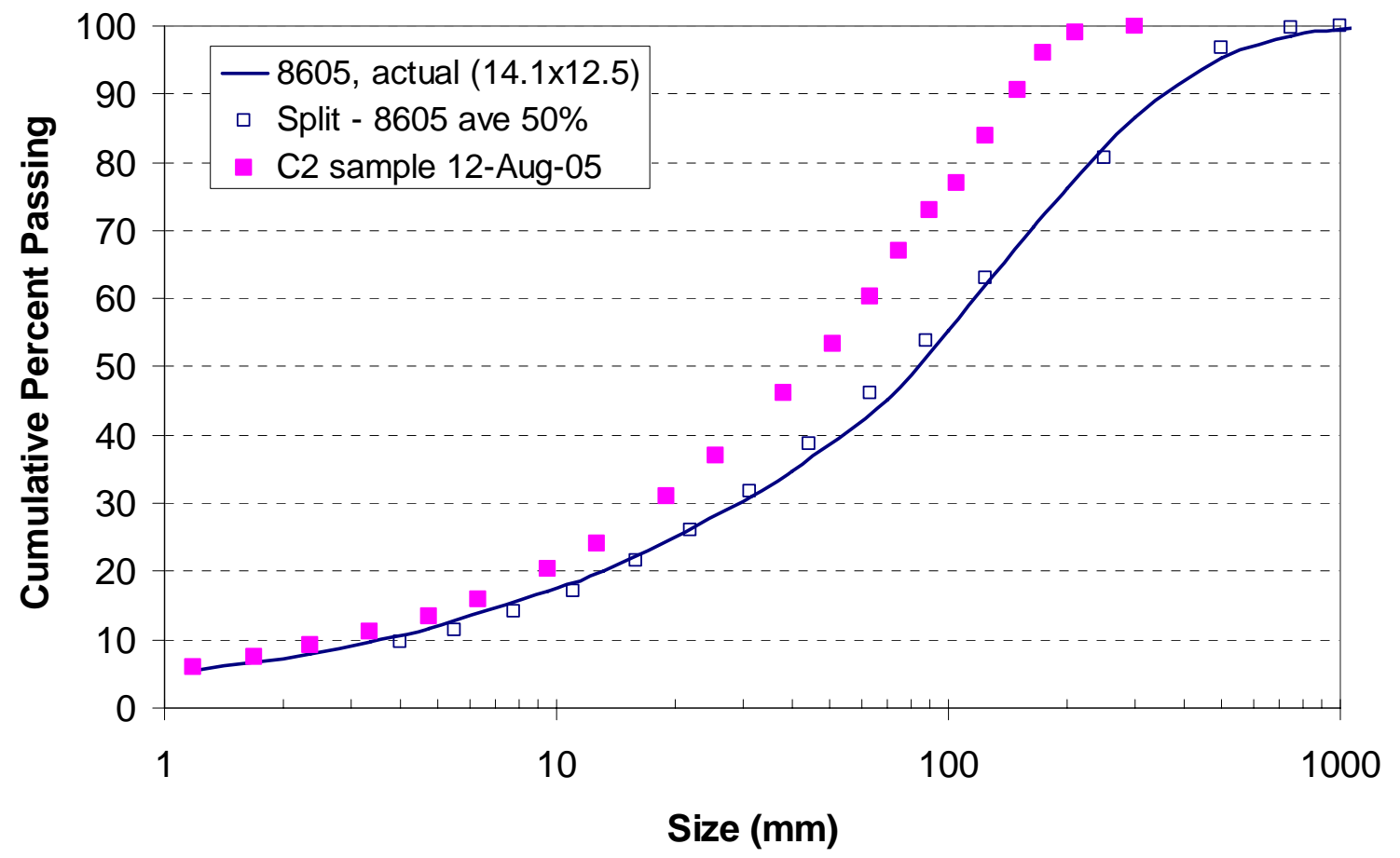

Figure 29. Pittsboro ROM Fragmentation for Blast 8605, model prediction and Split size analysis.

Plant Modeling: The modeling of the plant operation at the Pittsboro Quarry was a three stage process that involved determining the breakage characteristics of the ore, mass balancing the samples collected during the plant audit, and fitting the breakage data and mass-balanced sample data to the model equations contained in JKSimMet.

Impact breakage tests were performed on selected samples of the Pittsboro ore to characterize the breakage behavior of the rock. Since significant variability was observed in the geology at the Pittsboro Quarry, the impact breakage testing was extended to characterize five different rock types observed at the site (See Figure 30). The results of the impact breakage tests are summarized in Table 15.
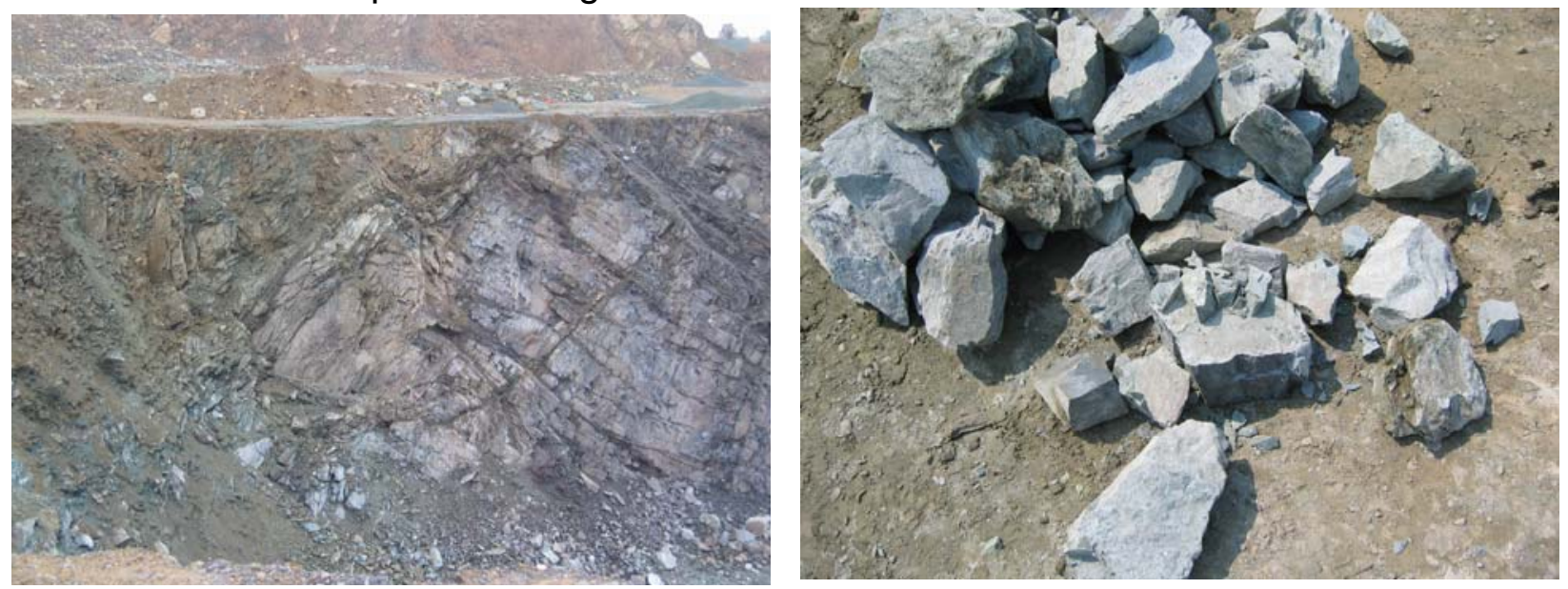

Figure 30. Example of Pittsboro ore variability; test shot face and C2 sample. 
Table 15. Summary of Ore Breakage Test Results.

\begin{tabular}{|c|c|c|c|c|c|c|c|}
\hline Ore Type & A & b & SG & $A^{*} b$ & $\begin{array}{l}\text { UCS* } \\
\text { (MPa) }\end{array}$ & SG & $\begin{array}{c}\text { UCS }(\mathrm{MPa})-\text { from } \\
\text { Point Load Tests (PLT) }\end{array}$ \\
\hline \multicolumn{6}{|c|}{ Survey Samples (from C2 belt cut) } & \multicolumn{2}{|c|}{ Spot Samples (from C2) } \\
\hline LS & 56 & 0.79 & 2.79 & 44.2 & 212 & & $19,66,97,183$ \\
\hline $3 \mathrm{M}$ & 53 & 0.69 & 2.83 & 36.2 & 303 & & $19,58,112,124,142,288$ \\
\hline \multicolumn{6}{|c|}{$31.5 \times 26.5 \mathrm{~mm}$ samples only } & \multirow{7}{*}{2.75} & \multirow{8}{*}{204} \\
\hline LS (composite) & 73 & 0.60 & & 43.8 & 216 & & \\
\hline 3M (composite) & 72 & 0.44 & & 31.8 & 385 & & \\
\hline Basalt & 66 & 0.66 & & 43.8 & 216 & & \\
\hline Dacite & 100 & 0.30 & & 30.0 & 424 & & \\
\hline Miscellaneous & 71 & 0.56 & & 39.9 & 255 & & \\
\hline Tuffs & 92 & 0.37 & & 34.2 & 336 & & \\
\hline Weathered & 55 & 1.15 & & 63.5 & 111 & 2.78 & \\
\hline
\end{tabular}

UCS $^{*}$ - estimated from $A$ and $b$ parameters using JKMRC proprietary correlations.

The characterization results are as expected in terms of the LS and 3M samples, and it appears that the five different ore types identified by the research team are also consistent. Clearly the $3 \mathrm{M}$ andesite is harder than the LS basalt. The weathered group is quite variable and has the lowest UCS with an average of around $90 \mathrm{MPa}$, while the basalt is much harder, with typical values around $200 \mathrm{MPa}$. The tuffs are in the same range as the $3 \mathrm{M}$ andesite, which, from previous measurements, has a UCS around 275 MPa. The miscellaneous ore type appears to be harder than the basalt but somewhat weaker than the $3 \mathrm{M}$ andesite and the dacite samples. The results on the spot C2 samples suggest that both the LS and 3M materials contain some softer rocks, but in general have a majority of the main rock type, basalt or andesite.

Following characterization of the rock, the data analysis and modeling were broken into four parts:

1. Primary: Luck Stone and $3 \mathrm{M}-1$ survey on each feed source

2. Secondary: Luck Stone - 7 surveys; $3 \mathrm{M}-1$ survey

3. Secondary: Bivitec - 2 surveys

4. Tertiary: Luck Stone - 3 surveys

In the case of the primary plant, where mass balancing was not possible, the only accurate sample was C2. The crusher feed size distribution was estimated using Split analysis of truck loads, with the last truck tipped into the grizzly feeder assumed to represent the feed responsible for the $\mathrm{C} 2$ result. As noted previously, the Rip-Rap oversize was not quantified precisely, and it was not possible to sample the grizzly oversize and undersize. The models for these three pieces of equipment relied on previous knowledge and the design criteria for the two screens and crusher. Hence the main parameter to be determined was the crusher $\mathrm{t}_{10}$ which describes the degree of ore 
breakage in the machine. Figure 31 shows the fitted and measured results using the calibrated JKSimMet model for the Luck Stone feed audit

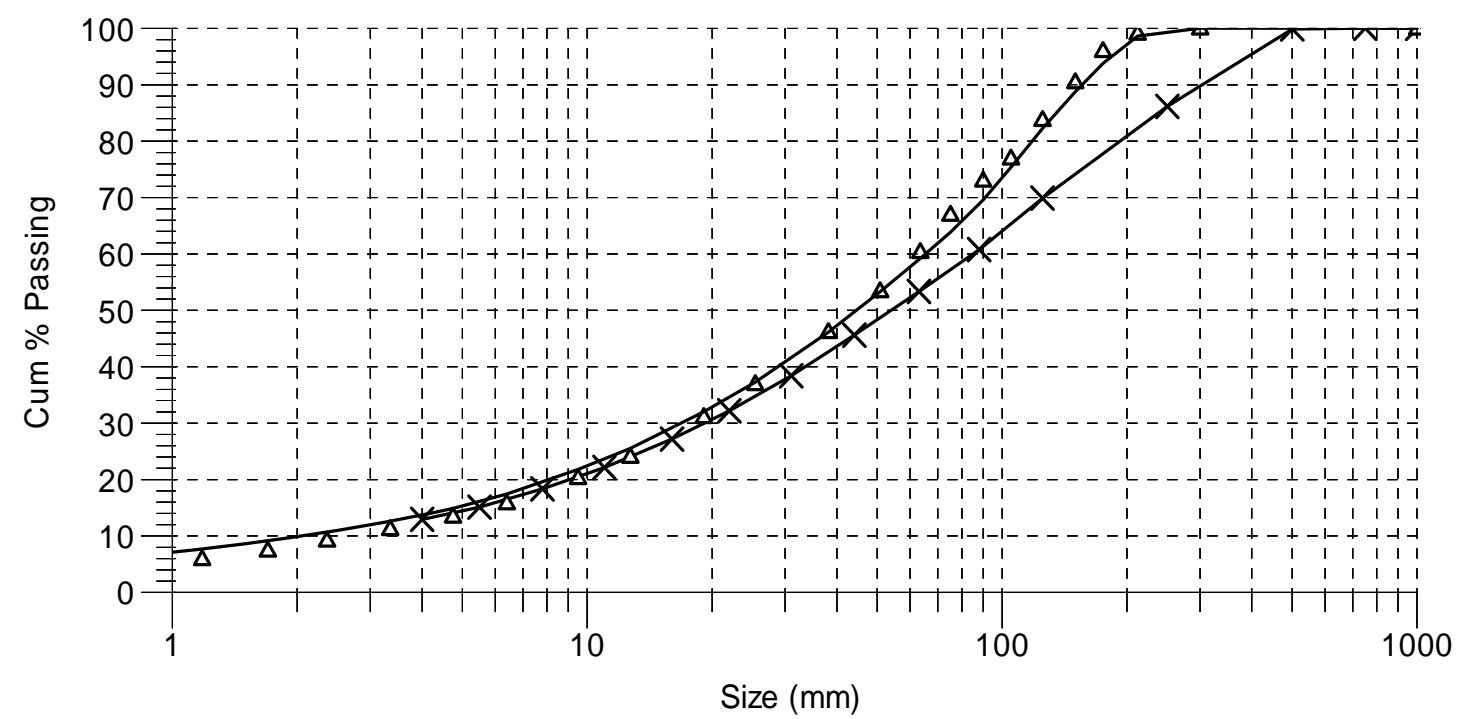

$* \quad$ 1:ROM Combiner, Fit $\quad \Delta \quad$ 2:Rip-Rap Screen U/S, Exp $\quad-\quad$ 2:Rip-Rap Screen U/S, Fit

Figure 31. Comparison of audit and fitted sizing results for Pittsboro primary plant survey - LS side (@ 1385 tph, gap=146 mm).

Before model calibration could start on the remainder of the plant, the secondary and tertiary audit data had to be mass balanced to provide consistent information around the screens, which were in closed-circuit with the crushers. The belt cuts and conveyor speeds provided initial estimates of the tonnage rates on each belt just prior to the plant being crash stopped, and weightometers on the main plant feed conveyors were assumed to be correct. Since the belt cuts were sized to be statistically large enough for each product, with the exception being the crusher feed, the resulting sizing data from each sample was considered to be representative. Due to the large oversize rocks present in the crusher feed, a statistically valid sample would have required around 25 tonnes. Hence the $400 \mathrm{~kg}$ samples were not expected to provide reliable data at the coarse end $(>125 \mathrm{~mm})$. Rather, the mass balance was expected to yield a good indication of the coarse end given all other samples and estimated flows.

The LS secondary plant data around the crusher showed the most variation from the belt cut tonnage rates, which is not surprising considering the cyclic nature of that plant (see Table 16). Consequently the circuit was split into two parts (see Figure 32), and the data were mass balanced assuming the $\mathrm{C} 13$ rate represented the actual crusher feed rate, whereas the top deck scalping screen oversize was back-calculated. This approach was successful in allowing the other streams to be easily balanced, and confirmed the extent of imbalance in the flows around the crusher, with only survey 7 having a screen oversize rate that matched the crusher feed rate. 
Table 16. Summary of Secondary Plant Survey Results.

\begin{tabular}{|c|c|c|c|c|c|c|c|c|c|c|}
\hline Survey & $\begin{array}{c}\text { Pile } \\
\text { Level }\end{array}$ & $\begin{array}{l}\text { CSS } \\
(\mathrm{mm})\end{array}$ & & C9 & C12 & C13 & C29 & C16 & Screen O/S & kWh/t \\
\hline 1 & $\mathrm{Hi}$ & 44 & $\begin{array}{l}\text { tph } \\
\text { F80 (mm) }\end{array}$ & $\begin{array}{r}483 \\
63\end{array}$ & $\begin{array}{l}147 \\
127\end{array}$ & $\begin{array}{c}147 \\
64\end{array}$ & $\begin{array}{l}307 \\
17.3\end{array}$ & $\begin{array}{l}222 \\
57.8\end{array}$ & $\begin{array}{l}102 \\
133\end{array}$ & 0.08 \\
\hline 2 & $\mathrm{Hi}$ & 44 & $\begin{array}{l}\mathrm{tph} \\
\mathrm{F} 80(\mathrm{~mm})\end{array}$ & $\begin{array}{r}595 \\
67\end{array}$ & $\begin{array}{l}313 \\
161\end{array}$ & $\begin{array}{c}313 \\
47\end{array}$ & $\begin{array}{l}453 \\
16.1\end{array}$ & $\begin{array}{l}317 \\
54.9\end{array}$ & $\begin{array}{l}136 \\
167\end{array}$ & 0.13 \\
\hline 3 & $\mathrm{Hi}$ & 51 & $\begin{array}{l}\text { tph } \\
\text { F80 (mm) }\end{array}$ & $\begin{array}{r}609 \\
69 \\
\end{array}$ & $\begin{array}{l}349 \\
125 \\
\end{array}$ & $\begin{array}{c}349 \\
56 \\
\end{array}$ & $\begin{array}{l}456 \\
16.8 \\
\end{array}$ & $\begin{array}{l}359 \\
58.4 \\
\end{array}$ & $\begin{array}{l}144 \\
154 \\
\end{array}$ & 0.15 \\
\hline 4 & $\mathrm{Hi}$ & 38 & $\begin{array}{l}\text { tph } \\
\text { F80 (mm) }\end{array}$ & $\begin{array}{r}579 \\
71 \\
\end{array}$ & $\begin{array}{l}343 \\
169 \\
\end{array}$ & $\begin{array}{c}343 \\
41 \\
\end{array}$ & $\begin{array}{l}463 \\
17.7 \\
\end{array}$ & $\begin{array}{l}290 \\
52.3 \\
\end{array}$ & $\begin{array}{l}168 \\
15.3 \\
\end{array}$ & 0.15 \\
\hline 5 & Lo & 44 & $\begin{array}{l}\text { tph } \\
\text { F80 (mm) }\end{array}$ & $\begin{array}{r}609 \\
51 \\
\end{array}$ & $\begin{array}{l}309 \\
118\end{array}$ & $\begin{array}{c}309 \\
49\end{array}$ & $\begin{array}{l}522 \\
16.4\end{array}$ & $\begin{array}{l}332 \\
57.1\end{array}$ & $\begin{array}{c}64 \\
128\end{array}$ & 0.10 \\
\hline 6 & Lo & 51 & $\begin{array}{l}\text { tph } \\
\text { F80 (mm) }\end{array}$ & $\begin{array}{l}583 \\
131\end{array}$ & $\begin{array}{l}362 \\
159\end{array}$ & $\begin{array}{c}362 \\
60\end{array}$ & $\begin{array}{l}223 \\
17.7\end{array}$ & $\begin{array}{l}380 \\
60.3\end{array}$ & $\begin{array}{l}341 \\
154\end{array}$ & 0.21 \\
\hline 7 & Lo & 44 & $\begin{array}{l}\text { tph } \\
\text { F80 (mm) }\end{array}$ & $\begin{array}{r}463 \\
87\end{array}$ & $\begin{array}{l}158 \\
147\end{array}$ & $\begin{array}{c}158 \\
59\end{array}$ & $\begin{array}{l}160 \\
19.8\end{array}$ & $\begin{array}{l}301 \\
59.1\end{array}$ & $\begin{array}{l}161 \\
124\end{array}$ & 0.09 \\
\hline
\end{tabular}

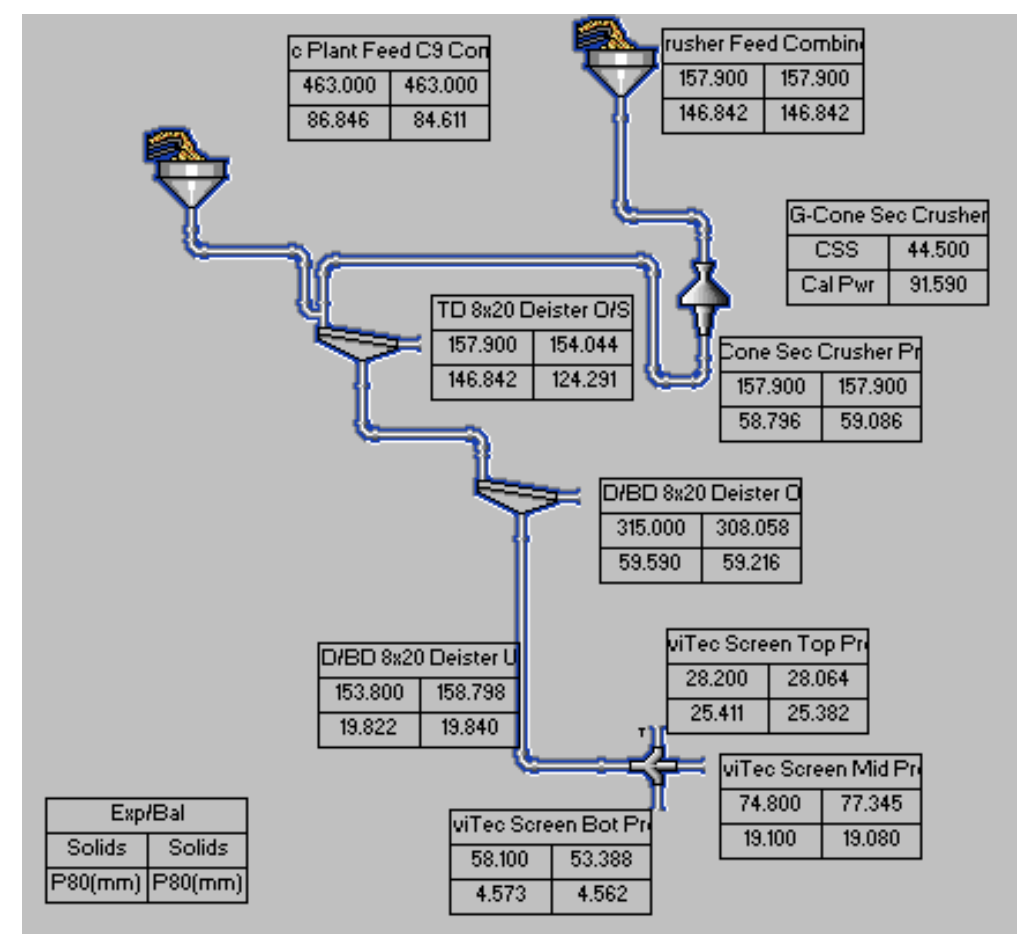

Figure 32. Example of LS secondary plant with split flowsheet concept used in mass balancing and model fitting. 
Figure 33 is an example of the balanced and fitted sizings from LS audit 7, showing a very close agreement. The key plant flows are summarized in Table 17.

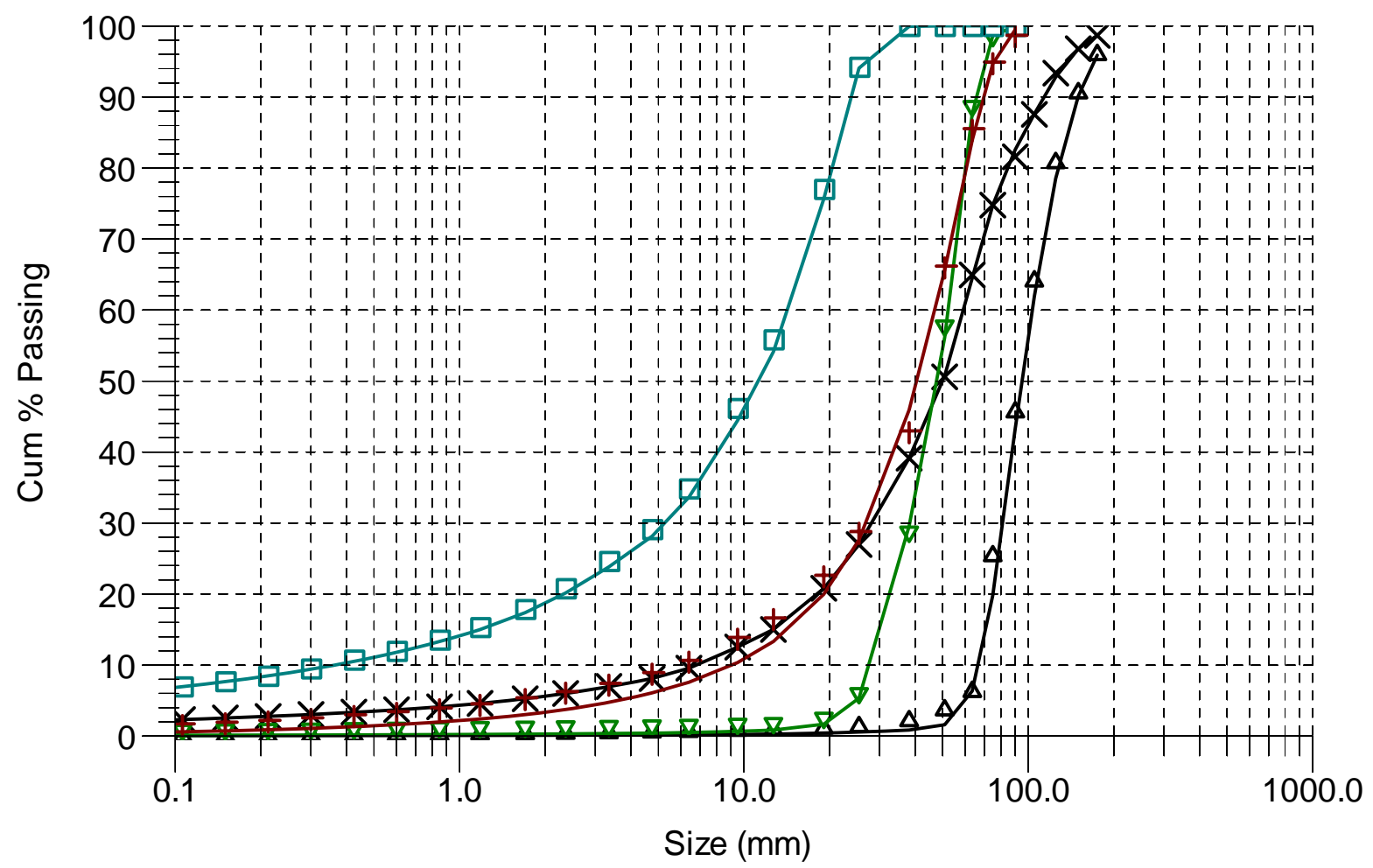

\begin{tabular}{|llll|}
\hline $\mathrm{X}$ & 1:New Feed Combiner, Exp & - & 1:New Feed Combiner, Fit \\
$\Delta$ & 2:TD 8X20 Deister O/S, Exp & 2:TD 8X20 Deister O/S, Fit \\
$\nabla$ & 3:MD/BD 8x20 Deister O/S, Exp & 3:MD/BD 8x20 Deister O/S, Fit \\
$\square$ & 4:MD/BD 8x20 Deister U/S, Exp & 4:MD/BD 8x20 Deister U/S, Fit \\
$+\quad$ 5:G-Cone GP300S Prod.Exp & 5:G-Cone GP300S Prod. Fit \\
\hline
\end{tabular}

Figure 33. Comparison of audit and fitted sizing results for Pittsboro secondary plant survey 7 - LS side (@ 463 tph, gap=44.5 mm).

Table 17. Comparison of Audit and Fitted Tonnage Rates for Pittsboro Secondary Plant - LS Side (Survey 7 @ 463 tph).

\begin{tabular}{|l|c|c|}
\hline \multirow{2}{*}{ Circuit } & \multicolumn{2}{|c|}{ Feed Rate (tph) } \\
\cline { 2 - 3 } Stream & Balanced & Fitted \\
\hline Sec. Plant Feed (C9) & 463 & 463 \\
Sec. Crusher Product (C13) & 158 & 158 \\
Tertiary Feed (38 mm o/size, C16) & 301 & 309 \\
Crusher Run (38 mm u/size, C29) & 160 & 163 \\
\hline
\end{tabular}


The Bivitec screen was handled separately due to the complexity of the system. The double-deck screen, with variable apertures down the 8-meter length posed a difficult problem since no single JKSimMet model was capable of describing the performance of such a screen. Also, the screen flexing is suspected to cause the bottom deck apertures to be 'stretched' during operation, which would change the effective cut-size. Furthermore, the top deck has blend gates which control the fraction of oversize that reports to the tertiary plant feed surge pile and crusher run.

To model this system, the screen was represented in JKSimMet as five separate decks in series, with a reduced efficiency in each section. The top deck oversize of the first section reports to the second top deck section, while the undersize reports to the first section of the bottom deck series, as illustrated in Figure 34. The model was developed using surveys 1 and 7, which only had flow and sizing data on C29 (screen feed), C14C (crusher run), C30 (tertiary feed) and C31 (waste).

The model was based on a simple efficiency curve, the parameters of which were selected to reflect the short screen sections and apertures used in each section. Since there were no intermediate data to calibrate the parameters for each section, the solution was based on previous JKMRC screen modeling experience. The model was found to fit the data very well (see Figure 35), considering the complexity of the model and assumptions made regarding top deck blend gates. The model was considered adequate for fine tuning the process and Mine-to-Mill simulations.

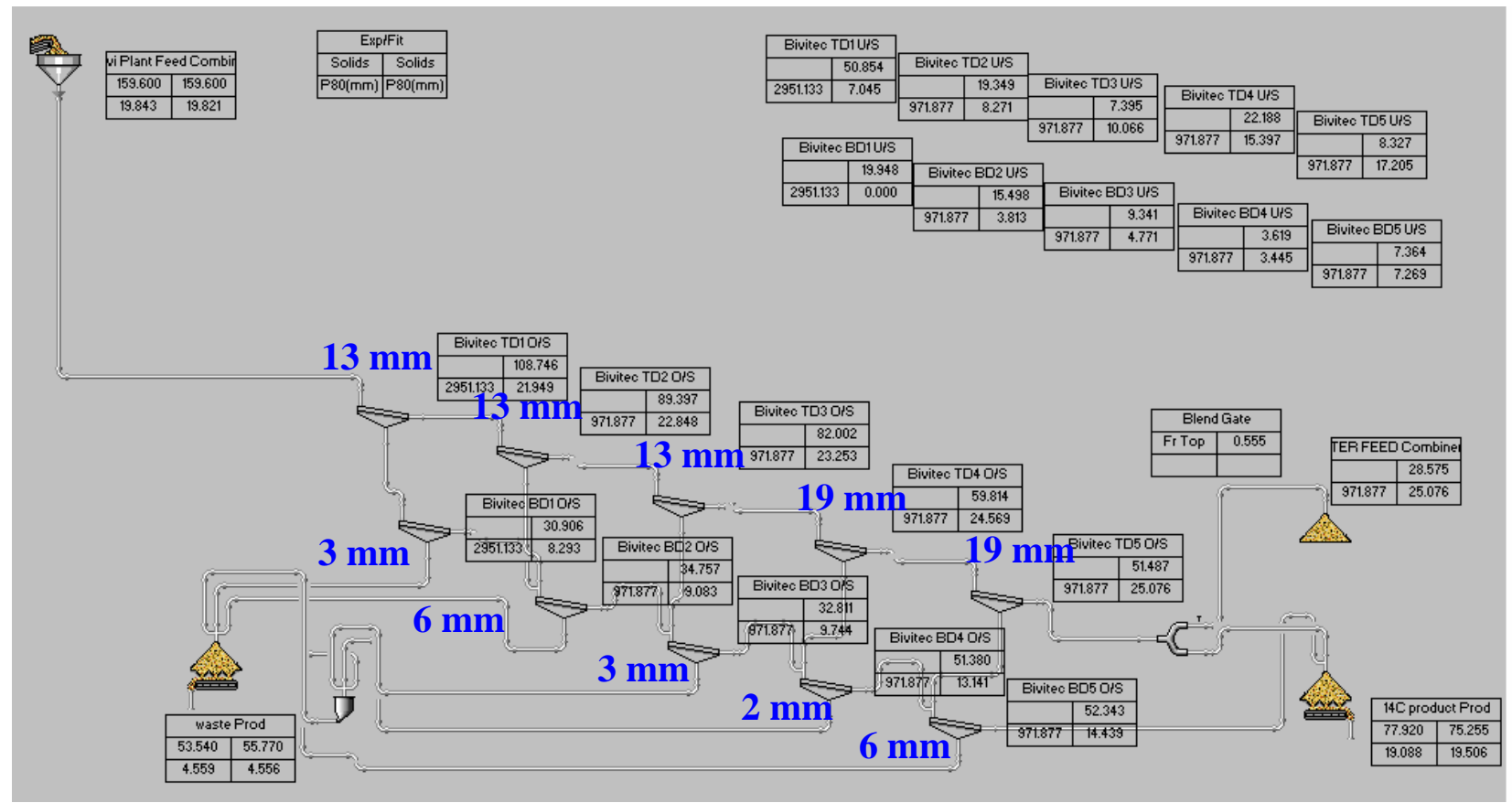

Fiqure 34. Representation of the Bivtec screen using 5 screens in series, both top and bottom decks modeled separately. 


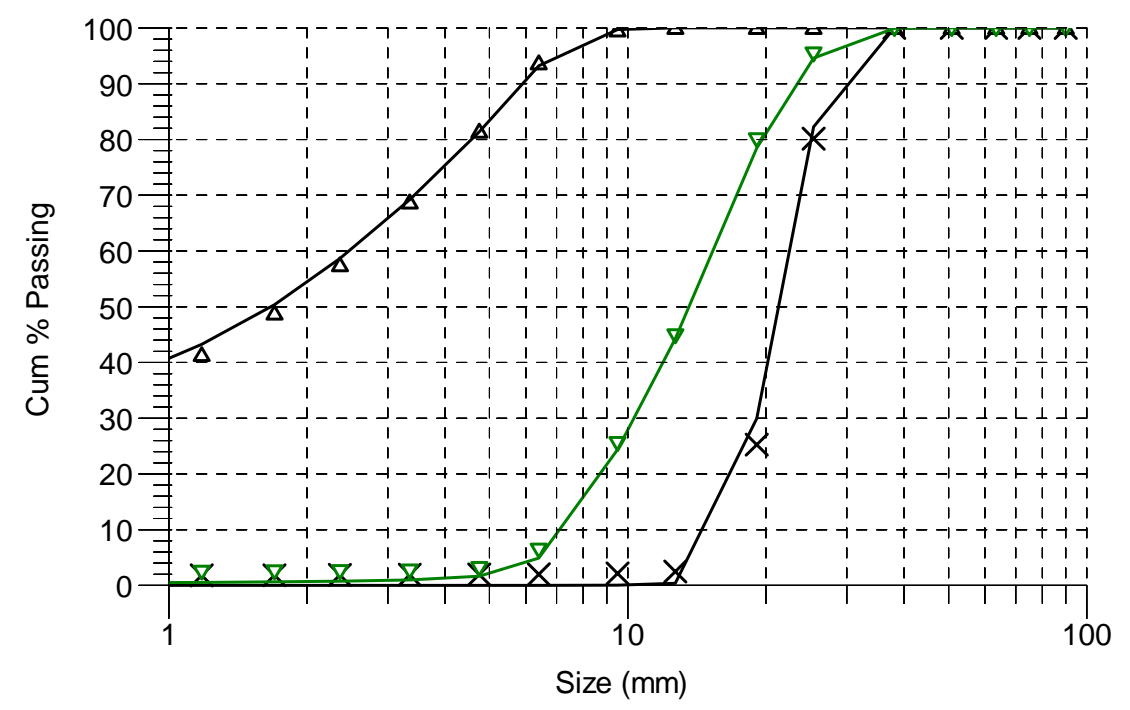

\begin{tabular}{|llll|}
\hline X & 1:Blend Gate Top Prod, Exp & - & 1:Blend Gate Top Prod, Fit \\
$\Delta$ & 2:waste Prod, Exp & 2:waste Prod, Fit \\
$\nabla$ & 3:14C product Prod, Exp & 3:14C product Prod, Fit \\
\hline
\end{tabular}

Figure 35. Comparison of audit and fitted sizing results for Bivitec screen (Survey 7 @ 161 tph screen feed rate).

The 3M secondary plant was mass balanced in closed circuit since the plant was able to run for long periods without the need for the crusher to stop. The model parameters were consistent with the $51 \mathrm{~mm}$ crusher gap and $100 \mathrm{~mm}$ screen aperture. Figure 36 shows an example of the balanced and fitted sizings.

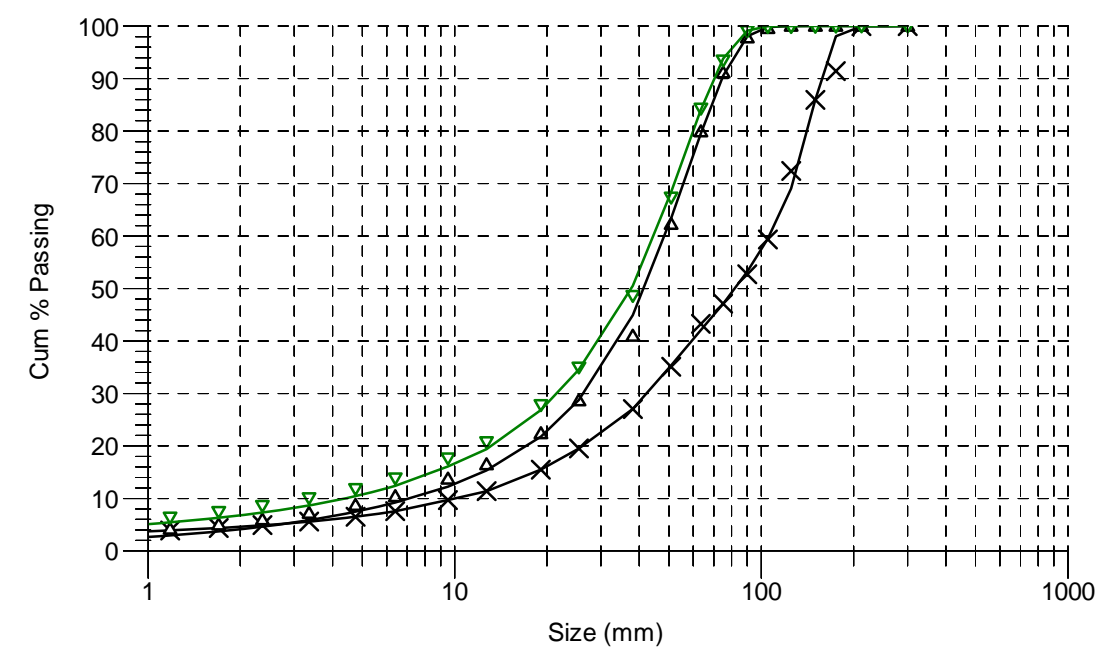

$$
\begin{array}{cl}
\hline \text { X } & \text { 1:3M Sec Plant Feed Combiner, Exp } \\
\Delta & \text { 2:G-Cone Sec Crusher Prod, Exp } \\
\nabla & \text { 3:N8x20SD 4" screen U/S, Exp } \\
\hline
\end{array}
$$$$
\begin{aligned}
& \text { 1:3M Sec Plant Feed Combiner, Fit } \\
& \text { 2:G-Cone Sec Crusher Prod, Fit } \\
& \text { 3:N8x20SD 4" screen U/S, Fit }
\end{aligned}
$$

Figure 36. Comparison of audit and fitted sizing results for Pittsboro secondary plant survey - 3M side (@633 tph, gap=51 mm). 
The tertiary plant data balanced well since the plant was close to steady-state prior to each crash stop. The variation from the belt cut tonnage rates was small, as expected. However, a discrepancy in the weightometers was noted suggesting there was an error in at least one of the product weightometers. To facilitate the analysis and modeling, the circuit was split into two parts: Dry and Wet (as shown in Figure 37).

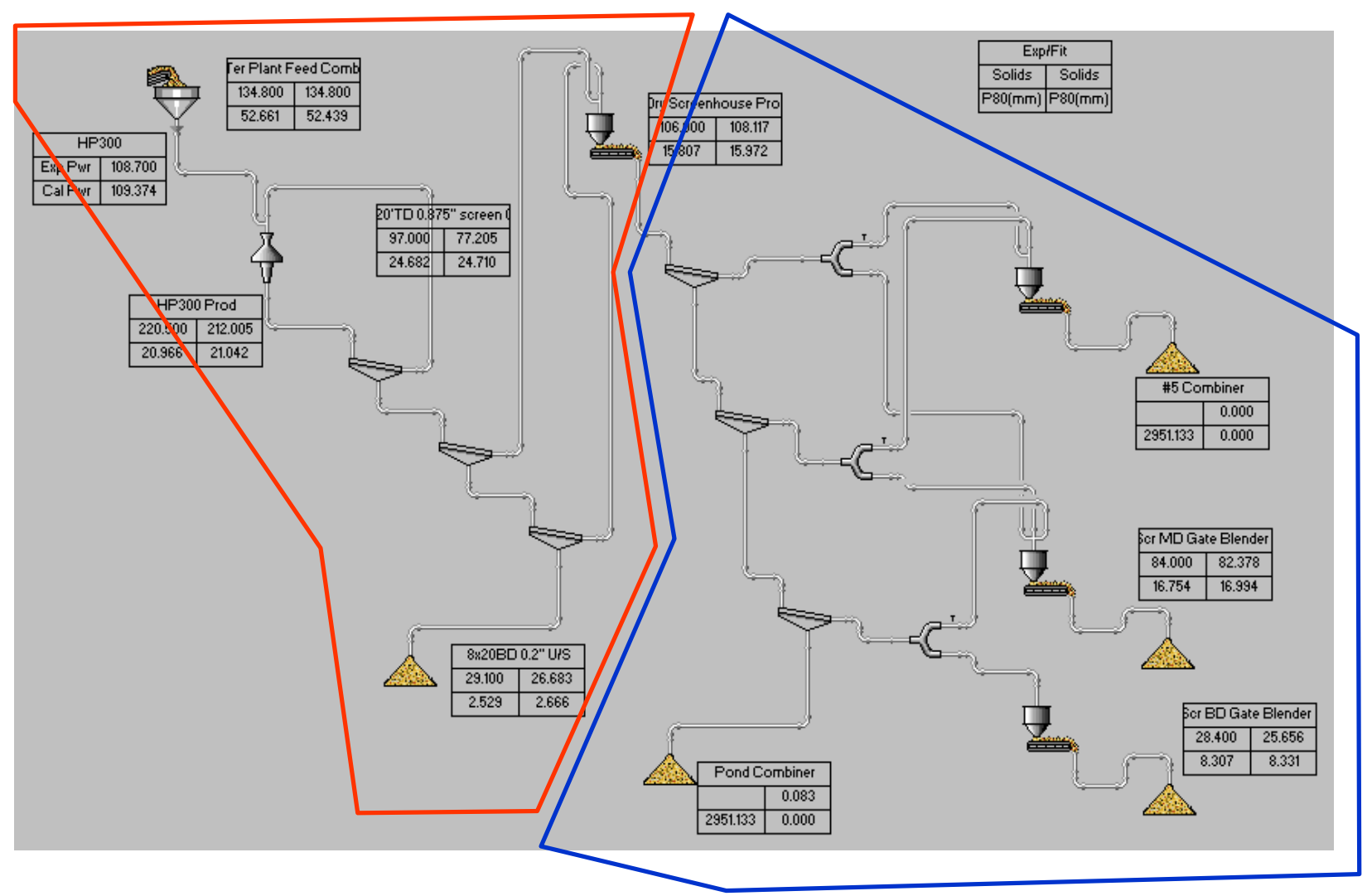

Figure 37. LS tertiary plant with split flowsheet concept used in model fitting.

Since there were no data on the middle deck, its parameters were based on previous knowledge of similar screen decks. The tertiary crusher and the screen model for the top and bottom decks in the dry plant were fitted together. The wet plant had limited data, requiring parameters to be fixed for the bottom deck $(0.5 \mathrm{~mm})$ and top deck (22 $\mathrm{mm}$ ). The blend gates were a source of doubt since the setup differed from normal operation during the survey ( 2 open/4 closed vs. 3 open/3 closed). Hence the only model fitted in the wet plant was the screen model for the middle deck. Figure 38 shows the balanced and fitted sizings from survey 2 , showing a very close agreement. The flows in the plant are summarized in Table 18.

Once the breakage characteristics of the ore had been determined and the data acquired through the plant audit had been mass balanced, this information was used in conjunction with the JKSimMet program to create the mathematical representation of the Pittsboro plant. 

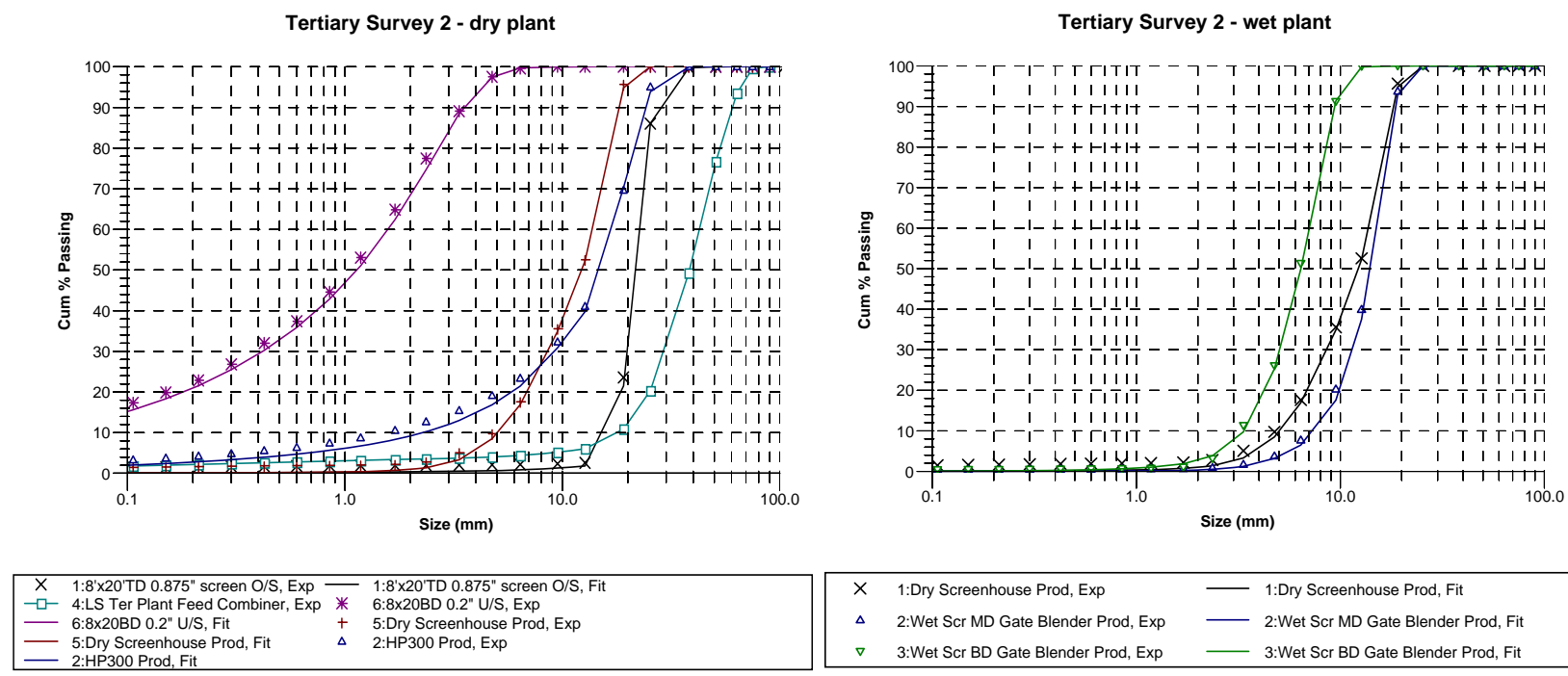

\begin{tabular}{|c|c|c|c|}
\hline$x$ & 1:Dry Screenhouse Prod, Exp & $\longrightarrow$ & 1:Dry Screenhouse Prod, Fit \\
\hline$\Delta$ & 2:Wet Scr MD Gate Blender Prod, Exp & - & 2:Wet Scr MD Gate Blender Prod, Fit \\
\hline$\nabla$ & 3:Wet Scr BD Gate Blender Prod, Exp & - & 3:Wet Scr BD Gate Blender Prod, Fit \\
\hline
\end{tabular}

Figure 38. Comparison of mass balance and fitted sizing results for Pittsboro tertiary plant (Survey 2 @ 135 tph, gap=22 mm).

Table 18. Comparison of Audit and Fitted Tonnage Rates for Pittsboro Tertiary Plant (Survey 2 @ 135 tph).

\begin{tabular}{|l|c|c|}
\hline \multirow{2}{*}{ Circuit } & \multicolumn{2}{|c|}{ Feed Rate (tph) } \\
\cline { 2 - 3 } Stream & Balanced & Fitted \\
\hline Ter. Plant Feed (C17) & 135 & 135 \\
HP300 Product (C18) & 221 & 212 \\
Recycle (22 mm o/s, C19) & 97 & 77 \\
Dust (4.5 mm u/s, C20) & 29 & 27 \\
\#5 (C23) & - & - \\
$\# 67$ (C24) & 84 & 83 \\
$\# 78$ (C26) & 28 & 25 \\
Waste (Pond) & 0.09 & 0.07 \\
\hline
\end{tabular}

The Anderson/Whiten crusher model (Napier-Munn et al, 1996) was used to model the Pittsboro crushers, based on the settings and ore breakage characteristics obtained from drop-weight test on the survey samples. For conventional reciprocating crushers such as jaw, gyratory and cone units these characteristics are represented by 3 parameters $\left(K_{1}, K_{2}\right.$ and $\left.t_{10}\right)$. These ideally equal to the closed side setting (CSS), open side setting (OSS) and the degree of size reduction that rock(s) undergo each time the crusher completes a cycle in its operation respectively. In practice factors such as liners design, wear and the shape of the product influence the actual values of these parameters. Tables 19, 20 and 21 list the crusher parameters and key operating conditions for the plant audits at Pittsboro. In the case of the primary crusher, the Split predicted ROM size distribution taken from the last truck dumped before C2 was stopped for sampling was assumed to be the feed to the grizzly feeder. 
Table 19. Summary of JKSimMet Primary Crusher Model Parameters and Operating Conditions.

\begin{tabular}{|l||c||c|}
\hline \multicolumn{1}{|c||}{ Parameter } & Luck Stone & 3M \\
\hline $\mathrm{K}_{1}$ & $\begin{array}{c}\text { CSS = 146 mm } \\
\text { Throw }=36 \mathrm{~mm}\end{array}$ & $\begin{array}{c}\text { CSS = 146 mm } \\
\text { Throw = 36 mm }\end{array}$ \\
\hline $\mathrm{K}_{2}$ & 146 & 146 \\
\hline $\mathrm{t}_{10}$ & 365 & 365 \\
\hline Plant Feed (tph) & 8.1 & 7.0 \\
\hline Plant F80 $(\mathrm{mm})$ & 1410 & 921 \\
\hline Crusher Feed $(\mathrm{tph})$ & 188 & 328 \\
\hline Crusher F80 $(\mathrm{mm})-$ pred & 400 & 361 \\
\hline Crusher P80 $(\mathrm{mm})-$ pred & 324 & 501 \\
\hline Power $(\mathrm{kW})$ & 185 & 192 \\
\hline kWh/t & 73 & 91 \\
\hline
\end{tabular}

The primary crusher parameter $\mathrm{K}_{2}$ is unusually high and, assuming the predicted ROM feed size distribution is valid, suggests the crusher is allowing large thin rocks to pass into the product without being broken. This is a common feature of jaw crushers which treat materials that fracture into 'slabby' pieces. The Rip-Rap screen removes these pieces before the secondary surge pile. The $t_{10}$ values are within the expected range for this type of crusher and feed size range. The LS audit reflects a much finer feed, as noted previously, resulting in a 50\% higher overall plant throughput.

The secondary crusher parameters in Table 20 are consistent with the secondary crusher models derived from the Bealeton June 2004 audit. As noted earlier, the very fine feed in six of the seven LS audits resulted in a wide range of performance in terms of the specific energy consumption and yield to the tertiary plant surge pile. Clearly if the feed is too fine, the yield to the tertiary plant is reduced, and the feed to the Bivitec screen will be commensurately increased. The results also point to a difference in the ore hardness between the LS and 3M feed. At similar feed conditions and crusher gap, the specific energy consumption is higher for the $3 \mathrm{M}$ andesite than the LS ore blend.

The performance variation seen in the LS audits suggests that an online feed size monitor might be a worthwhile addition to the existing control instrumentation. The opportunity lies in the option to regulate the feed rate and/or crusher gap based on the incoming feed size. Clearly, if the feed size is coarser, there appears to be scope to increase the feed rate without any risk of exceeding the load on the Bivitec screen. Conversely if the feed is very fine, the controller should be able to figure out by how much to reduce the feed and increase the gap to maintain the highest yield to the tertiary plant without impacting the Bivitec. 
Table 20. Summary of JKSimMet Secondary Cone Crusher Model Parameters and Operating Conditions.

\begin{tabular}{|c|c|c|c|c|c|c|c|c|}
\hline \multirow{2}{*}{$\begin{array}{l}\text { Parameter } \\
\text { Survey \# }\end{array}$} & \multicolumn{7}{|c|}{ Luck Stone } & \multirow{2}{*}{$\begin{array}{c}3 \mathrm{M} \\
1\end{array}$} \\
\hline & 1 & 2 & 3 & 4 & 5 & 6 & 7 & \\
\hline Throughput Set-Point (tph) & 450 & 590 & 590 & 590 & 590 & 590 & 450 & 635 \\
\hline Stockpile Height & $\mathrm{Hi}$ & $\mathrm{Hi}$ & $\mathrm{Hi}$ & $\mathrm{Hi}$ & Lo & Lo & Lo & $\mathrm{Hi}$ \\
\hline Crusher Setting CSS (mm) & 43.9 & 43.9 & 51.8 & 38.4 & 44.7 & 50.8 & 44.5 & 50.5 \\
\hline $\mathrm{K}_{1}$ & 49.1 & 48.8 & 55.5 & 41.5 & 49.3 & 58.7 & 48.5 & 56.8 \\
\hline $\mathrm{K}_{2}$ & 120.9 & 87.5 & 96.5 & 80.7 & 85.6 & 101.8 & 113.7 & 119.3 \\
\hline$t_{10}$ & 8.5 & 10.5 & 12.3 & 11.4 & 11.8 & 10.8 & 9.0 & 10.8 \\
\hline Plant Feed (tph) & 483 & 594 & 609 & 579 & 609 & 582 & 463 & 632 \\
\hline Plant F80 (mm) & 63.0 & 67.0 & 69.0 & 71.0 & 51.0 & 131.0 & 87.0 & 139.8 \\
\hline Crusher Feed (tph) & 147 & 313 & 348 & 343 & 308 & 362 & 158 & 330 \\
\hline Crusher F80 (mm) & 130 & 161 & 135 & 170 & 122 & 159 & 147 & 156 \\
\hline Crusher P80 (mm) & 63.6 & 49.6 & 57.4 & 42.6 & 50.1 & 60.2 & 60.3 & 63.9 \\
\hline Power (kW) & 39 & 86 & 87 & 109 & 87 & 84 & 44 & 112 \\
\hline $\mathrm{kWh} / \mathrm{t}$ & 0.08 & 0.14 & 0.14 & 0.19 & 0.14 & 0.14 & 0.10 & 0.18 \\
\hline $\begin{array}{l}\text { Crusher Run (tph and \% of } \\
\text { total production) }\end{array}$ & $\begin{array}{c}310 \\
(58 \%) \\
\end{array}$ & $\begin{array}{c}446 \\
(58 \%) \\
\end{array}$ & $\begin{array}{c}445 \\
(55 \%) \\
\end{array}$ & $\begin{array}{c}450 \\
(59 \%) \\
\end{array}$ & $\begin{array}{r}516 \\
(61 \%) \\
\end{array}$ & $\begin{array}{c}233 \\
(37 \%) \\
\end{array}$ & $\begin{array}{c}162 \\
(34 \%) \\
\end{array}$ & - \\
\hline $\begin{array}{l}\text { Tertiary Feed (tph and \% } \\
\text { of total production) }\end{array}$ & $\begin{array}{c}221 \\
(42 \%) \\
\end{array}$ & $\begin{array}{c}326 \\
(42 \%) \\
\end{array}$ & $\begin{array}{c}361 \\
(45 \%) \\
\end{array}$ & $\begin{array}{c}314 \\
(41 \%) \\
\end{array}$ & $\begin{array}{c}330 \\
(39 \%) \\
\end{array}$ & $\begin{array}{c}392 \\
(63 \%) \\
\end{array}$ & $\begin{array}{c}308 \\
(66 \%) \\
\end{array}$ & $\begin{array}{c}632 \\
(100 \%) \\
\end{array}$ \\
\hline
\end{tabular}

The tertiary crusher parameters in Table 21 are different from the previous tertiary models derived from the Bealeton June 2004 audit. The most significant difference was the higher $t_{10}$ values which are synonymous with higher fines generation. The relatively low $t_{10}$ values for the Omnicone and Symons machines at Bealeton suggest these units are very suitable for the aggregate industry that seeks to create minimal fines in the production of closely sized crushed products.

The impact of the crusher gap is clearly evident from the survey data. As the gap is reduced, the fines recycle load drops and the fines generation increases at the expense of a reduced yield of final products. The optimum setting appears to be close to survey 2 , where the gap was close to $22 \mathrm{~mm}$.

The Pittsboro results also confirm the trend seen at Bealeton, where the specific energy consumption is by far the highest in the tertiary plant.

Having successfully fitted the models using the secondary and tertiary audits (viz. tph and/or crusher gap), statistical analysis of the relationships between the parameters and operating conditions was carried out. A dependency of the crusher parameters $\mathrm{K}_{1}, \mathrm{~K}_{2}$ and $t_{10}$ on gap, throughput and feed coarseness was established. These relationships had the form: 


$$
\text { CrusherParameter }=\mathrm{a}+\mathrm{b} \times \mathrm{CSS}+\mathrm{c} \times \mathrm{TPH}+\mathrm{d} \times \mathrm{F} 80
$$

where $a, b, c$ and $d$ are the regression coefficients in each parameter relationship. These relationships were used in JKSimMet to allow simulations to take into account changes in gap and/or crusher operating conditions. As expected, the relationships derived from the Pittsboro audits were of similar form to those developed at Bealeton.

\section{Table 21. Summary of JKSimMet Tertiary Cone Crusher Model Parameters and Operating Conditions.}

\begin{tabular}{|c|c|c|c|}
\hline \multirow{2}{*}{$\begin{array}{l}\text { Parameter } \\
\text { Survey \# }\end{array}$} & \multicolumn{3}{|c|}{ Luck Stone } \\
\hline & 1 & 2 & 3 \\
\hline Gap Setting CSS & $27.9 \mathrm{~mm}$ & $22.4 \mathrm{~mm}$ & $18.8 \mathrm{~mm}$ \\
\hline $\mathrm{K}_{1}$ & 25.4 & 19.8 & 17.0 \\
\hline $\mathrm{K}_{2}$ & 36.8 & 41.4 & 34.6 \\
\hline $\mathrm{t}_{10}$ & 17.0 & 17.1 & 19.3 \\
\hline Plant Feed (tph) & 94 & 135 & 145 \\
\hline Plant F80 (mm) & 53.5 & 52.4 & 53.4 \\
\hline Crusher Feed (tph) & 201 & 212 & 185 \\
\hline Crusher F80 (mm) & 42.4 & 46.0 & 49.9 \\
\hline Crusher P80 (mm) & 23.9 & 21.0 & 17.3 \\
\hline Power (kW) & 84 & 109 & 135 \\
\hline $\mathrm{kWh} / \mathrm{t}$ & 0.89 & 0.81 & 0.93 \\
\hline $\begin{array}{l}\text { Recycle C13 (tph and } \\
\% \text { of plant feed) }\end{array}$ & $\begin{array}{c}106 \\
(112 \%)\end{array}$ & $\begin{array}{c}77 \\
(57 \%)\end{array}$ & $\begin{array}{c}40 \\
(28 \%)\end{array}$ \\
\hline $\begin{array}{l}\text { Dust C20 (tph and \% } \\
\text { of total production) }\end{array}$ & $\begin{array}{c}17.2 \\
(18.2 \%)\end{array}$ & $\begin{array}{c}26.7 \\
(19.8 \%)\end{array}$ & $\begin{array}{c}34.8 \\
(24.0 \%) \\
\end{array}$ \\
\hline $\begin{array}{l}\# 67 \text { C24 (tph and \% of } \\
\text { total production) }\end{array}$ & $\begin{array}{c}61.3 \\
(65.0 \%)\end{array}$ & $\begin{array}{c}82.4 \\
(61.0 \%)\end{array}$ & $\begin{array}{c}83.8 \\
(57.8 \%)\end{array}$ \\
\hline $\begin{array}{l}\# 78 \mathrm{C} 26 \text { (tph and \% of } \\
\text { total production) }\end{array}$ & $\begin{array}{c}15.8 \\
(16.8 \%)\end{array}$ & $\begin{array}{c}25.7 \\
(19.1 \%)\end{array}$ & $\begin{array}{c}26.1 \\
(18.0 \%)\end{array}$ \\
\hline
\end{tabular}

The Pittsboro vibrating screens were modeled using simple efficiency curves which are described by three parameters (Napier-Munn et al, 1999):

$$
\begin{array}{lll}
\alpha & - & \text { sharpness of the split } \\
C & \text { - } & \text { fines split to undersize } \\
d_{50}(c) & - & \text { cut-size, around } 70-90 \% \text { of the aperture depending on efficiency. }
\end{array}
$$

Information from the Pittsboro scalp and product screens collected in the audits were used to derive simple relations between the screen load $(\mathrm{tph} / \mathrm{screen} / \mathrm{m})$ and the efficiency curve parameters $\alpha, C$ and $d_{50}(c)$. However, $d_{50}(c)$ can also be calculated 
from the aperture and the $\alpha$ parameter, using a simple design relationship between the aperture and cut-size of the efficiency curve, given the expected screening efficiency.

Tables 22 through 25 summarize the parameters for all screens. In the case of the LS secondary and tertiary surveys, only the average parameters are shown. The screen parameters reflect the apertures and nature of operation of the different screens. The grizzly screen shows a relatively low sharpness of separation $(\alpha)$ for a coarse aperture screen, and reflects the inefficiency of that deck at the very high loads in the LS audit.

Table 22. JKSimMet Screen Model Parameters - Primary.

\begin{tabular}{|l|c|c||c|}
\hline Screen & Primary & Primary & Primary \\
\hline Parameter & Grizzly & Grizzly & Rip-Rap \\
\hline Nominal Setting & $165 \mathrm{~mm}$ & $165 \mathrm{~mm}$ & $230 / 280 \mathrm{~mm}$ \\
\hline Ave Load (tph) & 1410 & 921 & $1410-921$ \\
\hline$\alpha$ & 5.0 & 8.5 & 10.0 \\
\hline $\mathrm{C}$ & 99.9 & 99.9 & 99.9 \\
\hline $\mathrm{d}_{50}(\mathrm{c})$ & 150 & 175 & 250 \\
\hline
\end{tabular}

Table 23. JKSimMet Screen Model Parameters - Secondary.

\begin{tabular}{|l|c|c|c|}
\hline Screen & \multicolumn{2}{|c|}{ Luck Stone } & 3M \\
\hline Parameter & TD & BD & TD \\
\hline Nominal Setting & $89 \mathrm{~mm}$ & $38 \mathrm{~mm}$ & $100 \mathrm{~mm}$ \\
\hline Ave Load (tph) & 843 & 689 & 962 \\
\hline$\alpha$ & 11.5 & 9.1 & 13.8 \\
\hline $\mathrm{C}$ & 99.6 & 98.6 & 99.9 \\
\hline $\mathrm{d}_{50}(\mathrm{c})$ & 72.7 & 25.9 & 86.6 \\
\hline
\end{tabular}

Table 24. JKSimMet Screen Model Parameters - Tertiary.

\begin{tabular}{|l|c|c|c|c|c|c|}
\hline Screen & \multicolumn{3}{|c|}{ Dry } & \multicolumn{3}{c|}{ Wet } \\
\hline Parameter & TD & MD & BD & TD & MD & BD \\
\hline Nominal Setting & $22.2 \mathrm{~mm}$ & $12.7 \mathrm{~mm}$ & $4.5 \mathrm{~mm}$ & $22.2 \mathrm{~mm}$ & $12.7 \mathrm{~mm}$ & $0.5 \mathrm{~mm}$ \\
\hline Ave Load (tph) & 200 & 125 & 65 & 99 & 85 & 37 \\
\hline$\alpha$ & 10.7 & 8.9 & 4.2 & 11.0 & 10.9 & 1.5 \\
\hline C & 98.6 & 99.0 & 97.9 & 99.9 & 99.3 & 85.0 \\
\hline $\mathrm{d}_{50}(\mathrm{c})$ & 18.3 & 10.1 & 3.4 & 18.9 & 9.6 & 0.17 \\
\hline
\end{tabular}

As noted earlier, the Bivitec screen model (Table 25) consisted of a series of 5 double deck screen decks in series, each around 1.5 meters in length. The efficiency curve parameters for these sections were appropriately downgraded to reflect the short lengths but still achieve a final separation result commensurate with the performance seen in the two surveys. The cut-sizes for the top deck are consistent with the 
apertures, whereas the bottom deck cut-sizes are larger than first expected, probably because the slots were long and the very flexible screen cloth is 'stretched' during the operation, as claimed by the manufacturer. This stretching is intrinsic to the screen operation, designed to keep the cloth from blinding.

Table 25. JKSimMet Screen Model Parameters - Bivitec Screen.

\begin{tabular}{|l|c|c|c|c|c||c|c|c|c|c|}
\hline Screen & \multicolumn{4}{|c||}{ Top Deck Sections (1.5 $\mathbf{~})$} & \multicolumn{4}{c|}{ Bottom Deck Sections (1.5 m) } \\
\hline Parameter & $\mathbf{1}$ & $\mathbf{2}$ & $\mathbf{3}$ & $\mathbf{4}$ & $\mathbf{5}$ & $\mathbf{1}$ & $\mathbf{2}$ & $\mathbf{3}$ & $\mathbf{4}$ & $\mathbf{5}$ \\
\hline Nominal Setting (mm) & 12.7 & 12.7 & 12.7 & 19.1 & 19.1 & 3.0 & 3.7 & 3.0 & 2.0 & 6.4 \\
\hline Ave Load (tph) & 160 & 109 & 89 & 80 & 59 & 51 & 53 & 46 & 58 & 63 \\
\hline$\alpha$ & 6.7 & 6.8 & 6.8 & 6.9 & 6.9 & 5.4 & 5.4 & 5.4 & 5.4 & 5.4 \\
\hline $\mathrm{C}$ & 68.1 & 69.2 & 69.7 & 95.5 & 96.1 & 56.3 & 56.1 & 56.4 & 50.8 & 66.3 \\
\hline $\mathrm{d}_{50}(\mathrm{c})$ & 9.92 & 9.84 & 9.81 & 14.7 & 14.7 & 4.82 & 5.33 & 4.81 & 3.94 & 6.43 \\
\hline
\end{tabular}

Statistical analysis of the relationships between the screen parameters and operating conditions was carried out for each deck. A dependency of the screen parameters $\alpha, C$, and $d_{50}(c)$ on throughput and percent passing the nominal screen aperture was established. For example, in the case of the tertiary dry plant screen top deck, which has a $22.2 \mathrm{~mm}$ nominal aperture, the relationships had the form:

$$
\text { ScreenParameter }=p+q \times T P H+r \times \%-22.2 \mathrm{~mm}
$$

where $p, q$ and $r$ are the regression coefficients in each parameter relationship. These relationships were used to update the parameters in JKSimMet to allow simulations to take into account changes in screen operating conditions, particularly the load on the screen.

Overall, the August 2005 audit information and modeling analysis suggest the following average specific energy consumptions across the three crushing stages at Pittsboro.

Table 26. Comparison of Energy Consumptions for Pittsboro.

\begin{tabular}{|l|c|c|c|c|}
\hline Crusher Stage & Luck Stone & $\mathbf{3 M}$ & Total & $\mathbf{( \% )}$ \\
\hline Primary kWh/t & 0.05 & 0.10 & 0.15 & 11 \\
\hline Secondary kWh/t & 0.13 & 0.18 & 0.31 & 23 \\
\hline Tertiary kWh/t & 0.88 & - & 0.88 & 66 \\
\hline TOTAL kWh/t & $\mathbf{1 . 0 6}$ & $\mathbf{0 . 2 8}$ & $\mathbf{1 . 3 4}$ & $\mathbf{1 0 0}$ \\
\hline
\end{tabular}

The audit results suggest the overall specific energy consumption distribution at Pittsboro is similar to that of Bealeton, with $66 \%$ of the energy consumed in the tertiary plant. The primary component is only $11 \%$ at Pittsboro compared to $19 \%$ at Bealeton, suggesting the Bealeton primary crusher may be undersized for the duty. 
Plant Simulation: The models outlined above were used to construct JKSimMet baseline circuits for Luck Stone (primary, secondary, and tertiary) and 3M (primary and secondary). These flowsheets, shown in Figures 39 and 40, were designed to be used in testing the effect of alternative blast fragmentations and/or equipment configurations on plant performance.

The simulation approach was as follows:

1. The expected ROM size distribution was generated using JKSimBlast, based on rock and blast design parameters.

2. The ROM was input to the primary flowsheet as feed to the plant. The grizzly screen parameters were selected to suit the prevailing feed rate expected. The jaw crusher $t_{10}$ was adjusted in relation to the feed coarseness expected in the grizzly oversize.

3. The primary plant simulation generated an estimate of the feed to the secondary plant. The product from the primary plant was entered into the secondary flowsheet as feed to the plant. The top and bottom deck screen parameters were fine tuned using the simulated loads and coarseness.

4. The secondary plant simulation generated the feed to the tertiary surge stockpile and feed to the Bivitec screen. The Bivitec simulation completed the simulation to give estimates of the base and waste products.

5. The combined stream reporting to the tertiary surge pile from the secondary plant simulation was entered into the tertiary flowsheet as feed to the plant. The top and bottom deck dry screen and middle deck wet screen parameters were fine tuned using the simulated loads and coarseness. The simulation provided estimates of the final products, dust and waste streams.

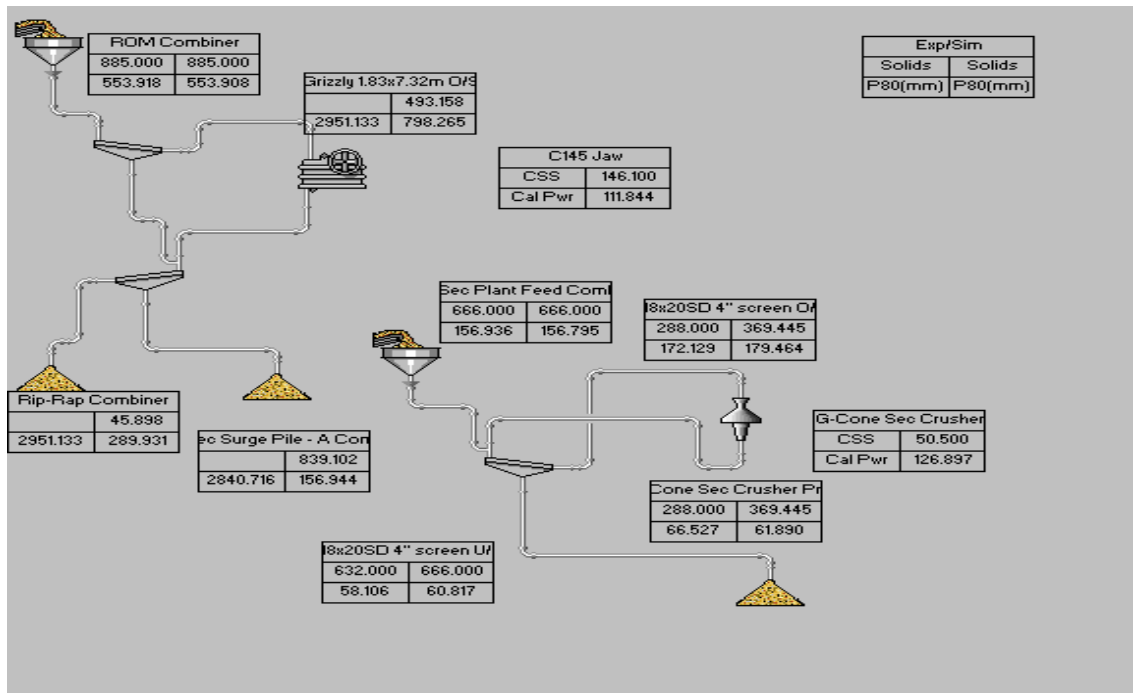

Figure 39. JKSimMet baseline flowsheet for Pittsboro 3M plant. 


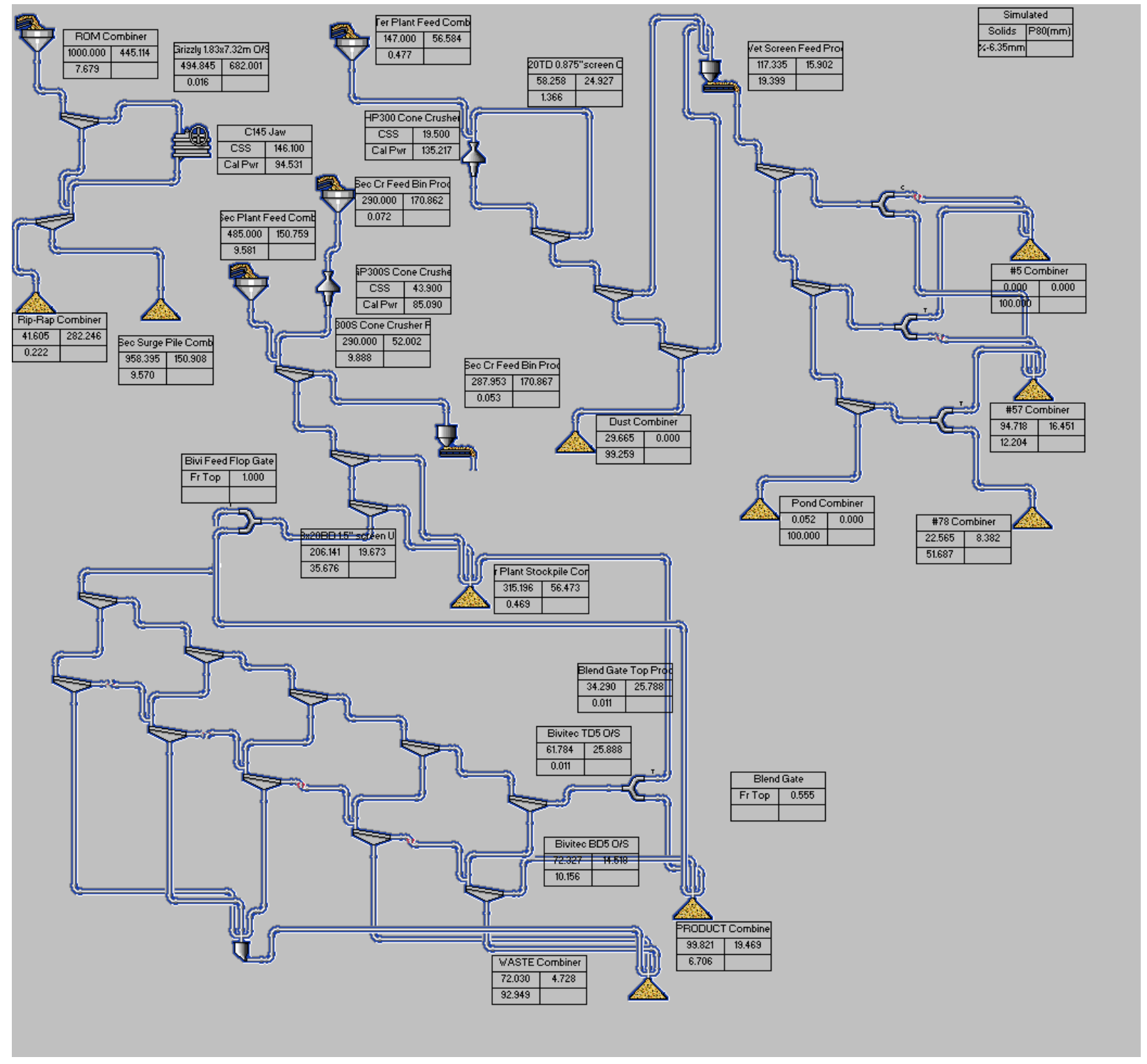

Figure 40. JKSimMet baseline flowsheet for Pittsboro Luck Stone plant.

Optimization and Alternative Designs: Having successfully modeled the baseline conditions, including blast fragmentation and plant response, the next phase was to investigate ways of reducing the energy consumption through alternative blast designs, looking at both the strategy and variables (explosive type, pattern, collar length etc). After reconciling the likely fragmentation and primary throughput from current practice, the Mine-to-Mill team worked with the Luck Stone drill \& blast team to come up with a sustainable and viable set of new guidelines. These guidelines would be sensitive to both corporate and practical limitations. In terms of current practice, the discussions led to a set of definitions related to the burden/spacing for angled holes and blasting domains that Pittsboro routinely encounter. These were: 
1. Fractured 21 and 12 meter benches (lifts 2 and 3 )

2. Blocky 21 and 12 meter benches (lifts 2 and 3 )

One of the critical discoveries made during these discussions was that in the 3-month period prior to the implementation of the new mine-to-mill blasting guidelines (Nov-05 to Jan-06), the majority of shots were fired in lift 2 (21 meter benches), whereas in the 3month period following implementation the reverse was expected, with the majority of shots in lift 3 (12 meter benches). In both lifts, most shots were expected to be in fractured geology, with less than $15 \%$ in blocky massive rock. The change from lift 2 to lift 3 meant that the comparison between the first and second 3-month performance could be compromised since the rock was expected to be harder in lift 3. As this was inevitable, Pittsboro operations were asked to keep a log of the times that single source material from lift 2 was being fed to the primary crusher. This was expected to help the MTM team extract information from the logging data on the productivity of lift 2 and lift 3 pre- and post- the new blasting guidelines.

Following the discussion of current practice and strategies, a set of potential modifications were proposed aiming to reduce the amount of $+150 \mathrm{~mm}$, especially oversize, while not increasing the percent crusher run $(-38 \mathrm{~mm})$ significantly. Three subjective blast domains were defined each requiring different designs to achieve the objectives of the project. The guidelines were to be used for all blasts on lifts $2 \& 3$. The blast designs outlined below were considered a starting point and it was expected that these designs would be refined over time as the results were assessed. The shot firer was given leeway to account for various other practical constraints that were likely to be encountered (e.g., face profile) and these guidelines were to be combined with knowledge of the objectives and site-specific experience to determine the final blast design.

As a general guide Luck Stone was asked to:

- Decrease the pattern dimensions to reduce coarse fragmentation, and

- Recognize that heavy ANFO and emulsion explosives will produce more fines than ANFO.

The modifications were designed to deal with the following ore domains/conditions:

1. Fractured 21 and 12 meter benches (lifts 2 and 3$)$ - Wet ( $4.3 \times 4.9 \mathrm{~m}$ pattern)

2. Fractured 21 and 12 meter benches (lifts 2 and 3) - Damp ( $4.0 \times 4.6 \mathrm{~m}$ pattern)

3. Blocky 21 and 12 meter benches (lifts 2 and 3 ) $-3.7 \times 4.3 \mathrm{~m}$ pattern

Table 27 summarizes the key components of the guidelines for the proposed modifications in blasting practice. 
Table 27. Proposed Blast Design Guidelines.

\begin{tabular}{|c|c|c|c|l|}
\hline \multirow{2}{*}{ Parameter } & \multicolumn{2}{|c|}{ Fractured } & \multirow{2}{*}{ Blocky } & \multicolumn{1}{|c|}{ Initiation and Timing } \\
\cline { 2 - 4 } & Wet & Damp & - & \\
\hline Burden $\times$ Spacing $(\mathrm{m})$ & $4.3 \times 4.9$ & $4.0 \times 4.6$ & $3.7 \times 4.3$ & \\
\hline Explosive Length & & & & Initiate from corner if possible \\
\hline Blend/Repump & All & Minimum & All & $\begin{array}{l}\text { Increase timing between last rows to } \\
\text { help protect free face }\end{array}$ \\
\hline ANFO & - & Maximum & - & $\begin{array}{l}\text { Consider reducing hole delay to } ~ \\
\text { ms to reduce detonator scatter }\end{array}$ \\
\hline
\end{tabular}

Additional, it was requested that Luck Stone:

- Continue with current procedure for front row design - nominally $5.5 \mathrm{~m}$ toe burden and $3.0 \mathrm{~m}$ spacing, but no more than $4.3 \mathrm{~m}$ at mid-bench level.

- Allow any corporate or site-specific policies to take precedence over these guidelines, e.g., maximum instantaneous charge weight per delay and total initiation duration.

- Aim for $3.7 \mathrm{~m}$ stemming but consider bench conditions as per current practice.

- Establish the designed burden at mid-bench level if the hole angle varies within a shot.

- Record any changes to pattern from these general guidelines.

The guidelines represented a modest increase (2-3\%) in powder factor for blocky lift 2 , fractured lift 2 (damp) and lift 3 (damp/wet) ore domains, a reduction in powder factor of $11 \%$ for the fractured (wet) lift 2 ore, and a significant increase of $28 \%$ for the blocky lift 3 domain. Figure 41 shows the key definitions used in setting up the proposed blast design guidelines for Pittsboro.

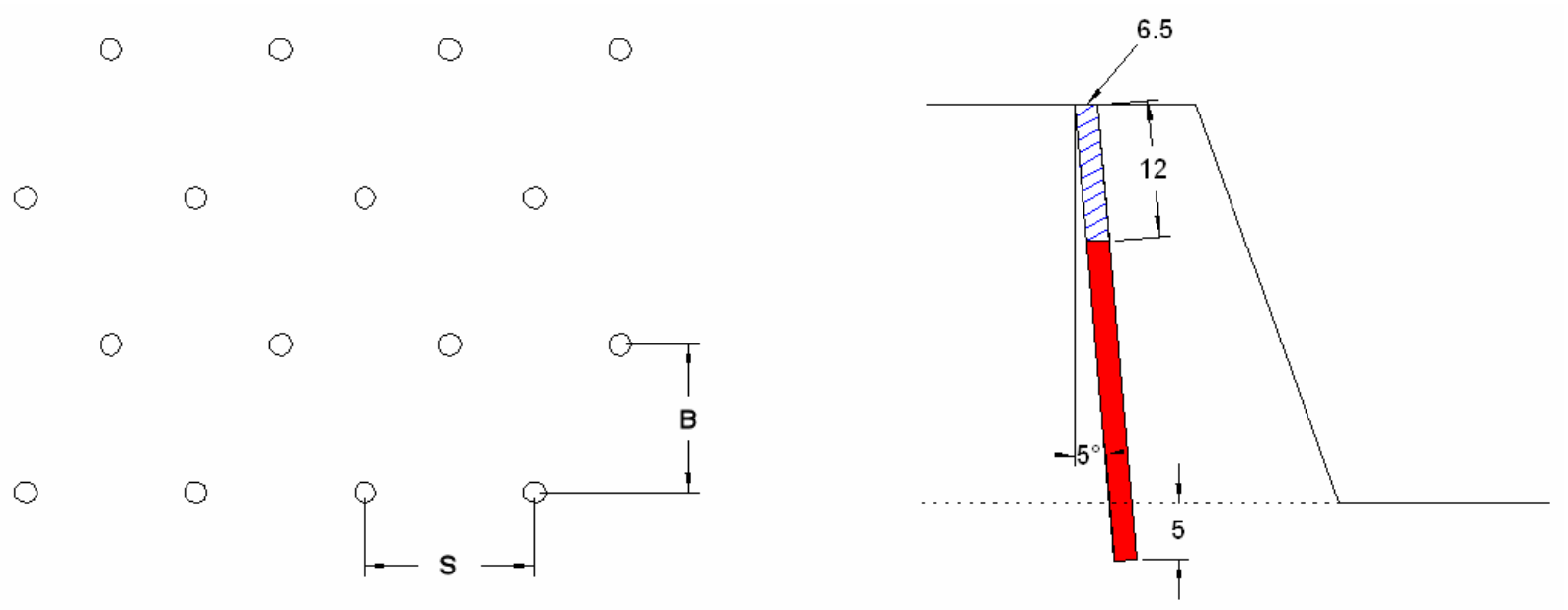

Figure 41. Blast design definitions. 
The Mine-to-Mill guidelines also extended to Continuous Improvement and Timing issues including:

\section{Continuous Improvement}

- Minimize the face burden through incremental steps, especially for blocky rock.

- Increase number of rows where feasible - aim for 5 or 6 rows.

- Review fines through the plant and discuss changes to blast design as necessary.

- Review designs for 3M blasts for optimum productivity.

$\underline{\text { Timing }}$

- When the front row is closer spaced than the rest of the rows, maintain consistent time between echelons. Any extra holes are "in-fill" and should be timed to initiate between the adjacent holes.

- Provide longer time between the last rows.

- The chart (Figure 42) shows the timing analysis where it can be seen that there are four times when two holes initiate with $8 \mathrm{~ms}$. For example, the red bar is when the two red holes are initiating (blue holes have already fired and green are yet to fire). If this is critical, it is possible to change some times to reduce this while still maintaining regular timing.

- The timing contours are indicated by the colored lines. Note they are straight and regularly spaced.

- The same principals apply if the holes are tied up as a flatter echelon.

The Mine-to-Mill team also suggested that Pittsboro include digital photos of each shot over the 3-month monitoring period to record the fragmentation. Similarly, the OpStat database (Luck Stone blasting data base) should be modified to allow the drill \& blast crew to record the ore structure (fractured/blocky) and ore type (andesite, dacite, basalt etc). This additional information should help the MTM team in the final review of the change in blasting practice.

Simulations were performed using the expected ROMs from both the current practice (21 $\mathrm{m}$ and $12 \mathrm{~m}$, fractured and blocky benches) and modified designs (21 m fractured wet/damp and blocky, and $12 \mathrm{~m}$ fractured wet/damp and blocky). Table 28 summarizes the results of these simulations. 


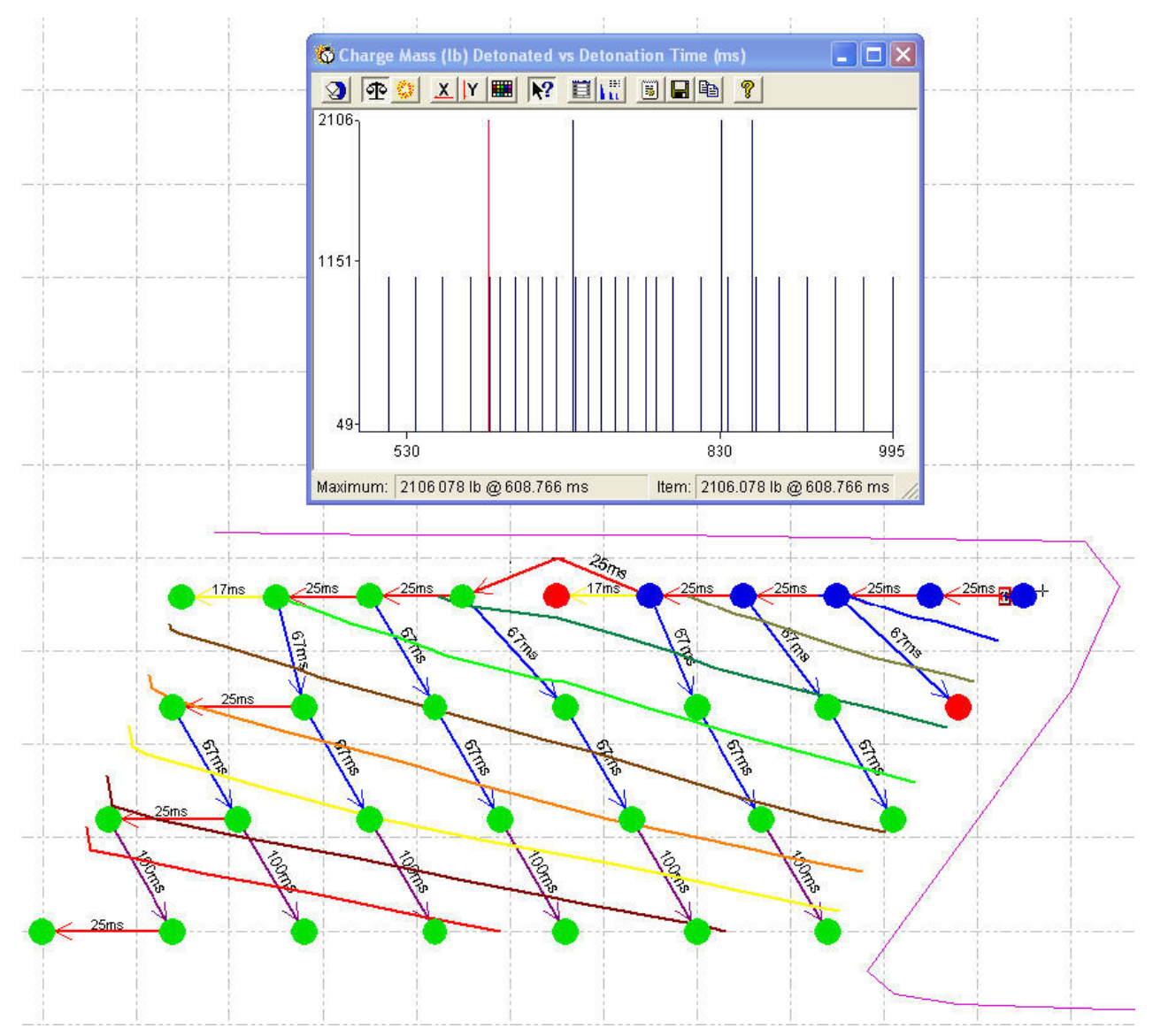

Figure 42. Example of surface timing.

Table 28. Comparison of Current Practice with Expected Benefits under New Blast Design Guidelines (based on computer simulations).

\begin{tabular}{|c|c|c|c|}
\hline \multicolumn{2}{|c|}{ Energy Consumption (kWh/t) } & Typical & Modified \\
\hline \multicolumn{2}{|l|}{ Plant } & LS & LS \\
\hline \multicolumn{2}{|l|}{ Primary } & 0.09 & 0.08 \\
\hline \multicolumn{2}{|l|}{ Secondary } & 0.17 & 0.16 \\
\hline \multicolumn{2}{|l|}{ Tertiary } & 0.93 & 0.93 \\
\hline TOTAL & & 1.19 & 1.17 \\
\hline \multicolumn{2}{|c|}{ Production Rates } & LS & LS \\
\hline \multirow[t]{2}{*}{ Primary } & tph & 1008 & 1156 \\
\hline & $\mathrm{kW}$ & 93 & 95 \\
\hline \multirow[t]{2}{*}{ Secondary } & tph & 485 & 515 \\
\hline & $\mathrm{kW}$ & 81 & 83 \\
\hline \multirow[t]{2}{*}{ Tertiary } & tph & 147 & 147 \\
\hline & $\mathrm{kW}$ & 136 & 137 \\
\hline
\end{tabular}

Note that in the simulations the primary crusher was assumed to run on a daily basis at $80 \%$ of rated capacity of a C145 jaw crusher. 
The simulation results indicate a potential to improve on the primary and secondary productivity ( $15 \%$ and $6 \%$ respectively), with a small flow-on gain in the tertiary feed production. Though the overall energy reduction is small (around $1-2 \%$ ), the benefit at the primary and secondary is $6 \%$. The impact on tertiary production is slight since the feed is a scalped size interval; no fines or coarse, just the middle sizes which are difficult to alter through blasting and crushing. Since Pittsboro must produce a base to meet NC regulations, they cannot adjust the screens in the secondary plant to send more material to the tertiary plant. Overall, the projected gains are still significant for a well run quarry that expends nearly $65 \%$ of its energy in the tertiary plant alone.

Implementation - Long-Term Monitoring Results: As a result of lessons learned from Phase I work at the Bealeton Quarry, it was determined that side-by-side comparison tests were not sufficient to quantify potential improvements and energy savings resulting from Mine-to-Mill optimization versus current quarry practice. As a result, a long-term monitoring approach was used to quantify results at the Pittsboro Quarry.

Detailed control system data on the Pittsboro plant were provided by Luck Stone on a monthly basis beginning November 1,2005 . This included primary, secondary and tertiary performance data recorded every 10 seconds for each day. The primary stacker position sensor, installed in October 2005, kept track of the rock source so that the primary crusher performance on Luck Stone and $3 \mathrm{M}$ material could be differentiated. Base-line monitoring was carried out for a period of three months from November 2005 - January 2006, although only 60 days of data out of a possible 92 were recorded due to public holidays, weekends and downtime. Likewise, monitoring of the mine-to-mill implementation was carried out for a three-month period from April 2006 - June 2006 with a total of 66 days of operation recorded out of a possible 91.

The results are presented for each plant in turn, comparing the baseline (LS) and MTM 3-month production totals and monthly production rates, which includes the specific power consumption and product yields where applicable. The distribution of the throughput to each plant over both 3-month periods is also discussed.

\section{Primary Section}

The monitoring results (see Table 29 and Table 30) suggest $3 \mathrm{M}$ takes around $62 \%$ of feed. Stockpile B, which can feed both $3 \mathrm{M}$ and LS secondary plants, saw $9 \%$ of the material in the Nov-Jan period, compared with only $1 \%$ in the Apr-Jun period. These figures are consistent with the production targets at Pittsboro. In terms of crusher utilization, represented by the Hours Run and Crushed per day, the figures suggest on average the overall utilization is around $85 \%$, meaning $15 \%$ of the time the crusher is not doing useful work. The percentage utilization did not change when the MTM blasting guidelines were introduced. 
Table 29. Production Totals for Primary Crushing - Baseline Period.

\begin{tabular}{|c|c|c||c||c|}
\hline $\begin{array}{c}\text { tonnes } \\
\text { A }\end{array}$ & $\begin{array}{c}\text { tonnes } \\
\text { B }\end{array}$ & $\begin{array}{c}\text { tonnes } \\
\text { C }\end{array}$ & $\begin{array}{c}\text { tonnes } \\
\text { LS }\end{array}$ & $\begin{array}{c}\text { tonnes } \\
\text { TOTAL }\end{array}$ \\
\hline 266,127 & 37,809 & 131,535 & 169,344 & 435,471 \\
\hline $61 \%$ & $9 \%$ & $30 \%$ & $39 \%$ & $100 \%$ \\
\hline
\end{tabular}

\begin{tabular}{|l|c|c||c|c|c||c|c|c|}
\hline \multicolumn{2}{|l|}{ LS (hours/day) } & Difference & \multicolumn{2}{|l|}{ 3M (hours/day) } & Difference & Total (hours/day) & Difference \\
\hline Run & Crushed & Run-Crushed & Run & Crushed & Run-Crushed & Run & Crushed & Run-Crushed \\
\hline 3.70 & 3.23 & $13 \%$ & 5.40 & 4.54 & $16 \%$ & 9.10 & 7.76 & $15 \%$ \\
\hline
\end{tabular}

Table 30. Production Totals for Primary Crushing - MTM Period.

\begin{tabular}{|c|c|c||c|c|}
\hline $\begin{array}{c}\text { tonnes } \\
\text { A }\end{array}$ & $\begin{array}{c}\text { tonnes } \\
\text { B }\end{array}$ & $\begin{array}{c}\text { tonnes } \\
\text { C }\end{array}$ & $\begin{array}{c}\text { tonnes } \\
\text { LS }\end{array}$ & $\begin{array}{c}\text { tonnes } \\
\text { TOTAL }\end{array}$ \\
\hline 202,726 & 4,046 & 112,594 & 116,640 & 319,366 \\
\hline $63 \%$ & $1 \%$ & $35 \%$ & $37 \%$ & $100 \%$ \\
\hline
\end{tabular}

\begin{tabular}{|c|c|c|c|c|c|c|c|c|}
\hline \multicolumn{2}{|c|}{ LS (hours/day) } & Difference & \multicolumn{2}{|c|}{ 3M (hours/day) } & Difference & \multicolumn{2}{|c|}{ Total (hours/day) } & \\
\hline Run & Crucho & shed & Run & Crushed & & & & \\
\hline 2.78 & 2 & $18 \%$ & 5.65 & 4.84 & $14 \%$ & 8.42 & 7.12 & $15 \%$ \\
\hline
\end{tabular}

Table 31 and Table 32 show the throughput and power consumptions for both Luck Stone and $3 \mathrm{M}$. The results for the first 3 months show a statistically significant difference between the LS and $3 \mathrm{M}$ production rates of around $110 \mathrm{tph}$, and corresponding lower specific energy consumption (0.10 vs. $0.14 \mathrm{kWh} / \mathrm{t})$. This is consistent with the earlier ore characterization work which suggested the $3 \mathrm{M}$ andesite is around $30-40 \%$ harder than the LS rock types. It appears the MTM blast changes have reduced the difference between LS and $3 \mathrm{M}$ production rates to approximately 90 tph, and similarly the difference in their specific energy consumptions has been significantly reduced (37\% to $19 \%)$.

Table 31. Production Rates for Primary Crushing - Baseline Period.

\begin{tabular}{|l|c|c|c|c|c|c|}
\hline Month & $\begin{array}{c}\text { LS } \\
\text { tph }\end{array}$ & $\begin{array}{c}\mathbf{3 M} \\
\text { tph }\end{array}$ & $\begin{array}{c}\text { LS } \\
\text { kWh/t }\end{array}$ & $\begin{array}{c}\mathbf{3 M} \\
\mathbf{k W h} / \mathbf{t}\end{array}$ & $\begin{array}{c}\text { LS } \\
\text { kW }\end{array}$ & $\begin{array}{c}\mathbf{3 M} \\
\mathbf{k W}\end{array}$ \\
\hline Nov & 1038 & 841 & 0.09 & 0.15 & 91 & 120 \\
\hline Dec & 945 & 842 & 0.13 & 0.15 & 122 & 129 \\
\hline Jan & 958 & 921 & 0.09 & 0.11 & 83 & 99 \\
\hline Overall & $\mathbf{9 8 0}$ & $\mathbf{8 6 9}$ & $\mathbf{0 . 1 0}$ & $\mathbf{0 . 1 4}$ & $\mathbf{9 5}$ & $\mathbf{1 1 6}$ \\
\hline
\end{tabular}


Table 32. Production Rates for Primary Crushing - MTM Period.

\begin{tabular}{|l|c|c||c|c|c|c|}
\hline Month & $\begin{array}{c}\text { LS } \\
\text { tph }\end{array}$ & $\begin{array}{c}\mathbf{3 M} \\
\mathbf{t p h}\end{array}$ & $\begin{array}{c}\text { LS } \\
\mathbf{k W h} / \mathbf{t}\end{array}$ & $\begin{array}{c}\mathbf{3 M} \\
\mathbf{k W h} / \mathbf{t}\end{array}$ & $\begin{array}{c}\text { LS } \\
\mathbf{k W}\end{array}$ & $\begin{array}{c}\mathbf{3 M} \\
\mathbf{k W}\end{array}$ \\
\hline Apr & 1018 & 882 & 0.12 & 0.15 & 116 & 131 \\
\hline May & 949 & 882 & 0.14 & 0.16 & 132 & 139 \\
\hline Jun & 1035 & 965 & 0.13 & 0.15 & 126 & 142 \\
\hline Total & $\mathbf{9 9 7}$ & $\mathbf{9 1 0}$ & $\mathbf{0 . 1 3}$ & $\mathbf{0 . 1 5}$ & $\mathbf{1 2 4}$ & $\mathbf{1 3 7}$ \\
\hline
\end{tabular}

In terms of the differences between the two 3-month periods, the MTM period shows improved production rates ( $2 \%$ on LS and $5 \%$ on $3 \mathrm{M}$ ), but at a significantly higher power consumption, across all three months. [With the exception of the $2 \%$ increase in LS production rate, all the other changes are significant at the $90 \%$ level.] This would suggest the rock fed to the crusher from April to June was on average harder, and at least equivalent to the rock mined in December 2005. If one compares the June and December results, which reflect similar power consumptions $(\mathrm{kWh} / \mathrm{t})$ and hence similar rock hardness, the MTM production rates are $9 \%$ higher for LS and 15\% higher for 3M rock. The improvement is higher on $3 \mathrm{M}$ than LS, as was expected from the MTM guideline objectives.

The apparent ore change was substantiated by the OpStat information provided by Pittsboro, which shows the distribution of shots in Lift 2 and 3, and the geology in each shot. The April-to-June period had $50 \%$ of the shots in Lift 2, more than the expected $15 \%$. However, the major unexpected finding was that $72 \%$ of all the shots were in Blocky geology, not $15 \%$ as originally expected in the simulations. In terms of the two lifts, $80 \%$ of the shots in Lift 2 were Blocky compared to $76 \%$ in Lift 3 . Hence the original expectation underestimated the ore hardness in the move to Lift 3 as it assumed only $15 \%$ would be in Blocky ore, not $72 \%$ as was realized in practice. The hardness of Blocky ore is confirmed by the OpStat records for the MTM period, which shows $80 \%$ of the oversize was in Blocky ore versus $20 \%$ in Fractured ore.

The variation in daily production rates was also examined to compare the LS and 3M operating statistics. Figure 43 shows the comparison, which includes a histogram chart for the frequency (defined as number of days in 50 stph bins), and a cumulative percent line which shows the percentage of days the daily throughput was at or below a given rate. The charts confirm there is a consistently higher production rate for the LS rock types. Also, the MTM period shows the distribution has shifted towards the right, with more days averaging well above 900 tph for both LS and 3M production. It appears that the MTM guidelines have improved the productivity of the primary crushing stage, despite the increased rock hardness. Clearly, had the rock remained the same, the improved blasting would have resulted in significant energy savings. Based on the figures above, and assuming the same monthly production targets, the MTM approach would have realized a 9\% saving in energy for LS and 13\% saving for $3 \mathrm{M}$ crushing. These results are consistent with the simulations which suggested $10 \%$ for LS. 
LS

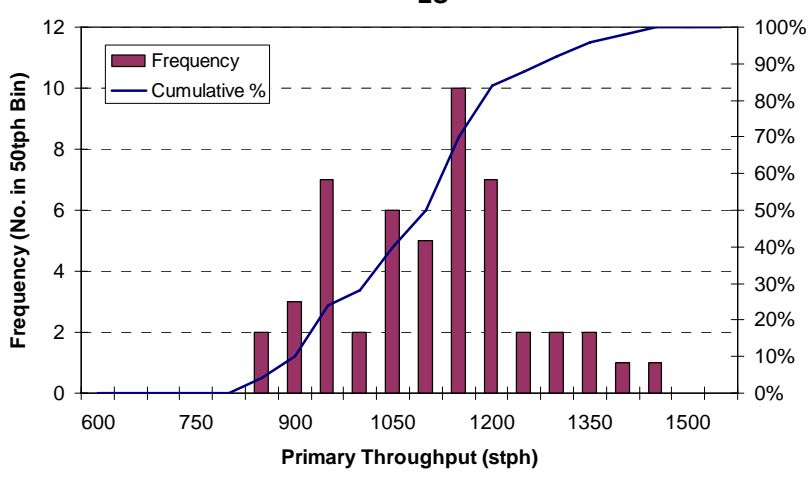

Baseline Period: Nov-05 to Jan-06

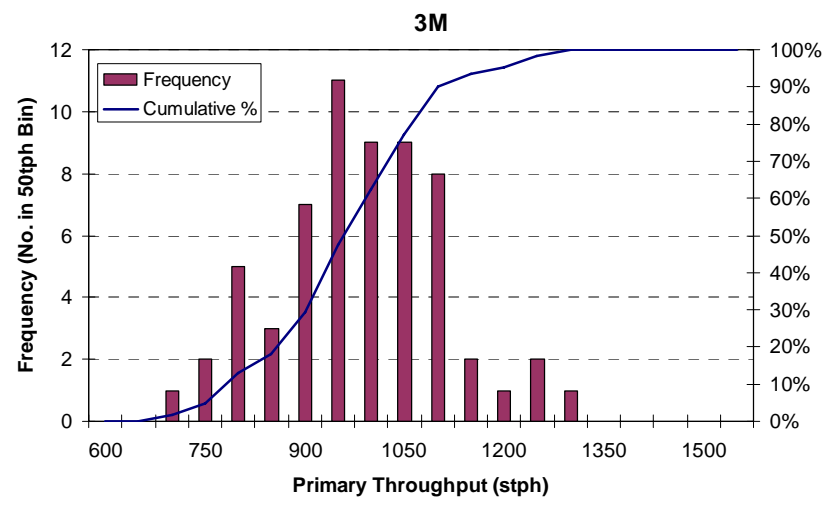

Baseline Period: Nov-05 to Jan-06

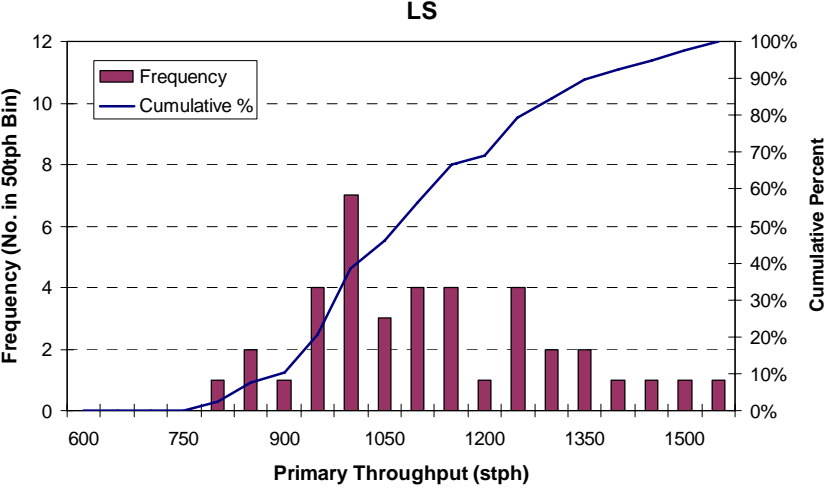

MTM Period: Apr-06 to Jun-06

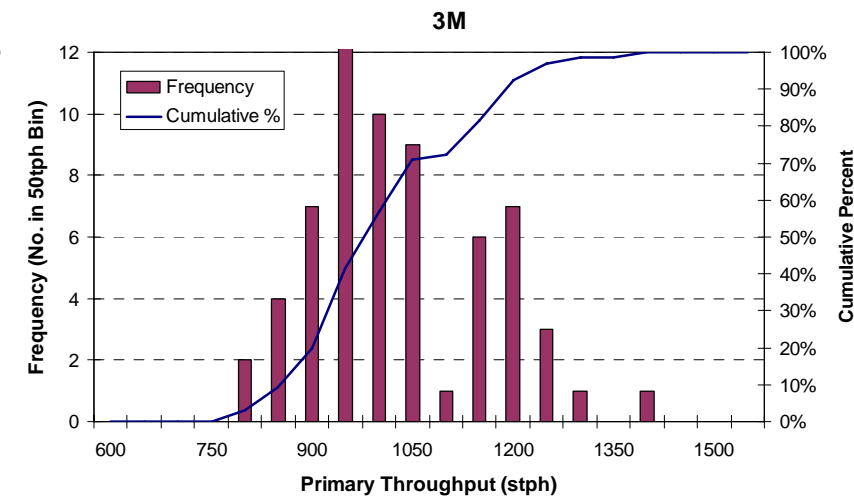

MTM Period: Apr-06 to Jun-06

Figure 43. Comparison of frequency distributions for LS and 3M primary crusher throughput rates.

\section{$\underline{\text { Luck Stone Secondary Section }}$}

One of the most significant findings from the monitoring results (see Table 33) is the impact of MTM on the crusher utilization, which reduced from $75 \%$ during baseline testing to $50 \%$ in the MTM period. This suggests the crusher had more idle time with the introduction of the MTM guidelines. Hence the MTM blasting appears to have changed the secondary plant feed size distribution significantly, reducing the amount of oversize and hence crusher feed. (Note that the crusher is idle while the feed bin level rises to an acceptable operating range for the crusher feed belt to start.)

During the baseline 3-month period, the crusher typically started and stopped five times for each hour of operation, with a 3 minute idle time during each stop. This equates to 15 minutes every hour or 25\%; consistent with the 3-month production statistics. Clearly under the MTM feed conditions the crusher was idle around 30 minutes per hour or $50 \%$. Tables 34 and 35 show the plant throughput and power consumption, crusher feed rate, production rate to tertiary surge pile, and dust feed rate to the base pile. 
Table 33. Production Totals for LS Secondary Crushing.

\begin{tabular}{|c|c|c|c|}
\hline $\begin{array}{c}\text { Total Tonnes } \\
\text { (LS) }\end{array}$ & $\begin{array}{c}\text { Hours Run/Day } \\
\text { (LS) }\end{array}$ & $\begin{array}{c}\text { Hours Crushed/Day } \\
\text { (LS) }\end{array}$ & $\begin{array}{c}\text { Difference } \\
\text { Run-Crushed }\end{array}$ \\
\hline \multicolumn{4}{|c|}{ Baseline 3-month Period } \\
\hline 147,391 & 6.32 & 4.73 & $25 \%$ \\
\hline \multicolumn{4}{|c|}{ MTM 3-month Period } \\
\hline 119,009 & 5.64 & 2.81 & $50 \%$ \\
\hline
\end{tabular}

Table 34. Production Rates for LS Secondary Crushing - Baseline Period.

\begin{tabular}{|l|c|c||c|c|c||c|c|c|}
\hline Month & $\begin{array}{c}\text { LS } \\
\text { tph }\end{array}$ & $\begin{array}{c}\text { LS } \\
\text { kWh/t }\end{array}$ & $\begin{array}{c}\text { Crusher Feed } \\
\text { tph }\end{array}$ & $\begin{array}{c}\text { Tertiary Feed } \\
\text { tph }\end{array}$ & $\begin{array}{c}\text { Dust Feed } \\
\text { tph }\end{array}$ & $\begin{array}{c}\text { Crusher } \\
\text { Circulating } \\
\text { Load\% }\end{array}$ & $\begin{array}{c}\text { Tertiary } \\
\text { Plant } \\
\text { Yield\% }\end{array}$ & $\begin{array}{c}\text { Crusher } \\
\text { Power } \\
\text { kW }\end{array}$ \\
\hline Nov & 425 & 0.190 & 209 & 200 & 36 & $51 \%$ & $48 \%$ & 75 \\
\hline Dec & 341 & 0.223 & 153 & 153 & 42 & $46 \%$ & $46 \%$ & 76 \\
\hline Jan & 436 & 0.128 & 231 & 192 & 45 & $54 \%$ & $44 \%$ & 67 \\
\hline Total & $\mathbf{4 0 2}$ & $\mathbf{0 . 1 8 6}$ & $\mathbf{2 2 0}$ & $\mathbf{1 8 1}$ & $\mathbf{4 2}$ & $\mathbf{5 1 \%}$ & $\mathbf{4 6 \%}$ & $\mathbf{7 2}$ \\
\hline
\end{tabular}

Table 35. Production Rates for LS Secondary Crushing - MTM Period.

\begin{tabular}{|l|c|c|c|c|c||c|c|c|}
\hline Month & $\begin{array}{c}\text { LS } \\
\text { tph }\end{array}$ & $\begin{array}{c}\text { LS } \\
\text { kWh/t }\end{array}$ & $\begin{array}{c}\text { Crusher Feed } \\
\text { tph }\end{array}$ & $\begin{array}{c}\text { Tertiary Feed } \\
\text { tph }\end{array}$ & $\begin{array}{c}\text { Dust Feed } \\
\text { tph }\end{array}$ & $\begin{array}{c}\text { Crusher } \\
\text { Circulating } \\
\text { Load\% }\end{array}$ & $\begin{array}{c}\text { Tertiary } \\
\text { Plant } \\
\text { Yield\% }\end{array}$ & $\begin{array}{c}\text { Crusher } \\
\text { Power } \\
\text { kW }\end{array}$ \\
\hline Apr & 401 & 0.248 & 244 & 179 & 53 & $62 \%$ & $45 \%$ & 98 \\
\hline May & 461 & 0.172 & 227 & 226 & 51 & $50 \%$ & $49 \%$ & 80 \\
\hline Jun & 417 & 0.159 & 206 & 217 & 57 & $50 \%$ & $52 \%$ & 66 \\
\hline Total & $\mathbf{4 2 6}$ & $\mathbf{0 . 1 9 7}$ & $\mathbf{2 2 8}$ & $\mathbf{2 0 6}$ & $\mathbf{5 4}$ & $\mathbf{5 4 \%}$ & $\mathbf{4 9 \%}$ & $\mathbf{8 3}$ \\
\hline
\end{tabular}

In terms of the differences between the two 3-month periods, the MTM period shows a $6 \%$ improvement in production rate, but at a slightly higher average power consumption. [With the exception of the $6 \%$ increase in specific power consumption, all the other changes are significant at the $90 \%$ level.] As noted in the primary, the secondary results also suggest the rock fed to the crusher from April to June was on average harder (0.197 vs. $0.186 \mathrm{kWh} / \mathrm{t}$ and 83 vs. $72 \mathrm{~kW}$ ). If one compares the May/June and November/January results, which reflect similar power consumptions and hence similar rock hardness, the MTM production rates are only $2 \%$ higher. It appears that the productivity increases made possible with the MTM blasting were not fully realized due to the 360 tph downstream Bivitec capacity limitation. Therefore any gain in fines that the MTM achieved could not be translated to an immediate gain in plant throughput without the risk of overloading the Bivitec. This conclusion is supported by the estimated Bivitec feed rates for April to June, derived using the daily plant and crusher 
feed rates and Split information on $\mathrm{C} 9$ and $\mathrm{C} 12$. The daily averages were found to be 333, 285 and 249 tph respectively for April, May and June. Clearly for Luck Stone to realize the maximum benefit of the MTM blasting guidelines, a more sophisticated control approach is required that would regulate the plant feed rate and crusher gap based on the available Bivitec capacity. Such a system can capitalize on the recently installed Split system and JKMRC models of the crusher and screen developed as part of the DOE project.

The other major benefit that the MTM guidelines appear to have contributed is a $7 \%$ relative increase in the yield to the tertiary plant stockpile. The rate of tertiary feed production also increased significantly, as expected from the simulations. This is a very significant outcome in terms of the overall economics of the operation, reducing the amount of incoming feed that reports to base and yet increasing the rate of tertiary feed production. The crusher circulating load appears to have increased during the MTM period, but this result does not properly account for the disconnect between the plant feed rate and crusher feed rate, and the control system that manipulates both to achieve the target set-points. If the plant feed rate is limited by the Bivitec, and the feed is fine, then the controller needs to increase the crusher feed rate if it is to achieve target amps and bowl levels. This in turn means the feed bin is emptied faster, and the crusher becomes idle more often. As a result, the apparent circulating load will be higher due to the increased crusher feed rate. The monitoring results support this conclusion since the crusher feed rate was $14 \%$ higher during the MTM period.

Figure 44 shows the variation in daily production rates over the two 3-month periods. The results suggest, during the Baseline period, the plant throughput varied significantly from day to day. This would suggest the feed size variation was significant. Under the MTM conditions, the plant feed rate appeared to be more under control, with a reduced variation. Clearly there are also many fewer days below 360 tph.

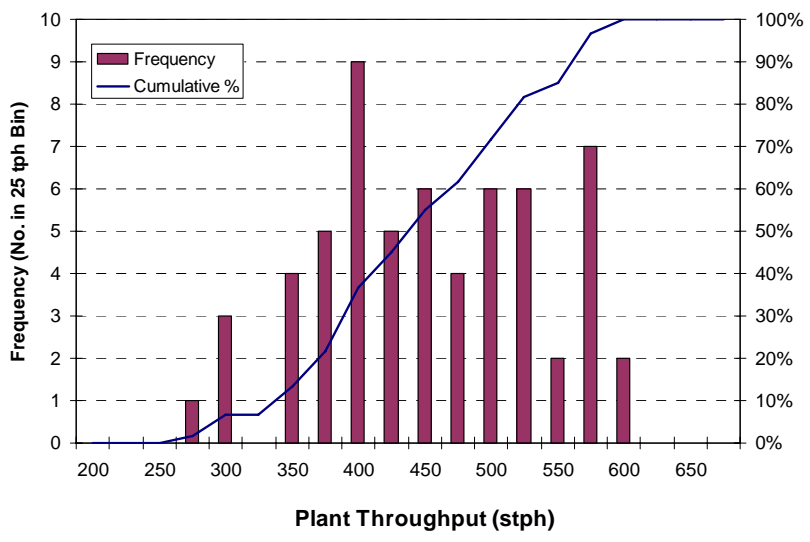

Baseline Period: Nov-05 to Jan-06

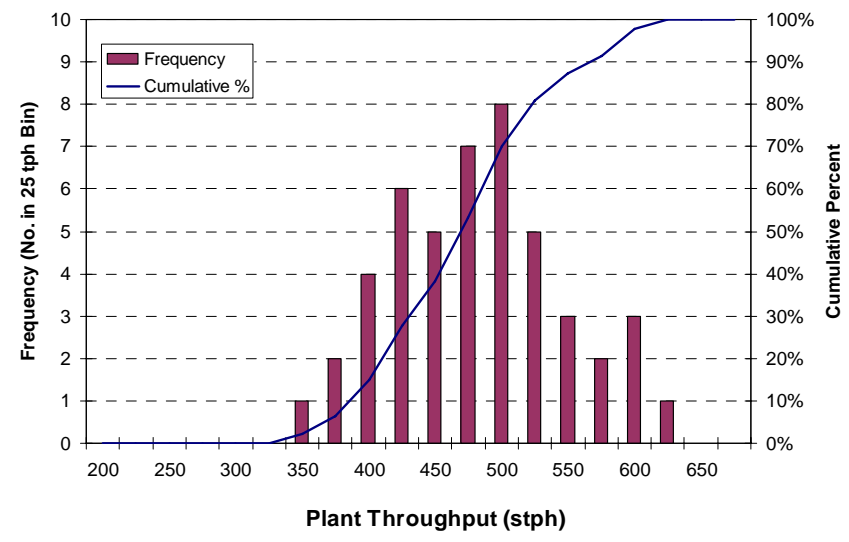

MTM Period: Apr-06 to Jun-06

Figure 44. Comparison of frequency distributions for LS secondary plant throughput rates. 
In terms of energy saving, it is very difficult to compare the two periods since the feed size and crusher gap were not recorded. However, the figures suggest the MTM feed achieved at least a $2 \%$ reduction at similar operating conditions (plant feedrate and crusher load). This result is consistent with the simulation results, which suggested $4 \%$.

\section{M Secondary Section}

The 3M monitoring results (see Table 36) show an increase in the average crusher utilization from $78 \%$ during baseline period to $85 \%$ for the MTM period. As in the LS plant, this utilization reflects the proportion of time the crusher was idle while the feed bin level rose to an acceptable operating range for the crusher feed belt to start. The crusher was also run longer each day during the MTM period, probably to mitigate the effect of relining the machine in mid April. According to Pittsboro personnel, a complete liner change was carried out on the $3 \mathrm{M}$ secondary crusher on the 12th of April. The new liner had a pretty dramatic impact on the throughput until it was worn in, resulting in a significant reduction in the productivity during the MTM period. The production rate information in Tables 37 and 38 shows the plant throughput, power consumption, crusher feed rate and circulating load. Due to the relining of the $3 \mathrm{M}$ secondary crusher, a valid comparison of the baseline and MTM periods for the $3 \mathrm{M}$ secondary plant is not possible.

Table 36. Production Totals for 3M Secondary Crushing.

\begin{tabular}{|c|c|c|c|}
\hline $\begin{array}{c}\text { Total Tonnes } \\
\text { (3M) }\end{array}$ & $\begin{array}{c}\text { Hours Run/Day } \\
\text { (3M) }\end{array}$ & $\begin{array}{c}\text { Hours Crushed/Day } \\
\text { (3M) }\end{array}$ & $\begin{array}{c}\text { Difference } \\
\text { Run-Crushed }\end{array}$ \\
\hline \multicolumn{4}{|c|}{ Baseline 3-month Period } \\
\hline 238,934 & 6.55 & 5.13 & $22 \%$ \\
\hline \multicolumn{4}{|c|}{ MTM 3-month Period } \\
\hline 315,952 & 8.16 & 6.93 & $15 \%$ \\
\hline
\end{tabular}

Table 37. Production Rates for 3M Secondary Crushing - Baseline Period.

\begin{tabular}{|c|c|c|c||c|c|}
\hline Month & $\begin{array}{c}\mathbf{3 M} \\
\text { tph }\end{array}$ & $\begin{array}{c}\text { 3M } \\
\text { kWh/t }\end{array}$ & $\begin{array}{c}\text { Crusher } \\
\text { Feed } \\
\text { tph }\end{array}$ & $\begin{array}{c}\text { Crusher } \\
\text { Circulating } \\
\text { Load\% }\end{array}$ & $\begin{array}{c}\text { Crusher } \\
\text { Power } \\
\text { kW }\end{array}$ \\
\hline Nov & 485 & 0.172 & 315 & $68 \%$ & 103 \\
\hline Dec & 502 & 0.198 & 329 & $68 \%$ & 128 \\
\hline Jan & 578 & 0.156 & 355 & $62 \%$ & 112 \\
\hline Total & $\mathbf{5 2 4}$ & $\mathbf{0 . 1 7 5}$ & $\mathbf{3 3 4}$ & $\mathbf{6 6 \%}$ & $\mathbf{1 1 4}$ \\
\hline
\end{tabular}


Table 38. Production Rates for 3M Secondary Crushing - MTM Period.

\begin{tabular}{|c|c|c||c|c|c|}
\hline Month & $\begin{array}{c}\mathbf{3 M} \\
\text { tph }\end{array}$ & $\begin{array}{c}\text { 3M } \\
\text { kWh/t }\end{array}$ & $\begin{array}{c}\text { Crusher } \\
\text { Feed } \\
\text { tph }\end{array}$ & $\begin{array}{c}\text { Crusher } \\
\text { Circulating } \\
\text { Load\% }\end{array}$ & $\begin{array}{c}\text { Crusher } \\
\text { Power } \\
\text { kW }\end{array}$ \\
\hline Apr & 411 & 0.200 & 281 & $75 \%$ & 98 \\
\hline May & 490 & 0.179 & 272 & $57 \%$ & 95 \\
\hline Jun & 436 & 0.184 & 291 & $72 \%$ & 90 \\
\hline Total & $\mathbf{4 4 7}$ & $\mathbf{0 . 1 8 7}$ & $\mathbf{2 8 1}$ & $\mathbf{6 8 \%}$ & $\mathbf{9 4}$ \\
\hline
\end{tabular}

Figure 45 shows the variation in daily production rates over the two 3-month periods. The results for the baseline period show a much wider operating range for the $3 \mathrm{M}$ secondary than observed for the LS secondary (Figure 44), although the $3 \mathrm{M}$ secondary had a higher average daily throughput (524 vs. 402 tph). The complete $3 \mathrm{M}$ crusher reline in April affected the operation significantly, resulting in a much wider operating envelope during the MTM period. On average the crusher recycle load was 66 to $68 \%$, which means around a third of the incoming feed was coarser than $100 \mathrm{~mm}$ (the screen deck aperture). The histogram chart for the frequency distributions of the daily throughput, shown in Figure 45, suggests that with a worn-in liner, the $3 \mathrm{M}$ plant will rarely be fed less than 450 tph, while it often sees throughputs close to $680 \mathrm{tph}$. Clearly minus any downstream restrictions like the Bivitec screen, and only having to reduce the feed to less than $100 \mathrm{~mm}$, the $3 \mathrm{M}$ secondary can easily attain higher overall throughputs than the LS secondary.

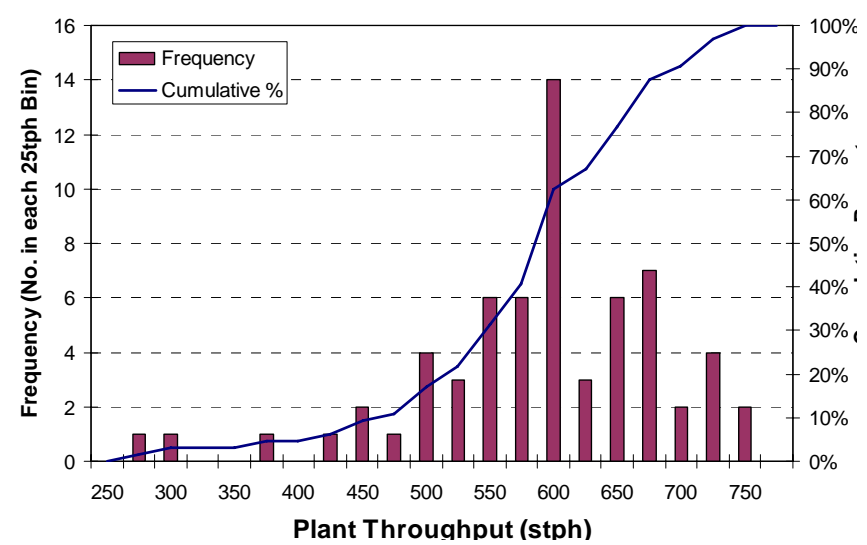

Baseline Period: Nov-05 to Jan-06

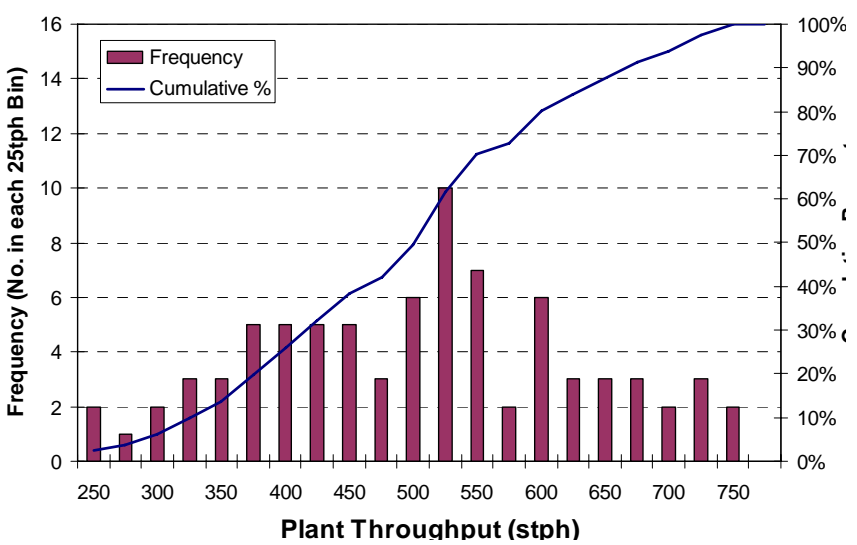

MTM Period: Apr-06 to Jun-06

Figure 45. Comparison of frequency distributions for $3 \mathrm{M}$ secondary plant throughput rates.

\section{$\underline{\text { Tertiary Section }}$}

The tertiary monitoring results (see Table 39) suggest that the crusher recycle load increased in the MTM period, with a small increase in the proportion of the feed 
reporting to the dust pile. In terms of overall production, the outgoing products accounted for $90 \%$ of the feed tons in the November-to-January period compared to $102 \%$ for the April-to-June period. This discrepancy reflected an error between the feed and product weightometers, which appears to have corrected itself after the lightening strikes in May and June. The major product during both 3-month periods was \#57, however the MTM period saw a $27 \%$ increase in the production of \#78.

Table 39. Production Totals for Tertiary Crushing.

\begin{tabular}{|c|c|c|c|c|c|c|}
\hline $\begin{array}{c}\text { Tertiary Circuit } \\
\begin{array}{c}\text { Feed } \\
\text { Tonnes }\end{array}\end{array}$ & $\begin{array}{c}\text { Crusher } \\
\text { Circulating Load } \\
\text { Tonnes }\end{array}$ & $\begin{array}{c}\text { Dust } \\
\text { Tonnes }\end{array}$ & $\begin{array}{c}\# 5 \\
\text { Tonnes }\end{array}$ & $\begin{array}{c}\# 57 \\
\text { Tonnes }\end{array}$ & $\begin{array}{c}\# 78 \\
\text { Tonnes }\end{array}$ & $\begin{array}{c}\text { Hours } \\
\text { Crushed }\end{array}$ \\
\hline \multicolumn{7}{|c|}{ Baseline 3-month Period } \\
\hline 80,295 & 29,681 & 17,691 & 8,743 & 39,053 & 6,876 & 8.55 \\
\hline $100 \%$ & $37 \%$ & $22 \%$ & $11 \%$ & $49 \%$ & $9 \%$ & \\
\hline \multicolumn{7}{|c|}{ MTM 3-month Period } \\
\hline $62,608^{\star}$ & 33,477 & 14,097 & 144 & 40,581 & 8,766 & 9.62 \\
\hline $100 \%$ & $53 \%$ & $23 \%$ & $0 \%$ & $65 \%$ & $14 \%$ & \\
\hline
\end{tabular}

"total excludes June 24 to 30 since no reliable scale data available post lightening strike.

The production rate information in Tables 40 and 41 shows the plant throughput, power consumption and all the product rates. The results suggest the plant feedrate was significantly lower in April and May than in the November-January period (102 vs. 147 tph), with a correspondingly higher crusher circulating load (65\% vs. 39\%). The specific power consumption was $27 \%$ higher for these two months compared to the Novemberto-January period (1.194 vs. $0.942 \mathrm{kWh} / \mathrm{t})$. These figures all point to major changes in the ore and/or tertiary crusher liners. According to Pittsboro personnel, the quarry was running more of the dacite from the second lift during the April and May period which would account for the increased power consumption (dacite is much harder than basalt as evident from the results in Table 15). Pittsboro also had a set of liners that did not crush as well as others had in the past. And lastly, some of the data could be suspect due to a lightening strike which took out most of the conveyor scales in the tertiary section in late April.

Table 40. Production Rates for Tertiary Crushing - Baseline Period.

\begin{tabular}{|c|c|c|c|c|c|c|c|c|c|c|c|c|}
\hline Month & $\begin{array}{c}\text { Circuit } \\
\text { Feed } \\
\text { tph }\end{array}$ & $\begin{array}{c}\text { Crusher } \\
\text { Energy } \\
\text { kWh/t }\end{array}$ & $\begin{array}{c}\text { Crusher } \\
\text { Power } \\
\text { kW }\end{array}$ & $\begin{array}{c}\text { Crusher } \\
\text { C.L. } \\
\text { tph }\end{array}$ & $\begin{array}{c}\text { Dust } \\
\text { tph }\end{array}$ & $\begin{array}{l}\text { Wash } \\
\text { Screen } \\
\text { Feed } \\
\text { tph }\end{array}$ & $\begin{array}{l}\# 5 \\
\text { tph }\end{array}$ & $\begin{array}{l}\# 57 \\
\text { tph }\end{array}$ & $\begin{array}{l}\# 78 \\
\text { tph }\end{array}$ & $\begin{array}{c}\text { Wash } \\
\text { Screen } \\
\text { Feed (calc) } \\
\text { tph }\end{array}$ & $\begin{array}{c}\text { Error } \\
\%\end{array}$ & $\begin{array}{c}\text { C.L. } \\
\%\end{array}$ \\
\hline Nov & 161 & 0.832 & 131 & 64 & 31 & 131 & 37 & 64 & 14 & 115 & $-12 \%$ & $38 \%$ \\
\hline Dec & 141 & 0.901 & 125 & 66 & 28 & 114 & 35 & 57 & 11 & 103 & $-8 \%$ & $45 \%$ \\
\hline Jan & 143 & 1.057 & 151 & 48 & 35 & 108 & 0 & 78 & 13 & 91 & $-16 \%$ & $35 \%$ \\
\hline Total & 147 & 0.942 & 137 & 58 & 31 & 116 & 22 & 67 & 12 & 101 & $-12 \%$ & $39 \%$ \\
\hline
\end{tabular}


Table 41. Production Rates for Tertiary Crushing - MTM Period.

\begin{tabular}{|c|c|c|c|c|c|c|c|c|c|c|c|c|}
\hline Month & $\begin{array}{c}\text { Circuit } \\
\text { Feed } \\
\text { tph }\end{array}$ & $\begin{array}{c}\text { Crusher } \\
\text { Energy } \\
\text { kWh/t }\end{array}$ & $\begin{array}{c}\text { Crusher } \\
\text { Power } \\
\text { kW } \\
\end{array}$ & $\begin{array}{c}\text { Crusher } \\
\text { C.L. } \\
\text { tph } \\
\end{array}$ & $\begin{array}{l}\text { Dust } \\
\text { tph }\end{array}$ & $\begin{array}{c}\text { Wash } \\
\text { Screen } \\
\text { Feed } \\
\text { tph }\end{array}$ & $\begin{array}{l}\# 5 \\
\text { tph }\end{array}$ & $\begin{array}{l}\# 57 \\
\text { tph }\end{array}$ & $\begin{array}{l}\# 78 \\
\text { tph }\end{array}$ & $\begin{array}{c}\text { Wash } \\
\text { Screen } \\
\text { Feed(calc) } \\
\text { tph }\end{array}$ & $\begin{array}{c}\text { Error } \\
\% \\
\end{array}$ & $\begin{array}{c}\text { C.L. } \\
\%\end{array}$ \\
\hline Apr & 101 & 1.230 & 124 & 70 & 22 & 79 & 0 & 60 & 11 & 71 & $-10 \%$ & $70 \%$ \\
\hline May & 103 & 1.159 & 119 & 58 & 25 & 78 & 0 & 68 & 18 & 86 & $14 \%$ & $60 \%$ \\
\hline Jun & 150 & 0.889 & 141 & 33 & 35 & 119 & 0 & 133 & 18 & 151 & $27 \%$ & $24 \%$ \\
\hline Total & 111 & 1.142 & 126 & 56 & 26 & 86 & 0 & 76 & 15 & 91 & $7 \%$ & $58 \%$ \\
\hline
\end{tabular}

Note that the tertiary plant suffered a second lightening strike on $23^{\text {rd }}$ June 2006. Scales on Circuit Feed and \#57 Product were damaged and were not reading or totalizing properly for the rest of the month. Hence June data is based on only 15 days.

As it stands only the June data could be considered comparable to the first 3-month period, based on the similar specific power consumptions. The figures for Nov/Dec when compared to June suggest the MTM guidelines did not make a significant impact on the tertiary throughput, though the circulating load decreased from $42 \%$ to $24 \%$. In terms of the energy consumption, it is very difficult to compare the two periods since the crusher gap was not recorded and the ore became harder in April and May. However, it appears the change was negligible when considering the overall results from Nov/Dec vs. June. This finding is also consistent with simulation results in Table 28.

In terms of final products, the MTM period increased the \#78 yield, saw virtually no production of \#5, resulting in an increase in \#57, and slightly increased the dust yield. The increased circulating load in April and May probably contributed to the increased dust generation. The increased yield of $\# 78$ and $\# 57$ is considered a benefit, since these are key products at Pittsboro and an increased inventory of \#78 is desirable. It is not clear if the change in ore hardness was the major cause of this increased inventory.

The daily throughput frequency distributions for the two 3-month periods, shown in Figure 46, clearly illustrate the shift in the plant feed rate in the Apr-Jun period. In the Nov-Jan period, the daily feed rate was always above 90 tph, typically 145 tph, and 10\% of the time exceeded $180 \mathrm{tph}$. This would indicate variation in the feed size to the plant, or that the crusher gap occasionally increased well above the 22 to $25 \mathrm{~mm}$ setting. In the Apr-Jun period, the feed rate was significantly lower, with the typical day being 100110 tph. As noted previously, the ore change and possibly the performance of the crusher liners are the most likely causes for the change in the tertiary performance. 


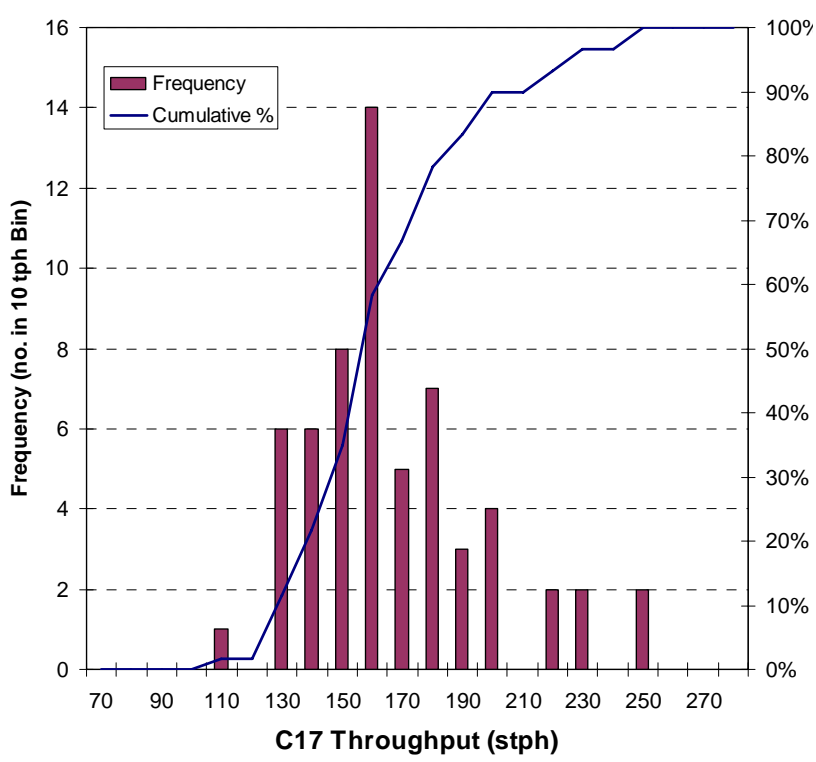

Baseline Period: Nov-05 to Jan-06

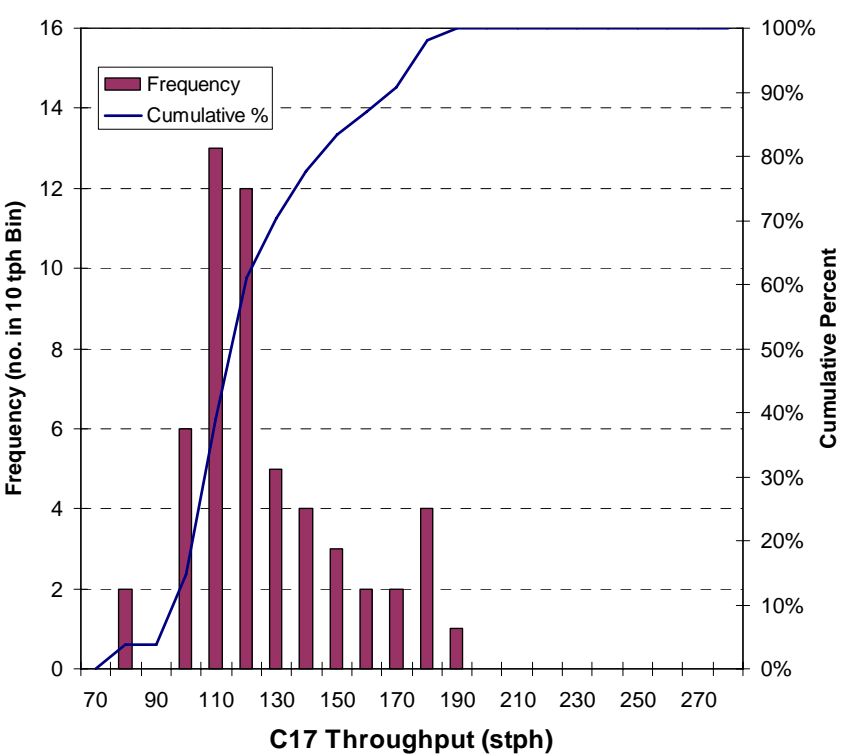

MTM Period: Apr-06 to Jun-06

Figure 46. Comparison of frequency distributions for tertiary plant throughput rates. 


\section{CONCLUSION}

Mine-to-Mill optimization, a total systems approach to energy and cost savings in the mining industry, has now been applied for the first time in the aggregates industry. This technology, developed at the JKMRC in Queensland, Australia, was successfully implemented at two quarries operated by Luck Stone Corporation of Richmond, Virginia over a period from June of 2004 to September of 2006. The following serves to summarize the major findings of the studies conducted at the Bealeton Quarry and the Pittsboro Quarry, and to highlight the major implications of this work as they pertain to the U.S. aggregates industry.

\section{Bealeton Quarry}

In June 2004, an extensive sampling campaign was conducted at the Bealeton Quarry to quantify the performance of the current operation. Based on the data collected, the blasting and processing operations were successfully modeled using JKSimBlast and JKSimMet simulation packages. These models were then used to simulate the affect of blast design on the ROM fragmentation, throughput, energy consumption and final product yields. On the basis of the simulations, it was determined that there was scope to reduce the overall energy consumption at the Bealeton site by approximately 4 - 5\% through changes in the blast design. These changes were implemented and a side-byside comparison test was conducted in November 2004 with one shot following the current Luck Stone (LS) procedure and a second shot following the recommended Mine-to-Mill (MTM) procedure. Both shots were extensively audited to provide a quantitative comparison. In addition, the long-term energy consumption and production rates were logged by Luck Stone personnel throughout the duration of both shots.

The plant audit suggests the MTM blast yielded an overall finer primary, secondary and tertiary feed size distribution than the corresponding LS standard shot, particularly in the 10 to $100 \mathrm{~mm}$ range. These results are consistent with the simulations carried out prior to implementation. The audits, though only snapshots of the overall production data for each shot, all indicate that the MTM material was easier to treat, resulting in higher throughputs and an overall reduction in energy consumption of $11.7 \%$, without any significant impact on product yields and their size distributions. This is consistent with the original DOE project objective of 5-10\%.

The results of the long-term implementation, however, were inconclusive since it appears the rockmass in the MTM shot was much blockier and harder than in the LS shot. This resulted in more difficult to handle oversize and a reduction in the overall excavator productivity. Thus, despite the additional energy in the MTM blast, the blockier and harder rockmass appears to have mitigated the benefit of this energy, resulting in an overall coarser feed to the primary crusher with a corresponding small reduction in throughput and increase in energy consumption. Had both shots been implemented in the hard rockmass encountered in the MTM shot, simulation results indicate that the MTM blast design would have reduced the overall energy consumption by about $5-6 \%$. 
In hindsight, it appears the most difficult issue in quantifying the benefits of Mine-to-Mill optimization in an aggregate context might be the method of comparison. Clearly, sideby-side benches are no guarantee of similar rockmass. The lessons learned at Bealeton support the idea of implementation over a longer period, e.g. three to six months, from which operating data on throughput and energy can be compared with previous long-term results, thus minimizing the effects of any short-term fluctuations.

\section{Pittsboro Quarry}

In August of 2005, the blasting and processing operations at the Pittsboro Quarry were successfully audited and modeled using JKSimBlast and JKSimMet. These models were used to investigate a range of new blast design recommendations aimed at reducing the amount of $+160 \mathrm{~mm}$ oversize, while not increasing the percent crusher run $(-38 \mathrm{~mm})$ significantly. According to the simulations, the modified blast designs were expected to increase the primary throughput by $15 \%$ and secondary throughput by approximately $6 \%$, with an overall specific energy reduction of around $1 \%$. The secondary plant feed size was expected to be finer, resulting in a lower circulating load around the crusher. Though the net yield to the tertiary plant was expected to reduce due to the increased base fraction in the ROM, the rate of tertiary feed production was likely to increase. The tertiary plant performance and product yields were not expected to change significantly. The impact of the new ROM fragmentation on the Bivitec needed to be closely monitored, particularly if the secondary feed rate was significantly increased and the feed became very fine.

As a result of lessons learned at the Bealeton Quarry, a 3-month MTM implementation phase was agreed upon by Luck Stone to evaluate the impact of the changes in ROM size distribution on excavation and productivity. The implementation phase started on April 1, 2006. The plant was closely monitored over the period to confirm the simulation results. The monitoring results from April to June 2006 were analyzed and compared with the initial 3-months of production data before the MTM guidelines were implemented (baseline period).

The key conclusions from the long-term monitoring analysis are as follows:

\section{Primary}

- The MTM guidelines led to improved productivity in the primary crushing stage (2\% on LS and $5 \%$ on $3 \mathrm{M}$ ), but at a significantly higher power consumption across all three months. This would suggest the rock fed to the crusher from April to June was harder than the baseline material (November to December).

- The move into harder ore was underestimated. The results show that $72 \%$ of the shots during the implementation phase were in hard, blocky geology as opposed to $15 \%$ anticipated by Luck Stone and used in the simulations to project improvements.

- Based on the June and December results, which reflect similar power consumptions and hence similar rock hardness, the MTM production rates were $9 \%$ higher for LS and $15 \%$ higher for $3 \mathrm{M}$ rock. The improvement is higher on $3 \mathrm{M}$ than LS, as was 
expected from the MTM guideline objectives. These increases are consistent with the simulation results, which suggested 15\% for LS.

- The MTM approach would have realized a 9\% saving in energy for LS and $13 \%$ saving for $3 \mathrm{M}$ crushing had the rock stayed the same. These results are also consistent with the simulation results, which suggested $10 \%$ for LS.

\section{Secondary Luck Stone}

- The crusher utilization reduced from $75 \%$ during the baseline period to $50 \%$ in the MTM period, suggesting that the MTM blasting design changed the secondary plant feed size distribution significantly, reducing the amount of oversize and hence crusher feed.

- The MTM period shows a 6\% improvement in production rate, but at a slightly higher average power consumption which again suggests the rock fed to the crusher from April to June was harder. This improvement is consistent with the simulation results which also suggested $6 \%$.

- The productivity increases made possible with the MTM blasting designs were not fully realized due to the downstream Bivitec capacity limitation. To realize the maximum benefit of the MTM blasting guidelines in the secondary plant, a more sophisticated control approach is required to regulate the plant feed rate and crusher gap based on the available Bivitec capacity. Split and JK models developed as part of the DOE project are key elements to this approach.

- The MTM guidelines appear to have delivered a 7\% relative increase in the yield to the tertiary plant stockpile. The rate of tertiary feed production has also increased significantly, as expected from the simulations.

- Under the MTM conditions, the plant feed rate appears to be better controlled, with a reduced variation. There are also fewer days below 400 tph.

- In terms of energy saving, the figures suggest the MTM feed achieved at least a $2 \%$ reduction at similar operating conditions (plant feedrate and crusher load). This result is consistent with the simulation results, which suggested $4 \%$.

\section{Secondary 3M}

- A complete liner change carried out on the $3 \mathrm{M}$ secondary crusher had a dramatic impact on throughput. This resulted in a significant reduction in the productivity from the crusher during the MTM period, and as such, a valid comparison was not possible.

\section{$\underline{\text { Tertiary }}$}

- A change in ore hardness and possibly crusher liners is believed to be the cause of the significantly lower tertiary throughput and correspondingly higher crusher circulating load in April and May. The specific power consumption was 27\% higher for these two months compared to the baseline period, confirming the ore hardness increase. 
- As it stands only the June data could be considered comparable to the baseline period, based on the similar specific power consumptions. The figures suggest the MTM guidelines did not make a significant impact on the tertiary throughput, though the circulating load was reduced from $42 \%$ to $24 \%$.

- In terms of the energy consumption, it is very difficult to compare the two periods since the crusher gap was not recorded and the ore was harder in April and May. However, it appears the change is negligible when we compare the November/December and June months. This finding is also consistent with simulation results.

- In terms of final products, during the MTM period the yield of \#78 increased, virtually no production of $\# 5$ was carried out resulting in an increase in $\# 57$, and the dust yield increased slightly. The increased yield of \#78 and \#57 would be considered a benefit since these are key products at Pittsboro.

\section{Implications to the Aggregate Industry}

A number of major conclusions can be drawn from the project, which should assist DOE in assessing the general applicability of the Mine-to-Mill approach to the aggregates industry.

1. Implementation of the MTM approach at Pittsboro has led to a tangible improvement in productivity, particularly in the primary and secondary plants. Though an apparent change in ore hardness occurred, it was clear from the results that the MTM guidelines represent an energy saving of around 5\% (primary and secondary) and an overall energy savings of around 1\%, consistent with the expected benefits projected from the simulations. This $1-5 \%$ energy savings is also consistent with the simulated results from Bealeton had the side-by-side shots been conducted in the same material.

2. In comparison to past experiences with aggregate producers, Luck Stone clearly runs their operations at a very high standard. Their technical and operating staff have demonstrated a high level of understanding across both mining and processing disciplines, forcing the MTM team to closely examine every aspect of the Luck Stone practice in order to identify areas for possible improvement. Hence the percentage improvement realized by the project (1-5\%) may represent the lower end of what might be obtained overall in the aggregates industry.

3. The variability in ore types across both Bealeton and Pittsboro suggests at least a 2:1 difference in hardness, which contradicts the common misconception, held by most people, that quarry rock is largely homogenous. The idea of comparing sideby-side blasts, as per the Bealeton study, is therefore not a viable method for validating the impact of the MTM approach and a longer term comparison stands the best chance of confirming the benefit of optimized blasting.

4. The 3-month monitoring period used at Pittsboro was critical to the success of the validation. In some cases an even longer period might be warranted to mitigate the effect of crusher relines and significant ore hardness changes. 
5. There are some clear limitations on how much improvement can be made in the aggregate industry due to the fixed feed size that generally reports to the tertiary section of an aggregate plant. This limitation restricts the MTM approach from exercising significant increases in blasting effort, which would otherwise only serve to increase the fines and hence reduce the yield of saleable products. Optimized blasting will therefore require a careful analysis of the rock conditions and plant configuration to ensure the most beneficial result for a given operation.

6. The key to the success at Pittsboro was the development of the MTM guidelines for the modified blasting practice in consultation with the Pittsboro drill \& blast crew. Their full buy-in was necessary to implement the optimized blasting in a sustained manner over the 3-month period. This process worked well and the Luck Stone staff were very happy with the outcome. Specifically, comments from Plant Superintendent Steve Demeyer indicate that without the implementation of the MTM guidelines, production rates would have been severely reduced as the operation moved into the harder rock. As a result, Pittsboro has now adopted the MTM guidelines as their standard practice.

7. The JKSimBlast and JKSimMet simulation packages have proven to be effective tools for examining blasting and processing at both Bealeton and Pittsboro. The blast models were based on blast design variables and rock properties. The plant models were based on detailed analysis of comprehensive plant audit data. These models should enable Luck Stone to transfer the MTM approach to other sites, with some further training as required. Split image analysis has been shown to be a very useful tool in the validation study, and offers potential for advanced plant control.

8. Calibration of the blast and plant models requires significant company resources, both in technical and operating areas. Luck Stone's assistance was exemplary. 


\section{ACKNOWLEDGEMENTS}

The authors would like to acknowledge the numerous individuals within the Luck Stone organization for their assistance and contributions to this project, with specific recognition to Bryan Smith serving as the lead for Luck Stone. We would also like to acknowledge the assistance of representatives from Austin Powder and Mellott Enterprises for their help during the plant audits and blasting surveys, and to Mark Richardson of Contract Support Services serving as the lead on the subcontract. Additional assistance in obtaining rock property data was provided by Dr. Mario Karfakis and assistance in obtaining this award was provided by Drs. Gerald Luttrell, Erik Westman, and Thomas Novak of the Department of Mining and Minerals Engineering at Virginia Tech. Finally, the authors would like to acknowledge Brent Bradshaw, Brian Parker, and Kwangmin Kim, the three graduate students assisting on this project, for their Herculean efforts in collecting and sizing nearly 25 tons of rock! 


\section{REFERENCES}

1. Atasoy, Y., Valery, W., and Skalski, A. (2001), "Primary Versus Secondary Crushing at St. Ives (WMC) SAG Mill Circuit", SAG 2001, Department of Mining and Mineral Process Engineering, University of British Columbia, Vancouver, British Columbia, Canada, pp. 248-261.

2. Comeau, W. (1996), "Explosive Energy Partitioning and Fragment Size Measurement - Importance of Correct Evaluation of Fines in Blasted Rock", Proceedings of the Fragblast-5 workshop on Measurement of Blast Fragmentation, Montreal, Canada, pp. 237-240.

3. Cunningham, C.V.B. (1983), "The Kuz-Ram Model for Prediction of Fragmentation from Blasting", 1st International Symposium of Rock Fragmentation by Blasting, Luleå, Sweden, pp. 439-453.

4. Cunningham, C.V.B. (1986), "Fragmentation Estimations and the Kuz-Ram Model Four Years On", 2nd International Symposium of Rock Fragmentation by Blasting, Colorado, pp. 475-487.

5. Grundstrom, C., Kanchibotla, S.S., Jankovic, A., and Thornton, D.M. (2001), "Blast Fragmentation for Maximising the SAG Mill Throughput at Porgera Gold Mine", Proceedings of the $27^{\text {th }}$ Annual Conference of Explosives and Blasting Technique, International Society of Explosives Engineers, Orlando, Florida, pp. 383-399.

6. Gy, P.M. (1976), "The Sampling of Particulate Materials - A General Theory", Symposium of Sampling Practices in the Mineral Industries, Melbourne, Australia, pp. 17-34 (AusIMM).

7. Hart, S., Valery, W., Clements, B., Reed, M., Song, M., and Dunne, R. (2001), "Optimisation of the Cadia Hill SAG Mill Circuit", SAG 2001, Department of Mining and Mineral Process Engineering, University of British Columbia, Vancouver, British Columbia, Canada, pp. 11-30.

8. Higgins, M. (1998), "JKSimBlast - Blast Simulation and Management", Presented at Blasting Analysis International Eighth High-Tech Seminar, Nashville, Tennessee, pp. 1-9.

9. Kanchibotla, S.S., Valery, W., and Morrell, S. (1999), "Modeling Fines in Blast Fragmentation and its Impact on Crushing and Grinding", Proc. Explo-99 Conf. Kalgoorlie, Austalia.

10. Karageorgos, J., Skrypniuk, J., Valery, W., and Ovens, G. (2001), "SAG Milling at the Fimiston Plant (KCGM)", SAG 2001, Department of Mining and Mineral Process Engineering, University of British Columbia, Vancouver, British Columbia, Canada, pp. 109-124. 
11. Kojovic, T., Michaux, S. and McKenzie, C., (1995), "Impact of Blast Fragmentation on Crushing and Screening Operations in Quarrying", EXPLO 95 Conference, AusIMM, Brisbane, Australia, pp. 427-436.

12. Lilly P.A., (1986), "An Empirical Method of Assessing Rock Mass Blastability", The AusIMM/I.E. Aust. Newman Combined Group, Large Open Pit Min. Conf., pp. 89-92.

13. Napier-Munn, T.J., Morrell, S., Morrison, R.D., Kojovic, T. (1999), Mineral Comminution Circuits - Their Operation and Optimisation, Julius Kruttschnitt Mineral Research Centre, Isles Road, Indooroopilly, Queensland 4068, Australia, 413 pp.

14.Paley, N., and Kojovic, T., (2001), "Adjusting blasting to increase SAG mill throughput at the Red Dog mine", Proc 27th ISEE Annual Conference, Orlando, January, pp. 65-80.

15. Smith, B. (2003), Personal Communication.

16. Tepordei, V.V. (1999), Natural Aggregates - Foundation of America's Future, http:// minerals.usgs.gov/minerals/pubs/commodity/aggregates/fs14497.pdf, USGS Fact Sheet FS 144-97, 4 pp.

17. Tepordei, V.V. (2006), Directory of Principal Aggregate Producers in the Conterminous United States in 2005, http://minerals.usgs.gov/minerals/pubs/ commodity/aggregates/Agdir05.pdf, USGS Mineral Industry Surveys, U.S. Geological Survey, Reston, Virginia, 21 pp.

18. Valery, W., Morrell, S., Kojovic, T., Kanchibotla, S.S., and Thornton, D.M. (2001), "Modeling and Simulation Techniques Applied for Optimisation of Mine to Mill Operations and Case Studies", Proceedings - VI Southern Hemisphere Meeting on Mineral Technology, CETEM/MCT, Rio de Janeiro, Brazil, pp. 107-116. 
Appendix I

\section{Summary of JKMRC Drop Weight Breakage Test Results}




\section{JKTech Drop Weight Test Results for Bealeton Quarry}

Client: Contract Support Services Inc

Ore Source: Luckstone Quarries

Diabase Rock (1751-1)

Order No:

Test Date: $\quad$ 18-Sep-04 JKTech Job Number: 4288

BASE DATA

$\begin{array}{cccccc}\text { T10 } & \text { Eis } & \text { T10 } & \text { Eis } & \text { T10 } & \text { Eis } \\ 10.55 & 0.34 & 7.81 & 0.24 & 4.30 & 0.10 \\ 32.24 & 0.98 & 8.34 & 0.25 & 3.73 & 0.10 \\ 53.35 & 2.50 & 28.25 & 0.99 & 6.66 & 0.25 \\ 50.55 & 2.49 & 25.06 & 1.00 & 5.54 & 0.25 \\ 49.51 & 2.50 & 22.78 & 1.00 & 6.47 & 0.25\end{array}$

SAG/FAG MILL PARAMETERS
A: $\quad 86.13$
B: $\quad 0.36$
Ta: $\quad 0.18$

CRUSHER PARAMETERS

APPEARANCE T10

$\begin{array}{ll}10 & 3.0 \\ 20 & 6.0 \\ 30 & 9.2\end{array}$

POWER

\begin{tabular}{cccccc} 
& 14.53 & 20.63 & 28.89 & 41.08 & 57.78 \\
T10 & \multicolumn{5}{c}{ Ecs (kWh/t) } \\
$\mathbf{1 0}$ & 0.39 & 0.38 & 0.34 & 0.27 & 0.27 \\
$\mathbf{2 0}$ & 0.84 & 0.81 & 0.71 & 0.58 & 0.58 \\
$\mathbf{3 0}$ & 1.34 & 1.29 & 1.14 & 0.93 & 0.93
\end{tabular}

$\begin{array}{lllllllll}\text { DENSITY DATA } & \text { Mean } & 2.99 & \text { Std Dev } & 0.09 & \text { Max } & 3.24 & \text { Min } & 2.86\end{array}$

\section{COMMENTS}

The Ecs values for $57.78 \mathrm{~mm}$ particles at $\mathrm{t} 10=10,20$ and 30 are doubtful. Values from the next finest particle size have been substituted. 
JKTech Drop Weight Test Results for Pittsboro Quarry (3M)

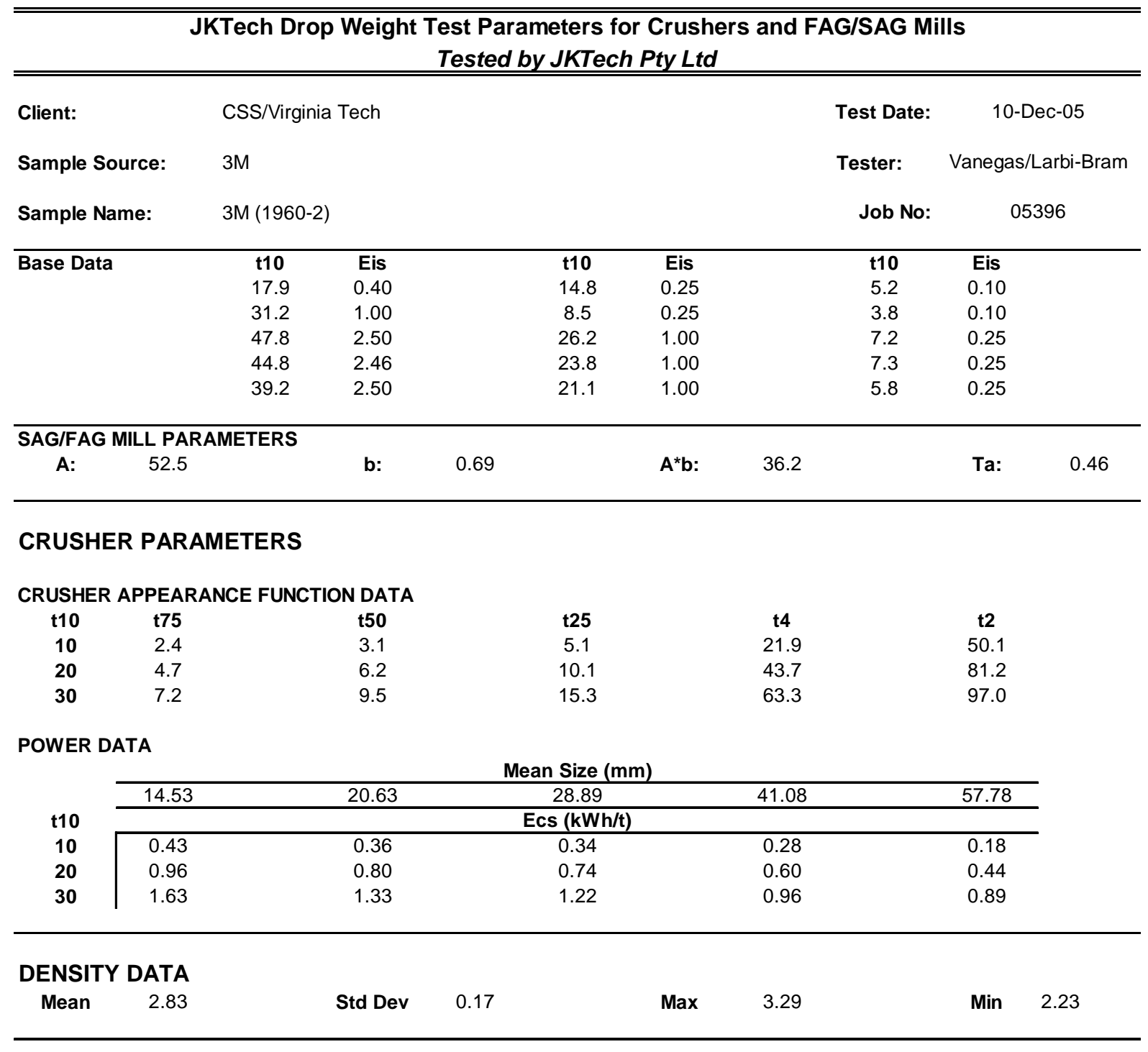

\section{COMMENTS}




\section{JKTech Drop Weight Test Results for Pittsboro Quarry (LS)}

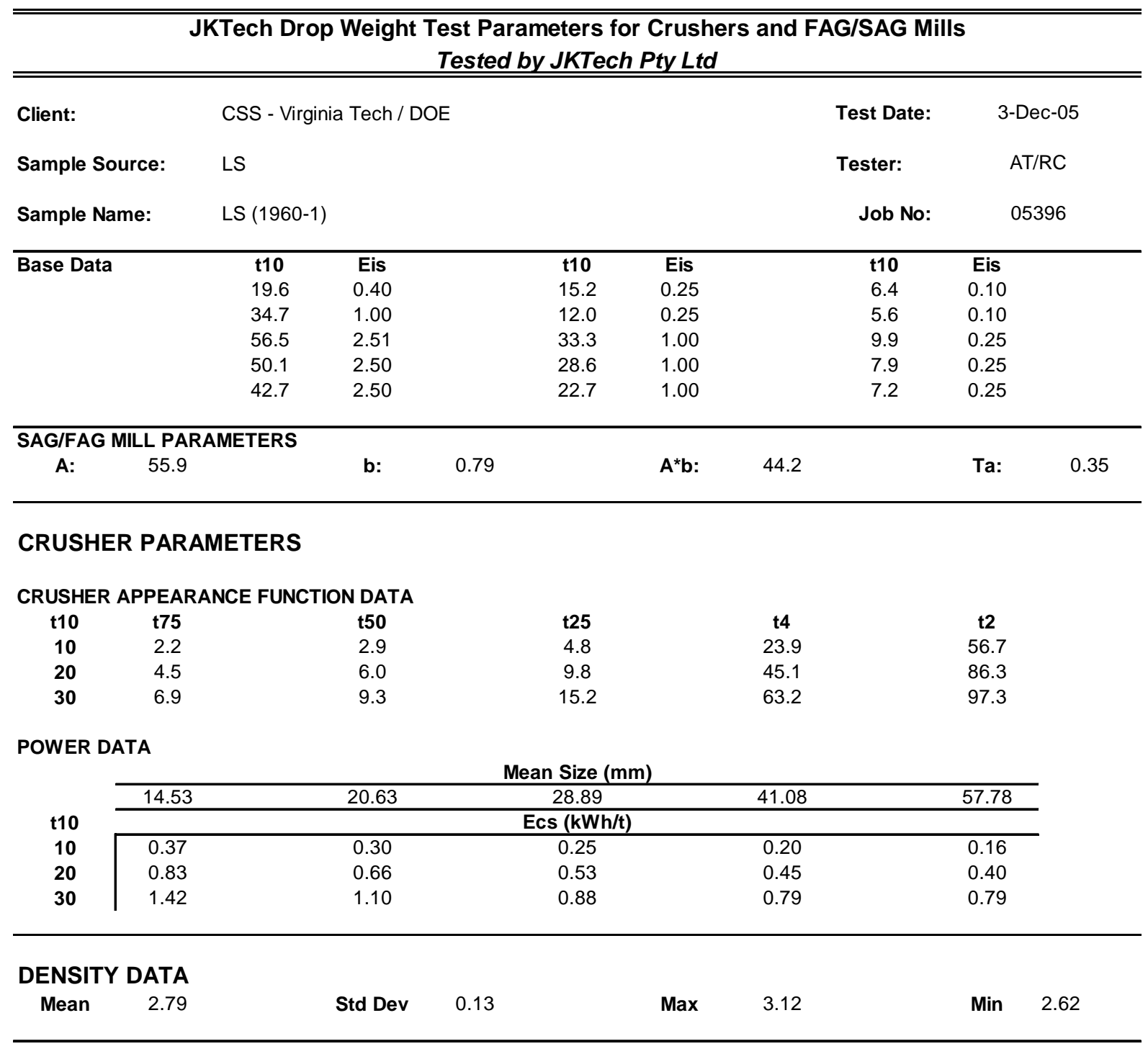

\section{COMMENTS}

The Ecs value for $57.78 \mathrm{~mm}$ particles at $\mathrm{t} 10=30$ is doubtful. The value from the next finest particle size has been substituted. 


\section{JKTech Drop Weight Test Results for Pittsboro Quarry (Basalt)}

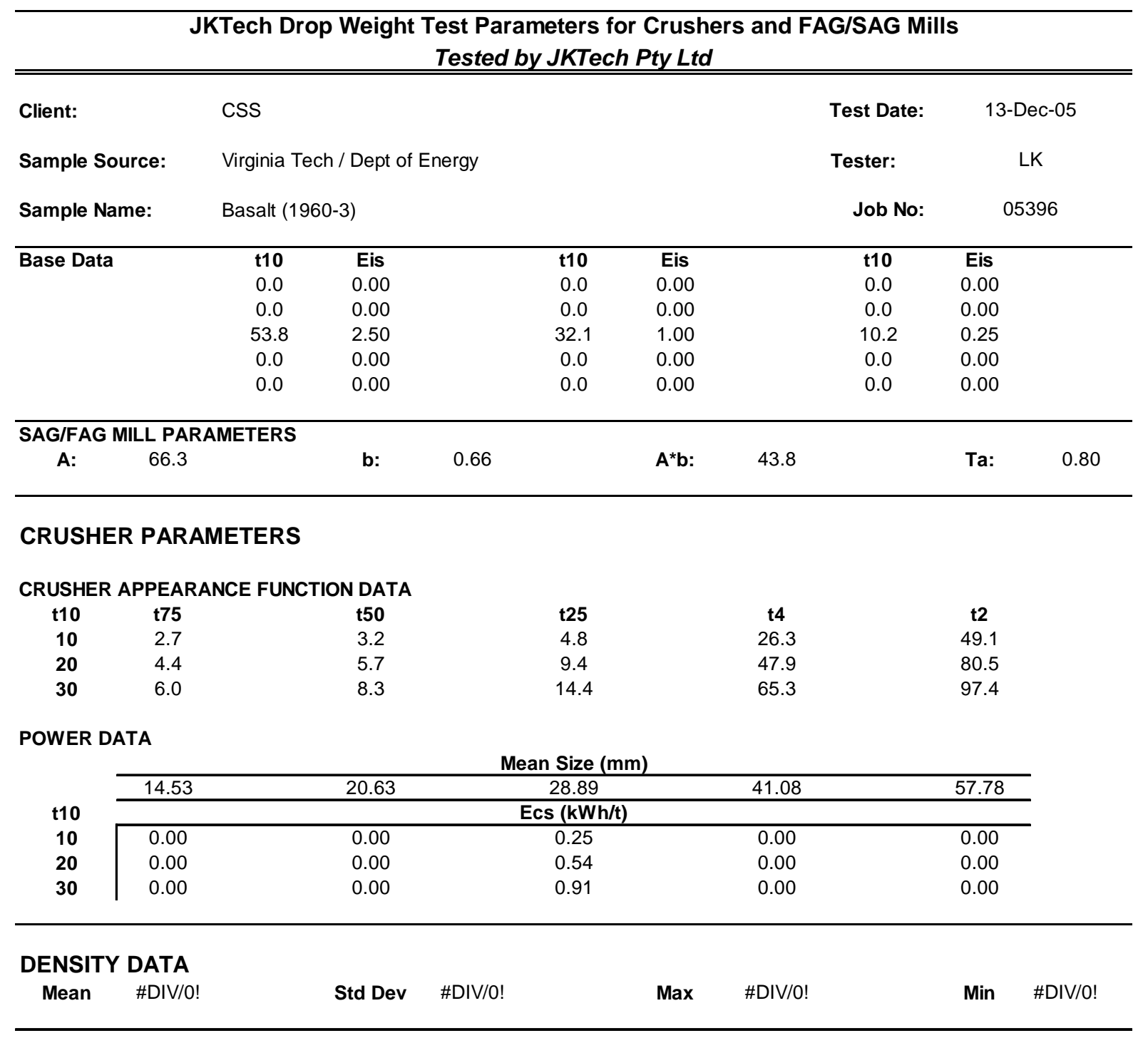

\section{COMMENTS}




\section{JKTech Drop Weight Test Results for Pittsboro Quarry (Dacite)}

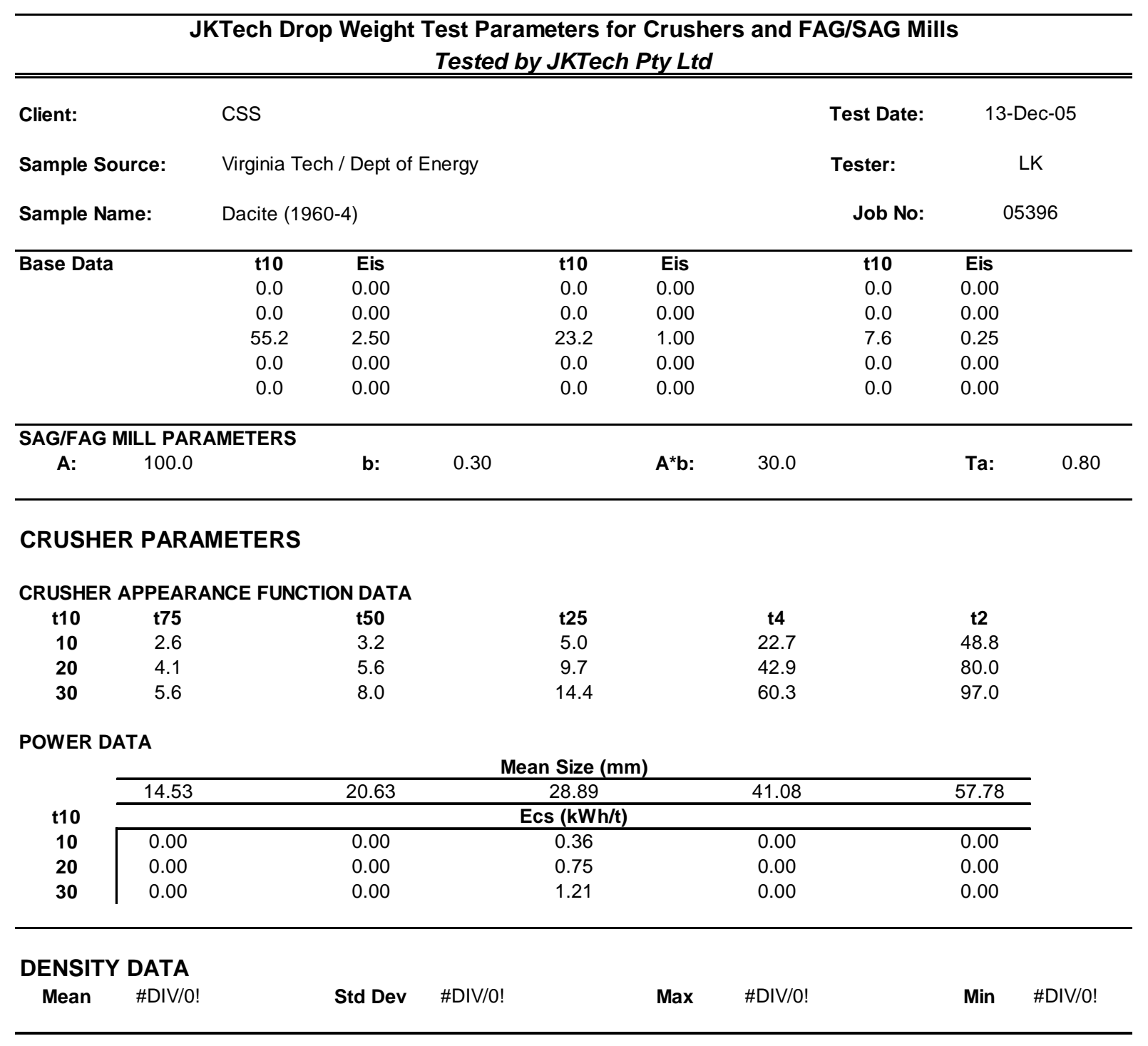

\section{COMMENTS}


JKTech Drop Weight Test Results for Pittsboro Quarry (Tuffs)

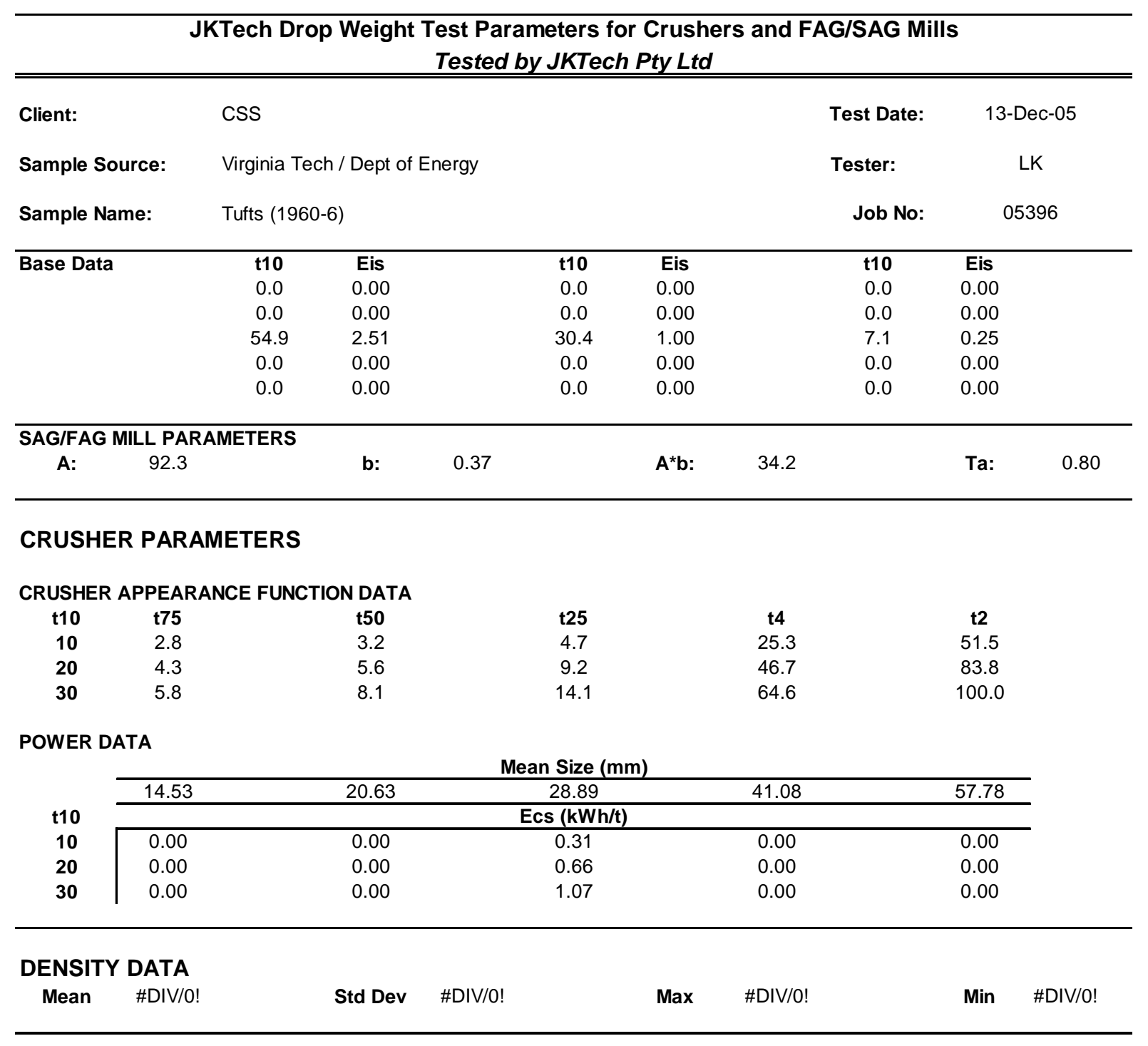

\section{COMMENTS}




\section{JKTech Drop Weight Test Results for Pittsboro Quarry (Weathered)}

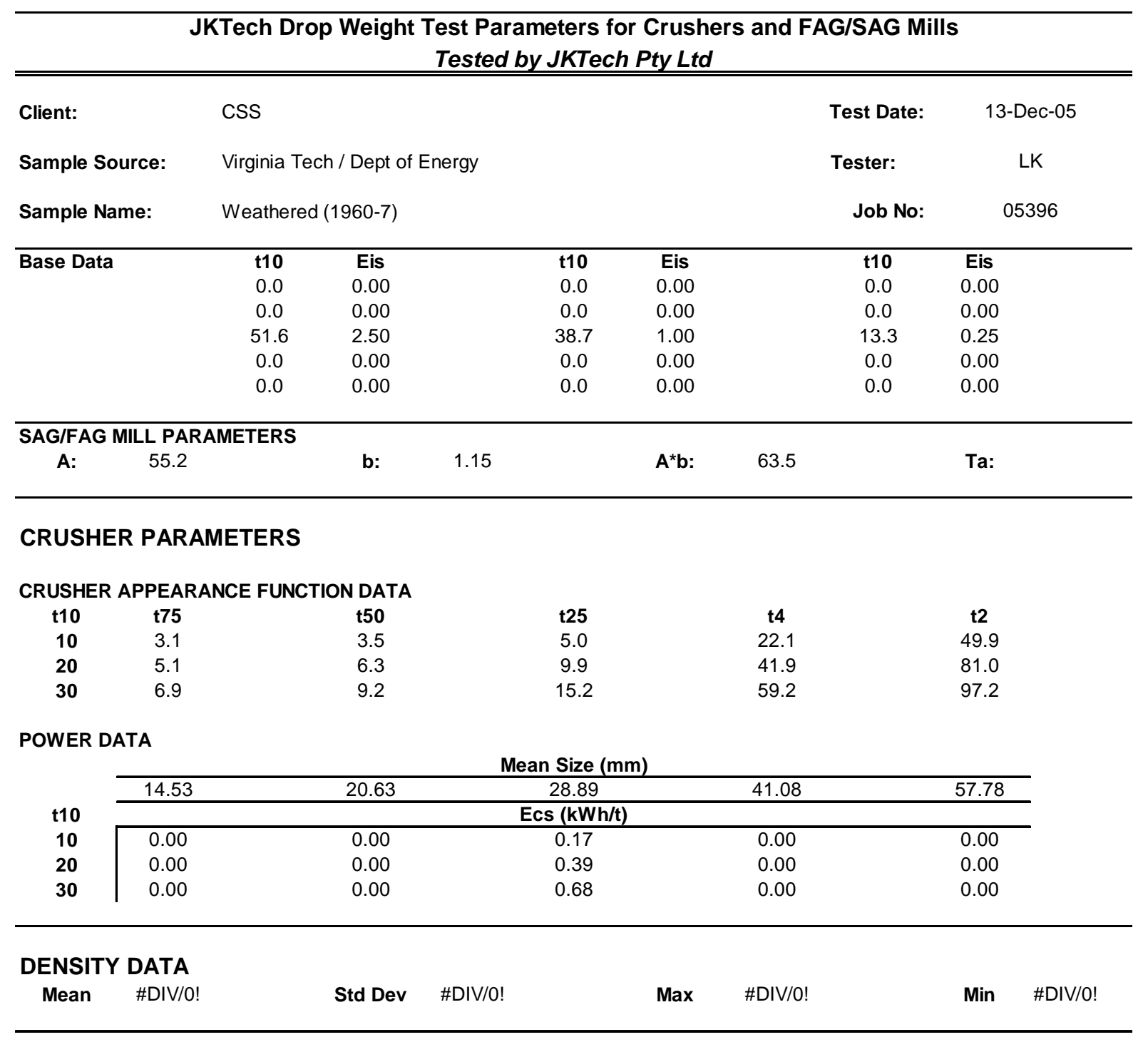

\section{COMMENTS}




\section{JKTech Drop Weight Test Results for Pittsboro Quarry (Miscellaneous)}

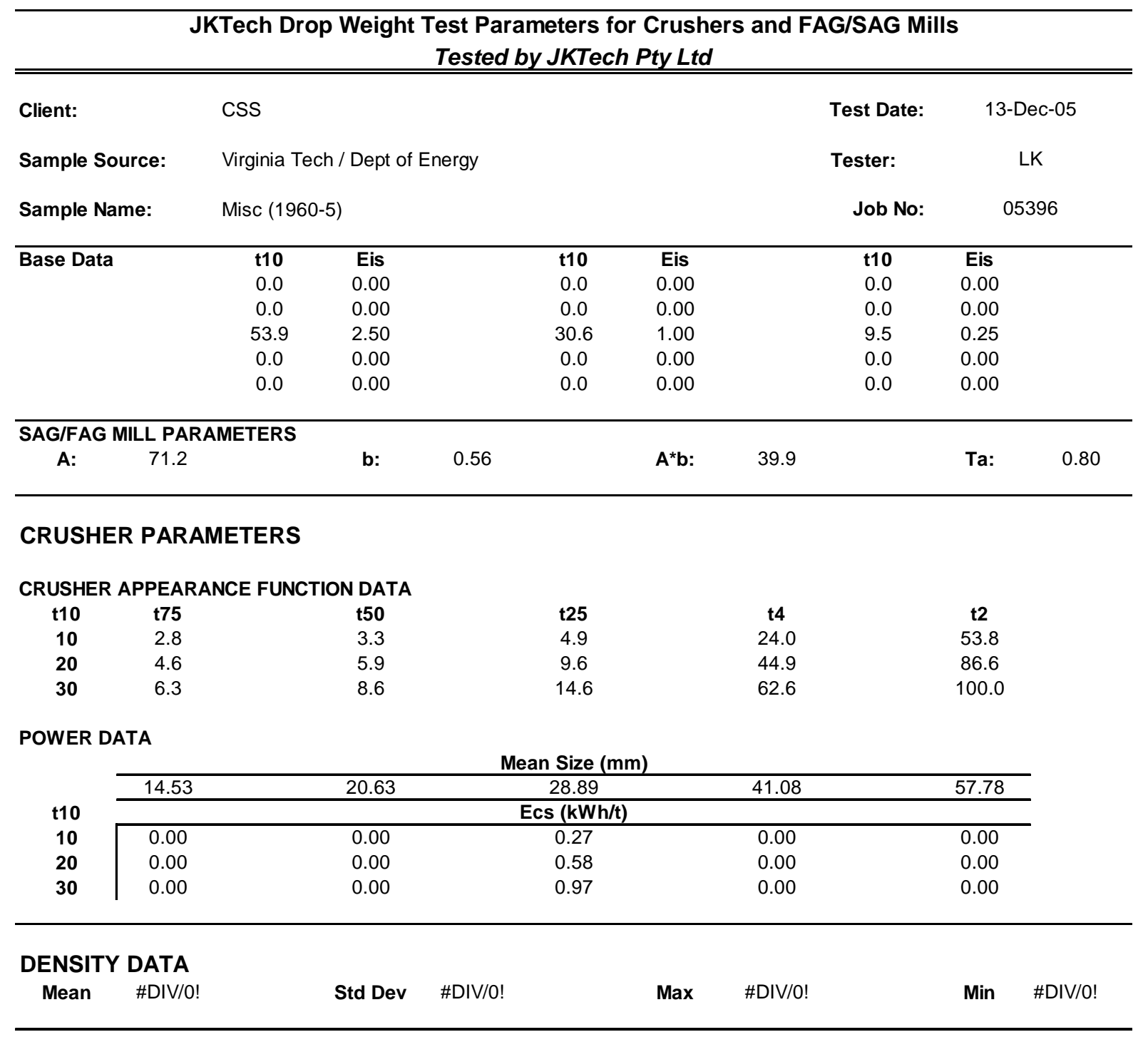

COMMENTS 
Appendix II

\section{Summary of Crusher Settings and Sampling Details}




\section{Bealeton Sampling Campaign - June 2004 Audit}

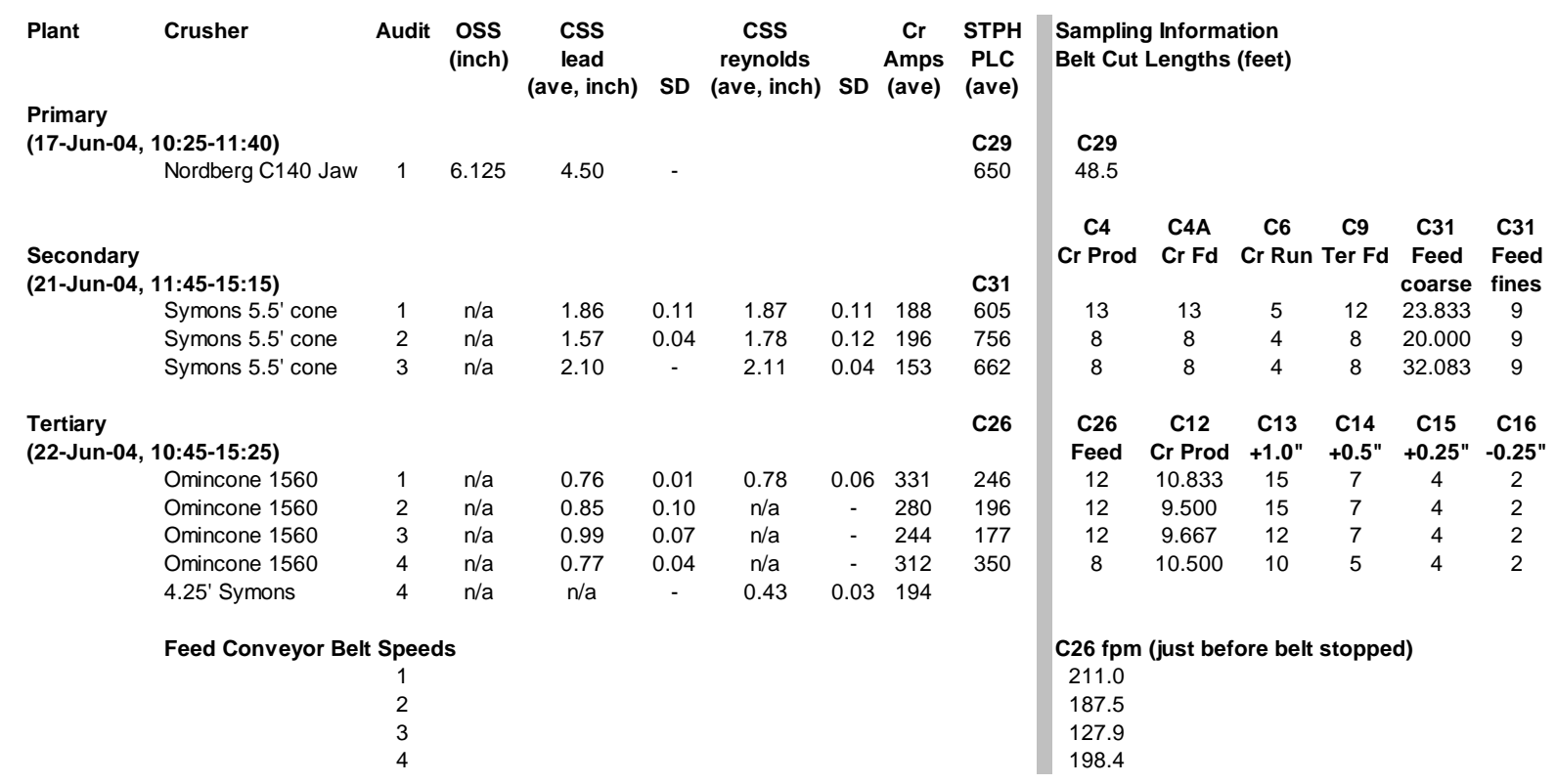

\section{Bealeton Sampling Campaign - November 2004 Side-by-Side Testing}

Summary of Crusher Settings and Sampling Details - 1Nov-11Nov'04

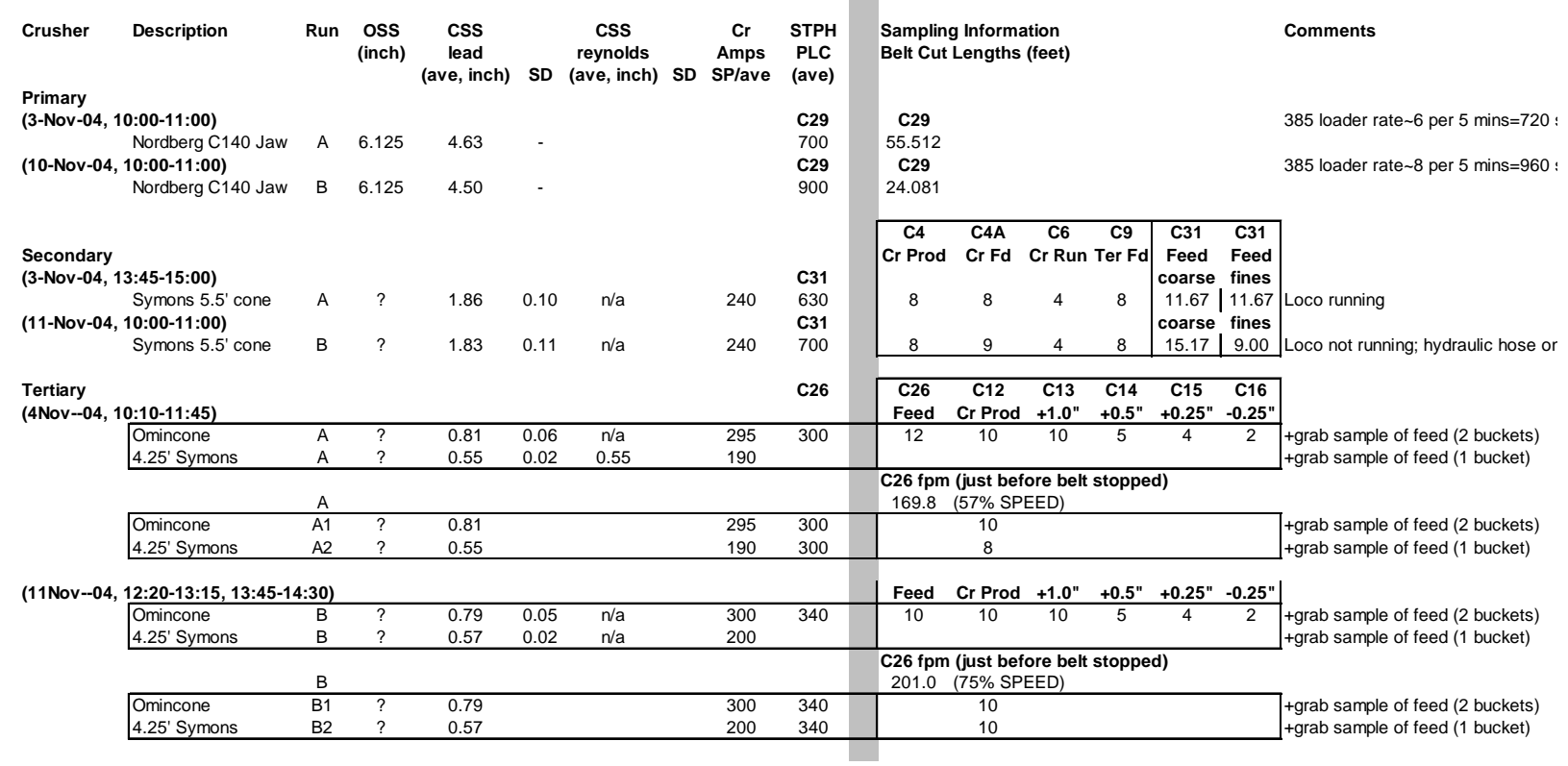




\section{Pittsboro Sampling Campaign - August 2005 Audit}

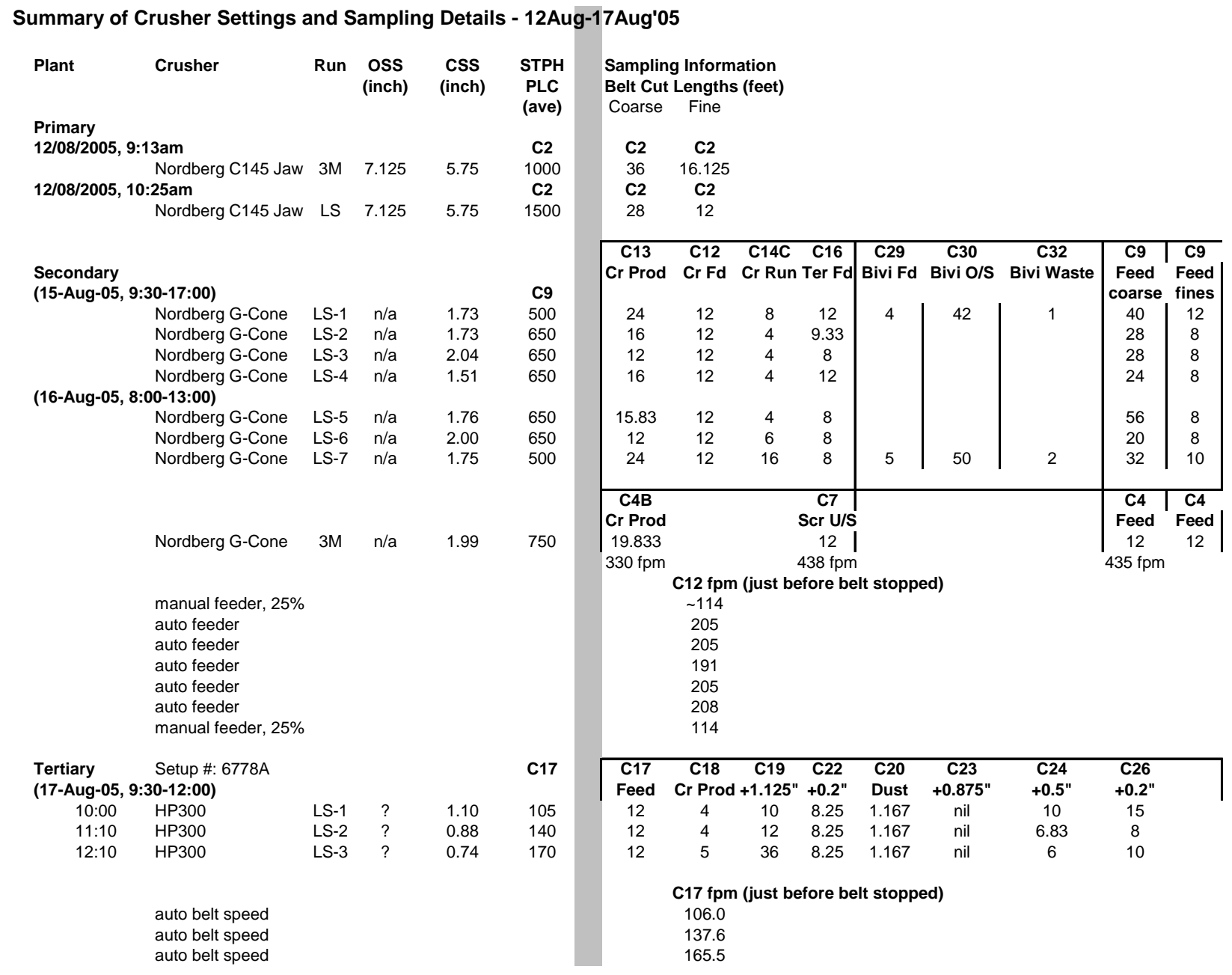




\section{Appendix III}

Plant Audit Sizing Results 


\section{Bealeton June 2004 Audit Sizing Results Primary Section}

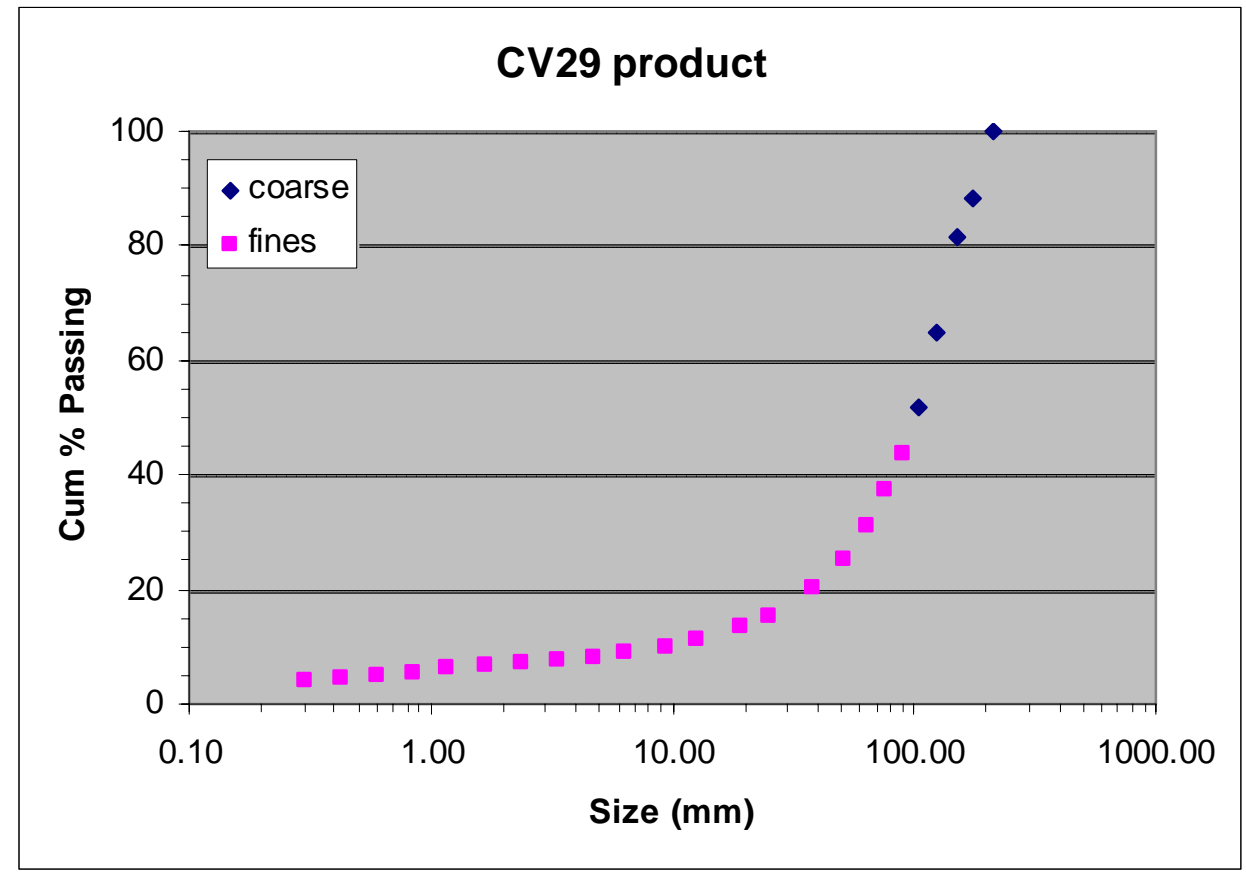

\begin{tabular}{|l|l|}
\hline size (mm) & Cum \% Passing \\
\hline
\end{tabular}

\begin{tabular}{|r|r|}
\hline 212.0 & 100.00 \\
\hline 175.0 & 88.39 \\
\hline 150.0 & 81.38 \\
\hline 125.0 & 64.99 \\
\hline 105.0 & 51.90 \\
\hline 90.0 & 43.55 \\
\hline 75.0 & 37.49 \\
\hline 63.5 & 31.12 \\
\hline 50.8 & 25.37 \\
\hline 38.1 & 20.14 \\
\hline 25.4 & 15.43 \\
\hline 19.1 & 13.38 \\
\hline 12.7 & 11.16 \\
\hline 9.5 & 10.08 \\
\hline 6.4 & 8.90 \\
\hline 4.75 & 8.26 \\
\hline 3.35 & 7.66 \\
\hline 2.36 & 7.13 \\
\hline 1.70 & 6.63 \\
\hline 1.18 & 6.11 \\
\hline 0.850 & 5.62 \\
\hline 0.600 & 5.13 \\
\hline 0.425 & 4.58 \\
\hline 0.300 & 4.07 \\
\hline 0.212 & 3.54 \\
\hline 0.150 & 3.07 \\
\hline 0.106 & 2.65 \\
\hline 0.075 & 2.31 \\
\hline
\end{tabular}




\section{Secondary Section - Audit 1}
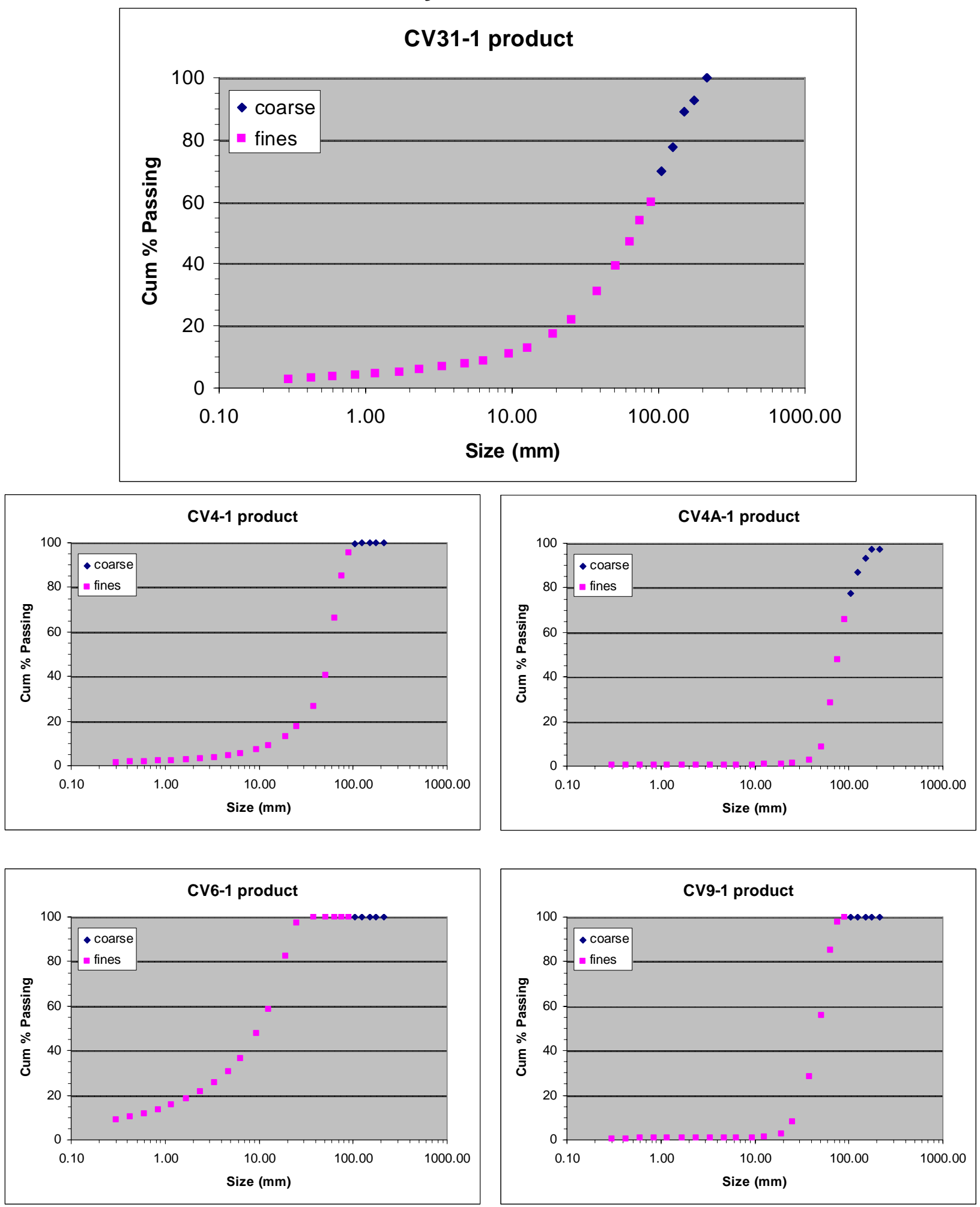
CV 31-1

\begin{tabular}{|r|r|}
\hline size (mm) & Cum \% Passing \\
\hline 212.0 & 100.00 \\
\hline 175.0 & 92.91 \\
\hline 150.0 & 89.01 \\
\hline 125.0 & 77.81 \\
\hline 105.0 & 69.88 \\
\hline 90.0 & 59.85 \\
\hline 75.0 & 53.66 \\
\hline 63.5 & 47.08 \\
\hline 50.8 & 39.43 \\
\hline 38.1 & 31.01 \\
\hline 25.4 & 21.88 \\
\hline 19.1 & 17.41 \\
\hline 12.7 & 12.93 \\
\hline 9.5 & 10.88 \\
\hline 6.4 & 8.69 \\
\hline 4.75 & 7.59 \\
\hline 3.35 & 6.66 \\
\hline 2.36 & 5.81 \\
\hline 1.70 & 5.11 \\
\hline 1.18 & 4.44 \\
\hline 0.850 & 3.94 \\
\hline 0.600 & 3.54 \\
\hline 0.425 & 3.19 \\
\hline 0.300 & 2.91 \\
\hline 0.212 & 2.64 \\
\hline 0.150 & 2.36 \\
\hline 0.106 & 2.10 \\
\hline 0.075 & 1.86 \\
\hline & \\
\hline
\end{tabular}

CV 4-1

\begin{tabular}{|c|c|}
\hline size $(\mathrm{mm})$ & Cum \% Passing \\
\hline 212.0 & 100.00 \\
\hline 175.0 & 100.00 \\
\hline 150.0 & 100.00 \\
\hline 125.0 & 100.00 \\
\hline 105.0 & 99.54 \\
\hline 90.0 & 95.58 \\
\hline 75.0 & 85.29 \\
\hline 63.5 & 66.28 \\
\hline 50.8 & 40.37 \\
\hline 38.1 & 26.79 \\
\hline 25.4 & 17.46 \\
\hline 19.1 & 13.19 \\
\hline 12.7 & 9.10 \\
\hline 9.5 & 7.26 \\
\hline 6.4 & 5.43 \\
\hline 4.75 & 4.52 \\
\hline 3.35 & 3.78 \\
\hline 2.36 & 3.15 \\
\hline 1.70 & 2.70 \\
\hline 1.18 & 2.32 \\
\hline 0.850 & 2.05 \\
\hline 0.600 & 1.83 \\
\hline 0.425 & 1.62 \\
\hline 0.300 & 1.46 \\
\hline 0.212 & 1.29 \\
\hline 0.150 & 1.12 \\
\hline 0.106 & 0.96 \\
\hline 0.075 & 0.82 \\
\hline
\end{tabular}

CV 4A-1

\begin{tabular}{|l|l|}
\hline size (mm) & Cum \% Passing \\
\hline
\end{tabular}

\begin{tabular}{|r|r|}
\hline 212.0 & 97.40 \\
\hline 175.0 & 97.40 \\
\hline 150.0 & 93.38 \\
\hline 125.0 & 87.12 \\
\hline 105.0 & 77.59 \\
\hline 90.0 & 65.65 \\
\hline 75.0 & 47.93 \\
\hline 63.5 & 28.27 \\
\hline 50.8 & 8.53 \\
\hline 38.1 & 2.80 \\
\hline 25.4 & 1.20 \\
\hline 19.1 & 0.88 \\
\hline 12.7 & 0.68 \\
\hline 9.5 & 0.61 \\
\hline 6.4 & 0.54 \\
\hline 4.75 & 0.51 \\
\hline 3.35 & 0.48 \\
\hline 2.36 & 0.45 \\
\hline 1.70 & 0.43 \\
\hline 1.18 & 0.41 \\
\hline 0.850 & 0.40 \\
\hline 0.600 & 0.38 \\
\hline 0.425 & 0.35 \\
\hline 0.300 & 0.33 \\
\hline 0.212 & 0.29 \\
\hline 0.150 & 0.25 \\
\hline 0.106 & 0.22 \\
\hline 0.075 & 0.18 \\
\hline & \\
\hline
\end{tabular}

CV 6-1

\begin{tabular}{|r|r|}
\hline size $(\mathbf{m m})$ & Cum \% Passing \\
\hline 212.0 & 100.00 \\
\hline 175.0 & 100.00 \\
\hline 150.0 & 100.00 \\
\hline 125.0 & 100.00 \\
\hline 105.0 & 100.00 \\
\hline 90.0 & 100.00 \\
\hline 75.0 & 100.00 \\
\hline 63.5 & 100.00 \\
\hline 50.8 & 100.00 \\
\hline 38.1 & 100.00 \\
\hline 25.4 & 97.30 \\
\hline 19.1 & 82.33 \\
\hline 12.7 & 58.68 \\
\hline 9.5 & 47.55 \\
\hline 6.4 & 36.41 \\
\hline 4.75 & 30.49 \\
\hline 3.35 & 25.78 \\
\hline 2.36 & 21.64 \\
\hline 1.70 & 18.46 \\
\hline 1.18 & 15.58 \\
\hline 0.850 & 13.40 \\
\hline 0.600 & 11.70 \\
\hline 0.425 & 10.27 \\
\hline 0.300 & 9.23 \\
\hline 0.212 & 8.25 \\
\hline 0.150 & 7.31 \\
\hline 0.106 & 6.44 \\
\hline 0.075 & 5.65 \\
\hline & \\
\hline
\end{tabular}

CV 9-1

\begin{tabular}{|c|c|}
\hline size $(\mathrm{mm})$ & Cum \% Passing \\
\hline 212.0 & 100.00 \\
\hline 175.0 & 100.00 \\
\hline 150.0 & 100.00 \\
\hline 125.0 & 100.00 \\
\hline 105.0 & 100.00 \\
\hline 90.0 & 100.00 \\
\hline 75.0 & 97.97 \\
\hline 63.5 & 85.06 \\
\hline 50.8 & 55.85 \\
\hline 38.1 & 28.21 \\
\hline 25.4 & 7.95 \\
\hline 19.1 & 2.53 \\
\hline 12.7 & 1.14 \\
\hline 9.5 & 0.97 \\
\hline 6.4 & 0.87 \\
\hline 4.75 & 0.83 \\
\hline 3.35 & 0.79 \\
\hline 2.36 & 0.77 \\
\hline 1.70 & 0.74 \\
\hline 1.18 & 0.72 \\
\hline 0.850 & 0.70 \\
\hline 0.600 & 0.68 \\
\hline 0.425 & 0.65 \\
\hline 0.300 & 0.62 \\
\hline 0.212 & 0.57 \\
\hline 0.150 & 0.51 \\
\hline 0.106 & 0.45 \\
\hline 0.075 & 0.39 \\
\hline
\end{tabular}




\section{Secondary Section - Audit 2}
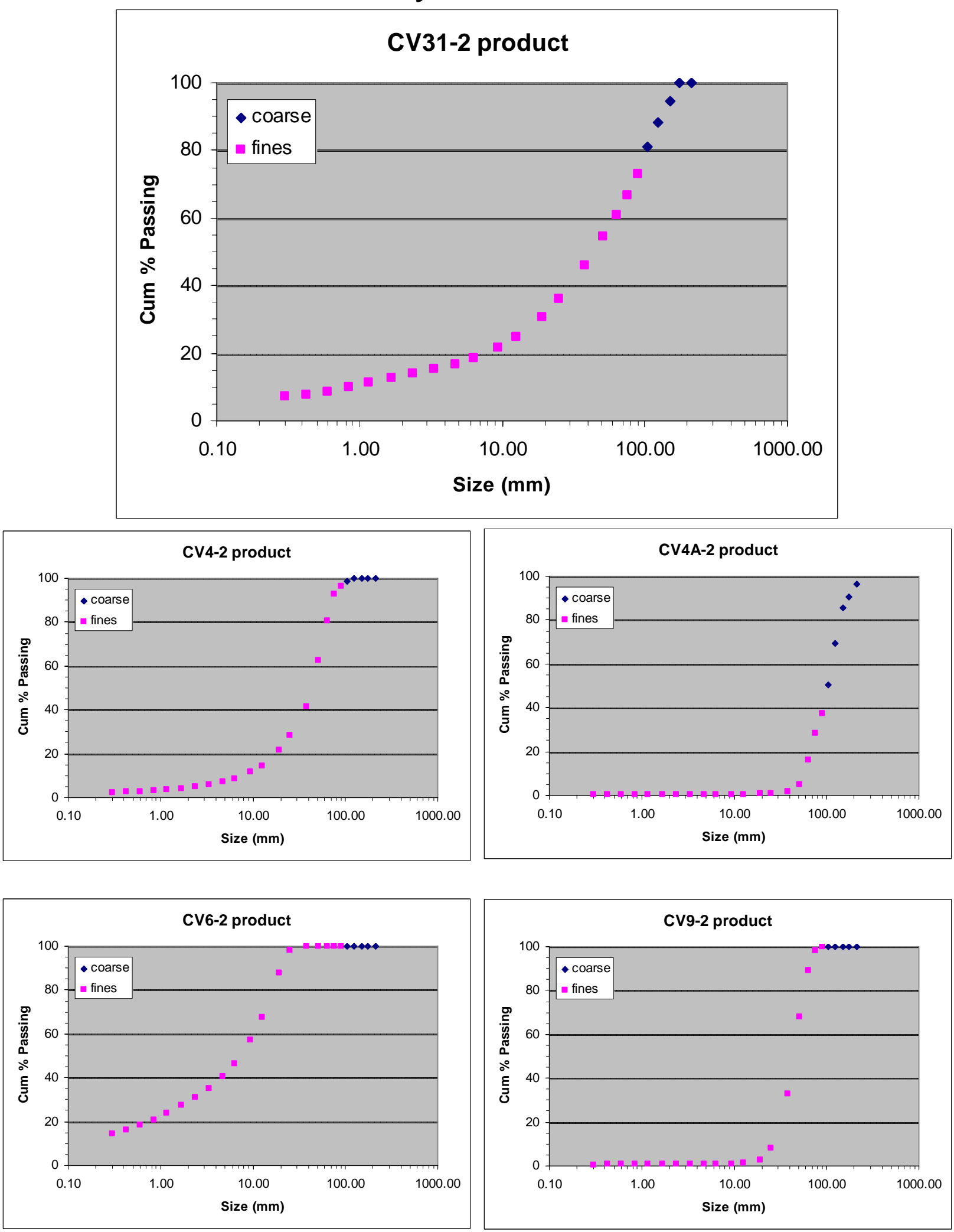
CV 31-2

\begin{tabular}{|r|r|}
\hline size $(\mathbf{m m})$ & Cum \% Passing \\
\hline 212.0 & 100.00 \\
\hline 175.0 & 100.00 \\
\hline 150.0 & 94.63 \\
\hline 125.0 & 88.41 \\
\hline 105.0 & 81.29 \\
\hline 90.0 & 73.07 \\
\hline 75.0 & 66.63 \\
\hline 63.5 & 60.76 \\
\hline 50.8 & 54.54 \\
\hline 38.1 & 45.78 \\
\hline 25.4 & 36.19 \\
\hline 19.1 & 30.79 \\
\hline 12.7 & 24.80 \\
\hline 9.5 & 21.84 \\
\hline 6.4 & 18.64 \\
\hline 4.75 & 16.87 \\
\hline 3.35 & 15.32 \\
\hline 2.36 & 13.85 \\
\hline 1.70 & 12.46 \\
\hline 1.18 & 11.05 \\
\hline 0.850 & 9.84 \\
\hline 0.600 & 8.77 \\
\hline 0.425 & 7.78 \\
\hline 0.300 & 7.04 \\
\hline 0.212 & 6.30 \\
\hline 0.150 & 5.60 \\
\hline 0.106 & 4.97 \\
\hline 0.075 & 4.40 \\
\hline & \\
\hline
\end{tabular}

\section{4-2}

\begin{tabular}{|r|r|}
\hline size $(\mathbf{m m})$ & Cum \% Passing \\
\hline 212.0 & 100.00 \\
\hline 175.0 & 100.00 \\
\hline 150.0 & 100.00 \\
\hline 125.0 & 100.00 \\
\hline 105.0 & 98.45 \\
\hline 90.0 & 96.22 \\
\hline 75.0 & 92.87 \\
\hline 63.5 & 80.73 \\
\hline 50.8 & 62.73 \\
\hline 38.1 & 41.43 \\
\hline 25.4 & 28.55 \\
\hline 19.1 & 21.72 \\
\hline 12.7 & 14.53 \\
\hline 9.5 & 11.60 \\
\hline 6.4 & 8.64 \\
\hline 4.75 & 7.16 \\
\hline 3.35 & 5.98 \\
\hline 2.36 & 4.96 \\
\hline 1.70 & 4.26 \\
\hline 1.18 & 3.66 \\
\hline 0.850 & 3.21 \\
\hline 0.600 & 2.85 \\
\hline 0.425 & 2.50 \\
\hline 0.300 & 2.24 \\
\hline 0.212 & 1.97 \\
\hline 0.150 & 1.70 \\
\hline 0.106 & 1.47 \\
\hline 0.075 & 1.26 \\
\hline & \\
\hline
\end{tabular}

CV 4A-2

\begin{tabular}{|l|l|}
\hline size (mm) & Cum \% Passing \\
\hline
\end{tabular}

\begin{tabular}{|r|r|}
\hline 212.0 & 96.29 \\
\hline 175.0 & 90.71 \\
\hline 150.0 & 85.39 \\
\hline 125.0 & 69.23 \\
\hline 105.0 & 50.48 \\
\hline 90.0 & 37.56 \\
\hline 75.0 & 28.23 \\
\hline 63.5 & 16.25 \\
\hline 50.8 & 4.85 \\
\hline 38.1 & 1.99 \\
\hline 25.4 & 1.09 \\
\hline 19.1 & 0.82 \\
\hline 12.7 & 0.65 \\
\hline 9.5 & 0.59 \\
\hline 6.4 & 0.55 \\
\hline 4.75 & 0.52 \\
\hline 3.35 & 0.50 \\
\hline 2.36 & 0.48 \\
\hline 1.70 & 0.47 \\
\hline 1.18 & 0.45 \\
\hline 0.850 & 0.42 \\
\hline 0.600 & 0.40 \\
\hline 0.425 & 0.37 \\
\hline 0.300 & 0.33 \\
\hline 0.212 & 0.30 \\
\hline 0.150 & 0.26 \\
\hline 0.106 & 0.22 \\
\hline 0.075 & 0.19 \\
\hline & \\
\hline
\end{tabular}

CV 6-2

\begin{tabular}{|r|r|}
\hline size (mm) & Cum \% Passing \\
\hline 212.0 & 100.00 \\
\hline 175.0 & 100.00 \\
\hline 150.0 & 100.00 \\
\hline 125.0 & 100.00 \\
\hline 105.0 & 100.00 \\
\hline 90.0 & 100.00 \\
\hline 75.0 & 100.00 \\
\hline 63.5 & 100.00 \\
\hline 50.8 & 100.00 \\
\hline 38.1 & 100.00 \\
\hline 25.4 & 98.16 \\
\hline 19.1 & 87.70 \\
\hline 12.7 & 67.58 \\
\hline 9.5 & 57.15 \\
\hline 6.4 & 46.18 \\
\hline 4.75 & 40.34 \\
\hline 3.35 & 35.29 \\
\hline 2.36 & 30.90 \\
\hline 1.70 & 27.29 \\
\hline 1.18 & 23.67 \\
\hline 0.850 & 20.72 \\
\hline 0.600 & 18.26 \\
\hline 0.425 & 16.12 \\
\hline 0.300 & 14.50 \\
\hline 0.212 & 12.97 \\
\hline 0.150 & 11.51 \\
\hline 0.106 & 10.16 \\
\hline 0.075 & 8.95 \\
\hline & \\
\hline
\end{tabular}

\section{9-2}

\begin{tabular}{|r|r|}
\hline size (mm) & Cum \% Passing \\
\hline 212.0 & 100.00 \\
\hline 175.0 & 100.00 \\
\hline 150.0 & 100.00 \\
\hline 125.0 & 100.00 \\
\hline 105.0 & 100.00 \\
\hline 90.0 & 100.00 \\
\hline 75.0 & 98.29 \\
\hline 63.5 & 89.07 \\
\hline 50.8 & 67.98 \\
\hline 38.1 & 32.79 \\
\hline 25.4 & 8.06 \\
\hline 19.1 & 2.91 \\
\hline 12.7 & 1.31 \\
\hline 9.5 & 1.09 \\
\hline 6.4 & 0.96 \\
\hline 4.75 & 0.92 \\
\hline 3.35 & 0.89 \\
\hline 2.36 & 0.86 \\
\hline 1.70 & 0.83 \\
\hline 1.18 & 0.81 \\
\hline 0.850 & 0.78 \\
\hline 0.600 & 0.75 \\
\hline 0.425 & 0.71 \\
\hline 0.300 & 0.65 \\
\hline 0.212 & 0.58 \\
\hline 0.150 & 0.50 \\
\hline 0.106 & 0.41 \\
\hline 0.075 & 0.34 \\
\hline & \\
\hline
\end{tabular}




\section{Secondary Section - Audit 3}
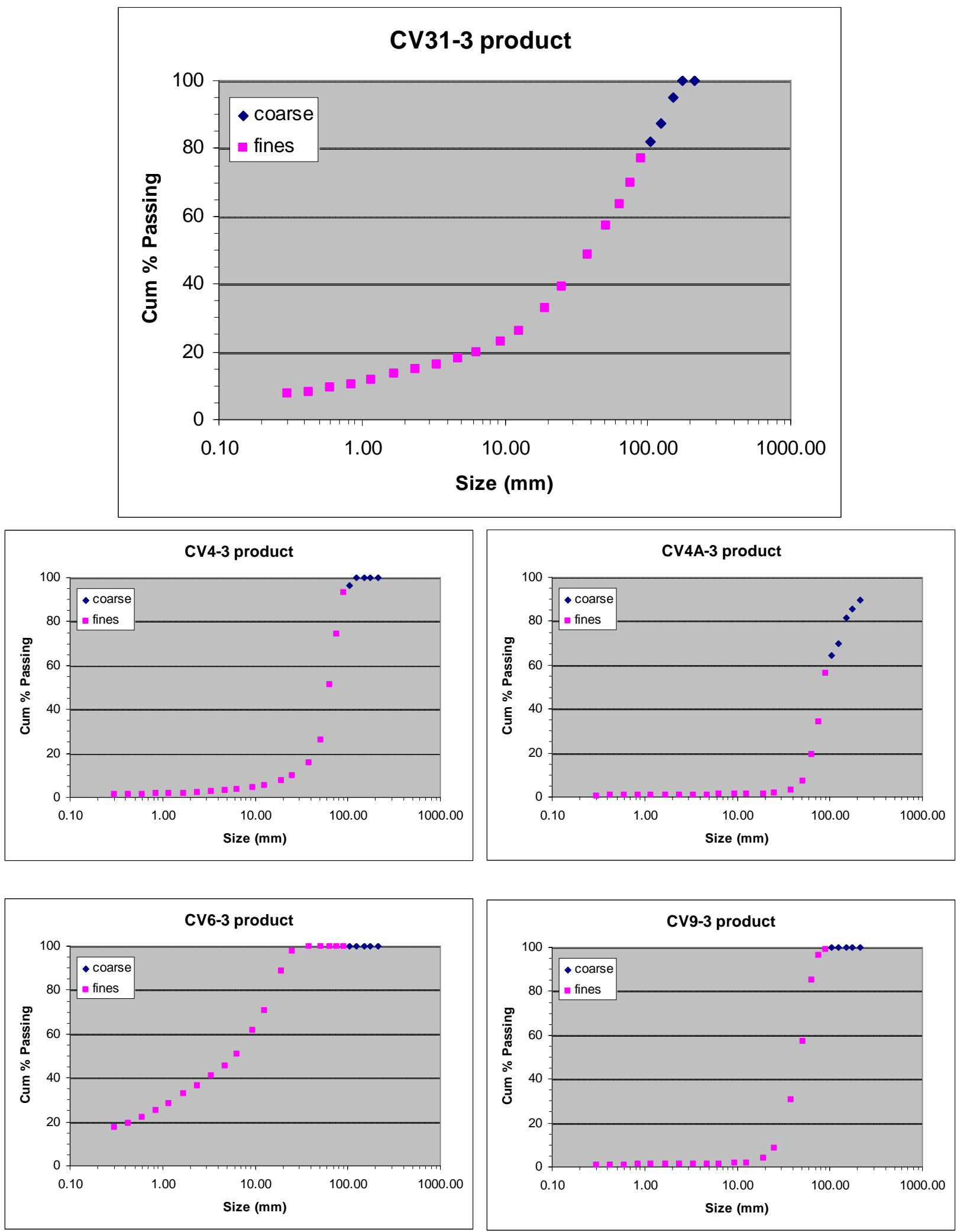
CV 31-3

\begin{tabular}{|r|r|}
\hline size (mm) & Cum \% Passing \\
\hline 212.0 & 100.00 \\
\hline 175.0 & 100.00 \\
\hline 150.0 & 95.01 \\
\hline 125.0 & 87.21 \\
\hline 105.0 & 82.11 \\
\hline 90.0 & 77.21 \\
\hline 75.0 & 70.01 \\
\hline 63.5 & 63.64 \\
\hline 50.8 & 57.38 \\
\hline 38.1 & 48.83 \\
\hline 25.4 & 39.30 \\
\hline 19.1 & 32.90 \\
\hline 12.7 & 26.31 \\
\hline 9.5 & 23.11 \\
\hline 6.4 & 19.70 \\
\hline 4.75 & 17.86 \\
\hline 3.35 & 16.24 \\
\hline 2.36 & 14.70 \\
\hline 1.70 & 13.33 \\
\hline 1.18 & 11.81 \\
\hline 0.850 & 10.52 \\
\hline 0.600 & 9.37 \\
\hline 0.425 & 8.32 \\
\hline 0.300 & 7.50 \\
\hline 0.212 & 6.71 \\
\hline 0.150 & 5.95 \\
\hline 0.106 & 5.25 \\
\hline 0.075 & 4.64 \\
\hline & \\
\hline
\end{tabular}

CV 4-3

\begin{tabular}{|l|l|}
\hline size (mm) & Cum \% Passing \\
\hline
\end{tabular}

\begin{tabular}{r|r|}
\hline 212.0 & 100.00 \\
\hline 175.0 & 100.00 \\
\hline 150.0 & 100.00 \\
\hline 125.0 & 100.00 \\
\hline 105.0 & 96.31 \\
\hline 90.0 & 93.02 \\
\hline 75.0 & 74.14 \\
\hline 63.5 & 51.51 \\
\hline 50.8 & 26.18 \\
\hline 38.1 & 15.81 \\
\hline 25.4 & 9.89 \\
\hline 19.1 & 7.67 \\
\hline 12.7 & 5.54 \\
\hline 9.5 & 4.50 \\
\hline 6.4 & 3.51 \\
\hline 4.75 & 3.00 \\
\hline 3.35 & 2.59 \\
\hline 2.36 & 2.26 \\
\hline 1.70 & 2.01 \\
\hline 1.18 & 1.80 \\
\hline 0.850 & 1.63 \\
\hline 0.600 & 1.49 \\
\hline 0.425 & 1.33 \\
\hline 0.300 & 1.20 \\
\hline 0.212 & 1.07 \\
\hline 0.150 & 0.93 \\
\hline 0.106 & 0.81 \\
\hline 0.075 & 0.71 \\
\hline & \\
\hline
\end{tabular}

CV 4A-3

\begin{tabular}{|l|l|}
\hline size (mm) & Cum \% Passing \\
\hline
\end{tabular}

\begin{tabular}{|r|r|}
\hline 212.0 & 89.86 \\
\hline 175.0 & 85.63 \\
\hline 150.0 & 81.73 \\
\hline 125.0 & 70.02 \\
\hline 105.0 & 64.46 \\
\hline 90.0 & 56.20 \\
\hline 75.0 & 34.11 \\
\hline 63.5 & 19.45 \\
\hline 50.8 & 7.15 \\
\hline 38.1 & 3.28 \\
\hline 25.4 & 1.82 \\
\hline 19.1 & 1.48 \\
\hline 12.7 & 1.25 \\
\hline 9.5 & 1.19 \\
\hline 6.4 & 1.15 \\
\hline 4.75 & 1.12 \\
\hline 3.35 & 1.09 \\
\hline 2.36 & 1.05 \\
\hline 1.70 & 1.01 \\
\hline 1.18 & 0.96 \\
\hline 0.850 & 0.90 \\
\hline 0.600 & 0.82 \\
\hline 0.425 & 0.72 \\
\hline 0.300 & 0.62 \\
\hline 0.212 & 0.51 \\
\hline 0.150 & 0.40 \\
\hline 0.106 & 0.30 \\
\hline 0.075 & 0.22 \\
\hline & \\
\hline &
\end{tabular}

CV 6-2

\begin{tabular}{|r|r|}
\hline size (mm) & Cum \% Passing \\
\hline 212.0 & 100.00 \\
\hline 175.0 & 100.00 \\
\hline 150.0 & 100.00 \\
\hline 125.0 & 100.00 \\
\hline 105.0 & 100.00 \\
\hline 90.0 & 100.00 \\
\hline 75.0 & 100.00 \\
\hline 63.5 & 100.00 \\
\hline 50.8 & 100.00 \\
\hline 38.1 & 100.00 \\
\hline 25.4 & 97.86 \\
\hline 19.1 & 88.69 \\
\hline 12.7 & 70.90 \\
\hline 9.5 & 61.64 \\
\hline 6.4 & 51.01 \\
\hline 4.75 & 45.54 \\
\hline 3.35 & 41.11 \\
\hline 2.36 & 36.62 \\
\hline 1.70 & 32.81 \\
\hline 1.18 & 28.58 \\
\hline 0.850 & 25.06 \\
\hline 0.600 & 22.09 \\
\hline 0.425 & 19.51 \\
\hline 0.300 & 17.68 \\
\hline 0.212 & 15.93 \\
\hline 0.150 & 14.26 \\
\hline 0.106 & 12.69 \\
\hline 0.075 & 11.27 \\
\hline & \\
\hline
\end{tabular}

CV 9-2

\begin{tabular}{|l|l|}
\hline size (mm) & Cum \% Passing \\
\hline
\end{tabular}

\begin{tabular}{|r|r|}
\hline 212.0 & 100.00 \\
\hline 175.0 & 100.00 \\
\hline 150.0 & 100.00 \\
\hline 125.0 & 100.00 \\
\hline 105.0 & 100.00 \\
\hline 90.0 & 99.19 \\
\hline 75.0 & 96.19 \\
\hline 63.5 & 85.22 \\
\hline 50.8 & 57.29 \\
\hline 38.1 & 30.83 \\
\hline 25.4 & 8.71 \\
\hline 19.1 & 3.88 \\
\hline 12.7 & 1.99 \\
\hline 9.5 & 1.72 \\
\hline 6.4 & 1.49 \\
\hline 4.75 & 1.41 \\
\hline 3.35 & 1.35 \\
\hline 2.36 & 1.30 \\
\hline 1.70 & 1.25 \\
\hline 1.18 & 1.21 \\
\hline 0.850 & 1.15 \\
\hline 0.600 & 1.09 \\
\hline 0.425 & 1.01 \\
\hline 0.300 & 0.93 \\
\hline 0.212 & 0.84 \\
\hline 0.150 & 0.73 \\
\hline 0.106 & 0.64 \\
\hline 0.075 & 0.55 \\
\hline & \\
\hline
\end{tabular}




\section{Tertiary Section - Audit 1}
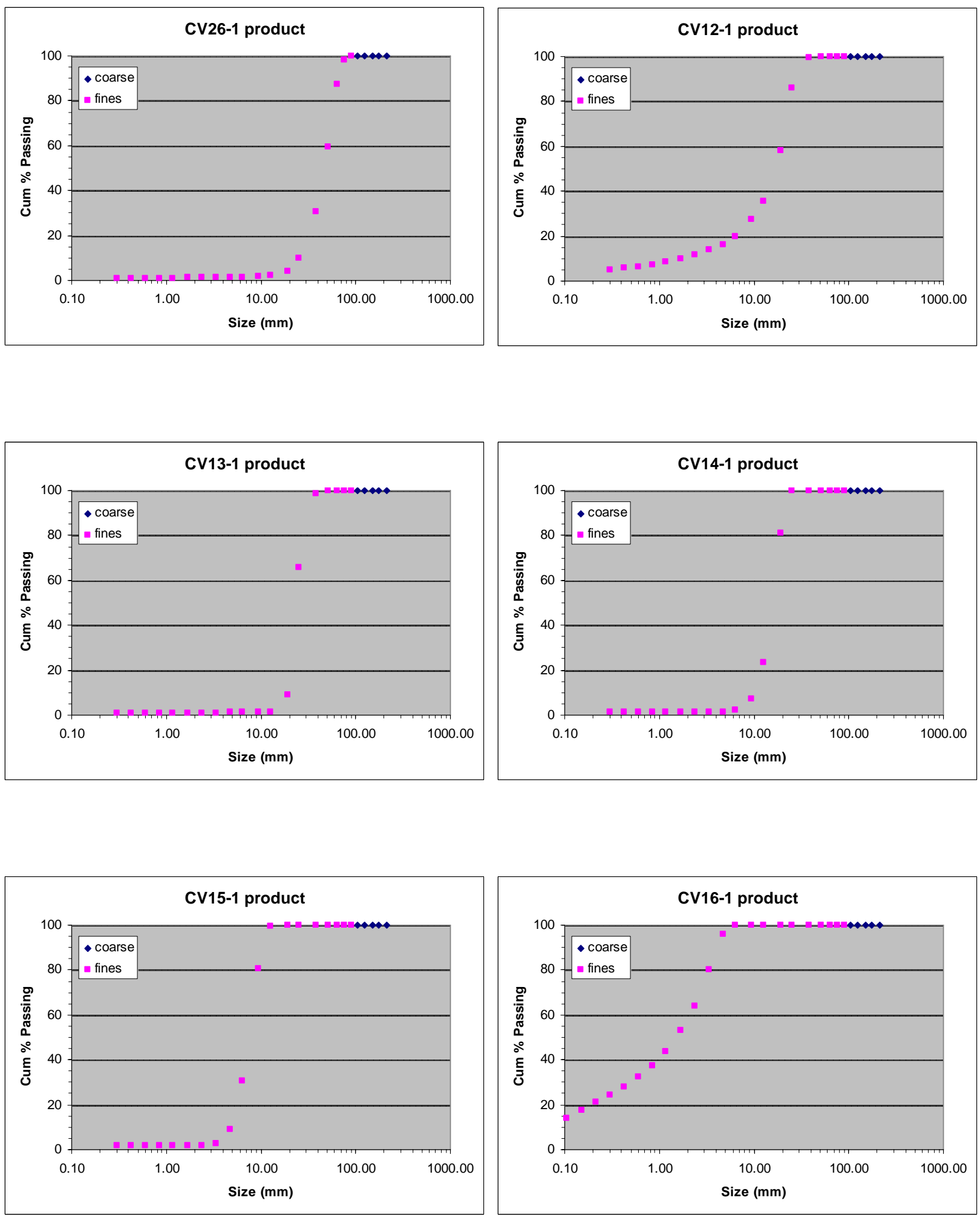
CV 26-1

\begin{tabular}{|r|r|}
\hline size (mm) & Cum \% Passing \\
\hline 212.0 & 100.00 \\
\hline 175.0 & 100.00 \\
\hline 150.0 & 100.00 \\
\hline 125.0 & 100.00 \\
\hline 105.0 & 100.00 \\
\hline 90.0 & 100.00 \\
\hline 75.0 & 98.20 \\
\hline 63.5 & 87.28 \\
\hline 50.8 & 59.44 \\
\hline 38.1 & 30.57 \\
\hline 25.4 & 9.75 \\
\hline 19.1 & 4.16 \\
\hline 12.7 & 2.12 \\
\hline 9.5 & 1.79 \\
\hline 6.4 & 1.50 \\
\hline 4.75 & 1.39 \\
\hline 3.35 & 1.31 \\
\hline 2.36 & 1.24 \\
\hline 1.70 & 1.18 \\
\hline 1.18 & 1.12 \\
\hline 0.850 & 1.07 \\
\hline 0.600 & 1.02 \\
\hline 0.425 & 0.96 \\
\hline 0.300 & 0.90 \\
\hline 0.212 & 0.83 \\
\hline 0.150 & 0.73 \\
\hline 0.106 & 0.64 \\
\hline 0.075 & 0.55 \\
\hline & \\
\hline
\end{tabular}

CV 12-1

\begin{tabular}{|r|r|}
\hline size (mm) & Cum \% Passing \\
\hline 212.0 & 100.00 \\
\hline 175.0 & 100.00 \\
\hline 150.0 & 100.00 \\
\hline 125.0 & 100.00 \\
\hline 105.0 & 100.00 \\
\hline 90.0 & 100.00 \\
\hline 75.0 & 100.00 \\
\hline 63.5 & 100.00 \\
\hline 50.8 & 100.00 \\
\hline 38.1 & 99.61 \\
\hline 25.4 & 86.12 \\
\hline 19.1 & 58.25 \\
\hline 12.7 & 35.57 \\
\hline 9.5 & 27.46 \\
\hline 6.4 & 19.94 \\
\hline 4.75 & 16.39 \\
\hline 3.35 & 13.75 \\
\hline 2.36 & 11.53 \\
\hline 1.70 & 9.87 \\
\hline 1.18 & 8.41 \\
\hline 0.850 & 7.32 \\
\hline 0.600 & 6.45 \\
\hline 0.425 & 5.67 \\
\hline 0.300 & 5.08 \\
\hline 0.212 & 4.49 \\
\hline 0.150 & 3.91 \\
\hline 0.106 & 3.37 \\
\hline 0.075 & 2.88 \\
\hline & \\
\hline
\end{tabular}

CV 13-1

\begin{tabular}{|l|l|}
\hline size (mm) & Cum \% Passing \\
\hline
\end{tabular}

\begin{tabular}{|r|r|}
\hline 212.0 & 100.00 \\
\hline 175.0 & 100.00 \\
\hline 150.0 & 100.00 \\
\hline 125.0 & 100.00 \\
\hline 105.0 & 100.00 \\
\hline 90.0 & 100.00 \\
\hline 75.0 & 100.00 \\
\hline 63.5 & 100.00 \\
\hline 50.8 & 100.00 \\
\hline 38.1 & 98.85 \\
\hline 25.4 & 65.79 \\
\hline 19.1 & 8.98 \\
\hline 12.7 & 1.42 \\
\hline 9.5 & 1.28 \\
\hline 6.4 & 1.20 \\
\hline 4.75 & 1.15 \\
\hline 3.35 & 1.12 \\
\hline 2.36 & 1.10 \\
\hline 1.70 & 1.08 \\
\hline 1.18 & 1.06 \\
\hline 0.850 & 1.05 \\
\hline 0.600 & 1.03 \\
\hline 0.425 & 1.01 \\
\hline 0.300 & 0.98 \\
\hline 0.212 & 0.95 \\
\hline 0.150 & 0.89 \\
\hline 0.106 & 0.82 \\
\hline 0.075 & 0.74 \\
\hline & \\
\hline
\end{tabular}

CV 14-1

\begin{tabular}{|r|r|}
\hline size (mm) & Cum \% Passing \\
\hline 212.0 & 100.00 \\
\hline 175.0 & 100.00 \\
\hline 150.0 & 100.00 \\
\hline 125.0 & 100.00 \\
\hline 105.0 & 100.00 \\
\hline 90.0 & 100.00 \\
\hline 75.0 & 100.00 \\
\hline 63.5 & 100.00 \\
\hline 50.8 & 100.00 \\
\hline 38.1 & 100.00 \\
\hline 25.4 & 100.00 \\
\hline 19.1 & 81.20 \\
\hline 12.7 & 23.45 \\
\hline 9.5 & 7.08 \\
\hline 6.4 & 2.44 \\
\hline 4.75 & 1.47 \\
\hline 3.35 & 1.32 \\
\hline 2.36 & 1.27 \\
\hline 1.70 & 1.24 \\
\hline 1.18 & 1.22 \\
\hline 0.850 & 1.21 \\
\hline 0.600 & 1.19 \\
\hline 0.425 & 1.17 \\
\hline 0.300 & 1.15 \\
\hline 0.212 & 1.11 \\
\hline 0.150 & 1.06 \\
\hline 0.106 & 0.99 \\
\hline 0.075 & 0.91 \\
\hline & \\
\hline
\end{tabular}

CV 15-1

\begin{tabular}{|r|r|}
\hline size $(\mathbf{m m})$ & Cum \% Passing \\
\hline 212.0 & 100.00 \\
\hline 175.0 & 100.00 \\
\hline 150.0 & 100.00 \\
\hline 125.0 & 100.00 \\
\hline 105.0 & 100.00 \\
\hline 90.0 & 100.00 \\
\hline 75.0 & 100.00 \\
\hline 63.5 & 100.00 \\
\hline 50.8 & 100.00 \\
\hline 38.1 & 100.00 \\
\hline 25.4 & 100.00 \\
\hline 19.1 & 100.00 \\
\hline 12.7 & 99.49 \\
\hline 9.5 & 80.49 \\
\hline 6.4 & 30.70 \\
\hline 4.75 & 9.06 \\
\hline 3.35 & 2.73 \\
\hline 2.36 & 2.01 \\
\hline 1.70 & 1.89 \\
\hline 1.18 & 1.82 \\
\hline 0.850 & 1.76 \\
\hline 0.600 & 1.72 \\
\hline 0.425 & 1.68 \\
\hline 0.300 & 1.64 \\
\hline 0.212 & 1.58 \\
\hline 0.150 & 1.50 \\
\hline 0.106 & 1.39 \\
\hline 0.075 & 1.26 \\
\hline & \\
\hline
\end{tabular}

CV 16-1

\begin{tabular}{|l|l|}
\hline size (mm) & Cum \% Passing \\
\hline
\end{tabular}

\begin{tabular}{|r|r|}
\hline 212.0 & 100.00 \\
\hline 175.0 & 100.00 \\
\hline 150.0 & 100.00 \\
\hline 125.0 & 100.00 \\
\hline 105.0 & 100.00 \\
\hline 90.0 & 100.00 \\
\hline 75.0 & 100.00 \\
\hline 63.5 & 100.00 \\
\hline 50.8 & 100.00 \\
\hline 38.1 & 100.00 \\
\hline 25.4 & 100.00 \\
\hline 19.1 & 100.00 \\
\hline 12.7 & 100.00 \\
\hline 9.5 & 100.00 \\
\hline 6.4 & 99.96 \\
\hline 4.75 & 95.80 \\
\hline 3.35 & 80.29 \\
\hline 2.36 & 64.04 \\
\hline 1.70 & 52.95 \\
\hline 1.18 & 43.83 \\
\hline 0.850 & 37.40 \\
\hline 0.600 & 32.34 \\
\hline 0.425 & 27.89 \\
\hline 0.300 & 24.42 \\
\hline 0.212 & 21.01 \\
\hline 0.150 & 17.74 \\
\hline 0.106 & 14.17 \\
\hline 0.075 & 11.74 \\
\hline &
\end{tabular}




\section{Tertiary Section - Audit 2}
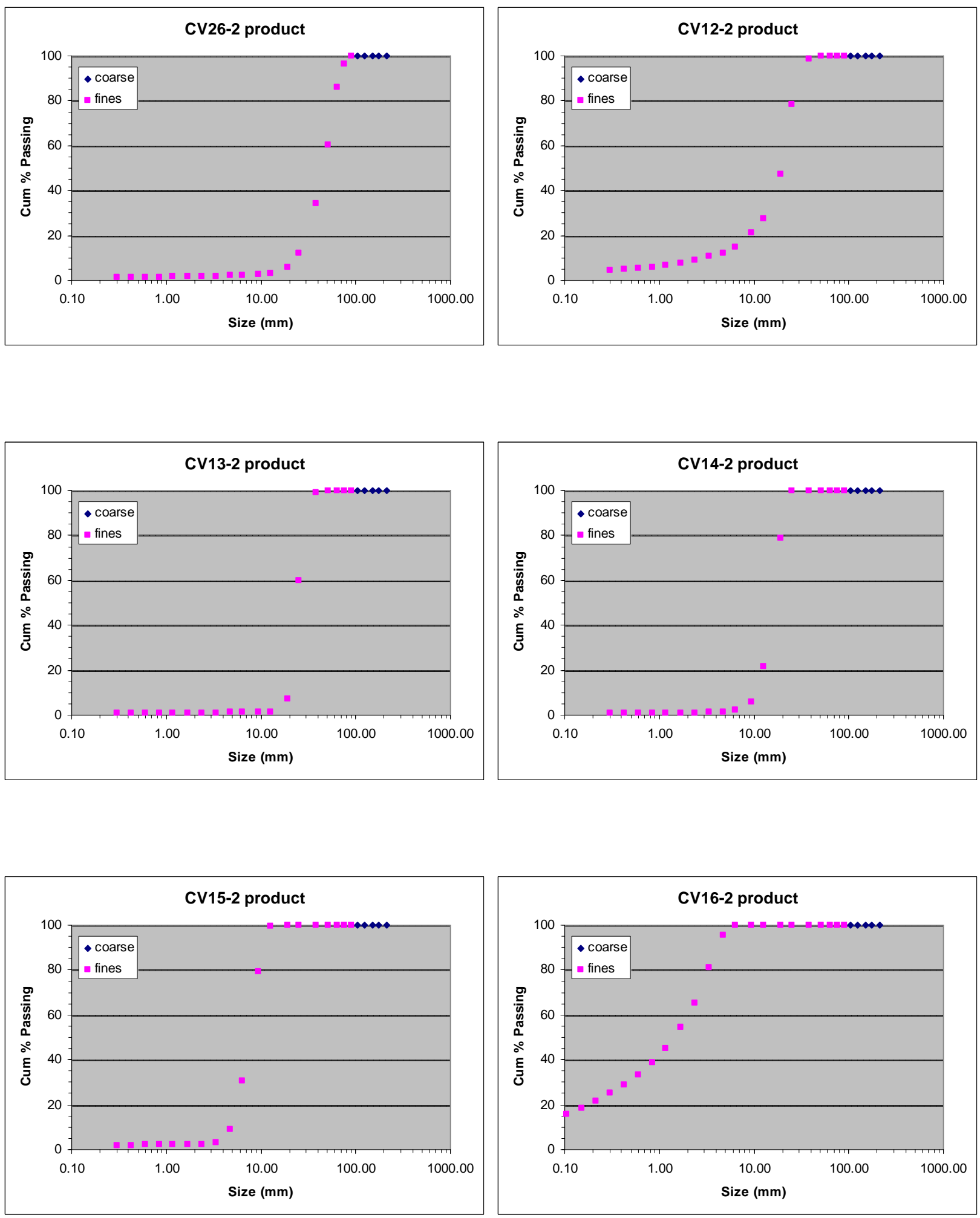
CV 26-2

\begin{tabular}{|r|r|}
\hline size (mm) & Cum \% Passing \\
\hline 212.0 & 100.00 \\
\hline 175.0 & 100.00 \\
\hline 150.0 & 100.00 \\
\hline 125.0 & 100.00 \\
\hline 105.0 & 100.00 \\
\hline 90.0 & 100.00 \\
\hline 75.0 & 96.36 \\
\hline 63.5 & 86.20 \\
\hline 50.8 & 60.51 \\
\hline 38.1 & 34.31 \\
\hline 25.4 & 12.35 \\
\hline 19.1 & 5.79 \\
\hline 12.7 & 3.21 \\
\hline 9.5 & 2.71 \\
\hline 6.4 & 2.29 \\
\hline 4.75 & 2.10 \\
\hline 3.35 & 1.95 \\
\hline 2.36 & 1.83 \\
\hline 1.70 & 1.73 \\
\hline 1.18 & 1.63 \\
\hline 0.850 & 1.55 \\
\hline 0.600 & 1.47 \\
\hline 0.425 & 1.37 \\
\hline 0.300 & 1.27 \\
\hline 0.212 & 1.15 \\
\hline 0.150 & 1.01 \\
\hline 0.106 & 0.89 \\
\hline 0.075 & 0.77 \\
\hline & \\
\hline
\end{tabular}

CV 12-2

\begin{tabular}{|r|r|}
\hline size $(\mathbf{m m})$ & Cum \% Passing \\
\hline 212.0 & 100.00 \\
\hline 175.0 & 100.00 \\
\hline 150.0 & 100.00 \\
\hline 125.0 & 100.00 \\
\hline 105.0 & 100.00 \\
\hline 90.0 & 100.00 \\
\hline 75.0 & 100.00 \\
\hline 63.5 & 100.00 \\
\hline 50.8 & 100.00 \\
\hline 38.1 & 98.85 \\
\hline 25.4 & 78.20 \\
\hline 19.1 & 47.12 \\
\hline 12.7 & 27.65 \\
\hline 9.5 & 21.03 \\
\hline 6.4 & 15.02 \\
\hline 4.75 & 12.30 \\
\hline 3.35 & 10.59 \\
\hline 2.36 & 9.00 \\
\hline 1.70 & 7.84 \\
\hline 1.18 & 6.80 \\
\hline 0.850 & 6.04 \\
\hline 0.600 & 5.41 \\
\hline 0.425 & 4.84 \\
\hline 0.300 & 4.38 \\
\hline 0.212 & 3.91 \\
\hline 0.150 & 3.42 \\
\hline 0.106 & 2.96 \\
\hline 0.075 & 2.53 \\
\hline & \\
\hline
\end{tabular}

CV 13-2

\begin{tabular}{|l|l|}
\hline size (mm) & Cum \% Passing \\
\hline
\end{tabular}

\begin{tabular}{|r|r|}
\hline 212.0 & 100.00 \\
\hline 175.0 & 100.00 \\
\hline 150.0 & 100.00 \\
\hline 125.0 & 100.00 \\
\hline 105.0 & 100.00 \\
\hline 90.0 & 100.00 \\
\hline 75.0 & 100.00 \\
\hline 63.5 & 100.00 \\
\hline 50.8 & 100.00 \\
\hline 38.1 & 99.21 \\
\hline 25.4 & 60.08 \\
\hline 19.1 & 7.24 \\
\hline 12.7 & 1.36 \\
\hline 9.5 & 1.23 \\
\hline 6.4 & 1.17 \\
\hline 4.75 & 1.14 \\
\hline 3.35 & 1.12 \\
\hline 2.36 & 1.10 \\
\hline 1.70 & 1.09 \\
\hline 1.18 & 1.07 \\
\hline 0.850 & 1.06 \\
\hline 0.600 & 1.04 \\
\hline 0.425 & 1.02 \\
\hline 0.300 & 1.00 \\
\hline 0.212 & 0.96 \\
\hline 0.150 & 0.90 \\
\hline 0.106 & 0.82 \\
\hline 0.075 & 0.73 \\
\hline & \\
\hline
\end{tabular}

CV 14-2

\begin{tabular}{|c|c|}
\hline size $(\mathrm{mm})$ & Cum \% Passing \\
\hline 212.0 & 100.00 \\
\hline 175.0 & 100.00 \\
\hline 150.0 & 100.00 \\
\hline 125.0 & 100.00 \\
\hline 105.0 & 100.00 \\
\hline 90.0 & 100.00 \\
\hline 75.0 & 100.00 \\
\hline 63.5 & 100.00 \\
\hline 50.8 & 100.00 \\
\hline 38.1 & 100.00 \\
\hline 25.4 & 100.00 \\
\hline 19.1 & 78.79 \\
\hline 12.7 & 21.49 \\
\hline 9.5 & 5.92 \\
\hline 6.4 & 2.12 \\
\hline 4.75 & 1.43 \\
\hline 3.35 & 1.17 \\
\hline 2.36 & 1.10 \\
\hline 1.70 & 1.06 \\
\hline 1.18 & 1.03 \\
\hline 0.850 & 1.01 \\
\hline 0.600 & 0.98 \\
\hline 0.425 & 0.96 \\
\hline 0.300 & 0.93 \\
\hline 0.212 & 0.89 \\
\hline 0.150 & 0.84 \\
\hline 0.106 & 0.76 \\
\hline 0.075 & 0.67 \\
\hline
\end{tabular}

CV 15-2

\begin{tabular}{|r|r|}
\hline size (mm) & Cum \% Passing \\
\hline 212.0 & 100.00 \\
\hline 175.0 & 100.00 \\
\hline 150.0 & 100.00 \\
\hline 125.0 & 100.00 \\
\hline 105.0 & 100.00 \\
\hline 90.0 & 100.00 \\
\hline 75.0 & 100.00 \\
\hline 63.5 & 100.00 \\
\hline 50.8 & 100.00 \\
\hline 38.1 & 100.00 \\
\hline 25.4 & 100.00 \\
\hline 19.1 & 100.00 \\
\hline 12.7 & 99.58 \\
\hline 9.5 & 79.17 \\
\hline 6.4 & 30.66 \\
\hline 4.75 & 9.02 \\
\hline 3.35 & 3.00 \\
\hline 2.36 & 2.38 \\
\hline 1.70 & 2.24 \\
\hline 1.18 & 2.16 \\
\hline 0.850 & 2.10 \\
\hline 0.600 & 2.05 \\
\hline 0.425 & 1.99 \\
\hline 0.300 & 1.95 \\
\hline 0.212 & 1.87 \\
\hline 0.150 & 1.77 \\
\hline 0.106 & 1.62 \\
\hline 0.075 & 1.44 \\
\hline & \\
\hline
\end{tabular}

CV 16-2

\begin{tabular}{|c|c|}
\hline size $(\mathrm{mm})$ & Cum \% Passing \\
\hline 212.0 & 100.00 \\
\hline 175.0 & 100.00 \\
\hline 150.0 & 100.00 \\
\hline 125.0 & 100.00 \\
\hline 105.0 & 100.00 \\
\hline 90.0 & 100.00 \\
\hline 75.0 & 100.00 \\
\hline 63.5 & 100.00 \\
\hline 50.8 & 100.00 \\
\hline 38.1 & 100.00 \\
\hline 25.4 & 100.00 \\
\hline 19.1 & 100.00 \\
\hline 12.7 & 100.00 \\
\hline 9.5 & 100.00 \\
\hline 6.4 & 99.90 \\
\hline 4.75 & 95.65 \\
\hline 3.35 & 81.20 \\
\hline 2.36 & 65.26 \\
\hline 1.70 & 54.33 \\
\hline 1.18 & 45.18 \\
\hline 0.850 & 38.59 \\
\hline 0.600 & 33.46 \\
\hline 0.425 & 28.83 \\
\hline 0.300 & 25.29 \\
\hline 0.212 & 21.84 \\
\hline 0.150 & 18.55 \\
\hline 0.106 & 15.70 \\
\hline 0.075 & 13.26 \\
\hline
\end{tabular}




\section{Tertiary Section - Audit 3}
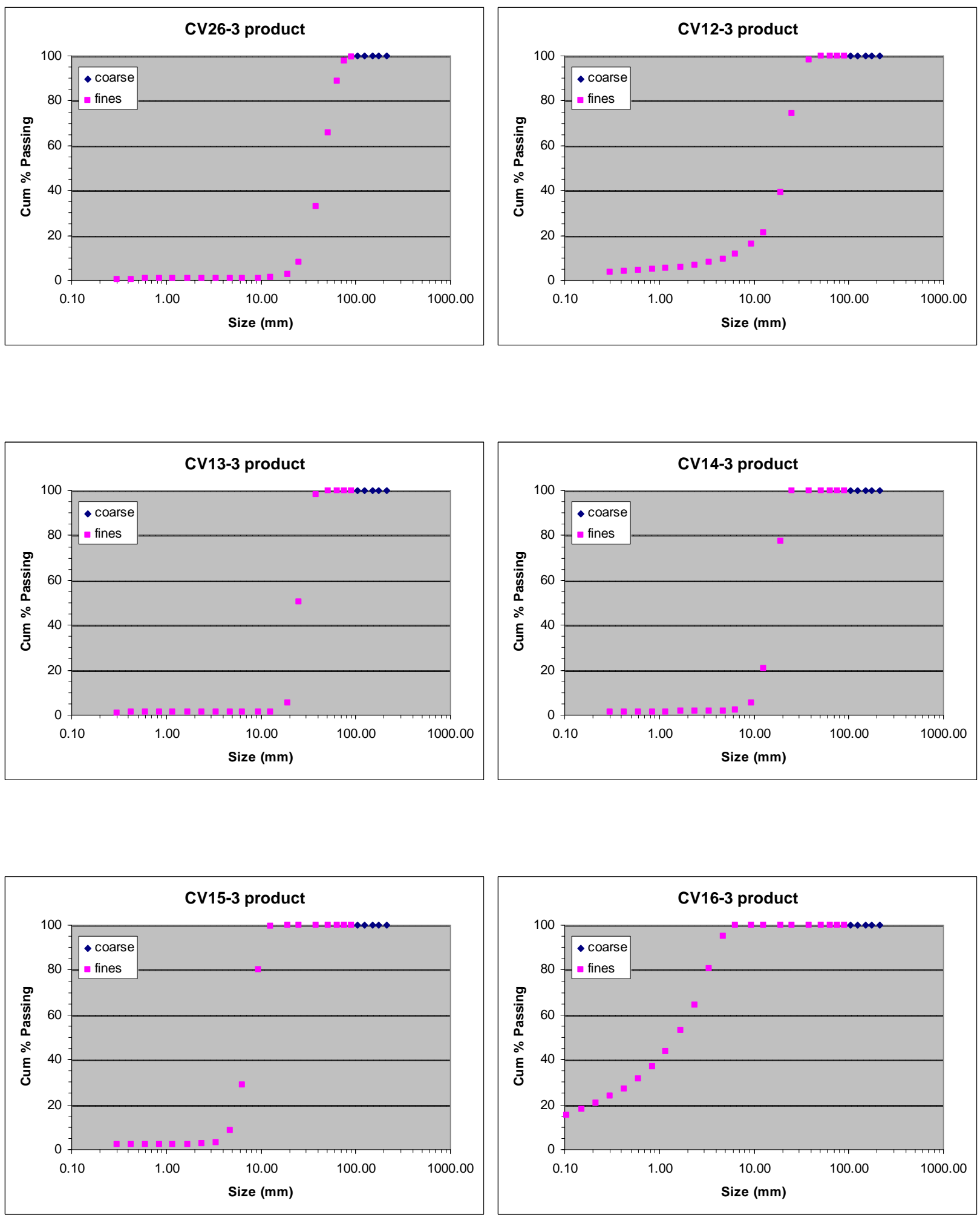
CV 26-3

\begin{tabular}{|r|r|}
\hline size (mm) & Cum \% Passing \\
\hline 212.0 & 100.00 \\
\hline 175.0 & 100.00 \\
\hline 150.0 & 100.00 \\
\hline 125.0 & 100.00 \\
\hline 105.0 & 100.00 \\
\hline 90.0 & 99.57 \\
\hline 75.0 & 97.56 \\
\hline 63.5 & 88.78 \\
\hline 50.8 & 65.96 \\
\hline 38.1 & 33.00 \\
\hline 25.4 & 8.26 \\
\hline 19.1 & 2.77 \\
\hline 12.7 & 1.24 \\
\hline 9.5 & 1.04 \\
\hline 6.4 & 0.91 \\
\hline 4.75 & 0.86 \\
\hline 3.35 & 0.83 \\
\hline 2.36 & 0.79 \\
\hline 1.70 & 0.77 \\
\hline 1.18 & 0.74 \\
\hline 0.850 & 0.72 \\
\hline 0.600 & 0.69 \\
\hline 0.425 & 0.66 \\
\hline 0.300 & 0.62 \\
\hline 0.212 & 0.57 \\
\hline 0.150 & 0.51 \\
\hline 0.106 & 0.45 \\
\hline 0.075 & 0.39 \\
\hline & \\
\hline
\end{tabular}

CV 12-3

\begin{tabular}{|r|r|}
\hline size $(\mathbf{m m})$ & Cum \% Passing \\
\hline 212.0 & 100.00 \\
\hline 175.0 & 100.00 \\
\hline 150.0 & 100.00 \\
\hline 125.0 & 100.00 \\
\hline 105.0 & 100.00 \\
\hline 90.0 & 100.00 \\
\hline 75.0 & 100.00 \\
\hline 63.5 & 100.00 \\
\hline 50.8 & 100.00 \\
\hline 38.1 & 98.16 \\
\hline 25.4 & 74.52 \\
\hline 19.1 & 39.09 \\
\hline 12.7 & 21.27 \\
\hline 9.5 & 16.01 \\
\hline 6.4 & 11.50 \\
\hline 4.75 & 9.49 \\
\hline 3.35 & 8.03 \\
\hline 2.36 & 6.83 \\
\hline 1.70 & 6.02 \\
\hline 1.18 & 5.31 \\
\hline 0.850 & 4.78 \\
\hline 0.600 & 4.34 \\
\hline 0.425 & 3.92 \\
\hline 0.300 & 3.59 \\
\hline 0.212 & 3.23 \\
\hline 0.150 & 2.86 \\
\hline 0.106 & 2.50 \\
\hline 0.075 & 2.16 \\
\hline & \\
\hline
\end{tabular}

CV 13-3

\begin{tabular}{|l|l|}
\hline size (mm) & Cum \% Passing \\
\hline
\end{tabular}

\begin{tabular}{|r|r|}
\hline 212.0 & 100.00 \\
\hline 175.0 & 100.00 \\
\hline 150.0 & 100.00 \\
\hline 125.0 & 100.00 \\
\hline 105.0 & 100.00 \\
\hline 90.0 & 100.00 \\
\hline 75.0 & 100.00 \\
\hline 63.5 & 100.00 \\
\hline 50.8 & 100.00 \\
\hline 38.1 & 98.31 \\
\hline 25.4 & 50.47 \\
\hline 19.1 & 5.40 \\
\hline 12.7 & 1.49 \\
\hline 9.5 & 1.34 \\
\hline 6.4 & 1.28 \\
\hline 4.75 & 1.26 \\
\hline 3.35 & 1.24 \\
\hline 2.36 & 1.23 \\
\hline 1.70 & 1.21 \\
\hline 1.18 & 1.20 \\
\hline 0.850 & 1.19 \\
\hline 0.600 & 1.17 \\
\hline 0.425 & 1.15 \\
\hline 0.300 & 1.12 \\
\hline 0.212 & 1.07 \\
\hline 0.150 & 1.01 \\
\hline 0.106 & 0.91 \\
\hline 0.075 & 0.80 \\
\hline & \\
\hline
\end{tabular}

CV 14-3

\begin{tabular}{|c|c|}
\hline size (mm) & Cum \% Passing \\
\hline 212.0 & 100.00 \\
\hline 175.0 & 100.00 \\
\hline 150.0 & 100.00 \\
\hline 125.0 & 100.00 \\
\hline 105.0 & 100.00 \\
\hline 90.0 & 100.00 \\
\hline 75.0 & 100.00 \\
\hline 63.5 & 100.00 \\
\hline 50.8 & 100.00 \\
\hline 38.1 & 100.00 \\
\hline 25.4 & 100.00 \\
\hline 19.1 & 77.46 \\
\hline 12.7 & 20.70 \\
\hline 9.5 & 5.60 \\
\hline 6.4 & 2.40 \\
\hline 4.75 & 1.82 \\
\hline 3.35 & 1.66 \\
\hline 2.36 & 1.62 \\
\hline 1.70 & 1.59 \\
\hline 1.18 & 1.56 \\
\hline 0.850 & 1.54 \\
\hline 0.600 & 1.52 \\
\hline 0.425 & 1.49 \\
\hline 0.300 & 1.46 \\
\hline 0.212 & 1.41 \\
\hline 0.150 & 1.33 \\
\hline 0.106 & 1.21 \\
\hline 0.075 & 1.07 \\
\hline
\end{tabular}

CV 15-3

\begin{tabular}{|r|r|}
\hline size (mm) & Cum \% Passing \\
\hline 212.0 & 100.00 \\
\hline 175.0 & 100.00 \\
\hline 150.0 & 100.00 \\
\hline 125.0 & 100.00 \\
\hline 105.0 & 100.00 \\
\hline 90.0 & 100.00 \\
\hline 75.0 & 100.00 \\
\hline 63.5 & 100.00 \\
\hline 50.8 & 100.00 \\
\hline 38.1 & 100.00 \\
\hline 25.4 & 100.00 \\
\hline 19.1 & 100.00 \\
\hline 12.7 & 99.61 \\
\hline 9.5 & 79.99 \\
\hline 6.4 & 28.61 \\
\hline 4.75 & 8.68 \\
\hline 3.35 & 2.99 \\
\hline 2.36 & 2.52 \\
\hline 1.70 & 2.42 \\
\hline 1.18 & 2.35 \\
\hline 0.850 & 2.29 \\
\hline 0.600 & 2.24 \\
\hline 0.425 & 2.18 \\
\hline 0.300 & 2.13 \\
\hline 0.212 & 2.06 \\
\hline 0.150 & 1.94 \\
\hline 0.106 & 1.78 \\
\hline 0.075 & 1.58 \\
\hline & \\
\hline
\end{tabular}

CV 16-3

\begin{tabular}{|c|c|}
\hline size (mm) & Cum \% Passing \\
\hline 212.0 & 100.00 \\
\hline 175.0 & 100.00 \\
\hline 150.0 & 100.00 \\
\hline 125.0 & 100.00 \\
\hline 105.0 & 100.00 \\
\hline 90.0 & 100.00 \\
\hline 75.0 & 100.00 \\
\hline 63.5 & 100.00 \\
\hline 50.8 & 100.00 \\
\hline 38.1 & 100.00 \\
\hline 25.4 & 100.00 \\
\hline 19.1 & 100.00 \\
\hline 12.7 & 100.00 \\
\hline 9.5 & 100.00 \\
\hline 6.4 & 99.92 \\
\hline 4.75 & 95.24 \\
\hline 3.35 & 80.59 \\
\hline 2.36 & 64.36 \\
\hline 1.70 & 52.99 \\
\hline 1.18 & 43.54 \\
\hline 0.850 & 36.88 \\
\hline 0.600 & 31.69 \\
\hline 0.425 & 27.23 \\
\hline 0.300 & 23.89 \\
\hline 0.212 & 20.73 \\
\hline 0.150 & 17.85 \\
\hline 0.106 & 15.24 \\
\hline 0.075 & 13.01 \\
\hline
\end{tabular}




\section{Tertiary Section - Audit 4}

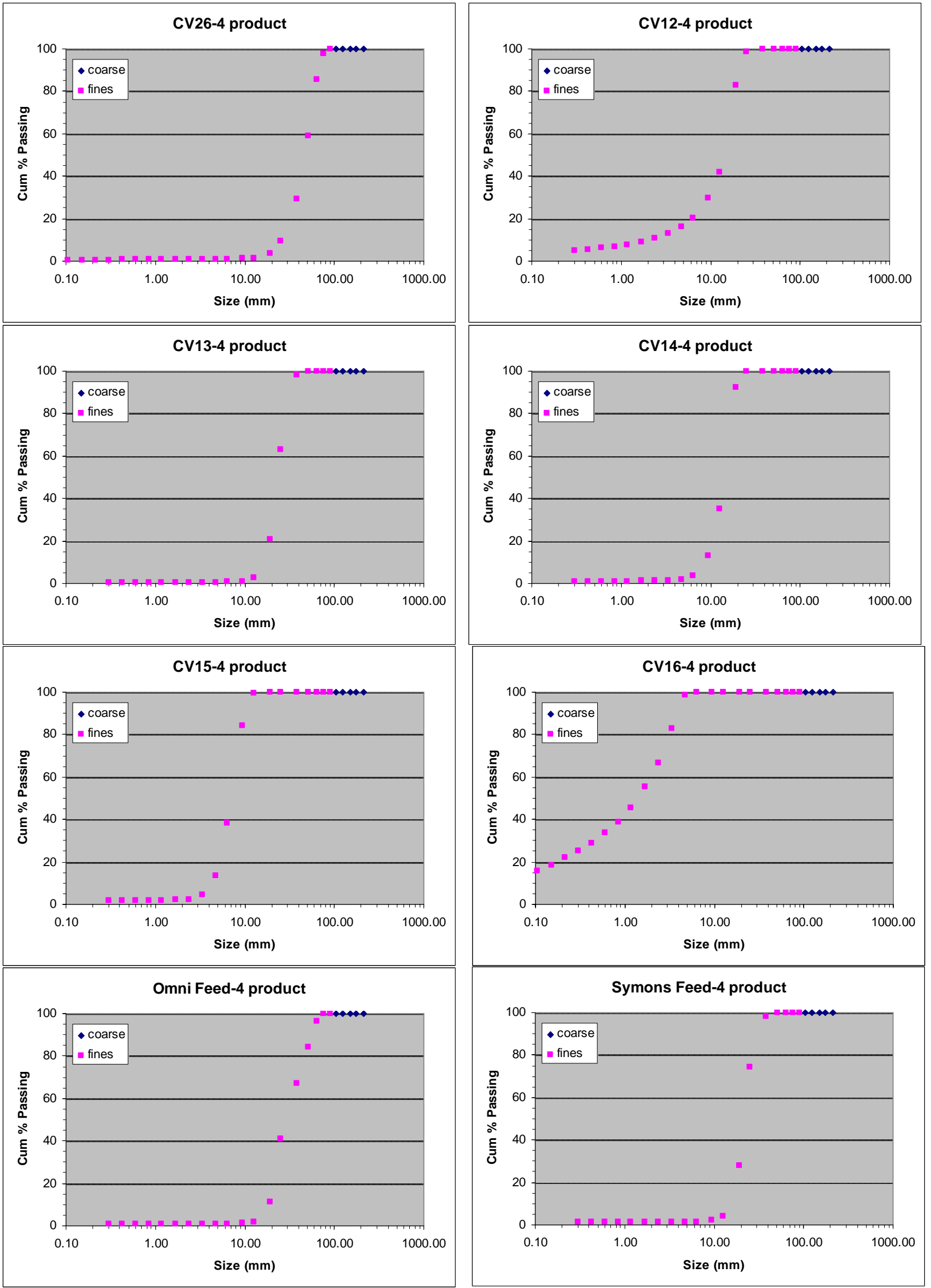


CV 26-4

\begin{tabular}{|r|r|}
\hline size $(\mathbf{m m})$ & Cum \% Passing \\
\hline 212.0 & 100.00 \\
\hline 175.0 & 100.00 \\
\hline 150.0 & 100.00 \\
\hline 125.0 & 100.00 \\
\hline 105.0 & 100.00 \\
\hline 90.0 & 100.00 \\
\hline 75.0 & 97.69 \\
\hline 63.5 & 85.49 \\
\hline 50.8 & 59.05 \\
\hline 38.1 & 29.47 \\
\hline 25.4 & 9.32 \\
\hline 19.1 & 3.41 \\
\hline 12.7 & 1.52 \\
\hline 9.5 & 1.23 \\
\hline 6.4 & 1.02 \\
\hline 4.75 & 0.96 \\
\hline 3.35 & 0.91 \\
\hline 2.36 & 0.86 \\
\hline 1.70 & 0.83 \\
\hline 1.18 & 0.80 \\
\hline 0.850 & 0.77 \\
\hline 0.600 & 0.74 \\
\hline 0.425 & 0.71 \\
\hline 0.300 & 0.67 \\
\hline 0.212 & 0.63 \\
\hline 0.150 & 0.57 \\
\hline 0.106 & 0.50 \\
\hline 0.075 & 0.44 \\
\hline & \\
\hline
\end{tabular}

CV 15-4

\begin{tabular}{|r|r|}
\hline size $(\mathbf{m m})$ & Cum \% Passing \\
\hline 212.0 & 100.00 \\
\hline 175.0 & 100.00 \\
\hline 150.0 & 100.00 \\
\hline 125.0 & 100.00 \\
\hline 105.0 & 100.00 \\
\hline 90.0 & 100.00 \\
\hline 75.0 & 100.00 \\
\hline 63.5 & 100.00 \\
\hline 50.8 & 100.00 \\
\hline 38.1 & 100.00 \\
\hline 25.4 & 100.00 \\
\hline 19.1 & 100.00 \\
\hline 12.7 & 99.52 \\
\hline 9.5 & 84.17 \\
\hline 6.4 & 38.37 \\
\hline 4.75 & 13.43 \\
\hline 3.35 & 4.44 \\
\hline 2.36 & 2.47 \\
\hline 1.70 & 2.14 \\
\hline 1.18 & 2.01 \\
\hline 0.850 & 1.93 \\
\hline 0.600 & 1.88 \\
\hline 0.425 & 1.83 \\
\hline 0.300 & 1.79 \\
\hline 0.212 & 1.74 \\
\hline 0.150 & 1.68 \\
\hline 0.106 & 1.58 \\
\hline 0.075 & 1.45 \\
\hline & \\
\hline
\end{tabular}

CV 12-4

\begin{tabular}{|r|r|}
\hline size (mm) & Cum \% Passing \\
\hline 212.0 & 100.00 \\
\hline 175.0 & 100.00 \\
\hline 150.0 & 100.00 \\
\hline 125.0 & 100.00 \\
\hline 105.0 & 100.00 \\
\hline 90.0 & 100.00 \\
\hline 75.0 & 100.00 \\
\hline 63.5 & 100.00 \\
\hline 50.8 & 100.00 \\
\hline 38.1 & 100.00 \\
\hline 25.4 & 98.43 \\
\hline 19.1 & 82.80 \\
\hline 12.7 & 41.93 \\
\hline 9.5 & 29.81 \\
\hline 6.4 & 20.11 \\
\hline 4.75 & 16.05 \\
\hline 3.35 & 13.06 \\
\hline 2.36 & 10.71 \\
\hline 1.70 & 9.15 \\
\hline 1.18 & 7.86 \\
\hline 0.850 & 6.93 \\
\hline 0.600 & 6.18 \\
\hline 0.425 & 5.51 \\
\hline 0.300 & 5.01 \\
\hline 0.212 & 4.50 \\
\hline 0.150 & 4.00 \\
\hline 0.106 & 3.50 \\
\hline 0.075 & 3.01 \\
\hline & \\
\hline &
\end{tabular}

CV 13-4

\begin{tabular}{|l|l|}
\hline size (mm) & Cum \% Passing \\
\hline
\end{tabular}

\begin{tabular}{|r|r|}
\hline 212.0 & 100.00 \\
\hline 175.0 & 100.00 \\
\hline 150.0 & 100.00 \\
\hline 125.0 & 100.00 \\
\hline 105.0 & 100.00 \\
\hline 90.0 & 100.00 \\
\hline 75.0 & 100.00 \\
\hline 63.5 & 100.00 \\
\hline 50.8 & 100.00 \\
\hline 38.1 & 98.41 \\
\hline 25.4 & 63.28 \\
\hline 19.1 & 20.65 \\
\hline 12.7 & 2.54 \\
\hline 9.5 & 1.06 \\
\hline 6.4 & 0.71 \\
\hline 4.75 & 0.66 \\
\hline 3.35 & 0.63 \\
\hline 2.36 & 0.61 \\
\hline 1.70 & 0.59 \\
\hline 1.18 & 0.58 \\
\hline 0.850 & 0.57 \\
\hline 0.600 & 0.56 \\
\hline 0.425 & 0.55 \\
\hline 0.300 & 0.54 \\
\hline 0.212 & 0.52 \\
\hline 0.150 & 0.49 \\
\hline 0.106 & 0.45 \\
\hline 0.075 & 0.40 \\
\hline & \\
\hline
\end{tabular}

Omni Feed

\begin{tabular}{|l|l|}
\hline size (mm) & Cum \% Passing \\
\hline
\end{tabular}

\begin{tabular}{|r|r|}
\hline 212.0 & 100.00 \\
\hline 175.0 & 100.00 \\
\hline 150.0 & 100.00 \\
\hline 125.0 & 100.00 \\
\hline 105.0 & 100.00 \\
\hline 90.0 & 100.00 \\
\hline 75.0 & 100.00 \\
\hline 63.5 & 96.60 \\
\hline 50.8 & 84.09 \\
\hline 38.1 & 67.12 \\
\hline 25.4 & 41.03 \\
\hline 19.1 & 11.33 \\
\hline 12.7 & 1.83 \\
\hline 9.5 & 1.26 \\
\hline 6.4 & 1.11 \\
\hline 4.75 & 1.07 \\
\hline 3.35 & 1.04 \\
\hline 2.36 & 1.02 \\
\hline 1.70 & 1.00 \\
\hline 1.18 & 0.97 \\
\hline 0.850 & 0.96 \\
\hline 0.600 & 0.93 \\
\hline 0.425 & 0.91 \\
\hline 0.300 & 0.88 \\
\hline 0.212 & 0.83 \\
\hline 0.150 & 0.77 \\
\hline 0.106 & 0.70 \\
\hline 0.075 & 0.61 \\
\hline & \\
\hline
\end{tabular}

CV 14-4

\begin{tabular}{|l|l|}
\hline size (mm) & Cum \% Passing \\
\hline
\end{tabular}

\begin{tabular}{|r|r|}
\hline 212.0 & 100.00 \\
\hline 175.0 & 100.00 \\
\hline 150.0 & 100.00 \\
\hline 125.0 & 100.00 \\
\hline 105.0 & 100.00 \\
\hline 90.0 & 100.00 \\
\hline 75.0 & 100.00 \\
\hline 63.5 & 100.00 \\
\hline 50.8 & 100.00 \\
\hline 38.1 & 100.00 \\
\hline 25.4 & 100.00 \\
\hline 19.1 & 92.48 \\
\hline 12.7 & 35.13 \\
\hline 9.5 & 12.96 \\
\hline 6.4 & 3.48 \\
\hline 4.75 & 1.67 \\
\hline 3.35 & 1.28 \\
\hline 2.36 & 1.19 \\
\hline 1.70 & 1.15 \\
\hline 1.18 & 1.12 \\
\hline 0.850 & 1.10 \\
\hline 0.600 & 1.08 \\
\hline 0.425 & 1.06 \\
\hline 0.300 & 1.04 \\
\hline 0.212 & 1.01 \\
\hline 0.150 & 0.97 \\
\hline 0.106 & 0.91 \\
\hline 0.075 & 0.83 \\
\hline & \\
\hline
\end{tabular}

\section{Symons Feed}

\begin{tabular}{|l|l|}
\hline size (mm) & Cum \% Passing \\
\hline
\end{tabular}

\begin{tabular}{|r|r|}
\hline size $(\mathbf{m m})$ & Cum \% Passing \\
\hline 212.0 & 100.00 \\
\hline 175.0 & 100.00 \\
\hline 150.0 & 100.00 \\
\hline 125.0 & 100.00 \\
\hline 105.0 & 100.00 \\
\hline 90.0 & 100.00 \\
\hline 75.0 & 100.00 \\
\hline 63.5 & 100.00 \\
\hline 50.8 & 100.00 \\
\hline 38.1 & 100.00 \\
\hline 25.4 & 100.00 \\
\hline 19.1 & 100.00 \\
\hline 12.7 & 100.00 \\
\hline 9.5 & 100.00 \\
\hline 6.4 & 99.93 \\
\hline 4.75 & 98.50 \\
\hline 3.35 & 82.66 \\
\hline 2.36 & 66.84 \\
\hline 1.70 & 55.22 \\
\hline 1.18 & 45.70 \\
\hline 0.850 & 38.93 \\
\hline 0.600 & 33.60 \\
\hline 0.425 & 28.82 \\
\hline 0.300 & 25.27 \\
\hline 0.212 & 21.85 \\
\hline 0.150 & 18.66 \\
\hline 0.106 & 15.84 \\
\hline 0.075 & 13.40 \\
\hline & \\
\hline
\end{tabular}

\begin{tabular}{|r|r|}
\hline 212.0 & 100.00 \\
\hline 175.0 & 100.00 \\
\hline 150.0 & 100.00 \\
\hline 125.0 & 100.00 \\
\hline 105.0 & 100.00 \\
\hline 90.0 & 100.00 \\
\hline 75.0 & 100.00 \\
\hline 63.5 & 100.00 \\
\hline 50.8 & 100.00 \\
\hline 38.1 & 98.15 \\
\hline 25.4 & 74.24 \\
\hline 19.1 & 27.74 \\
\hline 12.7 & 4.24 \\
\hline 9.5 & 2.15 \\
\hline 6.4 & 1.57 \\
\hline 4.75 & 1.46 \\
\hline 3.35 & 1.41 \\
\hline 2.36 & 1.37 \\
\hline 1.70 & 1.34 \\
\hline 1.18 & 1.31 \\
\hline 0.850 & 1.29 \\
\hline 0.600 & 1.27 \\
\hline 0.425 & 1.24 \\
\hline 0.300 & 1.21 \\
\hline 0.212 & 1.17 \\
\hline 0.150 & 1.11 \\
\hline 0.106 & 1.03 \\
\hline 0.075 & 0.93 \\
\hline & \\
\hline
\end{tabular}




\section{Bealeton November 2004 Side-by-Side Sizing Results Primary Section - LS Shot}

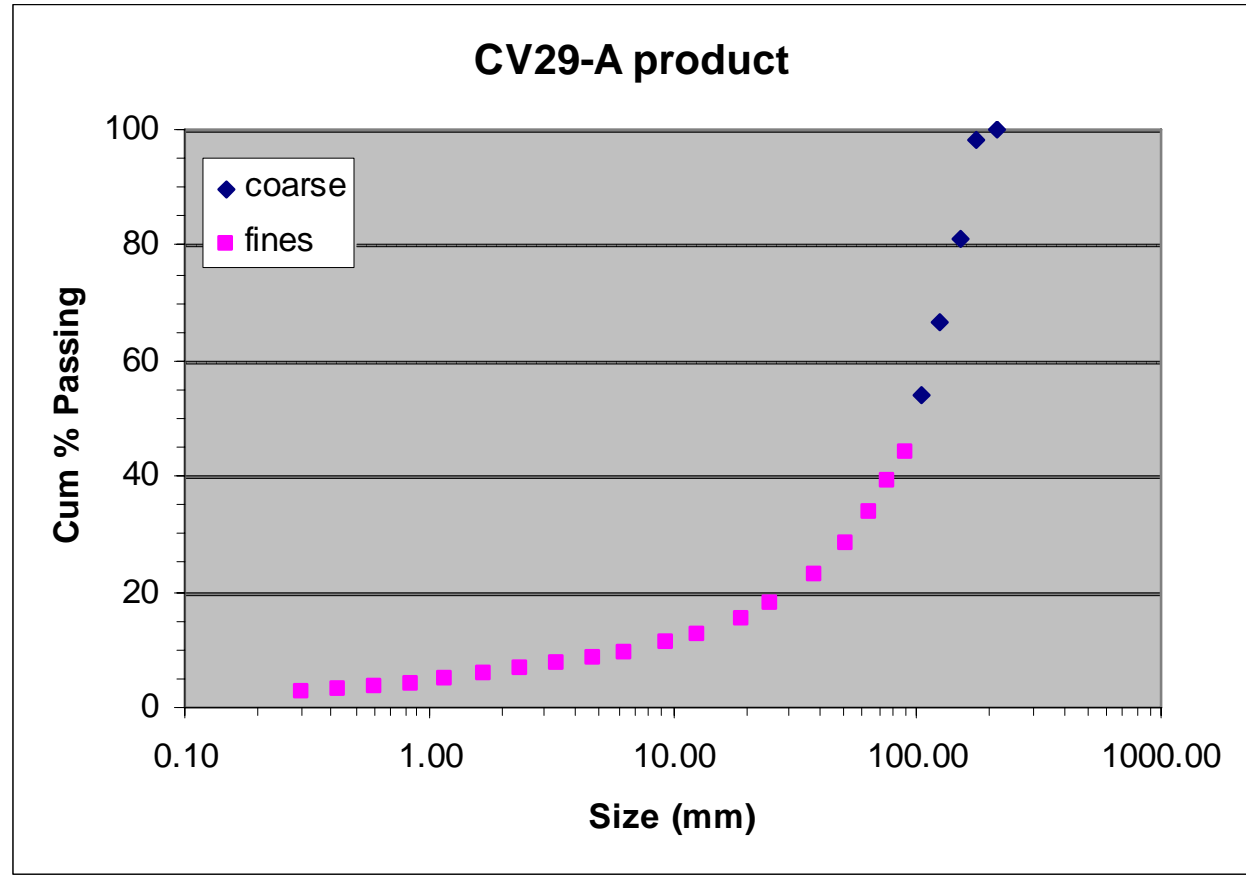

\begin{tabular}{|l|l|}
\hline size $(\mathrm{mm})$ & Cum \% Passing \\
\hline
\end{tabular}

\begin{tabular}{|c|c|}
\hline 212.0 & 100.00 \\
\hline 175.0 & 98.08 \\
\hline 150.0 & 80.86 \\
\hline 125.0 & 66.80 \\
\hline 105.0 & 54.15 \\
\hline 90.0 & 44.36 \\
\hline 75.0 & 39.10 \\
\hline 63.5 & 33.70 \\
\hline 50.8 & 28.56 \\
\hline 38.1 & 22.95 \\
\hline 25.4 & 17.82 \\
\hline 19.1 & 15.22 \\
\hline 12.7 & 12.49 \\
\hline 9.5 & 11.10 \\
\hline 6.4 & 9.43 \\
\hline 4.75 & 8.52 \\
\hline 3.35 & 7.64 \\
\hline 2.36 & 6.62 \\
\hline 1.70 & 5.64 \\
\hline 1.18 & 4.78 \\
\hline 0.850 & 4.14 \\
\hline 0.600 & 3.62 \\
\hline 0.425 & 3.15 \\
\hline 0.300 & 2.78 \\
\hline 0.212 & 2.41 \\
\hline 0.150 & 2.05 \\
\hline 0.106 & 1.74 \\
\hline 0.075 & 1.48 \\
\hline
\end{tabular}




\section{Primary Section - MTM Shot}

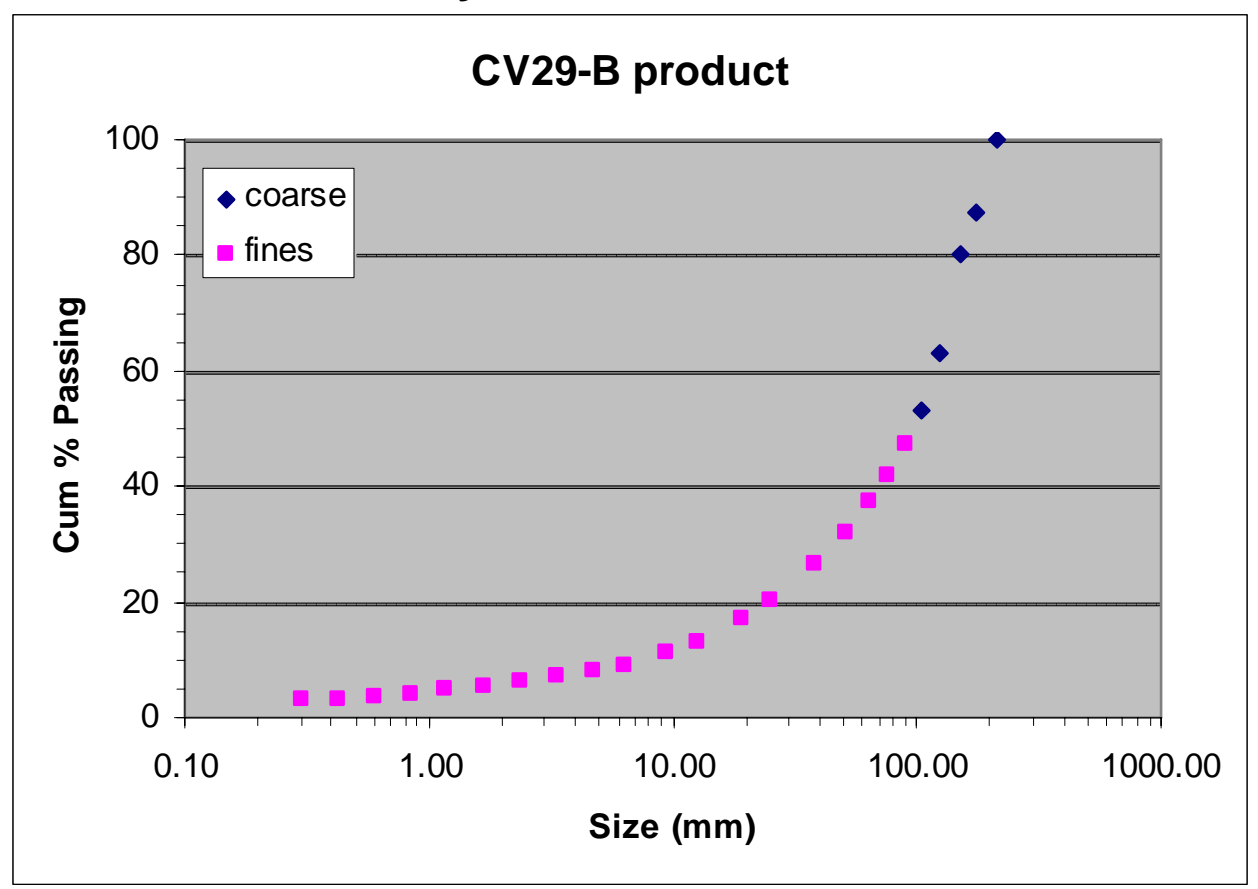

\begin{tabular}{|l|l|}
\hline size $(\mathrm{mm})$ & Cum \% Passing \\
\hline
\end{tabular}

\begin{tabular}{|r|r|}
\hline 212.0 & 100.00 \\
\hline 175.0 & 87.56 \\
\hline 150.0 & 80.10 \\
\hline 125.0 & 63.14 \\
\hline 105.0 & 53.08 \\
\hline 90.0 & 47.13 \\
\hline 75.0 & 41.99 \\
\hline 63.5 & 37.20 \\
\hline 50.8 & 31.92 \\
\hline 38.1 & 26.58 \\
\hline 25.4 & 20.24 \\
\hline 19.1 & 16.99 \\
\hline 12.7 & 13.19 \\
\hline 9.5 & 11.29 \\
\hline 6.4 & 9.18 \\
\hline 4.75 & 8.02 \\
\hline 3.35 & 7.14 \\
\hline 2.36 & 6.24 \\
\hline 1.70 & 5.46 \\
\hline 1.18 & 4.74 \\
\hline 0.850 & 4.19 \\
\hline 0.600 & 3.74 \\
\hline 0.425 & 3.36 \\
\hline 0.300 & 3.05 \\
\hline 0.212 & 2.73 \\
\hline 0.150 & 2.42 \\
\hline 0.106 & 2.13 \\
\hline 0.075 & 1.87 \\
\hline & \\
\hline
\end{tabular}




\section{Secondary Section - LS Shot}
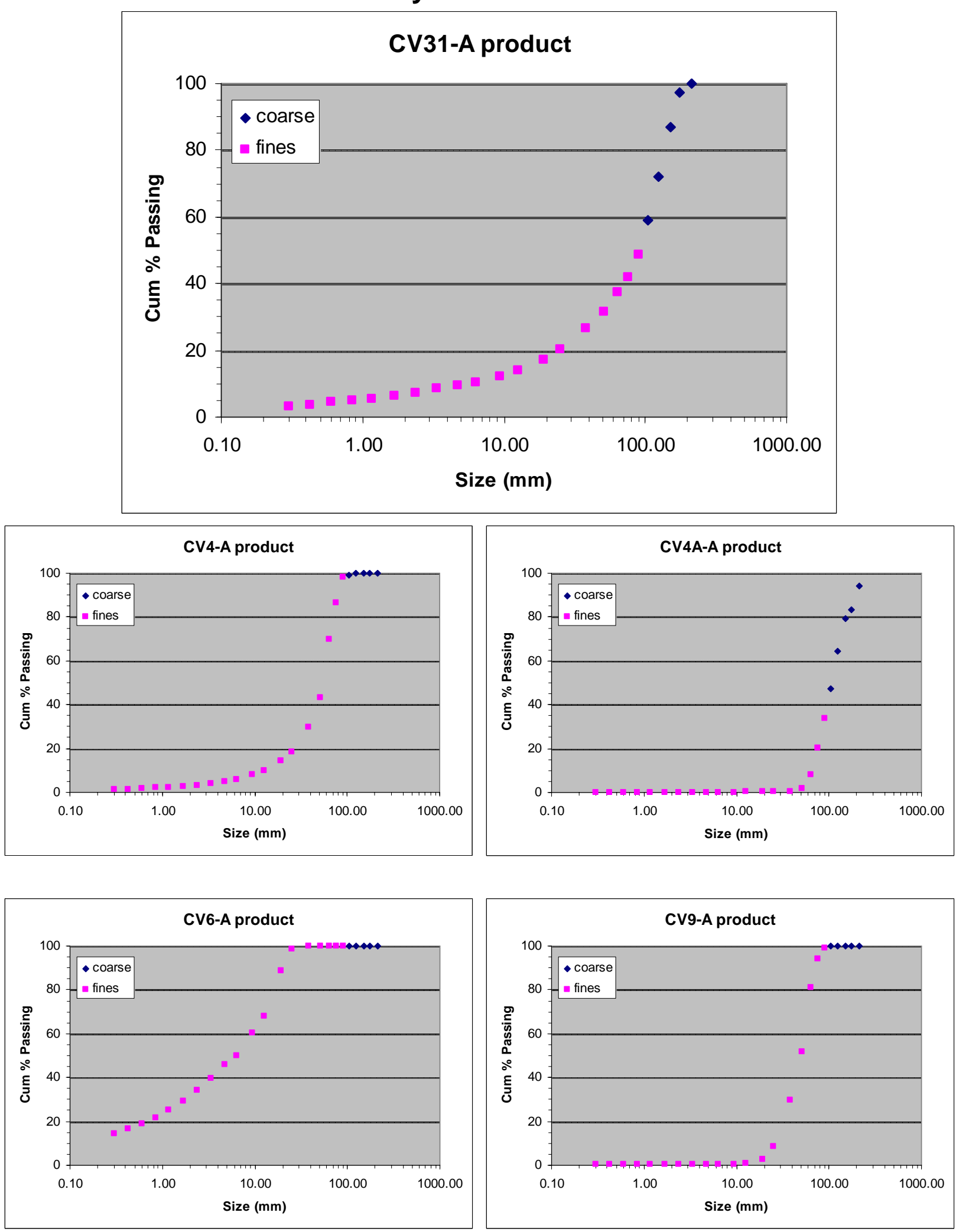
CV 31-A

\begin{tabular}{|r|r|}
\hline size $(\mathrm{mm})$ & Cum \% Passing \\
\hline 212.0 & 100.00 \\
\hline 175.0 & 97.41 \\
\hline 150.0 & 87.15 \\
\hline 125.0 & 72.09 \\
\hline 105.0 & 59.08 \\
\hline 90.0 & 48.82 \\
\hline 75.0 & 41.95 \\
\hline 63.5 & 37.30 \\
\hline 50.8 & 31.41 \\
\hline 38.1 & 26.60 \\
\hline 25.4 & 20.48 \\
\hline 19.1 & 17.28 \\
\hline 12.7 & 13.99 \\
\hline 9.5 & 12.39 \\
\hline 6.4 & 10.51 \\
\hline 4.75 & 9.46 \\
\hline 3.35 & 8.44 \\
\hline 2.36 & 7.43 \\
\hline 1.70 & 6.52 \\
\hline 1.18 & 5.63 \\
\hline 0.850 & 4.92 \\
\hline 0.600 & 4.31 \\
\hline 0.425 & 3.78 \\
\hline 0.300 & 3.37 \\
\hline 0.212 & 2.96 \\
\hline 0.150 & 2.58 \\
\hline 0.106 & 2.23 \\
\hline 0.075 & 1.93 \\
\hline & \\
\hline
\end{tabular}

CV 4-A

\begin{tabular}{|l|l|}
\hline size (mm) & Cum \% Passing \\
\hline
\end{tabular}

\begin{tabular}{|r|r|}
\hline 212.0 & 100.00 \\
\hline 175.0 & 100.00 \\
\hline 150.0 & 100.00 \\
\hline 125.0 & 100.00 \\
\hline 105.0 & 99.15 \\
\hline 90.0 & 98.25 \\
\hline 75.0 & 86.34 \\
\hline 63.5 & 69.86 \\
\hline 50.8 & 43.34 \\
\hline 38.1 & 29.87 \\
\hline 25.4 & 18.63 \\
\hline 19.1 & 14.33 \\
\hline 12.7 & 9.99 \\
\hline 9.5 & 7.99 \\
\hline 6.4 & 5.87 \\
\hline 4.75 & 4.87 \\
\hline 3.35 & 4.05 \\
\hline 2.36 & 3.33 \\
\hline 1.70 & 2.81 \\
\hline 1.18 & 2.38 \\
\hline 0.850 & 2.06 \\
\hline 0.600 & 1.80 \\
\hline 0.425 & 1.58 \\
\hline 0.300 & 1.39 \\
\hline 0.212 & 1.19 \\
\hline 0.150 & 1.00 \\
\hline 0.106 & 0.83 \\
\hline 0.075 & 0.68 \\
\hline & \\
\hline
\end{tabular}

CV 4A-A

\begin{tabular}{|l|l|}
\hline size $(\mathrm{mm})$ & Cum \% Passing \\
\hline
\end{tabular}

\begin{tabular}{r|r|}
\hline 212.0 & 94.17 \\
\hline 175.0 & 83.29 \\
\hline 150.0 & 79.35 \\
\hline 125.0 & 64.63 \\
\hline 105.0 & 47.10 \\
\hline 90.0 & 33.62 \\
\hline 75.0 & 20.43 \\
\hline 63.5 & 8.33 \\
\hline 50.8 & 1.59 \\
\hline 38.1 & 0.54 \\
\hline 25.4 & 0.37 \\
\hline 19.1 & 0.28 \\
\hline 12.7 & 0.25 \\
\hline 9.5 & 0.22 \\
\hline 6.4 & 0.20 \\
\hline 4.75 & 0.18 \\
\hline 3.35 & 0.17 \\
\hline 2.36 & 0.15 \\
\hline 1.70 & 0.14 \\
\hline 1.18 & 0.13 \\
\hline 0.850 & 0.12 \\
\hline 0.600 & 0.11 \\
\hline 0.425 & 0.10 \\
\hline 0.300 & 0.09 \\
\hline 0.212 & 0.09 \\
\hline 0.150 & 0.08 \\
\hline 0.106 & 0.06 \\
\hline 0.075 & 0.05 \\
\hline & \\
\hline
\end{tabular}

CV 6-A

\begin{tabular}{|r|r|}
\hline size $(\mathrm{mm})$ & Cum \% Passing \\
\hline 212.0 & 100.00 \\
\hline 175.0 & 100.00 \\
\hline 150.0 & 100.00 \\
\hline 125.0 & 100.00 \\
\hline 105.0 & 100.00 \\
\hline 90.0 & 100.00 \\
\hline 75.0 & 100.00 \\
\hline 63.5 & 100.00 \\
\hline 50.8 & 100.00 \\
\hline 38.1 & 100.00 \\
\hline 25.4 & 98.70 \\
\hline 19.1 & 88.69 \\
\hline 12.7 & 68.21 \\
\hline 9.5 & 60.26 \\
\hline 6.4 & 49.94 \\
\hline 4.75 & 46.10 \\
\hline 3.35 & 39.81 \\
\hline 2.36 & 34.12 \\
\hline 1.70 & 29.39 \\
\hline 1.18 & 25.08 \\
\hline 0.850 & 21.73 \\
\hline 0.600 & 18.97 \\
\hline 0.425 & 16.52 \\
\hline 0.300 & 14.62 \\
\hline 0.212 & 12.75 \\
\hline 0.150 & 11.00 \\
\hline 0.106 & 9.44 \\
\hline 0.075 & 8.10 \\
\hline & \\
\hline
\end{tabular}

CV 9-A

\begin{tabular}{|c|c|}
\hline size $(\mathrm{mm})$ & Cum \% Passing \\
\hline 212.0 & 100.00 \\
\hline 175.0 & 100.00 \\
\hline 150.0 & 100.00 \\
\hline 125.0 & 100.00 \\
\hline 105.0 & 100.00 \\
\hline 90.0 & 99.28 \\
\hline 75.0 & 94.19 \\
\hline 63.5 & 81.06 \\
\hline 50.8 & 51.87 \\
\hline 38.1 & 29.80 \\
\hline 25.4 & 8.50 \\
\hline 19.1 & 2.48 \\
\hline 12.7 & 0.82 \\
\hline 9.5 & 0.66 \\
\hline 6.4 & 0.54 \\
\hline 4.75 & 0.50 \\
\hline 3.35 & 0.46 \\
\hline 2.36 & 0.44 \\
\hline 1.70 & 0.41 \\
\hline 1.18 & 0.39 \\
\hline 0.850 & 0.37 \\
\hline 0.600 & 0.36 \\
\hline 0.425 & 0.34 \\
\hline 0.300 & 0.33 \\
\hline 0.212 & 0.31 \\
\hline 0.150 & 0.28 \\
\hline 0.106 & 0.25 \\
\hline 0.075 & 0.22 \\
\hline
\end{tabular}




\section{Secondary Section - MTM Shot}
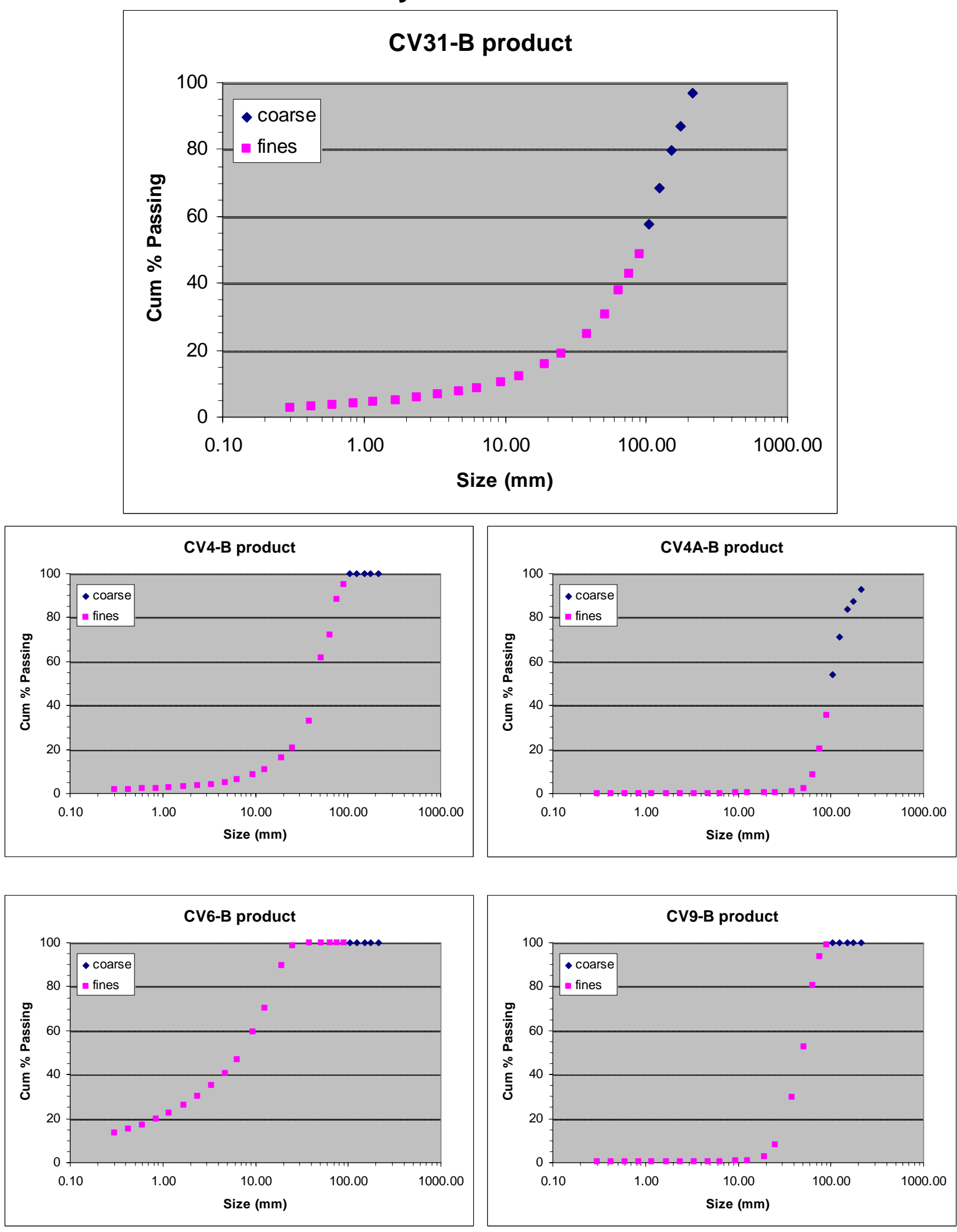
CV 31-B

\begin{tabular}{|r|r|}
\hline size $(\mathrm{mm})$ & Cum \% Passing \\
\hline 212.0 & 96.95 \\
\hline 175.0 & 86.75 \\
\hline 150.0 & 79.68 \\
\hline 125.0 & 68.30 \\
\hline 105.0 & 57.80 \\
\hline 90.0 & 48.77 \\
\hline 75.0 & 42.75 \\
\hline 63.5 & 37.90 \\
\hline 50.8 & 30.59 \\
\hline 38.1 & 24.98 \\
\hline 25.4 & 18.77 \\
\hline 19.1 & 15.64 \\
\hline 12.7 & 12.12 \\
\hline 9.5 & 10.39 \\
\hline 6.4 & 8.51 \\
\hline 4.75 & 7.49 \\
\hline 3.35 & 6.65 \\
\hline 2.36 & 5.79 \\
\hline 1.70 & 5.07 \\
\hline 1.18 & 4.39 \\
\hline 0.850 & 3.87 \\
\hline 0.600 & 3.44 \\
\hline 0.425 & 3.07 \\
\hline 0.300 & 2.77 \\
\hline 0.212 & 2.47 \\
\hline 0.150 & 2.17 \\
\hline 0.106 & 1.89 \\
\hline 0.075 & 1.64 \\
\hline & \\
\hline
\end{tabular}

CV 4-B

\begin{tabular}{|l|l|}
\hline size $(\mathrm{mm})$ & Cum \% Passing \\
\hline
\end{tabular}

\begin{tabular}{|r|r|}
\hline 212.0 & 100.00 \\
\hline 175.0 & 100.00 \\
\hline 150.0 & 100.00 \\
\hline 125.0 & 100.00 \\
\hline 105.0 & 100.00 \\
\hline 90.0 & 95.24 \\
\hline 75.0 & 88.08 \\
\hline 63.5 & 72.12 \\
\hline 50.8 & 61.90 \\
\hline 38.1 & 32.91 \\
\hline 25.4 & 20.79 \\
\hline 19.1 & 16.00 \\
\hline 12.7 & 10.79 \\
\hline 9.5 & 8.51 \\
\hline 6.4 & 6.18 \\
\hline 4.75 & 5.02 \\
\hline 3.35 & 4.27 \\
\hline 2.36 & 3.57 \\
\hline 1.70 & 3.07 \\
\hline 1.18 & 2.64 \\
\hline 0.850 & 2.32 \\
\hline 0.600 & 2.03 \\
\hline 0.425 & 1.79 \\
\hline 0.300 & 1.60 \\
\hline 0.212 & 1.39 \\
\hline 0.150 & 1.19 \\
\hline 0.106 & 1.00 \\
\hline 0.075 & 0.83 \\
\hline & \\
\hline
\end{tabular}

CV 4A-B

\begin{tabular}{|l|l|}
\hline size $(\mathrm{mm})$ & Cum \% Passing \\
\hline
\end{tabular}

\begin{tabular}{|r|r|}
\hline 212.0 & 93.00 \\
\hline 175.0 & 87.50 \\
\hline 150.0 & 83.90 \\
\hline 125.0 & 70.98 \\
\hline 105.0 & 53.97 \\
\hline 90.0 & 35.64 \\
\hline 75.0 & 20.07 \\
\hline 63.5 & 8.67 \\
\hline 50.8 & 2.17 \\
\hline 38.1 & 0.70 \\
\hline 25.4 & 0.37 \\
\hline 19.1 & 0.33 \\
\hline 12.7 & 0.27 \\
\hline 9.5 & 0.25 \\
\hline 6.4 & 0.22 \\
\hline 4.75 & 0.20 \\
\hline 3.35 & 0.19 \\
\hline 2.36 & 0.17 \\
\hline 1.70 & 0.16 \\
\hline 1.18 & 0.15 \\
\hline 0.850 & 0.14 \\
\hline 0.600 & 0.14 \\
\hline 0.425 & 0.13 \\
\hline 0.300 & 0.12 \\
\hline 0.212 & 0.11 \\
\hline 0.150 & 0.09 \\
\hline 0.106 & 0.08 \\
\hline 0.075 & 0.06 \\
\hline & \\
\hline
\end{tabular}

CV 6-A

\begin{tabular}{|r|r|}
\hline size $(\mathrm{mm})$ & Cum \% Passing \\
\hline 212.0 & 100.00 \\
\hline 175.0 & 100.00 \\
\hline 150.0 & 100.00 \\
\hline 125.0 & 100.00 \\
\hline 105.0 & 100.00 \\
\hline 90.0 & 100.00 \\
\hline 75.0 & 100.00 \\
\hline 63.5 & 100.00 \\
\hline 50.8 & 100.00 \\
\hline 38.1 & 100.00 \\
\hline 25.4 & 98.67 \\
\hline 19.1 & 89.67 \\
\hline 12.7 & 70.18 \\
\hline 9.5 & 59.51 \\
\hline 6.4 & 46.99 \\
\hline 4.75 & 40.62 \\
\hline 3.35 & 35.28 \\
\hline 2.36 & 30.19 \\
\hline 1.70 & 26.13 \\
\hline 1.18 & 22.43 \\
\hline 0.850 & 19.65 \\
\hline 0.600 & 17.34 \\
\hline 0.425 & 15.29 \\
\hline 0.300 & 13.65 \\
\hline 0.212 & 12.03 \\
\hline 0.150 & 10.49 \\
\hline 0.106 & 9.10 \\
\hline 0.075 & 7.90 \\
\hline & \\
\hline
\end{tabular}

CV 9-A

\begin{tabular}{|c|c|}
\hline size $(\mathrm{mm})$ & Cum \% Passing \\
\hline 212.0 & 100.00 \\
\hline 175.0 & 100.00 \\
\hline 150.0 & 100.00 \\
\hline 125.0 & 100.00 \\
\hline 105.0 & 100.00 \\
\hline 90.0 & 99.13 \\
\hline 75.0 & 93.56 \\
\hline 63.5 & 80.77 \\
\hline 50.8 & 52.49 \\
\hline 38.1 & 29.56 \\
\hline 25.4 & 8.29 \\
\hline 19.1 & 2.49 \\
\hline 12.7 & 0.99 \\
\hline 9.5 & 0.77 \\
\hline 6.4 & 0.66 \\
\hline 4.75 & 0.62 \\
\hline 3.35 & 0.59 \\
\hline 2.36 & 0.57 \\
\hline 1.70 & 0.55 \\
\hline 1.18 & 0.53 \\
\hline 0.850 & 0.51 \\
\hline 0.600 & 0.50 \\
\hline 0.425 & 0.48 \\
\hline 0.300 & 0.46 \\
\hline 0.212 & 0.43 \\
\hline 0.150 & 0.40 \\
\hline 0.106 & 0.35 \\
\hline 0.075 & 0.29 \\
\hline
\end{tabular}




\section{Tertiary Section - LS Shot}
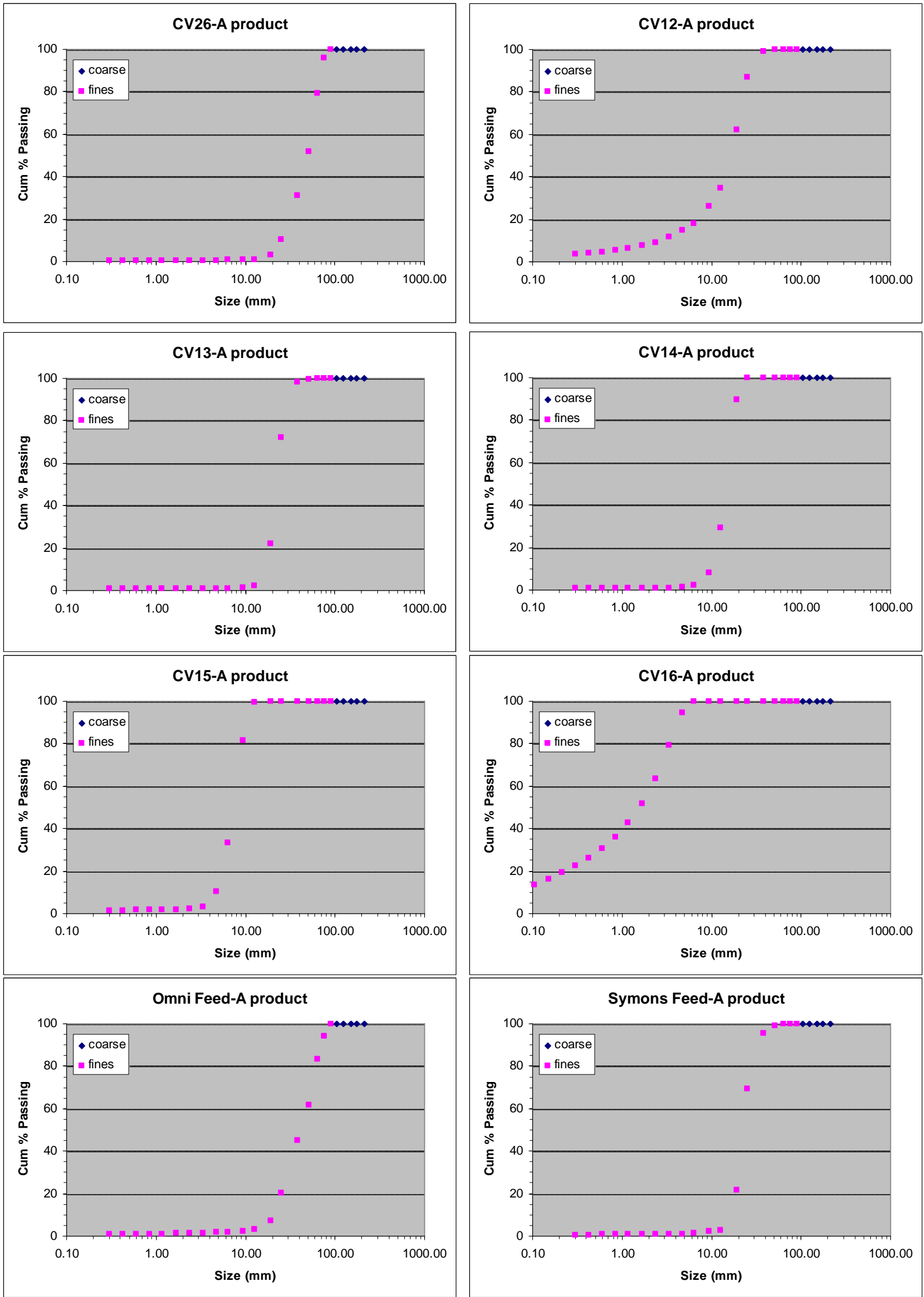
CV 26-A

\begin{tabular}{|r|r|}
\hline size $(\mathrm{mm})$ & Cum \% Passing \\
\hline 212.0 & 100.00 \\
\hline 175.0 & 100.00 \\
\hline 150.0 & 100.00 \\
\hline 125.0 & 100.00 \\
\hline 105.0 & 100.00 \\
\hline 90.0 & 100.00 \\
\hline 75.0 & 95.80 \\
\hline 63.5 & 79.42 \\
\hline 50.8 & 51.87 \\
\hline 38.1 & 31.15 \\
\hline 25.4 & 10.57 \\
\hline 19.1 & 3.22 \\
\hline 12.7 & 1.12 \\
\hline 9.5 & 0.87 \\
\hline 6.4 & 0.70 \\
\hline 4.75 & 0.63 \\
\hline 3.35 & 0.58 \\
\hline 2.36 & 0.52 \\
\hline 1.70 & 0.49 \\
\hline 1.18 & 0.45 \\
\hline 0.850 & 0.43 \\
\hline 0.600 & 0.41 \\
\hline 0.425 & 0.38 \\
\hline 0.300 & 0.36 \\
\hline 0.212 & 0.34 \\
\hline 0.150 & 0.31 \\
\hline 0.106 & 0.27 \\
\hline 0.075 & 0.24 \\
\hline & \\
\hline
\end{tabular}

CV 12-A

\begin{tabular}{|l|l|}
\hline size $(\mathrm{mm})$ & Cum \% Passing \\
\hline
\end{tabular}

\begin{tabular}{|r|r|}
\hline 212.0 & 100.00 \\
\hline 175.0 & 100.00 \\
\hline 150.0 & 100.00 \\
\hline 125.0 & 100.00 \\
\hline 105.0 & 100.00 \\
\hline 90.0 & 100.00 \\
\hline 75.0 & 100.00 \\
\hline 63.5 & 100.00 \\
\hline 50.8 & 99.94 \\
\hline 38.1 & 99.20 \\
\hline 25.4 & 87.03 \\
\hline 19.1 & 61.96 \\
\hline 12.7 & 34.88 \\
\hline 9.5 & 26.12 \\
\hline 6.4 & 18.23 \\
\hline 4.75 & 14.69 \\
\hline 3.35 & 11.71 \\
\hline 2.36 & 9.17 \\
\hline 1.70 & 7.51 \\
\hline 1.18 & 6.18 \\
\hline 0.850 & 5.28 \\
\hline 0.600 & 4.59 \\
\hline 0.425 & 4.01 \\
\hline 0.300 & 3.56 \\
\hline 0.212 & 3.12 \\
\hline 0.150 & 2.70 \\
\hline 0.106 & 2.33 \\
\hline 0.075 & 1.98 \\
\hline
\end{tabular}

CV 13-A

\begin{tabular}{|l|l|}
\hline size $(\mathrm{mm})$ & Cum $\%$ Passing \\
\hline
\end{tabular}

\begin{tabular}{|r|r|}
\hline 212.0 & 100.00 \\
\hline 175.0 & 100.00 \\
\hline 150.0 & 100.00 \\
\hline 125.0 & 100.00 \\
\hline 105.0 & 100.00 \\
\hline 90.0 & 100.00 \\
\hline 75.0 & 100.00 \\
\hline 63.5 & 100.00 \\
\hline 50.8 & 99.76 \\
\hline 38.1 & 98.29 \\
\hline 25.4 & 72.06 \\
\hline 19.1 & 22.21 \\
\hline 12.7 & 2.41 \\
\hline 9.5 & 1.35 \\
\hline 6.4 & 1.12 \\
\hline 4.75 & 1.07 \\
\hline 3.35 & 1.03 \\
\hline 2.36 & 1.00 \\
\hline 1.70 & 0.97 \\
\hline 1.18 & 0.95 \\
\hline 0.850 & 0.94 \\
\hline 0.600 & 0.92 \\
\hline 0.425 & 0.91 \\
\hline 0.300 & 0.89 \\
\hline 0.212 & 0.86 \\
\hline 0.150 & 0.83 \\
\hline 0.106 & 0.77 \\
\hline 0.075 & 0.70 \\
\hline
\end{tabular}

Omni Feed-A

\begin{tabular}{|l|l|}
\hline size $(\mathrm{mm})$ & Cum \% Passing \\
\hline
\end{tabular}

\begin{tabular}{|r|r|}
\hline 212.0 & 100.00 \\
\hline 175.0 & 100.00 \\
\hline 150.0 & 100.00 \\
\hline 125.0 & 100.00 \\
\hline 105.0 & 100.00 \\
\hline 90.0 & 100.00 \\
\hline 75.0 & 94.00 \\
\hline 63.5 & 83.27 \\
\hline 50.8 & 61.53 \\
\hline 38.1 & 45.03 \\
\hline 25.4 & 20.20 \\
\hline 19.1 & 7.18 \\
\hline 12.7 & 3.10 \\
\hline 9.5 & 2.43 \\
\hline 6.4 & 1.89 \\
\hline 4.75 & 1.64 \\
\hline 3.35 & 1.43 \\
\hline 2.36 & 1.26 \\
\hline 1.70 & 1.14 \\
\hline 1.18 & 1.03 \\
\hline 0.850 & 0.96 \\
\hline 0.600 & 0.89 \\
\hline 0.425 & 0.83 \\
\hline 0.300 & 0.77 \\
\hline 0.212 & 0.71 \\
\hline 0.150 & 0.65 \\
\hline 0.106 & 0.58 \\
\hline 0.075 & 0.52 \\
\hline &
\end{tabular}

CV 14-A

\begin{tabular}{|l|l|}
\hline Size $(\mathrm{mm})$ & Cum \% Passing \\
\hline
\end{tabular}

\begin{tabular}{|r|r|}
\hline 212.0 & 100.00 \\
\hline 175.0 & 100.00 \\
\hline 150.0 & 100.00 \\
\hline 125.0 & 100.00 \\
\hline 105.0 & 100.00 \\
\hline 90.0 & 100.00 \\
\hline 75.0 & 100.00 \\
\hline 63.5 & 100.00 \\
\hline 50.8 & 100.00 \\
\hline 38.1 & 100.00 \\
\hline 25.4 & 100.00 \\
\hline 19.1 & 89.80 \\
\hline 12.7 & 29.28 \\
\hline 9.5 & 8.01 \\
\hline 6.4 & 2.06 \\
\hline 4.75 & 1.27 \\
\hline 3.35 & 1.09 \\
\hline 2.36 & 1.02 \\
\hline 1.70 & 0.99 \\
\hline 1.18 & 0.96 \\
\hline 0.850 & 0.94 \\
\hline 0.600 & 0.92 \\
\hline 0.425 & 0.90 \\
\hline 0.300 & 0.88 \\
\hline 0.212 & 0.86 \\
\hline 0.150 & 0.83 \\
\hline 0.106 & 0.78 \\
\hline 0.075 & 0.72 \\
\hline
\end{tabular}

CV 15-A

\begin{tabular}{|r|r|}
\hline size $(\mathrm{mm})$ & Cum \% Passing \\
\hline 212.0 & 100.00 \\
\hline 175.0 & 100.00 \\
\hline 150.0 & 100.00 \\
\hline 125.0 & 100.00 \\
\hline 105.0 & 100.00 \\
\hline 90.0 & 100.00 \\
\hline 75.0 & 100.00 \\
\hline 63.5 & 100.00 \\
\hline 50.8 & 100.00 \\
\hline 38.1 & 100.00 \\
\hline 25.4 & 100.00 \\
\hline 19.1 & 100.00 \\
\hline 12.7 & 99.32 \\
\hline 9.5 & 81.75 \\
\hline 6.4 & 33.37 \\
\hline 4.75 & 10.53 \\
\hline 3.35 & 3.30 \\
\hline 2.36 & 2.03 \\
\hline 1.70 & 1.83 \\
\hline 1.18 & 1.73 \\
\hline 0.850 & 1.66 \\
\hline 0.600 & 1.61 \\
\hline 0.425 & 1.57 \\
\hline 0.300 & 1.53 \\
\hline 0.212 & 1.48 \\
\hline 0.150 & 1.42 \\
\hline 0.106 & 1.35 \\
\hline 0.075 & 1.24 \\
\hline
\end{tabular}

CV 16-A

\begin{tabular}{|r|r|}
\hline size $(\mathrm{mm})$ & Cum \% Passing \\
\hline 212.0 & 100.00 \\
\hline 175.0 & 100.00 \\
\hline 150.0 & 100.00 \\
\hline 125.0 & 100.00 \\
\hline 105.0 & 100.00 \\
\hline 90.0 & 100.00 \\
\hline 75.0 & 100.00 \\
\hline 63.5 & 100.00 \\
\hline 50.8 & 100.00 \\
\hline 38.1 & 100.00 \\
\hline 25.4 & 100.00 \\
\hline 19.1 & 100.00 \\
\hline 12.7 & 100.00 \\
\hline 9.5 & 100.00 \\
\hline 6.4 & 99.89 \\
\hline 4.75 & 94.70 \\
\hline 3.35 & 79.39 \\
\hline 2.36 & 63.50 \\
\hline 1.70 & 51.95 \\
\hline 1.18 & 42.61 \\
\hline 0.850 & 35.84 \\
\hline 0.600 & 30.79 \\
\hline 0.425 & 26.21 \\
\hline 0.300 & 22.74 \\
\hline 0.212 & 19.31 \\
\hline 0.150 & 16.16 \\
\hline 0.106 & 13.43 \\
\hline 0.075 & 11.14 \\
\hline
\end{tabular}

Symons Feed-A

\begin{tabular}{|c|c|}
\hline size $(\mathrm{mm})$ & Cum \% Passing \\
\hline 212.0 & 100.00 \\
\hline 175.0 & 100.00 \\
\hline 150.0 & 100.00 \\
\hline 125.0 & 100.00 \\
\hline 105.0 & 100.00 \\
\hline 90.0 & 100.00 \\
\hline 75.0 & 100.00 \\
\hline 63.5 & 100.00 \\
\hline 50.8 & 98.92 \\
\hline 38.1 & 95.37 \\
\hline 25.4 & 69.51 \\
\hline 19.1 & 21.62 \\
\hline 12.7 & 2.78 \\
\hline 9.5 & 2.04 \\
\hline 6.4 & 1.35 \\
\hline 4.75 & 1.11 \\
\hline 3.35 & 0.99 \\
\hline 2.36 & 0.89 \\
\hline 1.70 & 0.82 \\
\hline 1.18 & 0.76 \\
\hline 0.850 & 0.73 \\
\hline 0.600 & 0.70 \\
\hline 0.425 & 0.67 \\
\hline 0.300 & 0.65 \\
\hline 0.212 & 0.63 \\
\hline 0.150 & 0.60 \\
\hline 0.106 & 0.56 \\
\hline 0.075 & 0.50 \\
\hline
\end{tabular}


Tertiary Section - LS Shot (Omni Only)
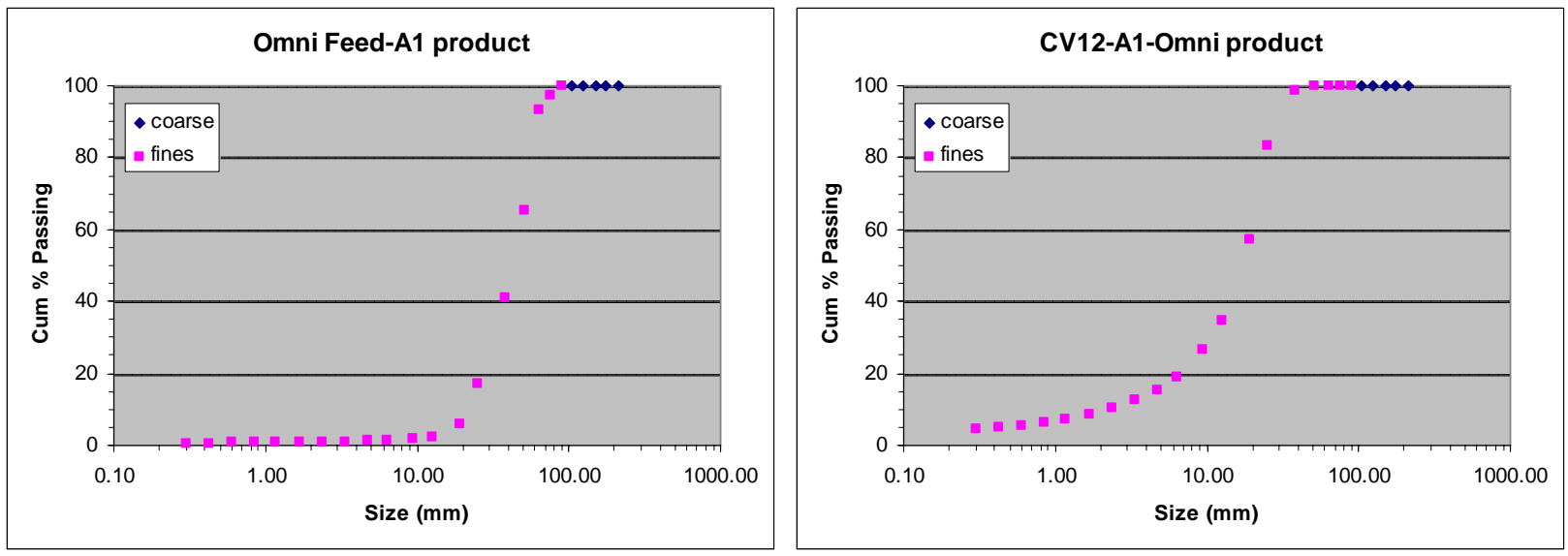

Omni Feed
\begin{tabular}{|r|r|}
\hline size $(\mathrm{mm})$ & Cum \% Passing \\
\hline 212.0 & 100.00 \\
\hline 175.0 & 100.00 \\
\hline 150.0 & 100.00 \\
\hline 125.0 & 100.00 \\
\hline 105.0 & 100.00 \\
\hline 90.0 & 100.00 \\
\hline 75.0 & 97.51 \\
\hline 63.5 & 93.38 \\
\hline 50.8 & 65.52 \\
\hline 38.1 & 40.93 \\
\hline 25.4 & 16.90 \\
\hline 19.1 & 5.64 \\
\hline 12.7 & 2.30 \\
\hline 9.5 & 1.70 \\
\hline 6.4 & 1.33 \\
\hline 4.75 & 1.18 \\
\hline 3.35 & 1.05 \\
\hline 2.36 & 0.93 \\
\hline 1.70 & 0.85 \\
\hline 1.18 & 0.78 \\
\hline 0.850 & 0.73 \\
\hline 0.600 & 0.68 \\
\hline 0.425 & 0.64 \\
\hline 0.300 & 0.60 \\
\hline 0.212 & 0.55 \\
\hline 0.150 & 0.50 \\
\hline 0.106 & 0.45 \\
\hline 0.075 & 0.39 \\
\hline & \\
\hline
\end{tabular}

Omni Product

\begin{tabular}{|r|r|}
\hline size $(\mathrm{mm})$ & Cum \% Passing \\
\hline 212.0 & 100.00 \\
\hline 175.0 & 100.00 \\
\hline 150.0 & 100.00 \\
\hline 125.0 & 100.00 \\
\hline 105.0 & 100.00 \\
\hline 90.0 & 100.00 \\
\hline 75.0 & 100.00 \\
\hline 63.5 & 100.00 \\
\hline 50.8 & 99.90 \\
\hline 38.1 & 98.85 \\
\hline 25.4 & 83.52 \\
\hline 19.1 & 57.20 \\
\hline 12.7 & 34.65 \\
\hline 9.5 & 26.53 \\
\hline 6.4 & 18.99 \\
\hline 4.75 & 15.40 \\
\hline 3.35 & 12.51 \\
\hline 2.36 & 10.20 \\
\hline 1.70 & 8.57 \\
\hline 1.18 & 7.23 \\
\hline 0.850 & 6.26 \\
\hline 0.600 & 5.49 \\
\hline 0.425 & 4.81 \\
\hline 0.300 & 4.29 \\
\hline 0.212 & 3.76 \\
\hline 0.150 & 3.25 \\
\hline 0.106 & 2.77 \\
\hline 0.075 & 2.35 \\
\hline & \\
\hline
\end{tabular}


Tertiary Section - LS Shot (Symons Only)
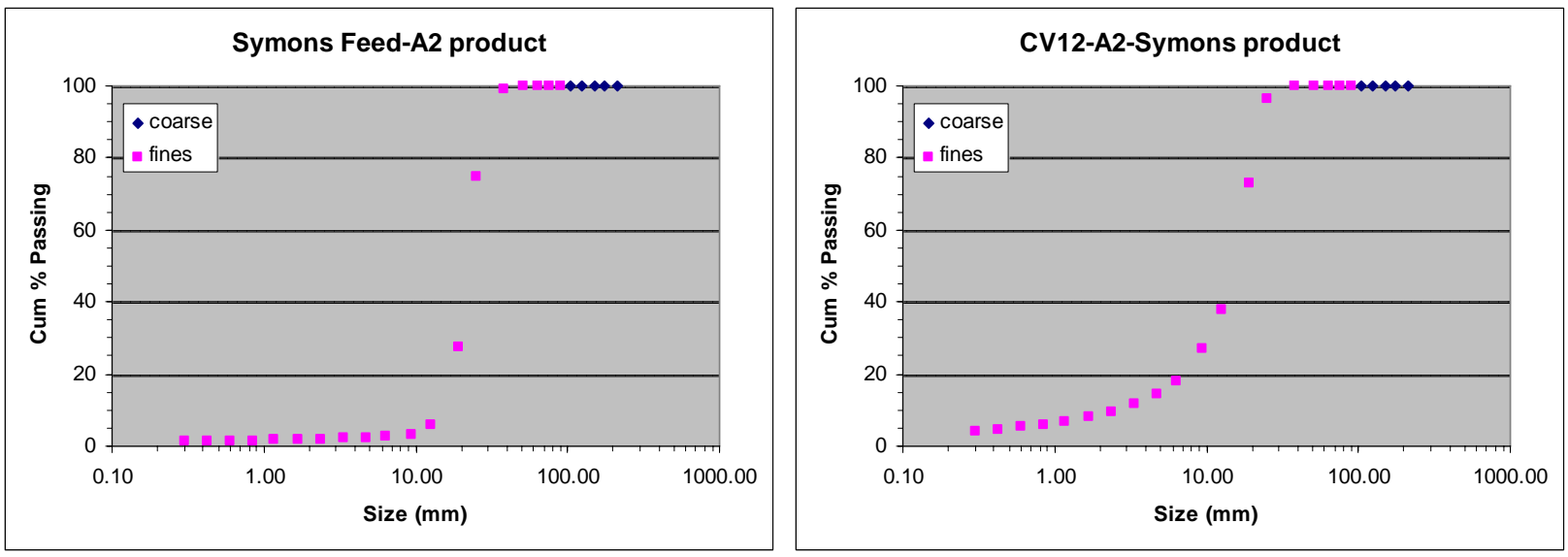

Symons Feed

\begin{tabular}{|r|r|}
\hline Size $(\mathrm{mm})$ & Cum \% Passing \\
\hline 212.0 & 100.00 \\
\hline 175.0 & 100.00 \\
\hline 150.0 & 100.00 \\
\hline 125.0 & 100.00 \\
\hline 105.0 & 100.00 \\
\hline 90.0 & 100.00 \\
\hline 75.0 & 100.00 \\
\hline 63.5 & 100.00 \\
\hline 50.8 & 100.00 \\
\hline 38.1 & 99.32 \\
\hline 25.4 & 74.74 \\
\hline 19.1 & 27.63 \\
\hline 12.7 & 5.66 \\
\hline 9.5 & 3.36 \\
\hline 6.4 & 2.53 \\
\hline 4.75 & 2.26 \\
\hline 3.35 & 2.04 \\
\hline 2.36 & 1.86 \\
\hline 1.70 & 1.72 \\
\hline 1.18 & 1.62 \\
\hline 0.850 & 1.56 \\
\hline 0.600 & 1.51 \\
\hline 0.425 & 1.46 \\
\hline 0.300 & 1.41 \\
\hline 0.212 & 1.34 \\
\hline 0.150 & 1.23 \\
\hline 0.106 & 1.11 \\
\hline 0.075 & 0.96 \\
\hline & \\
\hline
\end{tabular}

Symons Product

\begin{tabular}{|r|r|}
\hline size $(\mathrm{mm})$ & Cum \% Passing \\
\hline 212.0 & 100.00 \\
\hline 175.0 & 100.00 \\
\hline 150.0 & 100.00 \\
\hline 125.0 & 100.00 \\
\hline 105.0 & 100.00 \\
\hline 90.0 & 100.00 \\
\hline 75.0 & 100.00 \\
\hline 63.5 & 100.00 \\
\hline 50.8 & 100.00 \\
\hline 38.1 & 99.79 \\
\hline 25.4 & 96.52 \\
\hline 19.1 & 73.19 \\
\hline 12.7 & 37.86 \\
\hline 9.5 & 26.95 \\
\hline 6.4 & 18.20 \\
\hline 4.75 & 14.34 \\
\hline 3.35 & 11.55 \\
\hline 2.36 & 9.39 \\
\hline 1.70 & 7.92 \\
\hline 1.18 & 6.74 \\
\hline 0.850 & 5.93 \\
\hline 0.600 & 5.29 \\
\hline 0.425 & 4.72 \\
\hline 0.300 & 4.27 \\
\hline 0.212 & 3.81 \\
\hline 0.150 & 3.33 \\
\hline 0.106 & 2.87 \\
\hline 0.075 & 2.43 \\
\hline & \\
\hline
\end{tabular}




\section{Tertiary Section - MTM Shot}
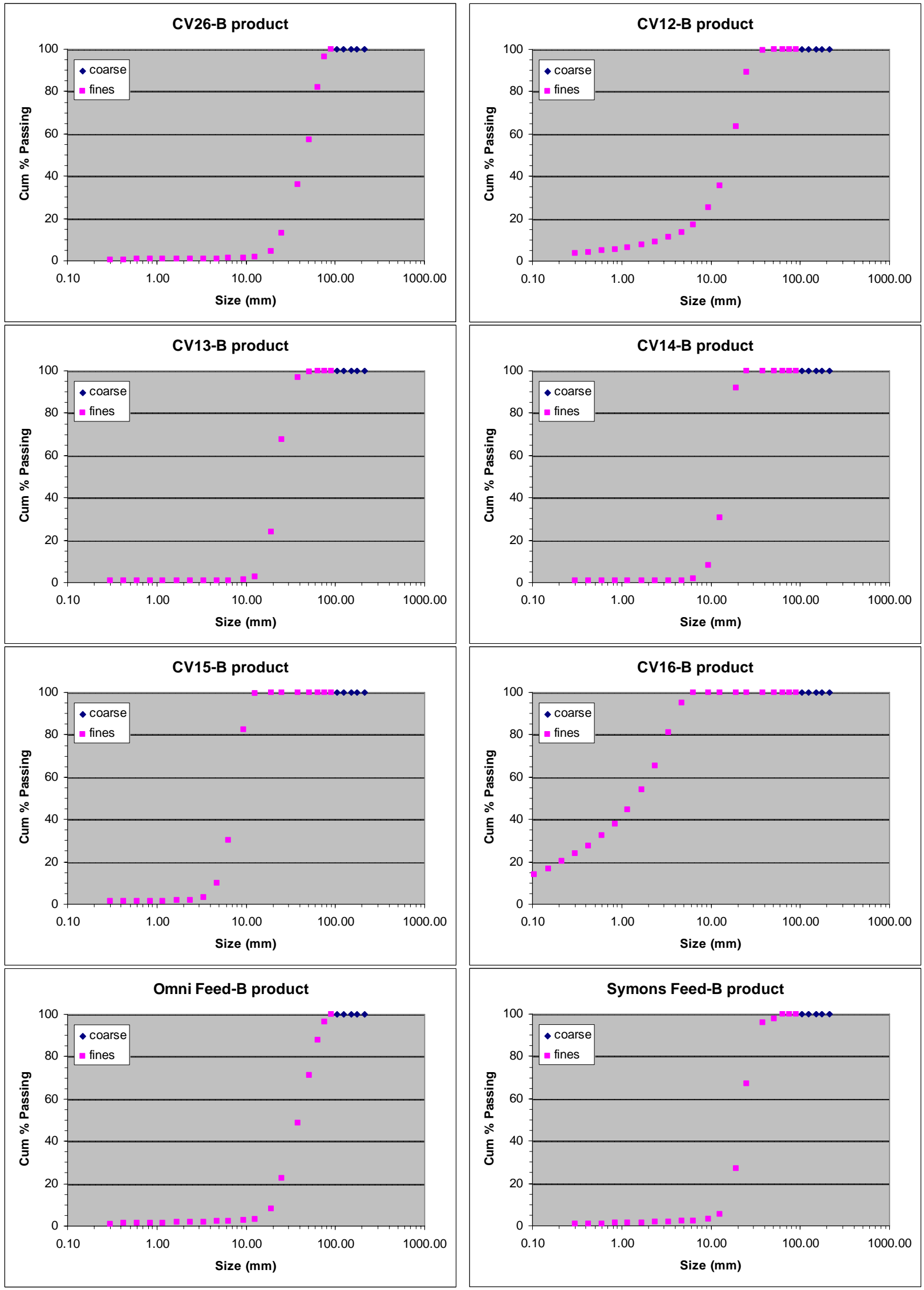
CV 26-B

\begin{tabular}{|r|r|}
\hline size $(\mathrm{mm})$ & Cum \% Passing \\
\hline 212.0 & 100.00 \\
\hline 175.0 & 100.00 \\
\hline 150.0 & 100.00 \\
\hline 125.0 & 100.00 \\
\hline 105.0 & 100.00 \\
\hline 90.0 & 100.00 \\
\hline 75.0 & 96.60 \\
\hline 63.5 & 82.01 \\
\hline 50.8 & 57.15 \\
\hline 38.1 & 35.91 \\
\hline 25.4 & 12.95 \\
\hline 19.1 & 4.47 \\
\hline 12.7 & 1.86 \\
\hline 9.5 & 1.48 \\
\hline 6.4 & 1.16 \\
\hline 4.75 & 1.05 \\
\hline 3.35 & 0.96 \\
\hline 2.36 & 0.89 \\
\hline 1.70 & 0.84 \\
\hline 1.18 & 0.79 \\
\hline 0.850 & 0.75 \\
\hline 0.600 & 0.71 \\
\hline 0.425 & 0.67 \\
\hline 0.300 & 0.63 \\
\hline 0.212 & 0.59 \\
\hline 0.150 & 0.54 \\
\hline 0.106 & 0.48 \\
\hline 0.075 & 0.41 \\
\hline & \\
\hline
\end{tabular}

CV 15-B

\begin{tabular}{|r|r|}
\hline size $(\mathrm{mm})$ & Cum \% Passing \\
\hline 212.0 & 100.00 \\
\hline 175.0 & 100.00 \\
\hline 150.0 & 100.00 \\
\hline 125.0 & 100.00 \\
\hline 105.0 & 100.00 \\
\hline 90.0 & 100.00 \\
\hline 75.0 & 100.00 \\
\hline 63.5 & 100.00 \\
\hline 50.8 & 100.00 \\
\hline 38.1 & 100.00 \\
\hline 25.4 & 100.00 \\
\hline 19.1 & 100.00 \\
\hline 12.7 & 99.47 \\
\hline 9.5 & 82.42 \\
\hline 6.4 & 30.11 \\
\hline 4.75 & 9.75 \\
\hline 3.35 & 3.04 \\
\hline 2.36 & 1.82 \\
\hline 1.70 & 1.62 \\
\hline 1.18 & 1.51 \\
\hline 0.850 & 1.45 \\
\hline 0.600 & 1.40 \\
\hline 0.425 & 1.36 \\
\hline 0.300 & 1.32 \\
\hline 0.212 & 1.28 \\
\hline 0.150 & 1.23 \\
\hline 0.106 & 1.17 \\
\hline 0.075 & 1.09 \\
\hline & \\
\hline
\end{tabular}

CV 12-B

\begin{tabular}{|l|l|}
\hline size $(\mathrm{mm})$ & Cum \% Passing \\
\hline
\end{tabular}

\begin{tabular}{|r|r|}
\hline 212.0 & 100.00 \\
\hline 175.0 & 100.00 \\
\hline 150.0 & 100.00 \\
\hline 125.0 & 100.00 \\
\hline 105.0 & 100.00 \\
\hline 90.0 & 100.00 \\
\hline 75.0 & 100.00 \\
\hline 63.5 & 100.00 \\
\hline 50.8 & 99.90 \\
\hline 38.1 & 99.51 \\
\hline 25.4 & 88.98 \\
\hline 19.1 & 63.63 \\
\hline 12.7 & 35.64 \\
\hline 9.5 & 25.13 \\
\hline 6.4 & 16.99 \\
\hline 4.75 & 13.66 \\
\hline 3.35 & 11.19 \\
\hline 2.36 & 9.03 \\
\hline 1.70 & 7.54 \\
\hline 1.18 & 6.30 \\
\hline 0.850 & 5.44 \\
\hline 0.600 & 4.76 \\
\hline 0.425 & 4.17 \\
\hline 0.300 & 3.71 \\
\hline 0.212 & 3.25 \\
\hline 0.150 & 2.81 \\
\hline 0.106 & 2.40 \\
\hline 0.075 & 2.03 \\
\hline & \\
\hline
\end{tabular}

\section{16-B}

\begin{tabular}{|l|l|}
\hline size $(\mathrm{mm})$ & Cum \% Passing \\
\hline
\end{tabular}

\begin{tabular}{|r|r|}
\hline 212.0 & 100.00 \\
\hline 175.0 & 100.00 \\
\hline 150.0 & 100.00 \\
\hline 125.0 & 100.00 \\
\hline 105.0 & 100.00 \\
\hline 90.0 & 100.00 \\
\hline 75.0 & 100.00 \\
\hline 63.5 & 100.00 \\
\hline 50.8 & 100.00 \\
\hline 38.1 & 100.00 \\
\hline 25.4 & 100.00 \\
\hline 19.1 & 100.00 \\
\hline 12.7 & 100.00 \\
\hline 9.5 & 100.00 \\
\hline 6.4 & 99.87 \\
\hline 4.75 & 95.17 \\
\hline 3.35 & 81.15 \\
\hline 2.36 & 65.38 \\
\hline 1.70 & 53.95 \\
\hline 1.18 & 44.51 \\
\hline 0.850 & 37.78 \\
\hline 0.600 & 32.41 \\
\hline 0.425 & 27.59 \\
\hline 0.300 & 23.90 \\
\hline 0.212 & 20.27 \\
\hline 0.150 & 16.87 \\
\hline 0.106 & 13.91 \\
\hline 0.075 & 11.40 \\
\hline & \\
\hline
\end{tabular}

CV 13-B

\begin{tabular}{|l|l|}
\hline size $(\mathrm{mm})$ & Cum \% Passing \\
\hline
\end{tabular}

\begin{tabular}{|r|r|}
\hline 212.0 & 100.00 \\
\hline 175.0 & 100.00 \\
\hline 150.0 & 100.00 \\
\hline 125.0 & 100.00 \\
\hline 105.0 & 100.00 \\
\hline 90.0 & 100.00 \\
\hline 75.0 & 100.00 \\
\hline 63.5 & 100.00 \\
\hline 50.8 & 99.77 \\
\hline 38.1 & 96.99 \\
\hline 25.4 & 67.58 \\
\hline 19.1 & 23.94 \\
\hline 12.7 & 2.69 \\
\hline 9.5 & 1.28 \\
\hline 6.4 & 0.98 \\
\hline 4.75 & 0.92 \\
\hline 3.35 & 0.88 \\
\hline 2.36 & 0.85 \\
\hline 1.70 & 0.83 \\
\hline 1.18 & 0.81 \\
\hline 0.850 & 0.79 \\
\hline 0.600 & 0.78 \\
\hline 0.425 & 0.76 \\
\hline 0.300 & 0.75 \\
\hline 0.212 & 0.73 \\
\hline 0.150 & 0.70 \\
\hline 0.106 & 0.66 \\
\hline 0.075 & 0.60 \\
\hline & \\
\hline
\end{tabular}

Omni Feed-B

\begin{tabular}{|l|l|}
\hline size (mm) & Cum \% Passing \\
\hline
\end{tabular} \begin{tabular}{|r|r|}
\hline 212.0 & 100.00 \\
\hline 175.0
\end{tabular} \begin{tabular}{|r|r|}
\hline 175.0 & 100.00 \\
\hline 150.0 & 100.00 \\
\hline
\end{tabular} \begin{tabular}{|r|r|}
\hline 150.0 & 100.00 \\
\hline 125.0 & 100.00 \\
\hline
\end{tabular} \begin{tabular}{|r|r|}
\hline 125.0 & 100.00 \\
\hline 105.0 & 100.00 \\
\hline 90.0 & 100.00 \\
\hline
\end{tabular} \begin{tabular}{|r|r|}
\hline 90.0 & 100.00 \\
\hline 75.0 & 96.61 \\
\hline 63.5 & 87.89 \\
\hline
\end{tabular} \begin{tabular}{|r|r|}
\hline 63.5 & 87.89 \\
\hline 50.8 & 71.25 \\
\hline 38.1 & 48.65 \\
\hline
\end{tabular} \begin{tabular}{|r|r|}
\hline 50.8 & 71.25 \\
\hline 38.1 & 48.65 \\
\hline 25.4 & 22.60 \\
\hline 19.1 & 7.95 \\
\hline
\end{tabular} \begin{tabular}{|r|r|}
\hline 19.1 & 22.60 \\
\hline 12.7 & 3.31 \\
\hline 9.5 & 2.75 \\
\hline
\end{tabular} \begin{tabular}{|r|r|}
\hline 12.7 & 3.31 \\
\hline 9.5 & 2.75 \\
\hline 6.4 & 2.32 \\
\hline
\end{tabular} \begin{tabular}{|r|r|}
\hline 6.4 & 2.32 \\
\hline 4.75 & 2.10 \\
\hline 3.35 & 1.92 \\
\hline
\end{tabular} \begin{tabular}{|r|r|}
\hline 4.75 & 2.10 \\
\hline 3.35 & 1.92 \\
\hline 2.36 & 1.73 \\
\hline
\end{tabular} \begin{tabular}{|r|r|}
\hline 2.36 & 1.73 \\
\hline 1.70 & 1.59 \\
\hline 1.18 & 1.45 \\
\hline
\end{tabular}

\begin{tabular}{|r|r|}
\hline 1.18 & 1.59 \\
\hline 0.850 & 1.45 \\
\hline
\end{tabular}

\begin{tabular}{|r|r|}
\hline 0.850 & 1.33 \\
\hline 0.600 & 1.24 \\
\hline
\end{tabular}

\begin{tabular}{|r|r|}
\hline 0.600 & 1.24 \\
\hline 0.425 & 1.14 \\
\hline
\end{tabular}

\begin{tabular}{|l|l|}
\hline 0.425 & 1.24 \\
\hline 0.300 & 1.14 \\
\hline 0.212 & 05 \\
\hline
\end{tabular}

\begin{tabular}{|l|r|}
\hline 0.300 & 1.05 \\
\hline 0.212 & 0.96 \\
\hline 0.150 & 0.85 \\
\hline
\end{tabular}

\begin{tabular}{|r|r|}
\hline 0.150 & 0.85 \\
\hline 0.106 & 0.75 \\
\hline 0.075 & 0.65 \\
\hline
\end{tabular}

CV 14-B

\begin{tabular}{|l|l|}
\hline size $(\mathrm{mm})$ & Cum \% Passing \\
\hline
\end{tabular}

\begin{tabular}{|r|r|}
\hline 212.0 & 100.00 \\
\hline 175.0 & 100.00 \\
\hline 150.0 & 100.00 \\
\hline 125.0 & 100.00 \\
\hline 105.0 & 100.00 \\
\hline 90.0 & 100.00 \\
\hline 75.0 & 100.00 \\
\hline 63.5 & 100.00 \\
\hline 50.8 & 100.00 \\
\hline 38.1 & 100.00 \\
\hline 25.4 & 100.00 \\
\hline 19.1 & 91.86 \\
\hline 12.7 & 30.53 \\
\hline 9.5 & 8.30 \\
\hline 6.4 & 1.97 \\
\hline 4.75 & 1.10 \\
\hline 3.35 & 0.89 \\
\hline 2.36 & 0.82 \\
\hline 1.70 & 0.78 \\
\hline 1.18 & 0.75 \\
\hline 0.850 & 0.73 \\
\hline 0.600 & 0.71 \\
\hline 0.425 & 0.70 \\
\hline 0.300 & 0.68 \\
\hline 0.212 & 0.66 \\
\hline 0.150 & 0.64 \\
\hline 0.106 & 0.61 \\
\hline 0.075 & 0.57 \\
\hline & \\
\hline
\end{tabular}

Symons Feed-B

\begin{tabular}{|l|l|}
\hline size $(\mathrm{mm})$ & Cum \% Passing \\
\hline
\end{tabular}

\begin{tabular}{|r|r|}
\hline 212.0 & 100.00 \\
\hline 175.0 & 100.00 \\
\hline 150.0 & 100.00 \\
\hline 125.0 & 100.00 \\
\hline 105.0 & 100.00 \\
\hline 90.0 & 100.00 \\
\hline 75.0 & 100.00 \\
\hline 63.5 & 100.00 \\
\hline 50.8 & 97.89 \\
\hline 38.1 & 96.09 \\
\hline 25.4 & 67.19 \\
\hline 19.1 & 27.09 \\
\hline 12.7 & 5.22 \\
\hline 9.5 & 3.34 \\
\hline 6.4 & 2.46 \\
\hline 4.75 & 2.12 \\
\hline 3.35 & 1.85 \\
\hline 2.36 & 1.60 \\
\hline 1.70 & 1.42 \\
\hline 1.18 & 1.26 \\
\hline 0.850 & 1.15 \\
\hline 0.600 & 1.07 \\
\hline 0.425 & 1.01 \\
\hline 0.300 & 0.97 \\
\hline 0.212 & 0.92 \\
\hline 0.150 & 0.88 \\
\hline 0.106 & 0.82 \\
\hline 0.075 & 0.75 \\
\hline & \\
\hline
\end{tabular}


Tertiary Section - MTM Shot (Omni Only)
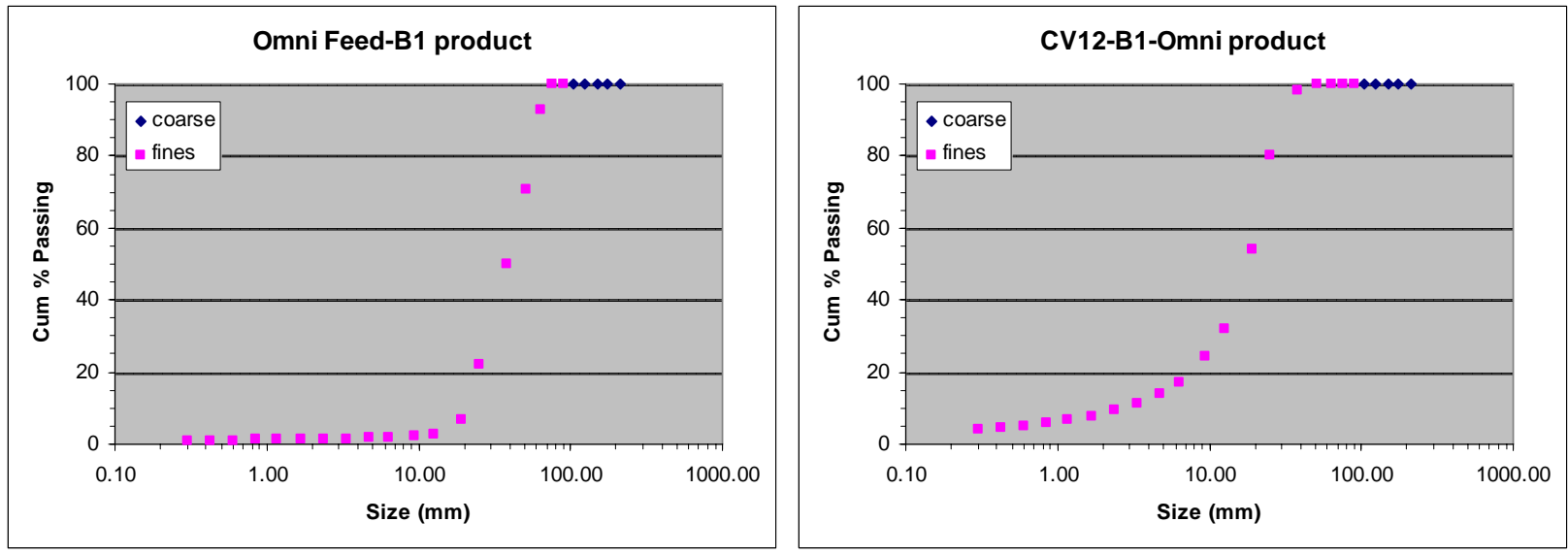

Omni Feed
\begin{tabular}{|r|r|}
\hline size $(\mathrm{mm})$ & Cum \% Passing \\
\hline 212.0 & 100.00 \\
\hline 175.0 & 100.00 \\
\hline 150.0 & 100.00 \\
\hline 125.0 & 100.00 \\
\hline 105.0 & 100.00 \\
\hline 90.0 & 100.00 \\
\hline 75.0 & 100.00 \\
\hline 63.5 & 92.97 \\
\hline 50.8 & 70.70 \\
\hline 38.1 & 50.05 \\
\hline 25.4 & 21.92 \\
\hline 19.1 & 6.94 \\
\hline 12.7 & 2.93 \\
\hline 9.5 & 2.25 \\
\hline 6.4 & 1.83 \\
\hline 4.75 & 1.65 \\
\hline 3.35 & 1.52 \\
\hline 2.36 & 1.41 \\
\hline 1.70 & 1.33 \\
\hline 1.18 & 1.25 \\
\hline 0.850 & 1.17 \\
\hline 0.600 & 1.11 \\
\hline 0.425 & 1.03 \\
\hline 0.300 & 0.97 \\
\hline 0.212 & 0.89 \\
\hline 0.150 & 0.80 \\
\hline 0.106 & 0.71 \\
\hline 0.075 & 0.61 \\
\hline & \\
\hline
\end{tabular}

Omni Product

\begin{tabular}{|r|r|}
\hline size (mm) & Cum \% Passing \\
\hline 212.0 & 100.00 \\
\hline 175.0 & 100.00 \\
\hline 150.0 & 100.00 \\
\hline 125.0 & 100.00 \\
\hline 105.0 & 100.00 \\
\hline 90.0 & 100.00 \\
\hline 75.0 & 100.00 \\
\hline 63.5 & 100.00 \\
\hline 50.8 & 100.00 \\
\hline 38.1 & 98.29 \\
\hline 25.4 & 80.05 \\
\hline 19.1 & 53.97 \\
\hline 12.7 & 32.16 \\
\hline 9.5 & 24.36 \\
\hline 6.4 & 17.20 \\
\hline 4.75 & 13.92 \\
\hline 3.35 & 11.42 \\
\hline 2.36 & 9.33 \\
\hline 1.70 & 7.83 \\
\hline 1.18 & 6.57 \\
\hline 0.850 & 5.68 \\
\hline 0.600 & 4.98 \\
\hline 0.425 & 4.36 \\
\hline 0.300 & 3.87 \\
\hline 0.212 & 3.38 \\
\hline 0.150 & 2.91 \\
\hline 0.106 & 2.47 \\
\hline 0.075 & 2.07 \\
\hline & \\
\hline
\end{tabular}


Tertiary Section - MTM Shot (Symons Only)
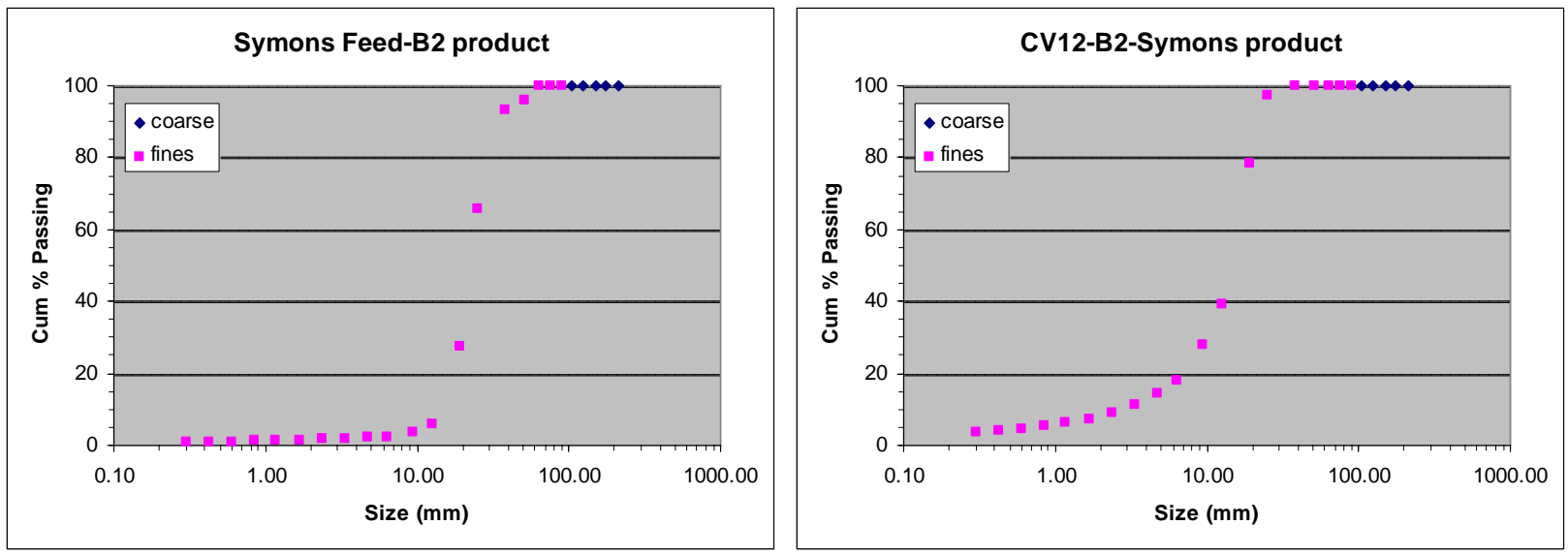

Symons Feed

\begin{tabular}{|r|r|}
\hline size $(\mathrm{mm})$ & Cum \% Passing \\
\hline 212.0 & 100.00 \\
\hline 175.0 & 100.00 \\
\hline 150.0 & 100.00 \\
\hline 125.0 & 100.00 \\
\hline 105.0 & 100.00 \\
\hline 90.0 & 100.00 \\
\hline 75.0 & 100.00 \\
\hline 63.5 & 100.00 \\
\hline 50.8 & 96.05 \\
\hline 38.1 & 93.26 \\
\hline 25.4 & 65.74 \\
\hline 19.1 & 27.47 \\
\hline 12.7 & 5.87 \\
\hline 9.5 & 3.53 \\
\hline 6.4 & 2.45 \\
\hline 4.75 & 2.11 \\
\hline 3.35 & 1.83 \\
\hline 2.36 & 1.62 \\
\hline 1.70 & 1.45 \\
\hline 1.18 & 1.30 \\
\hline 0.850 & 1.20 \\
\hline 0.600 & 1.12 \\
\hline 0.425 & 1.06 \\
\hline 0.300 & 1.01 \\
\hline 0.212 & 0.97 \\
\hline 0.150 & 0.91 \\
\hline 0.106 & 0.85 \\
\hline 0.075 & 0.77 \\
\hline & \\
\hline
\end{tabular}

Symons Product

\begin{tabular}{|r|r|}
\hline size $(\mathrm{mm})$ & Cum \% Passing \\
\hline 212.0 & 100.00 \\
\hline 175.0 & 100.00 \\
\hline 150.0 & 100.00 \\
\hline 125.0 & 100.00 \\
\hline 105.0 & 100.00 \\
\hline 90.0 & 100.00 \\
\hline 75.0 & 100.00 \\
\hline 63.5 & 100.00 \\
\hline 50.8 & 100.00 \\
\hline 38.1 & 100.00 \\
\hline 25.4 & 97.37 \\
\hline 19.1 & 78.18 \\
\hline 12.7 & 39.11 \\
\hline 9.5 & 27.77 \\
\hline 6.4 & 18.21 \\
\hline 4.75 & 14.30 \\
\hline 3.35 & 11.42 \\
\hline 2.36 & 8.98 \\
\hline 1.70 & 7.39 \\
\hline 1.18 & 6.12 \\
\hline 0.850 & 5.23 \\
\hline 0.600 & 4.53 \\
\hline 0.425 & 3.91 \\
\hline 0.300 & 3.44 \\
\hline 0.212 & 2.97 \\
\hline 0.150 & 2.53 \\
\hline 0.106 & 2.13 \\
\hline 0.075 & 1.77 \\
\hline & \\
\hline
\end{tabular}


Tertiary Section - MTM Shot (Omni Only - After Reline)
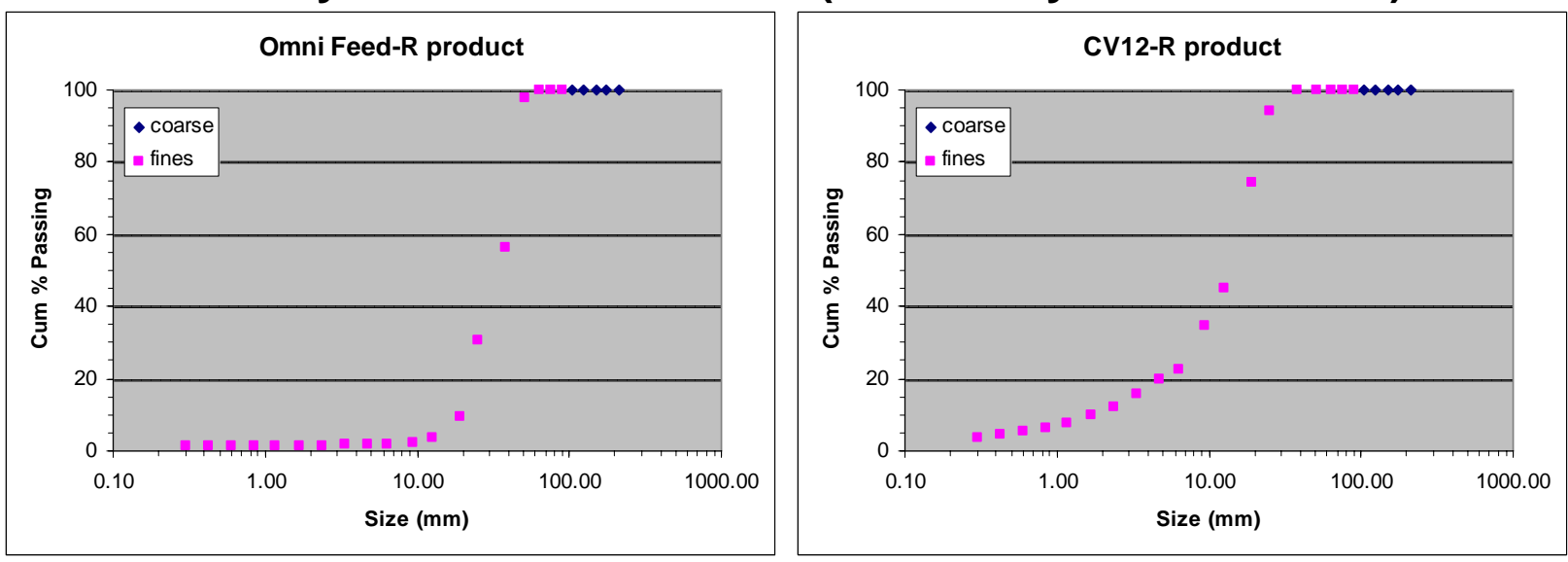

Omni Feed
\begin{tabular}{|r|r|}
\hline size $(\mathrm{mm})$ & Cum \% Passing \\
\hline 212.0 & 100.00 \\
\hline 175.0 & 100.00 \\
\hline 150.0 & 100.00 \\
\hline 125.0 & 100.00 \\
\hline 105.0 & 100.00 \\
\hline 90.0 & 100.00 \\
\hline 75.0 & 100.00 \\
\hline 63.5 & 100.00 \\
\hline 50.8 & 97.81 \\
\hline 38.1 & 56.51 \\
\hline 25.4 & 30.62 \\
\hline 19.1 & 9.25 \\
\hline 12.7 & 3.47 \\
\hline 9.5 & 2.14 \\
\hline 6.4 & 1.96 \\
\hline 4.75 & 1.67 \\
\hline 3.35 & 1.59 \\
\hline 2.36 & 1.52 \\
\hline 1.70 & 1.47 \\
\hline 1.18 & 1.41 \\
\hline 0.850 & 1.37 \\
\hline 0.600 & 1.31 \\
\hline 0.425 & 1.26 \\
\hline 0.300 & 1.19 \\
\hline 0.212 & 1.12 \\
\hline 0.150 & 1.02 \\
\hline 0.106 & 0.92 \\
\hline 0.075 & 0.80 \\
\hline
\end{tabular}

Omni Product

\begin{tabular}{|r|r|}
\hline size (mm) & Cum \% Passing \\
\hline 212.0 & 100.00 \\
\hline 175.0 & 100.00 \\
\hline 150.0 & 100.00 \\
\hline 125.0 & 100.00 \\
\hline 105.0 & 100.00 \\
\hline 90.0 & 100.00 \\
\hline 75.0 & 100.00 \\
\hline 63.5 & 100.00 \\
\hline 50.8 & 100.00 \\
\hline 38.1 & 100.00 \\
\hline 25.4 & 94.14 \\
\hline 19.1 & 74.17 \\
\hline 12.7 & 45.23 \\
\hline 9.5 & 34.82 \\
\hline 6.4 & 22.70 \\
\hline 4.75 & 19.86 \\
\hline 3.35 & 15.88 \\
\hline 2.36 & 12.23 \\
\hline 1.70 & 9.94 \\
\hline 1.18 & 7.84 \\
\hline 0.850 & 6.49 \\
\hline 0.600 & 5.30 \\
\hline 0.425 & 4.51 \\
\hline 0.300 & 3.75 \\
\hline 0.212 & 3.20 \\
\hline 0.150 & 2.64 \\
\hline 0.106 & 2.22 \\
\hline 0.075 & 1.80 \\
\hline & \\
\hline
\end{tabular}




\section{Pittsboro August 2005 Audit Sizing Results \\ Primary Section - Luck Stone Audit}

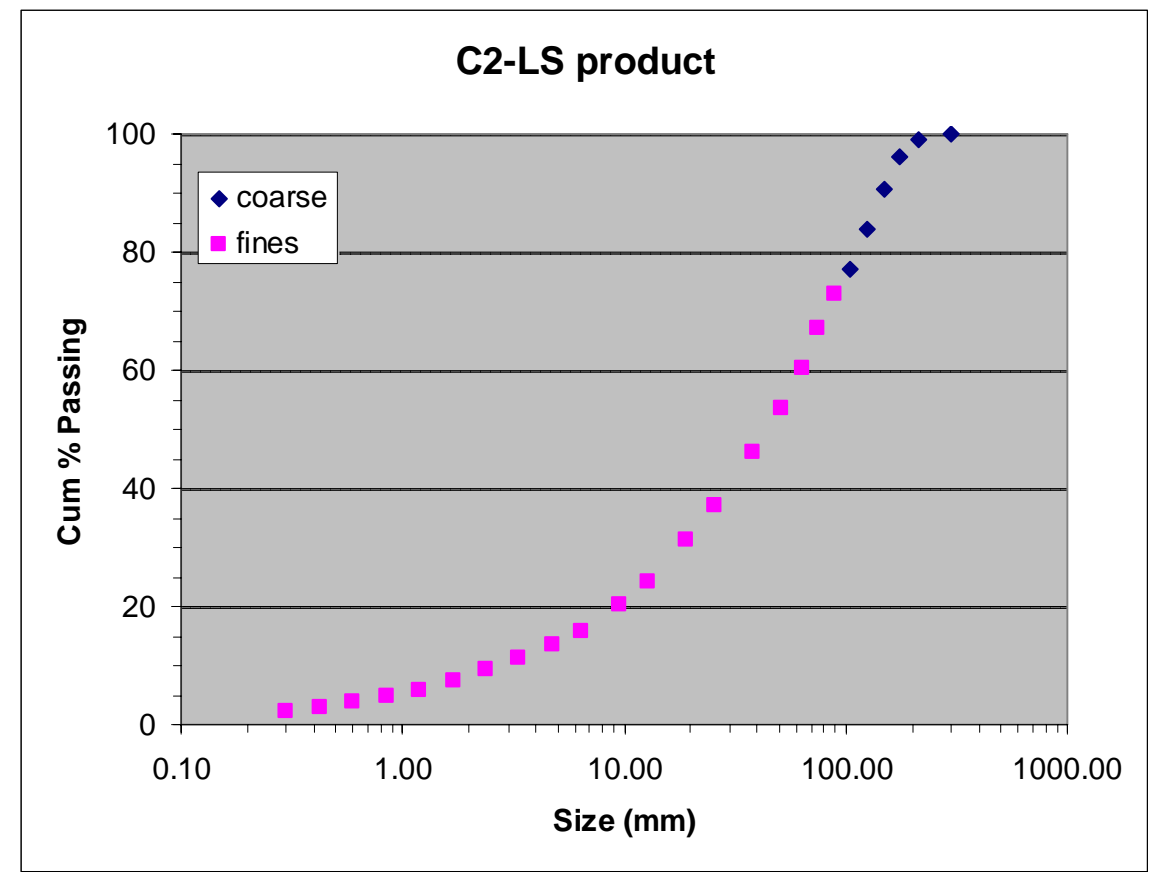

\begin{tabular}{|c|c|}
\hline size (mm) & Cum \% Passing \\
\hline 300.0 & 100.00 \\
\hline 212.0 & 99.08 \\
\hline 175.0 & 96.04 \\
\hline 150.0 & 90.49 \\
\hline 125.0 & 83.79 \\
\hline 105.0 & 76.96 \\
\hline 90.0 & 73.04 \\
\hline 75.0 & 66.99 \\
\hline 63.5 & 60.38 \\
\hline 50.8 & 53.44 \\
\hline 38.1 & 46.18 \\
\hline 25.4 & 36.95 \\
\hline 19.1 & 31.13 \\
\hline 12.7 & 24.07 \\
\hline 9.5 & 20.30 \\
\hline 6.4 & 15.84 \\
\hline 4.75 & 13.47 \\
\hline 3.35 & 11.26 \\
\hline 2.36 & 9.20 \\
\hline 1.70 & 7.47 \\
\hline 1.18 & 5.94 \\
\hline 0.850 & 4.74 \\
\hline 0.600 & 3.75 \\
\hline 0.425 & 3.06 \\
\hline 0.300 & 2.36 \\
\hline 0.212 & 1.80 \\
\hline 0.150 & 1.38 \\
\hline 0.106 & 0.99 \\
\hline 0.075 & 0.63 \\
\hline
\end{tabular}


Primary Section - 3M Audit

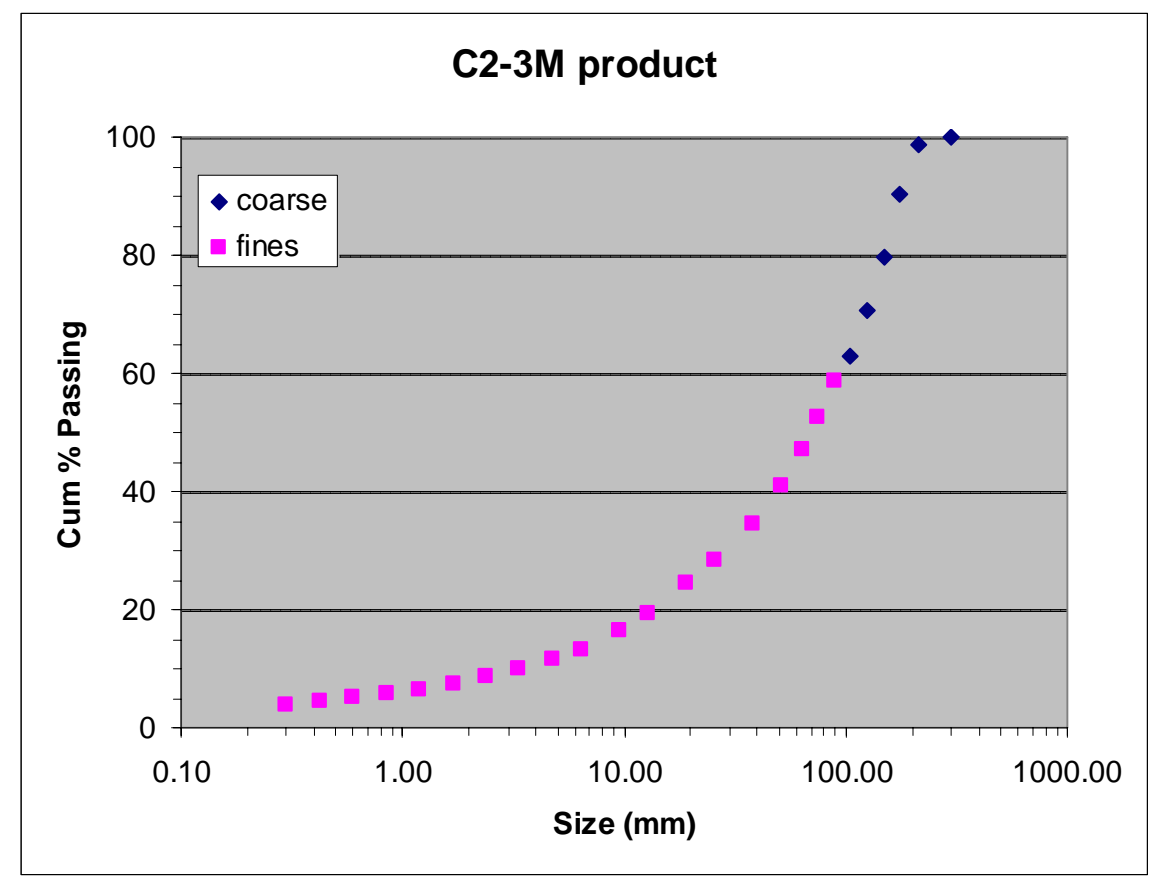

\begin{tabular}{|l|l|}
\hline Size (mm) Cum \% Passing \\
\hline
\end{tabular}

\begin{tabular}{|r|r|}
\hline 300.0 & 100.00 \\
\hline 212.0 & 98.82 \\
\hline 175.0 & 90.34 \\
\hline 150.0 & 79.56 \\
\hline 125.0 & 70.63 \\
\hline 105.0 & 63.00 \\
\hline 90.0 & 58.83 \\
\hline 75.0 & 52.68 \\
\hline 63.5 & 47.08 \\
\hline 50.8 & 40.97 \\
\hline 38.1 & 34.49 \\
\hline 25.4 & 28.51 \\
\hline 19.1 & 24.42 \\
\hline 12.7 & 19.30 \\
\hline 9.5 & 16.58 \\
\hline 6.4 & 13.27 \\
\hline 4.75 & 11.47 \\
\hline 3.35 & 9.94 \\
\hline 2.36 & 8.55 \\
\hline 1.70 & 7.45 \\
\hline 1.18 & 6.45 \\
\hline 0.850 & 5.68 \\
\hline 0.600 & 5.00 \\
\hline 0.425 & 4.51 \\
\hline 0.300 & 4.00 \\
\hline 0.212 & 3.60 \\
\hline 0.150 & 3.27 \\
\hline 0.106 & 2.97 \\
\hline 0.075 & 2.71 \\
\hline
\end{tabular}




\section{Secondary Section - Audit 1}
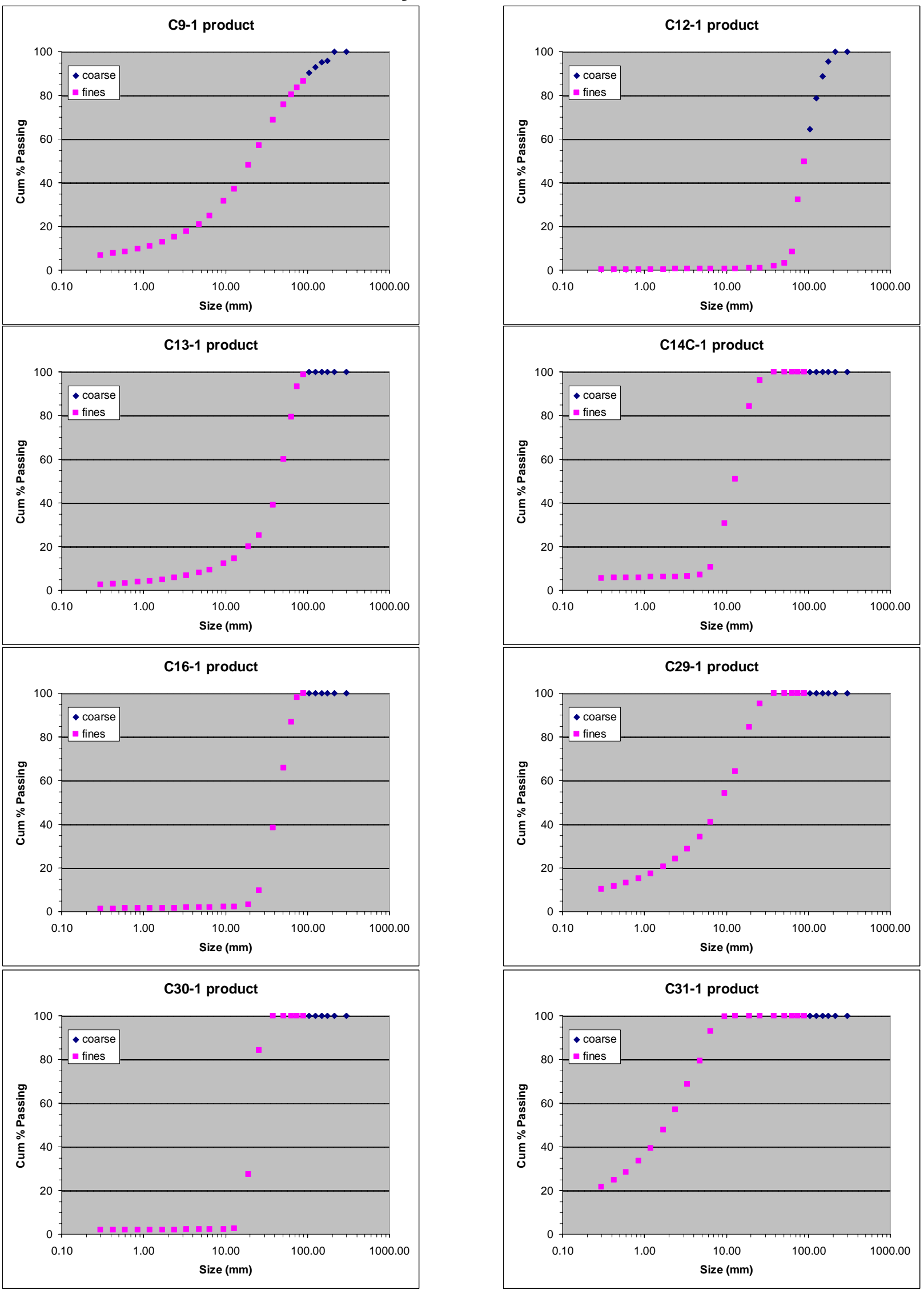
C 9-1

\begin{tabular}{|r|r|}
\hline size (mm) & Cum \% Passing \\
\hline 300.0 & 100.00 \\
\hline 212.0 & 100.00 \\
\hline 175.0 & 95.91 \\
\hline 150.0 & 95.26 \\
\hline 125.0 & 92.93 \\
\hline 105.0 & 90.43 \\
\hline 90.0 & 86.58 \\
\hline 75.0 & 83.63 \\
\hline 63.5 & 80.17 \\
\hline 50.8 & 75.65 \\
\hline 38.1 & 68.77 \\
\hline 25.4 & 57.19 \\
\hline 19.1 & 48.05 \\
\hline 12.7 & 37.19 \\
\hline 9.5 & 31.72 \\
\hline 6.4 & 24.69 \\
\hline 4.75 & 20.97 \\
\hline 3.35 & 17.70 \\
\hline 2.36 & 15.09 \\
\hline 1.70 & 12.97 \\
\hline 1.18 & 11.04 \\
\hline 0.850 & 9.69 \\
\hline 0.600 & 8.53 \\
\hline 0.425 & 7.67 \\
\hline 0.300 & 6.83 \\
\hline 0.212 & 6.16 \\
\hline 0.150 & 5.63 \\
\hline 0.106 & 5.13 \\
\hline 0.075 & 4.68 \\
\hline & \\
\hline
\end{tabular}

C 16-1

\begin{tabular}{|r|r|}
\hline size (mm) & Cum \% Passing \\
\hline 300.0 & 100.00 \\
\hline 212.0 & 100.00 \\
\hline 175.0 & 100.00 \\
\hline 150.0 & 100.00 \\
\hline 125.0 & 100.00 \\
\hline 105.0 & 100.00 \\
\hline 90.0 & 100.00 \\
\hline 75.0 & 98.13 \\
\hline 63.5 & 86.74 \\
\hline 50.8 & 65.85 \\
\hline 38.1 & 38.53 \\
\hline 25.4 & 9.66 \\
\hline 19.1 & 3.36 \\
\hline 12.7 & 2.29 \\
\hline 9.5 & 2.14 \\
\hline 6.4 & 1.97 \\
\hline 4.75 & 1.89 \\
\hline 3.35 & 1.82 \\
\hline 2.36 & 1.76 \\
\hline 1.70 & 1.71 \\
\hline 1.18 & 1.64 \\
\hline 0.850 & 1.58 \\
\hline 0.600 & 1.50 \\
\hline 0.425 & 1.42 \\
\hline 0.300 & 1.31 \\
\hline 0.212 & 1.20 \\
\hline 0.150 & 1.10 \\
\hline 0.106 & 1.00 \\
\hline 0.075 & 0.91 \\
\hline & \\
\hline
\end{tabular}

C 12-1

\begin{tabular}{|l|l|}
\hline size (mm) & Cum \% Passing \\
\hline
\end{tabular}

\begin{tabular}{|r|r|}
\hline 300.0 & 100.00 \\
\hline 212.0 & 100.00 \\
\hline 175.0 & 95.62 \\
\hline 150.0 & 88.81 \\
\hline 125.0 & 78.79 \\
\hline 105.0 & 64.50 \\
\hline 90.0 & 49.73 \\
\hline 75.0 & 32.30 \\
\hline 63.5 & 8.27 \\
\hline 50.8 & 3.34 \\
\hline 38.1 & 1.81 \\
\hline 25.4 & 1.05 \\
\hline 19.1 & 0.83 \\
\hline 12.7 & 0.72 \\
\hline 9.5 & 0.66 \\
\hline 6.4 & 0.60 \\
\hline 4.75 & 0.56 \\
\hline 3.35 & 0.53 \\
\hline 2.36 & 0.49 \\
\hline 1.70 & 0.46 \\
\hline 1.18 & 0.42 \\
\hline 0.850 & 0.39 \\
\hline 0.600 & 0.35 \\
\hline 0.425 & 0.32 \\
\hline 0.300 & 0.28 \\
\hline 0.212 & 0.25 \\
\hline 0.150 & 0.22 \\
\hline 0.106 & 0.19 \\
\hline 0.075 & 0.17 \\
\hline & \\
\hline
\end{tabular}

C 29-1

\begin{tabular}{|r|r|}
\hline size $(\mathbf{m m})$ & Cum \% Passing \\
\hline 300.0 & 100.00 \\
\hline 212.0 & 100.00 \\
\hline 175.0 & 100.00 \\
\hline 150.0 & 100.00 \\
\hline 125.0 & 100.00 \\
\hline 105.0 & 100.00 \\
\hline 90.0 & 100.00 \\
\hline 75.0 & 100.00 \\
\hline 63.5 & 100.00 \\
\hline 50.8 & 100.00 \\
\hline 38.1 & 100.00 \\
\hline 25.4 & 95.26 \\
\hline 19.1 & 84.38 \\
\hline 12.7 & 64.32 \\
\hline 9.5 & 54.28 \\
\hline 6.4 & 41.13 \\
\hline 4.75 & 34.26 \\
\hline 3.35 & 28.78 \\
\hline 2.36 & 24.31 \\
\hline 1.70 & 20.66 \\
\hline 1.18 & 17.46 \\
\hline 0.850 & 15.12 \\
\hline 0.600 & 13.11 \\
\hline 0.425 & 11.63 \\
\hline 0.300 & 10.22 \\
\hline 0.212 & 9.14 \\
\hline 0.150 & 8.29 \\
\hline 0.106 & 7.52 \\
\hline 0.075 & 6.80 \\
\hline & \\
\hline
\end{tabular}

C 13-1

\begin{tabular}{|l|l|}
\hline size (mm) & Cum \% Passing \\
\hline
\end{tabular}

\begin{tabular}{|r|r|}
\hline 300.0 & 100.00 \\
\hline 212.0 & 100.00 \\
\hline 175.0 & 100.00 \\
\hline 150.0 & 100.00 \\
\hline 125.0 & 100.00 \\
\hline 105.0 & 100.00 \\
\hline 90.0 & 98.80 \\
\hline 75.0 & 93.14 \\
\hline 63.5 & 79.28 \\
\hline 50.8 & 60.09 \\
\hline 38.1 & 39.15 \\
\hline 25.4 & 25.29 \\
\hline 19.1 & 19.86 \\
\hline 12.7 & 14.50 \\
\hline 9.5 & 12.15 \\
\hline 6.4 & 9.34 \\
\hline 4.75 & 7.91 \\
\hline 3.35 & 6.67 \\
\hline 2.36 & 5.70 \\
\hline 1.70 & 4.96 \\
\hline 1.18 & 4.27 \\
\hline 0.850 & 3.74 \\
\hline 0.600 & 3.24 \\
\hline 0.425 & 2.84 \\
\hline 0.300 & 2.45 \\
\hline 0.212 & 2.15 \\
\hline 0.150 & 1.91 \\
\hline 0.106 & 1.71 \\
\hline 0.075 & 1.52 \\
\hline & \\
\hline
\end{tabular}

\section{30-1}

\begin{tabular}{|l|l|}
\hline size (mm) & Cum \% Passing \\
\hline
\end{tabular}

\begin{tabular}{|r|r|}
\hline 300.0 & 100.00 \\
\hline 212.0 & 100.00 \\
\hline 175.0 & 100.00 \\
\hline 150.0 & 100.00 \\
\hline 125.0 & 100.00 \\
\hline 105.0 & 100.00 \\
\hline 90.0 & 100.00 \\
\hline 75.0 & 100.00 \\
\hline 63.5 & 100.00 \\
\hline 50.8 & 100.00 \\
\hline 38.1 & 100.00 \\
\hline 25.4 & 84.08 \\
\hline 19.1 & 27.30 \\
\hline 12.7 & 2.46 \\
\hline 9.5 & 2.26 \\
\hline 6.4 & 2.19 \\
\hline 4.75 & 2.15 \\
\hline 3.35 & 2.12 \\
\hline 2.36 & 2.09 \\
\hline 1.70 & 2.06 \\
\hline 1.18 & 2.03 \\
\hline 0.850 & 1.99 \\
\hline 0.600 & 1.94 \\
\hline 0.425 & 1.88 \\
\hline 0.300 & 1.79 \\
\hline 0.212 & 1.68 \\
\hline 0.150 & 1.57 \\
\hline 0.106 & 1.44 \\
\hline 0.075 & 1.32 \\
\hline & \\
\hline
\end{tabular}

C 14C-1

\begin{tabular}{|l|l|}
\hline size (mm) & Cum \% Passing \\
\hline
\end{tabular}

\begin{tabular}{|r|r|}
\hline 300.0 & 100.00 \\
\hline 212.0 & 100.00 \\
\hline 175.0 & 100.00 \\
\hline 150.0 & 100.00 \\
\hline 125.0 & 100.00 \\
\hline 105.0 & 100.00 \\
\hline 90.0 & 100.00 \\
\hline 75.0 & 100.00 \\
\hline 63.5 & 100.00 \\
\hline 50.8 & 100.00 \\
\hline 38.1 & 100.00 \\
\hline 25.4 & 96.21 \\
\hline 19.1 & 84.16 \\
\hline 12.7 & 51.07 \\
\hline 9.5 & 30.65 \\
\hline 6.4 & 10.63 \\
\hline 4.75 & 7.11 \\
\hline 3.35 & 6.31 \\
\hline 2.36 & 6.14 \\
\hline 1.70 & 6.09 \\
\hline 1.18 & 6.02 \\
\hline 0.850 & 5.95 \\
\hline 0.600 & 5.85 \\
\hline 0.425 & 5.73 \\
\hline 0.300 & 5.51 \\
\hline 0.212 & 5.22 \\
\hline 0.150 & 4.90 \\
\hline 0.106 & 4.54 \\
\hline 0.075 & 4.15 \\
\hline & \\
\hline
\end{tabular}

C 31-1

\begin{tabular}{|r|r|}
\hline size (mm) & Cum \% Passing \\
\hline 300.0 & 100.00 \\
\hline 212.0 & 100.00 \\
\hline 175.0 & 100.00 \\
\hline 150.0 & 100.00 \\
\hline 125.0 & 100.00 \\
\hline 105.0 & 100.00 \\
\hline 90.0 & 100.00 \\
\hline 75.0 & 100.00 \\
\hline 63.5 & 100.00 \\
\hline 50.8 & 100.00 \\
\hline 38.1 & 100.00 \\
\hline 25.4 & 100.00 \\
\hline 19.1 & 100.00 \\
\hline 12.7 & 100.00 \\
\hline 9.5 & 99.81 \\
\hline 6.4 & 92.93 \\
\hline 4.75 & 79.38 \\
\hline 3.35 & 68.81 \\
\hline 2.36 & 57.00 \\
\hline 1.70 & 47.64 \\
\hline 1.18 & 39.37 \\
\hline 0.850 & 33.48 \\
\hline 0.600 & 28.50 \\
\hline 0.425 & 24.91 \\
\hline 0.300 & 21.61 \\
\hline 0.212 & 19.25 \\
\hline 0.150 & 17.51 \\
\hline 0.106 & 15.97 \\
\hline 0.075 & 14.55 \\
\hline & \\
\hline
\end{tabular}




\section{Secondary Section - Audit 2}
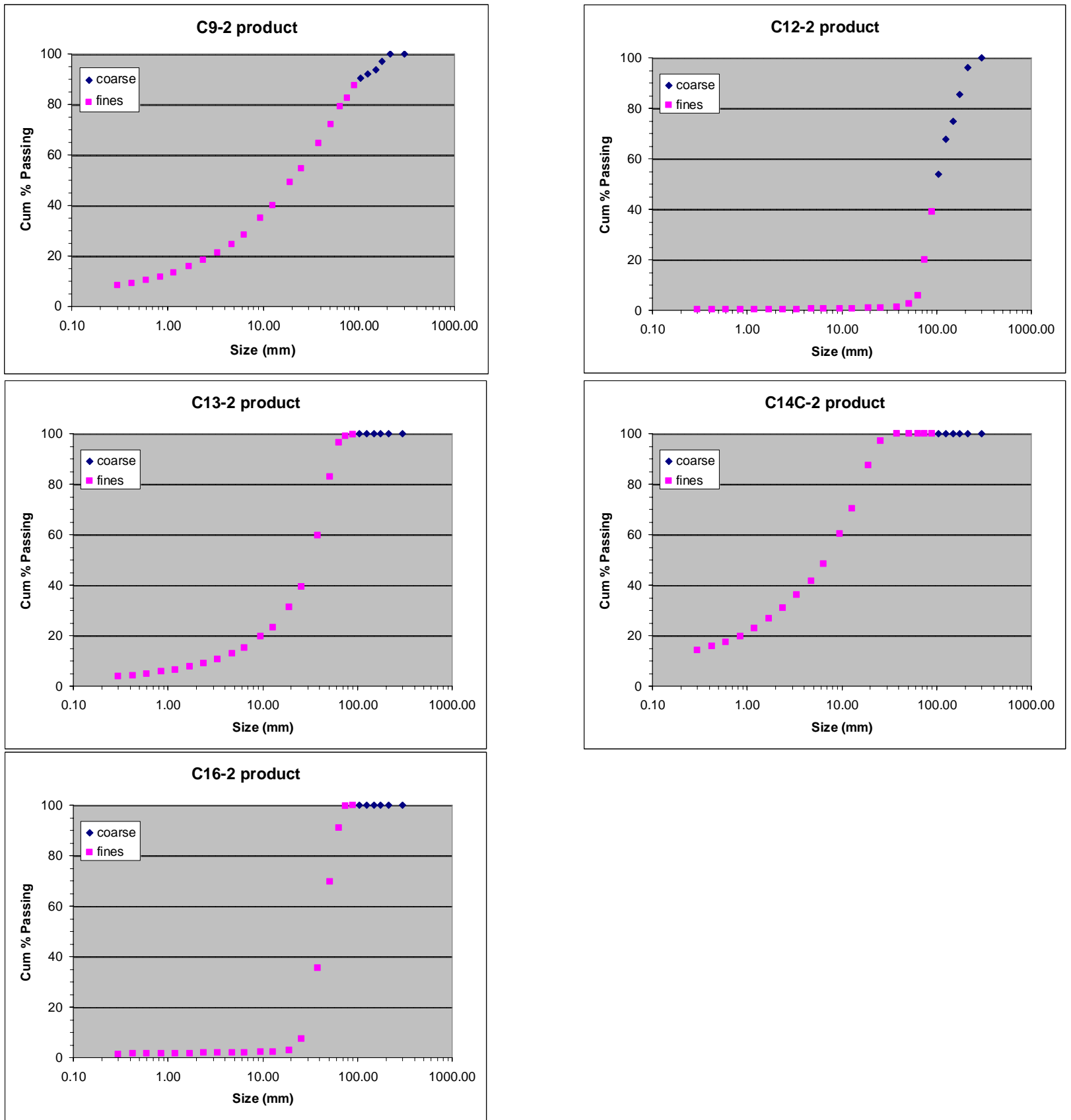
C 9-2

\begin{tabular}{|r|r|}
\hline size (mm) & Cum \% Passing \\
\hline 300.0 & 100.00 \\
\hline 212.0 & 100.00 \\
\hline 175.0 & 97.10 \\
\hline 150.0 & 93.88 \\
\hline 125.0 & 92.09 \\
\hline 105.0 & 90.29 \\
\hline 90.0 & 87.38 \\
\hline 75.0 & 82.42 \\
\hline 63.5 & 78.98 \\
\hline 50.8 & 71.88 \\
\hline 38.1 & 64.51 \\
\hline 25.4 & 54.45 \\
\hline 19.1 & 49.05 \\
\hline 12.7 & 39.86 \\
\hline 9.5 & 34.99 \\
\hline 6.4 & 28.43 \\
\hline 4.75 & 24.64 \\
\hline 3.35 & 21.21 \\
\hline 2.36 & 18.31 \\
\hline 1.70 & 15.81 \\
\hline 1.18 & 13.51 \\
\hline 0.850 & 11.87 \\
\hline 0.600 & 10.42 \\
\hline 0.425 & 9.34 \\
\hline 0.300 & 8.28 \\
\hline 0.212 & 7.43 \\
\hline 0.150 & 6.76 \\
\hline 0.106 & 6.13 \\
\hline 0.075 & 5.56 \\
\hline & \\
\hline
\end{tabular}

C 12-2

\begin{tabular}{|l|l|}
\hline size (mm) & Cum \% Passing \\
\hline
\end{tabular}

\begin{tabular}{|c|c|}
\hline 300.0 & 100.00 \\
\hline 212.0 & 96.12 \\
\hline 175.0 & 85.39 \\
\hline 150.0 & 74.91 \\
\hline 125.0 & 67.67 \\
\hline 105.0 & 53.92 \\
\hline 90.0 & 39.11 \\
\hline 75.0 & 20.10 \\
\hline 63.5 & 5.73 \\
\hline 50.8 & 2.56 \\
\hline 38.1 & 1.41 \\
\hline 25.4 & 1.00 \\
\hline 19.1 & 0.82 \\
\hline 12.7 & 0.68 \\
\hline 9.5 & 0.63 \\
\hline 6.4 & 0.56 \\
\hline 4.75 & 0.52 \\
\hline 3.35 & 0.48 \\
\hline 2.36 & 0.44 \\
\hline 1.70 & 0.41 \\
\hline 1.18 & 0.37 \\
\hline 0.850 & 0.34 \\
\hline 0.600 & 0.30 \\
\hline 0.425 & 0.27 \\
\hline 0.300 & 0.24 \\
\hline 0.212 & 0.21 \\
\hline 0.150 & 0.19 \\
\hline 0.106 & 0.17 \\
\hline 0.075 & 0.15 \\
\hline
\end{tabular}

C 13-2

\begin{tabular}{|l|l|}
\hline size (mm) & Cum \% Passing \\
\hline
\end{tabular}

\begin{tabular}{|r|r|}
\hline 300.0 & 100.00 \\
\hline 212.0 & 100.00 \\
\hline 175.0 & 100.00 \\
\hline 150.0 & 100.00 \\
\hline 125.0 & 100.00 \\
\hline 105.0 & 100.00 \\
\hline
\end{tabular}

\begin{tabular}{|r|r|}
\hline 105.0 & 100.00 \\
\hline 90.0 & 99.73 \\
\hline 75.0 & 99.08 \\
\hline 63.5 & 96.46 \\
\hline
\end{tabular}

\begin{tabular}{|r|r|}
\hline 63.5 & 96.46 \\
\hline 50.8 & 82.81 \\
\hline 38.1 & 59.68 \\
\hline
\end{tabular}

\begin{tabular}{|r|r|}
\hline 38.1 & 59.68 \\
\hline 25.4 & 39.36 \\
\hline 19.1 & 31.30 \\
\hline
\end{tabular}

\begin{tabular}{|r|r|}
\hline 19.1 & 31.30 \\
\hline 12.7 & 23.29 \\
\hline 9.5 & 19.69 \\
\hline
\end{tabular}

\begin{tabular}{|r|r|}
\hline 12.7 & 23.29 \\
\hline 9.5 & 19.69 \\
\hline 6.4 & 15.31 \\
\hline
\end{tabular}

\begin{tabular}{|r|r|}
\hline 6.4 & 15.31 \\
\hline 4.75 & 13.02 \\
\hline 3.35 & 10.75 \\
\hline 2.36 & 9.11 \\
\hline 1.70 & 7.75 \\
\hline 1.18 & 6.52 \\
\hline 0.850 & 5.66 \\
\hline 0.600 & 4.90 \\
\hline 0.425 & 4.34 \\
\hline 0.300 & 3.79 \\
\hline 0.212 & 3.36 \\
\hline 0.150 & 3.03 \\
\hline 0.106 & 2.74 \\
\hline 0.075 & 2.49 \\
\hline
\end{tabular}

C 14C-2

\begin{tabular}{|l|l|}
\hline size (mm) & Cum \% Passing \\
\hline
\end{tabular}

\begin{tabular}{|r|r|}
\hline 300.0 & 100.00 \\
\hline 212.0 & 100.00 \\
\hline 175.0 & 100.00 \\
\hline 150.0 & 100.00 \\
\hline 125.0 & 100.00 \\
\hline 105.0 & 100.00 \\
\hline 90.0 & 100.00 \\
\hline 75.0 & 100.00 \\
\hline 63.5 & 100.00 \\
\hline 50.8 & 100.00 \\
\hline 38.1 & 100.00 \\
\hline 25.4 & 97.15 \\
\hline 19.1 & 87.27 \\
\hline 12.7 & 70.16 \\
\hline 9.5 & 60.27 \\
\hline 6.4 & 48.23 \\
\hline 4.75 & 41.54 \\
\hline 3.35 & 36.02 \\
\hline 2.36 & 30.81 \\
\hline 1.70 & 26.61 \\
\hline 1.18 & 22.78 \\
\hline 0.850 & 19.82 \\
\hline 0.600 & 17.40 \\
\hline 0.425 & 15.75 \\
\hline 0.300 & 14.12 \\
\hline 0.212 & 12.82 \\
\hline 0.150 & 11.88 \\
\hline 0.106 & 10.98 \\
\hline 0.075 & 10.13 \\
\hline & \\
\hline
\end{tabular}

\section{16-2}

\begin{tabular}{|r|r|}
\hline size (mm) & Cum \% Passing \\
\hline 300.0 & 100.00 \\
\hline 212.0 & 100.00 \\
\hline 175.0 & 100.00 \\
\hline 150.0 & 100.00 \\
\hline 125.0 & 100.00 \\
\hline 105.0 & 100.00 \\
\hline 90.0 & 100.00 \\
\hline 75.0 & 99.53 \\
\hline 63.5 & 90.84 \\
\hline 50.8 & 69.66 \\
\hline 38.1 & 35.56 \\
\hline 25.4 & 7.40 \\
\hline 19.1 & 2.97 \\
\hline 12.7 & 2.25 \\
\hline 9.5 & 2.12 \\
\hline 6.4 & 2.00 \\
\hline 4.75 & 1.94 \\
\hline 3.35 & 1.88 \\
\hline 2.36 & 1.82 \\
\hline 1.70 & 1.77 \\
\hline 1.18 & 1.69 \\
\hline 0.850 & 1.62 \\
\hline 0.600 & 1.54 \\
\hline 0.425 & 1.46 \\
\hline 0.300 & 1.36 \\
\hline 0.212 & 1.26 \\
\hline 0.150 & 1.17 \\
\hline 0.106 & 1.07 \\
\hline 0.075 & 0.98 \\
\hline & \\
\hline
\end{tabular}




\section{Secondary Section - Audit 3}
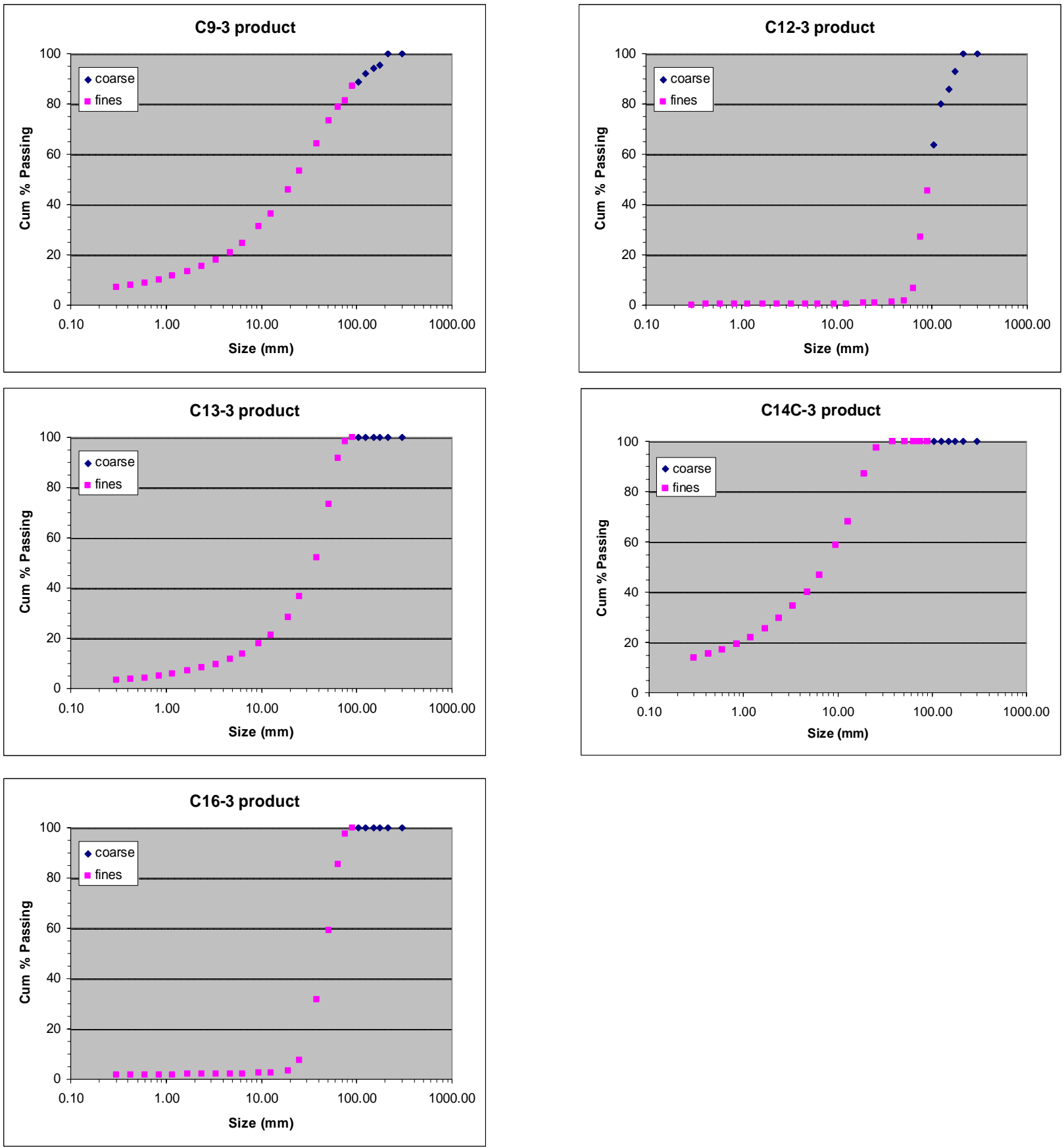
C 9-3

\begin{tabular}{|r|r|}
\hline size (mm) & Cum \% Passing \\
\hline 300.0 & 100.00 \\
\hline 212.0 & 100.00 \\
\hline 175.0 & 95.46 \\
\hline 150.0 & 94.33 \\
\hline 125.0 & 91.89 \\
\hline 105.0 & 88.77 \\
\hline 90.0 & 87.09 \\
\hline 75.0 & 81.28 \\
\hline 63.5 & 78.56 \\
\hline 50.8 & 73.34 \\
\hline 38.1 & 64.25 \\
\hline 25.4 & 53.42 \\
\hline 19.1 & 45.92 \\
\hline 12.7 & 36.21 \\
\hline 9.5 & 31.18 \\
\hline 6.4 & 24.58 \\
\hline 4.75 & 21.03 \\
\hline 3.35 & 17.84 \\
\hline 2.36 & 15.34 \\
\hline 1.70 & 13.37 \\
\hline 1.18 & 11.48 \\
\hline 0.850 & 10.09 \\
\hline 0.600 & 8.87 \\
\hline 0.425 & 7.96 \\
\hline 0.300 & 7.08 \\
\hline 0.212 & 6.38 \\
\hline 0.150 & 5.82 \\
\hline 0.106 & 5.32 \\
\hline 0.075 & 4.86 \\
\hline & \\
\hline
\end{tabular}

C 12-3

\begin{tabular}{|r|r|}
\hline size (mm) & Cum \% Passing \\
\hline 300.0 & 100.00 \\
\hline 212.0 & 100.00 \\
\hline 175.0 & 92.83 \\
\hline 150.0 & 85.71 \\
\hline 125.0 & 79.98 \\
\hline 105.0 & 63.84 \\
\hline 90.0 & 45.26 \\
\hline 75.0 & 27.21 \\
\hline 63.5 & 6.58 \\
\hline 50.8 & 1.68 \\
\hline 38.1 & 1.22 \\
\hline 25.4 & 0.79 \\
\hline 19.1 & 0.69 \\
\hline 12.7 & 0.58 \\
\hline 9.5 & 0.54 \\
\hline 6.4 & 0.47 \\
\hline 4.75 & 0.44 \\
\hline 3.35 & 0.40 \\
\hline 2.36 & 0.37 \\
\hline 1.70 & 0.34 \\
\hline 1.18 & 0.30 \\
\hline 0.850 & 0.27 \\
\hline 0.600 & 0.24 \\
\hline 0.425 & 0.21 \\
\hline 0.300 & 0.18 \\
\hline 0.212 & 0.16 \\
\hline 0.150 & 0.14 \\
\hline 0.106 & 0.12 \\
\hline 0.075 & 0.11 \\
\hline & \\
\hline &
\end{tabular}

C 13-3

\begin{tabular}{|r|r|}
\hline size $(\mathbf{m m})$ & Cum \% Passing \\
\hline 300.0 & 100.00 \\
\hline 212.0 & 100.00 \\
\hline 175.0 & 100.00 \\
\hline 150.0 & 100.00 \\
\hline 125.0 & 100.00 \\
\hline 105.0 & 100.00 \\
\hline 90.0 & 100.00 \\
\hline 75.0 & 98.16 \\
\hline 63.5 & 91.53 \\
\hline 50.8 & 73.31 \\
\hline 38.1 & 51.96 \\
\hline 25.4 & 36.78 \\
\hline 19.1 & 28.50 \\
\hline 12.7 & 21.23 \\
\hline 9.5 & 17.85 \\
\hline 6.4 & 13.84 \\
\hline 4.75 & 11.74 \\
\hline 3.35 & 9.76 \\
\hline 2.36 & 8.26 \\
\hline 1.70 & 7.03 \\
\hline 1.18 & 5.87 \\
\hline 0.850 & 5.04 \\
\hline 0.600 & 4.30 \\
\hline 0.425 & 3.72 \\
\hline 0.300 & 3.16 \\
\hline 0.212 & 2.72 \\
\hline 0.150 & 2.37 \\
\hline 0.106 & 2.07 \\
\hline 0.075 & 1.81 \\
\hline & \\
\hline
\end{tabular}

C 14C-3

\begin{tabular}{|r|r|}
\hline size (mm) & Cum \% Passing \\
\hline 300.0 & 100.00 \\
\hline 212.0 & 100.00 \\
\hline 175.0 & 100.00 \\
\hline 150.0 & 100.00 \\
\hline 125.0 & 100.00 \\
\hline 105.0 & 100.00 \\
\hline 90.0 & 100.00 \\
\hline 75.0 & 100.00 \\
\hline 63.5 & 100.00 \\
\hline 50.8 & 100.00 \\
\hline 38.1 & 100.00 \\
\hline 25.4 & 97.28 \\
\hline 19.1 & 87.18 \\
\hline 12.7 & 68.10 \\
\hline 9.5 & 58.85 \\
\hline 6.4 & 46.79 \\
\hline 4.75 & 40.09 \\
\hline 3.35 & 34.47 \\
\hline 2.36 & 29.59 \\
\hline 1.70 & 25.61 \\
\hline 1.18 & 22.06 \\
\hline 0.850 & 19.31 \\
\hline 0.600 & 17.04 \\
\hline 0.425 & 15.52 \\
\hline 0.300 & 13.96 \\
\hline 0.212 & 12.69 \\
\hline 0.150 & 11.77 \\
\hline 0.106 & 10.91 \\
\hline 0.075 & 10.14 \\
\hline & \\
\hline
\end{tabular}

\section{16-3}

\begin{tabular}{|r|r|}
\hline size (mm) & Cum \% Passing \\
\hline 300.0 & 100.00 \\
\hline 212.0 & 100.00 \\
\hline 175.0 & 100.00 \\
\hline 150.0 & 100.00 \\
\hline 125.0 & 100.00 \\
\hline 105.0 & 100.00 \\
\hline 90.0 & 100.00 \\
\hline 75.0 & 97.46 \\
\hline 63.5 & 85.48 \\
\hline 50.8 & 59.18 \\
\hline 38.1 & 31.55 \\
\hline 25.4 & 7.32 \\
\hline 19.1 & 3.18 \\
\hline 12.7 & 2.43 \\
\hline 9.5 & 2.30 \\
\hline 6.4 & 2.18 \\
\hline 4.75 & 2.11 \\
\hline 3.35 & 2.04 \\
\hline 2.36 & 1.98 \\
\hline 1.70 & 1.92 \\
\hline 1.18 & 1.85 \\
\hline 0.850 & 1.77 \\
\hline 0.600 & 1.68 \\
\hline 0.425 & 1.59 \\
\hline 0.300 & 1.47 \\
\hline 0.212 & 1.36 \\
\hline 0.150 & 1.25 \\
\hline 0.106 & 1.14 \\
\hline 0.075 & 1.04 \\
\hline & \\
\hline
\end{tabular}




\section{Secondary Section - Audit 4}
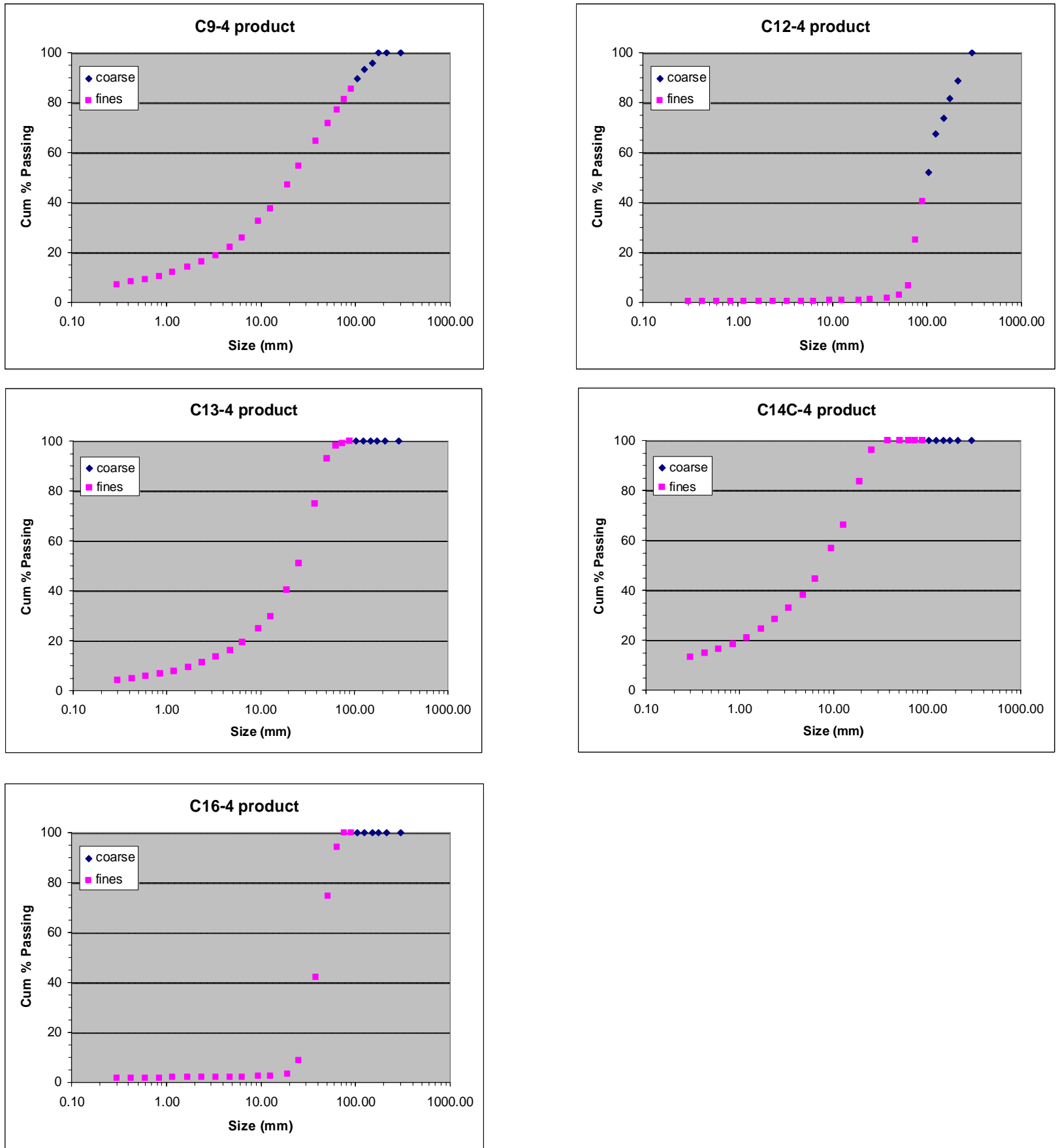
C 9-4

\begin{tabular}{|r|r|}
\hline size (mm) & Cum \% Passing \\
\hline 300.0 & 100.00 \\
\hline 212.0 & 100.00 \\
\hline 175.0 & 100.00 \\
\hline 150.0 & 95.68 \\
\hline 125.0 & 93.39 \\
\hline 105.0 & 89.77 \\
\hline 90.0 & 85.34 \\
\hline 75.0 & 81.21 \\
\hline 63.5 & 77.15 \\
\hline 50.8 & 71.80 \\
\hline 38.1 & 64.62 \\
\hline 25.4 & 54.39 \\
\hline 19.1 & 47.16 \\
\hline 12.7 & 37.58 \\
\hline 9.5 & 32.47 \\
\hline 6.4 & 25.78 \\
\hline 4.75 & 22.14 \\
\hline 3.35 & 18.93 \\
\hline 2.36 & 16.11 \\
\hline 1.70 & 13.98 \\
\hline 1.18 & 11.98 \\
\hline 0.850 & 10.48 \\
\hline 0.600 & 9.17 \\
\hline 0.425 & 8.18 \\
\hline 0.300 & 7.21 \\
\hline 0.212 & 6.44 \\
\hline 0.150 & 5.83 \\
\hline 0.106 & 5.26 \\
\hline 0.075 & 4.75 \\
\hline & \\
\hline
\end{tabular}

\section{16-4}

\begin{tabular}{|r|r|}
\hline size (mm) & Cum \% Passing \\
\hline 300.0 & 100.00 \\
\hline 212.0 & 100.00 \\
\hline 175.0 & 100.00 \\
\hline 150.0 & 100.00 \\
\hline 125.0 & 100.00 \\
\hline 105.0 & 100.00 \\
\hline 90.0 & 100.00 \\
\hline 75.0 & 100.00 \\
\hline 63.5 & 94.00 \\
\hline 50.8 & 74.67 \\
\hline 38.1 & 41.89 \\
\hline 25.4 & 8.90 \\
\hline 19.1 & 3.50 \\
\hline 12.7 & 2.55 \\
\hline 9.5 & 2.40 \\
\hline 6.4 & 2.25 \\
\hline 4.75 & 2.18 \\
\hline 3.35 & 2.12 \\
\hline 2.36 & 2.05 \\
\hline 1.70 & 1.99 \\
\hline 1.18 & 1.91 \\
\hline 0.850 & 1.83 \\
\hline 0.600 & 1.73 \\
\hline 0.425 & 1.63 \\
\hline 0.300 & 1.49 \\
\hline 0.212 & 1.35 \\
\hline 0.150 & 1.23 \\
\hline 0.106 & 1.10 \\
\hline 0.075 & 0.98 \\
\hline & \\
\hline &
\end{tabular}

C 12-4

\begin{tabular}{|r|r|}
\hline size (mm) & Cum \% Passing \\
\hline 300.0 & 100.00 \\
\hline 212.0 & 88.61 \\
\hline 175.0 & 81.53 \\
\hline 150.0 & 73.69 \\
\hline 125.0 & 67.46 \\
\hline 105.0 & 52.03 \\
\hline 90.0 & 40.51 \\
\hline 75.0 & 25.08 \\
\hline 63.5 & 6.75 \\
\hline 50.8 & 3.08 \\
\hline 38.1 & 1.82 \\
\hline 25.4 & 1.09 \\
\hline 19.1 & 0.87 \\
\hline 12.7 & 0.71 \\
\hline 9.5 & 0.65 \\
\hline 6.4 & 0.57 \\
\hline 4.75 & 0.53 \\
\hline 3.35 & 0.49 \\
\hline 2.36 & 0.45 \\
\hline 1.70 & 0.41 \\
\hline 1.18 & 0.37 \\
\hline 0.850 & 0.33 \\
\hline 0.600 & 0.29 \\
\hline 0.425 & 0.26 \\
\hline 0.300 & 0.22 \\
\hline 0.212 & 0.19 \\
\hline 0.150 & 0.17 \\
\hline 0.106 & 0.15 \\
\hline 0.075 & 0.13 \\
\hline & \\
\hline &
\end{tabular}

C 13-4

\begin{tabular}{|l|l|}
\hline size (mm) & Cum \% Passing \\
\hline
\end{tabular}

\begin{tabular}{|r|r|}
\hline 300.0 & 100.00 \\
\hline 212.0 & 100.00 \\
\hline 175.0 & 100.00 \\
\hline
\end{tabular}

\begin{tabular}{|r|r|}
\hline 175.0 & 100.00 \\
\hline 150.0 & 100.00 \\
\hline 125.0 & 100.00 \\
\hline
\end{tabular}

\begin{tabular}{|r|r|}
\hline 125.0 & 100.00 \\
\hline 105.0 & 100.00 \\
\hline 90.0 & 100.00 \\
\hline
\end{tabular}

\begin{tabular}{|r|r|}
\hline 90.0 & 100.00 \\
\hline 75.0 & 99.10 \\
\hline 63.5 & 97.97 \\
\hline
\end{tabular}

\begin{tabular}{|r|r|}
\hline 63.5 & 97.97 \\
\hline 50.8 & 92.88 \\
\hline 38.1 & 74.89 \\
\hline
\end{tabular}

\begin{tabular}{|r|r|}
\hline 38.1 & 74.89 \\
\hline 25.4 & 50.82 \\
\hline 19.1 & 40.28 \\
\hline 12.7 & 29.67 \\
\hline
\end{tabular}

\begin{tabular}{|r|r|}
\hline 19.1 & 40.28 \\
\hline 12.7 & 29.67 \\
\hline 9.5 & 24.99 \\
\hline 6.4 & 19.26 \\
\hline
\end{tabular}

\begin{tabular}{|r|r|}
\hline 6.4 & 19.26 \\
\hline 4.75 & 16.24 \\
\hline 3.35 & 13.46 \\
\hline
\end{tabular}

\begin{tabular}{|r|r|}
\hline 4.75 & 16.24 \\
\hline 3.35 & 13.46 \\
\hline 2.36 & 11.22 \\
\hline 1.70 & 9.47 \\
\hline 1.18 & 7.85 \\
\hline 0.850 & 6.68 \\
\hline 0.600 & 5.66 \\
\hline 0.425 & 4.89 \\
\hline 0.300 & 4.15 \\
\hline 0.212 & 3.58 \\
\hline 0.150 & 3.13 \\
\hline 0.106 & 2.74 \\
\hline 0.075 & 2.41 \\
\hline
\end{tabular}

C 14C-4

\begin{tabular}{|r|r|}
\hline size (mm) & Cum \% Passing \\
\hline 300.0 & 100.00 \\
\hline 212.0 & 100.00 \\
\hline 175.0 & 100.00 \\
\hline 150.0 & 100.00 \\
\hline 125.0 & 100.00 \\
\hline 105.0 & 100.00 \\
\hline 90.0 & 100.00 \\
\hline 75.0 & 100.00 \\
\hline 63.5 & 100.00 \\
\hline 50.8 & 100.00 \\
\hline 38.1 & 100.00 \\
\hline 25.4 & 96.11 \\
\hline 19.1 & 83.66 \\
\hline 12.7 & 66.28 \\
\hline 9.5 & 56.83 \\
\hline 6.4 & 44.61 \\
\hline 4.75 & 37.95 \\
\hline 3.35 & 32.89 \\
\hline 2.36 & 28.28 \\
\hline 1.70 & 24.56 \\
\hline 1.18 & 21.13 \\
\hline 0.850 & 18.52 \\
\hline 0.600 & 16.33 \\
\hline 0.425 & 14.79 \\
\hline 0.300 & 13.21 \\
\hline 0.212 & 11.97 \\
\hline 0.150 & 10.97 \\
\hline 0.106 & 10.05 \\
\hline 0.075 & 9.21 \\
\hline & \\
\hline
\end{tabular}




\section{Secondary Section - Audit 5}
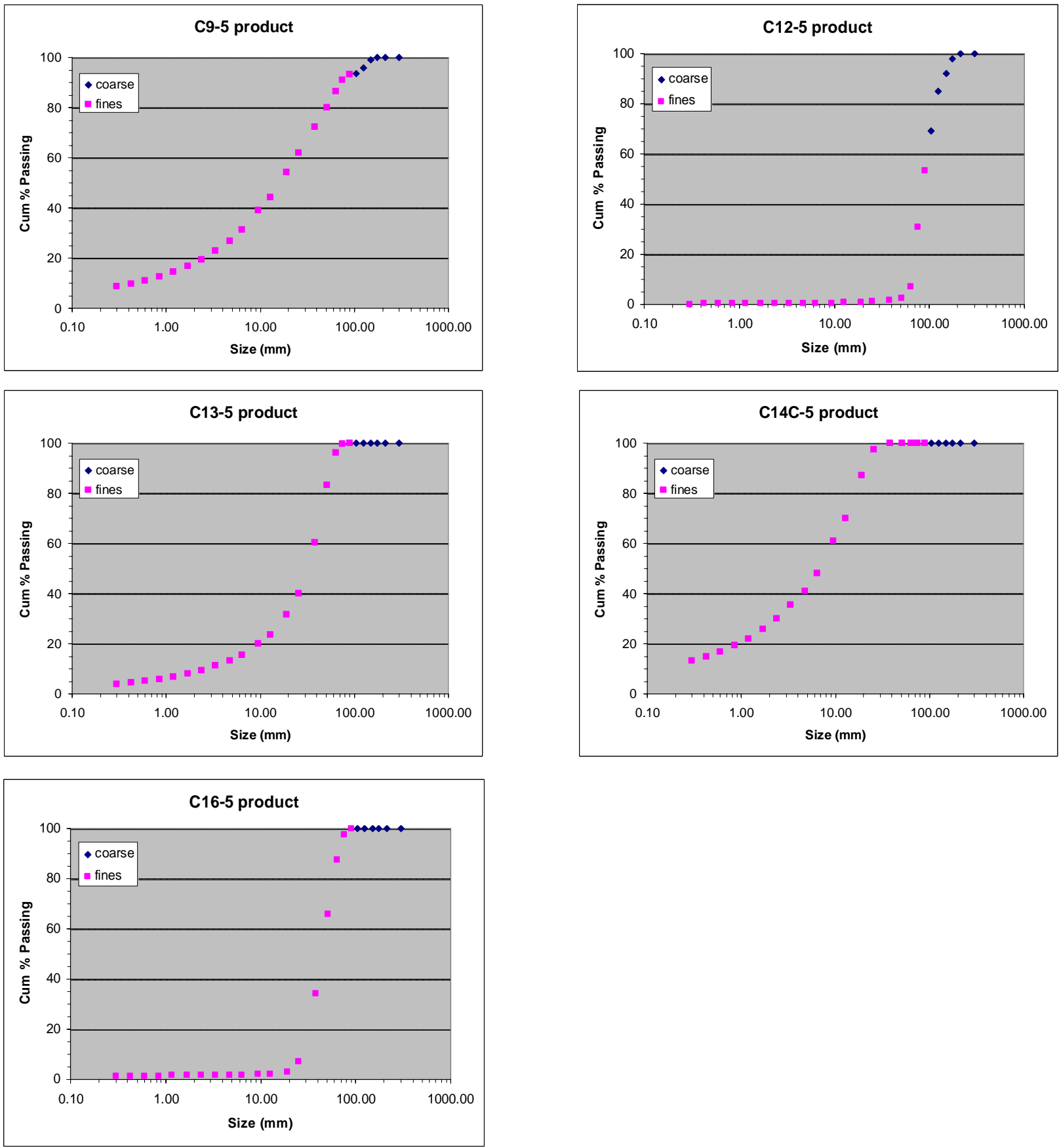
C 9-5

\begin{tabular}{|l|l|}
\hline size (mm) & Cum \% Passing \\
\hline
\end{tabular}

\begin{tabular}{|r|r|}
\hline 300.0 & 100.00 \\
\hline 212.0 & 100.00 \\
\hline 175.0 & 100.00 \\
\hline 150.0 & 98.89 \\
\hline 125.0 & 95.95 \\
\hline 105.0 & 93.61 \\
\hline 90.0 & 93.18 \\
\hline 75.0 & 91.08 \\
\hline 63.5 & 86.41 \\
\hline 50.8 & 79.89 \\
\hline 38.1 & 72.35 \\
\hline 25.4 & 61.85 \\
\hline 19.1 & 54.19 \\
\hline 12.7 & 44.28 \\
\hline 9.5 & 38.93 \\
\hline 6.4 & 31.21 \\
\hline 4.75 & 26.93 \\
\hline 3.35 & 22.90 \\
\hline 2.36 & 19.49 \\
\hline 1.70 & 16.88 \\
\hline 1.18 & 14.37 \\
\hline 0.850 & 12.55 \\
\hline 0.600 & 10.94 \\
\hline 0.425 & 9.74 \\
\hline 0.300 & 8.57 \\
\hline 0.212 & 7.65 \\
\hline 0.150 & 6.93 \\
\hline 0.106 & 6.27 \\
\hline 0.075 & 5.66 \\
\hline & \\
\hline
\end{tabular}

C 12-5

\begin{tabular}{|l|l|}
\hline size (mm) & Cum \% Passing \\
\hline
\end{tabular}

\begin{tabular}{|r|r|}
\hline 300.0 & 100.00 \\
\hline 212.0 & 100.00 \\
\hline 175.0 & 98.01 \\
\hline 150.0 & 92.22 \\
\hline 125.0 & 84.98 \\
\hline 105.0 & 68.97 \\
\hline 90.0 & 53.35 \\
\hline 75.0 & 30.72 \\
\hline 63.5 & 7.09 \\
\hline 50.8 & 2.68 \\
\hline 38.1 & 1.71 \\
\hline 25.4 & 1.15 \\
\hline 19.1 & 0.89 \\
\hline 12.7 & 0.69 \\
\hline 9.5 & 0.62 \\
\hline 6.4 & 0.55 \\
\hline 4.75 & 0.50 \\
\hline 3.35 & 0.46 \\
\hline 2.36 & 0.41 \\
\hline 1.70 & 0.38 \\
\hline 1.18 & 0.34 \\
\hline 0.850 & 0.30 \\
\hline 0.600 & 0.27 \\
\hline 0.425 & 0.24 \\
\hline 0.300 & 0.21 \\
\hline 0.212 & 0.18 \\
\hline 0.150 & 0.16 \\
\hline 0.106 & 0.14 \\
\hline 0.075 & 0.12 \\
\hline & \\
\hline
\end{tabular}

C 13-5

\begin{tabular}{|l|l|}
\hline size (mm) & Cum \% Passing \\
\hline
\end{tabular}

\begin{tabular}{|r|r|}
\hline 300.0 & 100.00 \\
\hline 212.0 & 100.00 \\
\hline 175.0 & 100.00 \\
\hline 150.0 & 100.00 \\
\hline 125.0 & 100.00 \\
\hline 105.0 & 100.00 \\
\hline 90.0 & 100.00 \\
\hline
\end{tabular}

\begin{tabular}{|r|r|}
\hline 90.0 & 100.00 \\
\hline 75.0 & 99.67 \\
\hline 63.5 & 96.10 \\
\hline
\end{tabular}

\begin{tabular}{r|r|}
\hline 63.5 & 96.10 \\
\hline 50.8 & 83.34 \\
\hline
\end{tabular}

\begin{tabular}{|r|r|}
\hline 50.8 & 83.34 \\
\hline 38.1 & 60.18 \\
\hline 25.4 & 40.05 \\
\hline 19.1 & 31.71 \\
\hline
\end{tabular}

\begin{tabular}{|r|r|}
\hline 25.4 & 40.05 \\
\hline 19.1 & 31.71 \\
\hline 12.7 & 23.47 \\
\hline 9.5 & 19.94 \\
\hline
\end{tabular}

\begin{tabular}{|r|r|}
\hline 12.7 & 23.47 \\
\hline 9.5 & 19.94 \\
\hline 6.4 & 15.57 \\
\hline
\end{tabular}

\begin{tabular}{|r|r|}
\hline 4.75 & 15.57 \\
\hline 3.35 & 13.30 \\
\hline
\end{tabular}

\begin{tabular}{|r|r|}
\hline 3.35 & 11.13 \\
\hline 2.36 & 9.42 \\
\hline 1.70 & 8.05 \\
\hline 1.18 & 6.80 \\
\hline 0.850 & 5.88 \\
\hline 0.600 & 5.07 \\
\hline 0.425 & 4.45 \\
\hline 0.300 & 3.85 \\
\hline 0.212 & 3.37 \\
\hline 0.150 & 3.00 \\
\hline 0.106 & 2.67 \\
\hline 0.075 & 2.38 \\
\hline
\end{tabular}

\section{14C-5}

\begin{tabular}{|l|l|}
\hline size (mm) & Cum \% Passing \\
\hline
\end{tabular}

\begin{tabular}{|r|r|}
\hline 300.0 & 100.00 \\
\hline 212.0 & 100.00 \\
\hline 175.0 & 100.00 \\
\hline 150.0 & 100.00 \\
\hline 125.0 & 100.00 \\
\hline 105.0 & 100.00 \\
\hline 90.0 & 100.00 \\
\hline 75.0 & 100.00 \\
\hline 63.5 & 100.00 \\
\hline 50.8 & 100.00 \\
\hline 38.1 & 100.00 \\
\hline 25.4 & 97.50 \\
\hline 19.1 & 87.13 \\
\hline 12.7 & 70.01 \\
\hline 9.5 & 60.86 \\
\hline 6.4 & 48.19 \\
\hline 4.75 & 41.08 \\
\hline 3.35 & 35.33 \\
\hline 2.36 & 30.05 \\
\hline 1.70 & 25.82 \\
\hline 1.18 & 22.05 \\
\hline 0.850 & 19.20 \\
\hline 0.600 & 16.72 \\
\hline 0.425 & 14.95 \\
\hline 0.300 & 13.20 \\
\hline 0.212 & 11.85 \\
\hline 0.150 & 10.80 \\
\hline 0.106 & 9.83 \\
\hline 0.075 & 8.97 \\
\hline & \\
\hline
\end{tabular}

\section{16-5}

\begin{tabular}{|l|l|}
\hline size (mm) & Cum \% Passing \\
\hline
\end{tabular}

\begin{tabular}{|r|r|}
\hline 300.0 & 100.00 \\
\hline 212.0 & 100.00 \\
\hline 175.0 & 100.00 \\
\hline 150.0 & 100.00 \\
\hline 125.0 & 100.00 \\
\hline 105.0 & 100.00 \\
\hline 90.0 & 100.00 \\
\hline 75.0 & 97.33 \\
\hline 63.5 & 87.62 \\
\hline 50.8 & 65.67 \\
\hline 38.1 & 34.01 \\
\hline 25.4 & 7.01 \\
\hline 19.1 & 2.73 \\
\hline 12.7 & 2.04 \\
\hline 9.5 & 1.91 \\
\hline 6.4 & 1.80 \\
\hline 4.75 & 1.74 \\
\hline 3.35 & 1.67 \\
\hline 2.36 & 1.61 \\
\hline 1.70 & 1.55 \\
\hline 1.18 & 1.48 \\
\hline 0.850 & 1.42 \\
\hline 0.600 & 1.35 \\
\hline 0.425 & 1.28 \\
\hline 0.300 & 1.18 \\
\hline 0.212 & 1.08 \\
\hline 0.150 & 0.98 \\
\hline 0.106 & 0.88 \\
\hline 0.075 & 0.79 \\
\hline & \\
\hline
\end{tabular}




\section{Secondary Section - Audit 6}
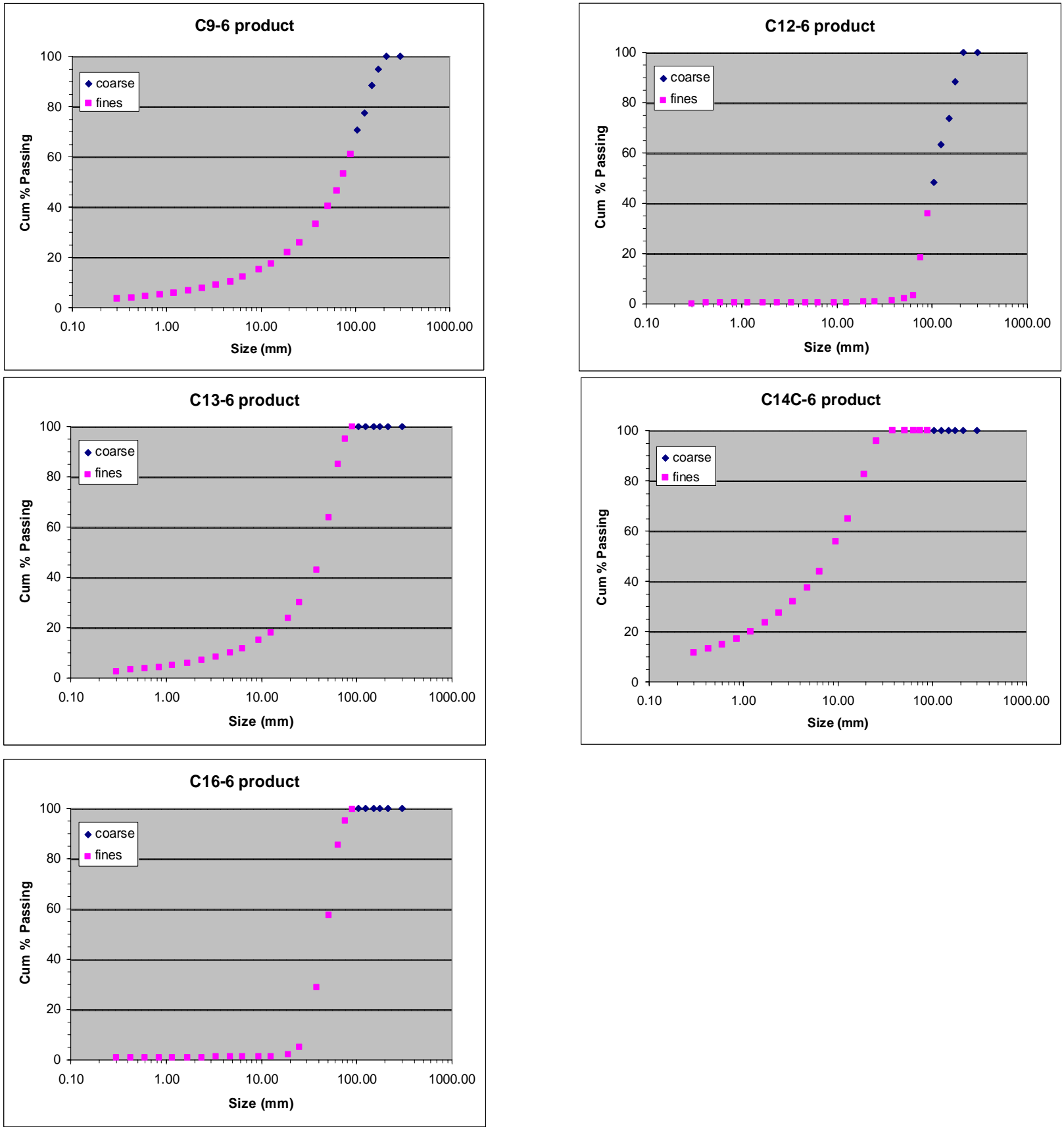
C 9-6

\begin{tabular}{|r|r|}
\hline size (mm) & Cum \% Passing \\
\hline 300.0 & 100.00 \\
\hline 212.0 & 100.00 \\
\hline 175.0 & 94.71 \\
\hline 150.0 & 88.36 \\
\hline 125.0 & 77.32 \\
\hline 105.0 & 70.63 \\
\hline 90.0 & 60.99 \\
\hline 75.0 & 53.26 \\
\hline 63.5 & 46.37 \\
\hline 50.8 & 40.28 \\
\hline 38.1 & 33.30 \\
\hline 25.4 & 25.92 \\
\hline 19.1 & 21.85 \\
\hline 12.7 & 17.27 \\
\hline 9.5 & 15.09 \\
\hline 6.4 & 12.10 \\
\hline 4.75 & 10.44 \\
\hline 3.35 & 9.03 \\
\hline 2.36 & 7.74 \\
\hline 1.70 & 6.71 \\
\hline 1.18 & 5.76 \\
\hline 0.850 & 5.04 \\
\hline 0.600 & 4.40 \\
\hline 0.425 & 3.93 \\
\hline 0.300 & 3.46 \\
\hline 0.212 & 3.09 \\
\hline 0.150 & 2.79 \\
\hline 0.106 & 2.53 \\
\hline 0.075 & 2.28 \\
\hline & \\
\hline
\end{tabular}

C 12-6

\begin{tabular}{|r|r|}
\hline size (mm) & Cum \% Passing \\
\hline 300.0 & 100.00 \\
\hline 212.0 & 100.00 \\
\hline 175.0 & 88.52 \\
\hline 150.0 & 73.84 \\
\hline 125.0 & 63.33 \\
\hline 105.0 & 48.15 \\
\hline 90.0 & 35.63 \\
\hline 75.0 & 18.36 \\
\hline 63.5 & 3.48 \\
\hline 50.8 & 2.08 \\
\hline 38.1 & 1.44 \\
\hline 25.4 & 0.96 \\
\hline 19.1 & 0.77 \\
\hline 12.7 & 0.62 \\
\hline 9.5 & 0.54 \\
\hline 6.4 & 0.48 \\
\hline 4.75 & 0.43 \\
\hline 3.35 & 0.39 \\
\hline 2.36 & 0.35 \\
\hline 1.70 & 0.32 \\
\hline 1.18 & 0.29 \\
\hline 0.850 & 0.26 \\
\hline 0.600 & 0.23 \\
\hline 0.425 & 0.21 \\
\hline 0.300 & 0.18 \\
\hline 0.212 & 0.16 \\
\hline 0.150 & 0.15 \\
\hline 0.106 & 0.13 \\
\hline 0.075 & 0.12 \\
\hline & \\
\hline
\end{tabular}

C 13-6

\begin{tabular}{|c|c|}
\hline size (mm) & Cum \% Passing \\
\hline 300.0 & 100.00 \\
\hline 212.0 & 100.00 \\
\hline 175.0 & 100.00 \\
\hline 150.0 & 100.00 \\
\hline 125.0 & 100.00 \\
\hline 105.0 & 100.00 \\
\hline 90.0 & 100.00 \\
\hline 75.0 & 94.85 \\
\hline 63.5 & 84.99 \\
\hline 50.8 & 63.79 \\
\hline 38.1 & 43.04 \\
\hline 25.4 & 29.81 \\
\hline 19.1 & 23.94 \\
\hline 12.7 & 17.87 \\
\hline 9.5 & 15.11 \\
\hline 6.4 & 11.68 \\
\hline 4.75 & 9.88 \\
\hline 3.35 & 8.26 \\
\hline 2.36 & 6.96 \\
\hline 1.70 & 5.92 \\
\hline 1.18 & 4.95 \\
\hline 0.850 & 4.25 \\
\hline 0.600 & 3.64 \\
\hline 0.425 & 3.17 \\
\hline 0.300 & 2.70 \\
\hline 0.212 & 2.31 \\
\hline 0.150 & 2.01 \\
\hline 0.106 & 1.75 \\
\hline 0.075 & 1.55 \\
\hline
\end{tabular}

C 14C-6

\begin{tabular}{|r|r|}
\hline size (mm) & Cum \% Passing \\
\hline 300.0 & 100.00 \\
\hline 212.0 & 100.00 \\
\hline 175.0 & 100.00 \\
\hline 150.0 & 100.00 \\
\hline 125.0 & 100.00 \\
\hline 105.0 & 100.00 \\
\hline 90.0 & 100.00 \\
\hline 75.0 & 100.00 \\
\hline 63.5 & 100.00 \\
\hline 50.8 & 100.00 \\
\hline 38.1 & 100.00 \\
\hline 25.4 & 95.93 \\
\hline 19.1 & 82.73 \\
\hline 12.7 & 64.80 \\
\hline 9.5 & 55.73 \\
\hline 6.4 & 43.86 \\
\hline 4.75 & 37.33 \\
\hline 3.35 & 32.05 \\
\hline 2.36 & 27.34 \\
\hline 1.70 & 23.43 \\
\hline 1.18 & 19.96 \\
\hline 0.850 & 17.24 \\
\hline 0.600 & 14.91 \\
\hline 0.425 & 13.26 \\
\hline 0.300 & 11.60 \\
\hline 0.212 & 10.32 \\
\hline 0.150 & 9.33 \\
\hline 0.106 & 8.44 \\
\hline 0.075 & 7.67 \\
\hline & \\
\hline
\end{tabular}

\section{16-6}

\begin{tabular}{|r|r|}
\hline size (mm) & Cum \% Passing \\
\hline 300.0 & 100.00 \\
\hline 212.0 & 100.00 \\
\hline 175.0 & 100.00 \\
\hline 150.0 & 100.00 \\
\hline 125.0 & 100.00 \\
\hline 105.0 & 100.00 \\
\hline 90.0 & 99.40 \\
\hline 75.0 & 95.07 \\
\hline 63.5 & 85.39 \\
\hline 50.8 & 57.55 \\
\hline 38.1 & 28.76 \\
\hline 25.4 & 4.86 \\
\hline 19.1 & 1.89 \\
\hline 12.7 & 1.38 \\
\hline 9.5 & 1.27 \\
\hline 6.4 & 1.17 \\
\hline 4.75 & 1.11 \\
\hline 3.35 & 1.06 \\
\hline 2.36 & 1.01 \\
\hline 1.70 & 0.97 \\
\hline 1.18 & 0.92 \\
\hline 0.850 & 0.87 \\
\hline 0.600 & 0.82 \\
\hline 0.425 & 0.77 \\
\hline 0.300 & 0.71 \\
\hline 0.212 & 0.65 \\
\hline 0.150 & 0.59 \\
\hline 0.106 & 0.53 \\
\hline 0.075 & 0.47 \\
\hline & \\
\hline
\end{tabular}




\section{Secondary Section - Audit 7}
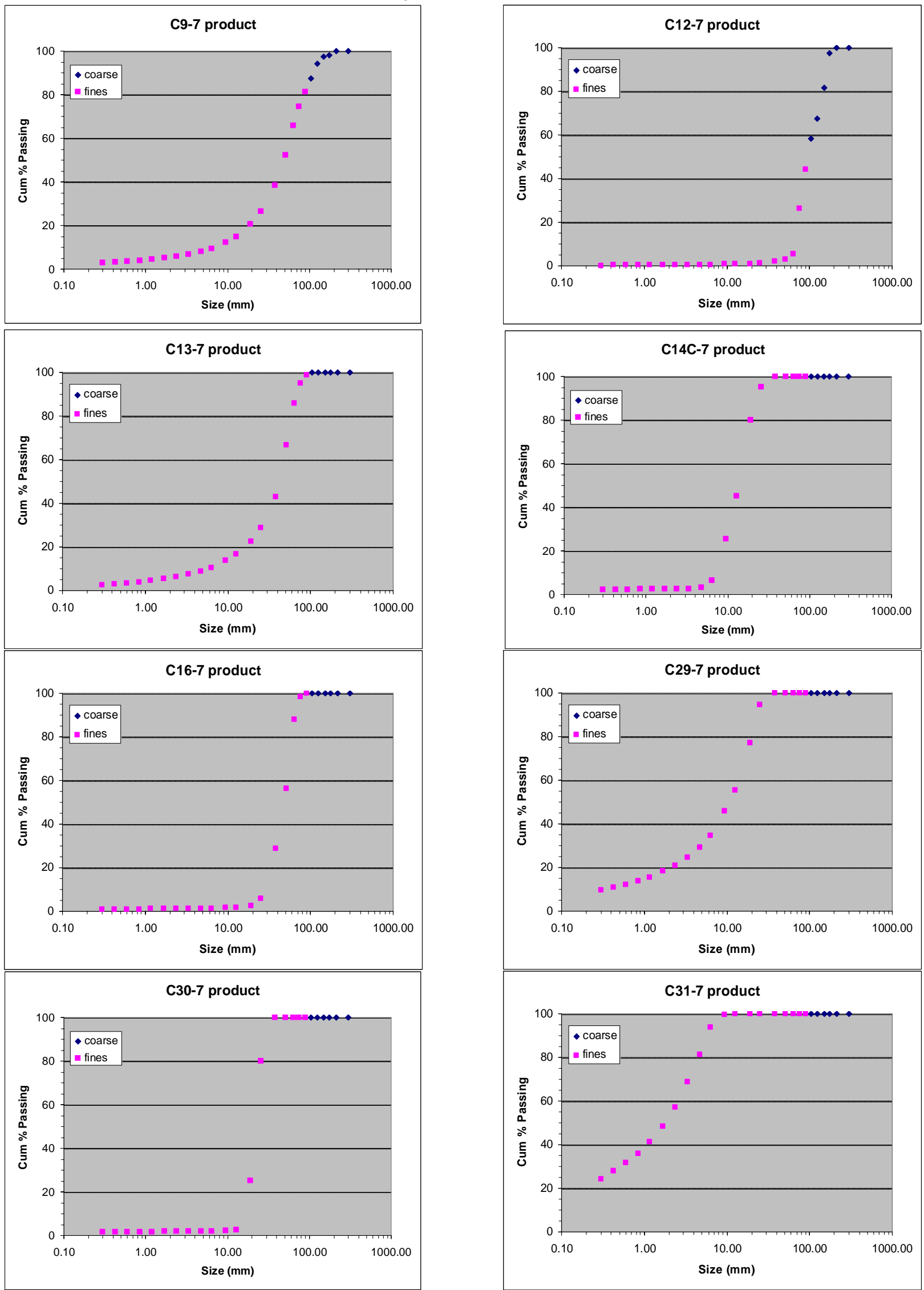
C 9-7

\begin{tabular}{|r|r|}
\hline size (mm) & Cum \% Passing \\
\hline 300.0 & 100.00 \\
\hline 212.0 & 100.00 \\
\hline 175.0 & 98.17 \\
\hline 150.0 & 97.34 \\
\hline 125.0 & 94.29 \\
\hline 105.0 & 87.57 \\
\hline 90.0 & 81.25 \\
\hline 75.0 & 74.57 \\
\hline 63.5 & 65.94 \\
\hline 50.8 & 52.17 \\
\hline 38.1 & 38.24 \\
\hline 25.4 & 26.36 \\
\hline 19.1 & 20.60 \\
\hline 12.7 & 14.73 \\
\hline 9.5 & 12.38 \\
\hline 6.4 & 9.37 \\
\hline 4.75 & 7.94 \\
\hline 3.35 & 6.79 \\
\hline 2.36 & 5.83 \\
\hline 1.70 & 5.10 \\
\hline 1.18 & 4.44 \\
\hline 0.850 & 3.97 \\
\hline 0.600 & 3.55 \\
\hline 0.425 & 3.22 \\
\hline 0.300 & 2.90 \\
\hline 0.212 & 2.63 \\
\hline 0.150 & 2.42 \\
\hline 0.106 & 2.22 \\
\hline 0.075 & 2.04 \\
\hline & \\
\hline
\end{tabular}

C 16-7

\begin{tabular}{|l|l|}
\hline size (mm) & Cum \% Passing \\
\hline
\end{tabular}

\begin{tabular}{|r|r|}
\hline 300.0 & 100.00 \\
\hline 212.0 & 100.00 \\
\hline 175.0 & 100.00 \\
\hline 150.0 & 100.00 \\
\hline 125.0 & 100.00 \\
\hline 105.0 & 100.00 \\
\hline 90.0 & 100.00 \\
\hline 75.0 & 98.39 \\
\hline 63.5 & 87.73 \\
\hline 50.8 & 56.27 \\
\hline 38.1 & 28.74 \\
\hline 25.4 & 5.91 \\
\hline 19.1 & 2.36 \\
\hline 12.7 & 1.63 \\
\hline 9.5 & 1.52 \\
\hline 6.4 & 1.36 \\
\hline 4.75 & 1.29 \\
\hline 3.35 & 1.23 \\
\hline 2.36 & 1.18 \\
\hline 1.70 & 1.13 \\
\hline 1.18 & 1.08 \\
\hline 0.850 & 1.03 \\
\hline 0.600 & 0.98 \\
\hline 0.425 & 0.92 \\
\hline 0.300 & 0.85 \\
\hline 0.212 & 0.78 \\
\hline 0.150 & 0.72 \\
\hline 0.106 & 0.65 \\
\hline 0.075 & 0.59 \\
\hline & \\
\hline
\end{tabular}

C 12-7

\begin{tabular}{|r|r|}
\hline size (mm) & Cum \% Passing \\
\hline 300.0 & 100.00 \\
\hline 212.0 & 100.00 \\
\hline 175.0 & 97.31 \\
\hline 150.0 & 81.52 \\
\hline 125.0 & 67.36 \\
\hline 105.0 & 58.14 \\
\hline 90.0 & 44.33 \\
\hline 75.0 & 26.08 \\
\hline 63.5 & 5.53 \\
\hline 50.8 & 3.03 \\
\hline 38.1 & 1.96 \\
\hline 25.4 & 1.18 \\
\hline 19.1 & 0.95 \\
\hline 12.7 & 0.77 \\
\hline 9.5 & 0.68 \\
\hline 6.4 & 0.57 \\
\hline 4.75 & 0.51 \\
\hline 3.35 & 0.45 \\
\hline 2.36 & 0.40 \\
\hline 1.70 & 0.36 \\
\hline 1.18 & 0.32 \\
\hline 0.850 & 0.28 \\
\hline 0.600 & 0.25 \\
\hline 0.425 & 0.22 \\
\hline 0.300 & 0.19 \\
\hline 0.212 & 0.17 \\
\hline 0.150 & 0.15 \\
\hline 0.106 & 0.13 \\
\hline 0.075 & 0.11 \\
\hline & \\
\hline &
\end{tabular}

C 29-7

\begin{tabular}{|l|l|}
\hline size (mm) & Cum \% Passing \\
\hline
\end{tabular}

\begin{tabular}{|r|r|}
\hline 300.0 & 100.00 \\
\hline 212.0 & 100.00 \\
\hline 175.0 & 100.00 \\
\hline 150.0 & 100.00 \\
\hline 125.0 & 100.00 \\
\hline 105.0 & 100.00 \\
\hline 90.0 & 100.00 \\
\hline 75.0 & 100.00 \\
\hline 63.5 & 100.00 \\
\hline 50.8 & 100.00 \\
\hline 38.1 & 100.00 \\
\hline 25.4 & 94.73 \\
\hline 19.1 & 77.02 \\
\hline 12.7 & 55.37 \\
\hline 9.5 & 45.80 \\
\hline 6.4 & 34.64 \\
\hline 4.75 & 29.13 \\
\hline 3.35 & 24.73 \\
\hline 2.36 & 21.02 \\
\hline 1.70 & 18.16 \\
\hline 1.18 & 15.57 \\
\hline 0.850 & 13.72 \\
\hline 0.600 & 12.09 \\
\hline 0.425 & 10.84 \\
\hline 0.300 & 9.62 \\
\hline 0.212 & 8.65 \\
\hline 0.150 & 7.88 \\
\hline 0.106 & 7.18 \\
\hline 0.075 & 6.56 \\
\hline & \\
\hline
\end{tabular}

C 13-7

\begin{tabular}{|l|l|}
\hline size (mm) & Cum \% Passing \\
\hline
\end{tabular}

\begin{tabular}{|r|r|}
\hline 300.0 & 100.00 \\
\hline 212.0 & 100.00 \\
\hline 175.0 & 100.00 \\
\hline 150.0 & 100.00 \\
\hline 125.0 & 100.00 \\
\hline 105.0 & 100.00 \\
\hline 90.0 & 98.70 \\
\hline 75.0 & 94.93 \\
\hline 63.5 & 85.98 \\
\hline 50.8 & 66.78 \\
\hline 38.1 & 42.72 \\
\hline 25.4 & 28.62 \\
\hline 19.1 & 22.61 \\
\hline 12.7 & 16.57 \\
\hline 9.5 & 13.86 \\
\hline 6.4 & 10.61 \\
\hline 4.75 & 8.91 \\
\hline 3.35 & 7.36 \\
\hline 2.36 & 6.23 \\
\hline 1.70 & 5.34 \\
\hline 1.18 & 4.52 \\
\hline 0.850 & 3.91 \\
\hline 0.600 & 3.39 \\
\hline 0.425 & 2.96 \\
\hline 0.300 & 2.53 \\
\hline 0.212 & 2.19 \\
\hline 0.150 & 1.93 \\
\hline 0.106 & 1.69 \\
\hline 0.075 & 1.48 \\
\hline & \\
\hline
\end{tabular}

C 30-7

\begin{tabular}{|l|l|}
\hline size (mm) & Cum \% Passing \\
\hline
\end{tabular}

\begin{tabular}{|r|r|}
\hline 300.0 & 100.00 \\
\hline 212.0 & 100.00 \\
\hline 175.0 & 100.00 \\
\hline 150.0 & 100.00 \\
\hline 125.0 & 100.00 \\
\hline 105.0 & 100.00 \\
\hline 90.0 & 100.00 \\
\hline 75.0 & 100.00 \\
\hline 63.5 & 100.00 \\
\hline 50.8 & 100.00 \\
\hline 38.1 & 100.00 \\
\hline 25.4 & 79.93 \\
\hline 19.1 & 25.11 \\
\hline 12.7 & 2.48 \\
\hline 9.5 & 2.14 \\
\hline 6.4 & 1.99 \\
\hline 4.75 & 1.95 \\
\hline 3.35 & 1.89 \\
\hline 2.36 & 1.85 \\
\hline 1.70 & 1.81 \\
\hline 1.18 & 1.77 \\
\hline 0.850 & 1.73 \\
\hline 0.600 & 1.68 \\
\hline 0.425 & 1.63 \\
\hline 0.300 & 1.55 \\
\hline 0.212 & 1.47 \\
\hline 0.150 & 1.38 \\
\hline 0.106 & 1.27 \\
\hline 0.075 & 1.16 \\
\hline & \\
\hline
\end{tabular}

C 14C-7

\begin{tabular}{|r|r|}
\hline size $(\mathbf{m m})$ & Cum \% Passing \\
\hline 300.0 & 100.00 \\
\hline 212.0 & 100.00 \\
\hline 175.0 & 100.00 \\
\hline 150.0 & 100.00 \\
\hline 125.0 & 100.00 \\
\hline 105.0 & 100.00 \\
\hline 90.0 & 100.00 \\
\hline 75.0 & 100.00 \\
\hline 63.5 & 100.00 \\
\hline 50.8 & 100.00 \\
\hline 38.1 & 100.00 \\
\hline 25.4 & 95.24 \\
\hline 19.1 & 80.00 \\
\hline 12.7 & 45.13 \\
\hline 9.5 & 25.59 \\
\hline 6.4 & 6.47 \\
\hline 4.75 & 3.13 \\
\hline 3.35 & 2.67 \\
\hline 2.36 & 2.58 \\
\hline 1.70 & 2.53 \\
\hline 1.18 & 2.47 \\
\hline 0.850 & 2.43 \\
\hline 0.600 & 2.37 \\
\hline 0.425 & 2.32 \\
\hline 0.300 & 2.23 \\
\hline 0.212 & 2.12 \\
\hline 0.150 & 2.01 \\
\hline 0.106 & 1.86 \\
\hline 0.075 & 1.69 \\
\hline & \\
\hline
\end{tabular}

C 31-7

\begin{tabular}{|l|l|}
\hline size (mm) & Cum \% Passing \\
\hline
\end{tabular}

\begin{tabular}{|r|r|}
\hline 300.0 & 100.00 \\
\hline 212.0 & 100.00 \\
\hline 175.0 & 100.00 \\
\hline 150.0 & 100.00 \\
\hline 125.0 & 100.00 \\
\hline 105.0 & 100.00 \\
\hline 90.0 & 100.00 \\
\hline 75.0 & 100.00 \\
\hline 63.5 & 100.00 \\
\hline 50.8 & 100.00 \\
\hline 38.1 & 100.00 \\
\hline 25.4 & 100.00 \\
\hline 19.1 & 100.00 \\
\hline 12.7 & 100.00 \\
\hline 9.5 & 99.53 \\
\hline 6.4 & 93.67 \\
\hline 4.75 & 81.27 \\
\hline 3.35 & 68.62 \\
\hline 2.36 & 57.18 \\
\hline 1.70 & 48.37 \\
\hline 1.18 & 41.05 \\
\hline 0.850 & 36.01 \\
\hline 0.600 & 31.47 \\
\hline 0.425 & 27.92 \\
\hline 0.300 & 24.36 \\
\hline 0.212 & 21.51 \\
\hline 0.150 & 19.35 \\
\hline 0.106 & 17.44 \\
\hline 0.075 & 15.77 \\
\hline
\end{tabular}




\section{Secondary Section - 3M Audit}
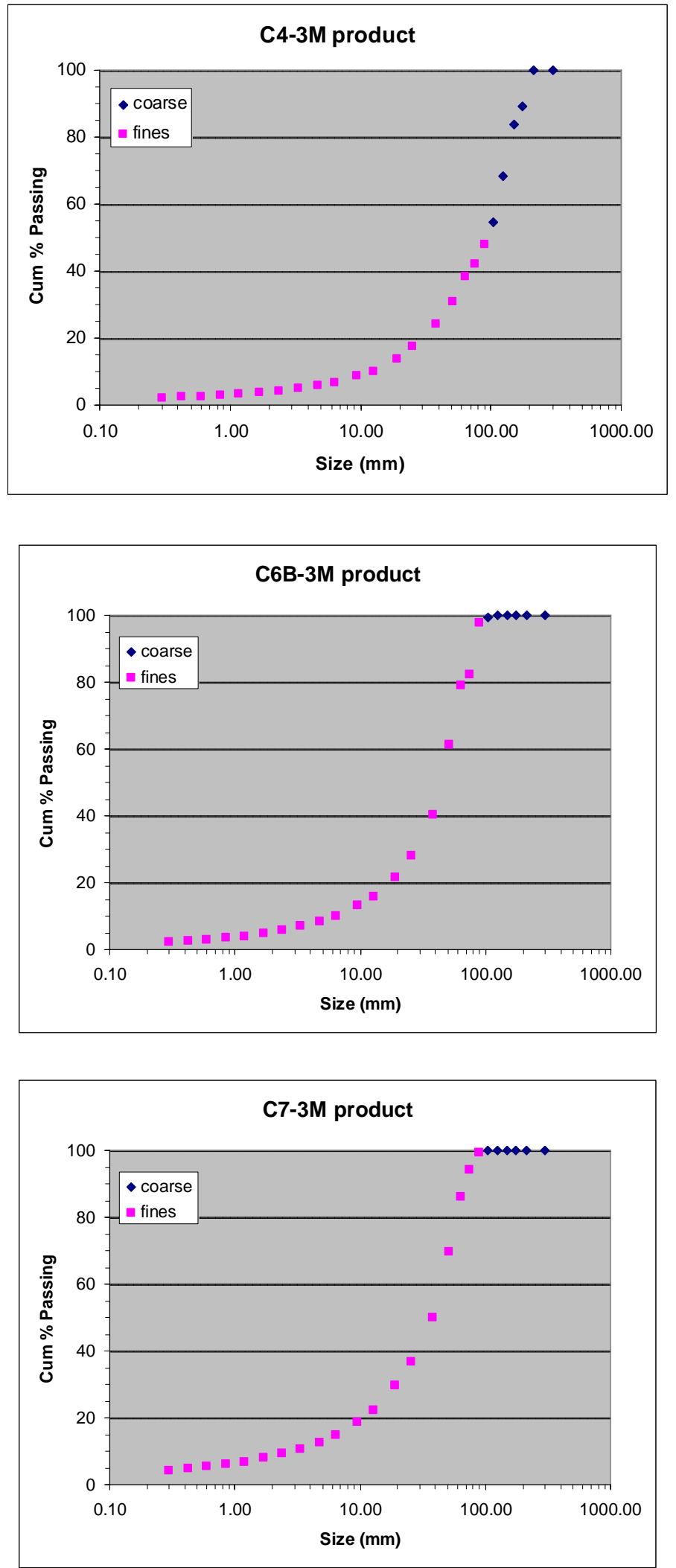
C 4

\begin{tabular}{|r|r|}
\hline size $\mathbf{( m m )}$ & Cum \% Passing \\
\hline 300.0 & 100.00 \\
\hline 212.0 & 100.00 \\
\hline 175.0 & 89.18 \\
\hline 150.0 & 83.62 \\
\hline 125.0 & 68.47 \\
\hline 105.0 & 54.43 \\
\hline 90.0 & 47.77 \\
\hline 75.0 & 42.26 \\
\hline 63.5 & 38.45 \\
\hline 50.8 & 30.99 \\
\hline 38.1 & 24.22 \\
\hline 25.4 & 17.42 \\
\hline 19.1 & 13.76 \\
\hline 12.7 & 10.06 \\
\hline 9.5 & 8.55 \\
\hline 6.4 & 6.65 \\
\hline 4.75 & 5.68 \\
\hline 3.35 & 4.85 \\
\hline 2.36 & 4.24 \\
\hline 1.70 & 3.76 \\
\hline 1.18 & 3.32 \\
\hline 0.850 & 3.00 \\
\hline 0.600 & 2.70 \\
\hline 0.425 & 2.46 \\
\hline 0.300 & 2.21 \\
\hline 0.212 & 1.99 \\
\hline 0.150 & 1.81 \\
\hline 0.106 & 1.64 \\
\hline 0.075 & 1.47 \\
\hline & \\
\hline
\end{tabular}

C 6B

\begin{tabular}{|r|r|}
\hline size $\mathbf{( m m}$ ) & Cum \% Passing \\
\hline 300.0 & 100.00 \\
\hline 212.0 & 100.00 \\
\hline 175.0 & 100.00 \\
\hline 150.0 & 100.00 \\
\hline 125.0 & 100.00 \\
\hline 105.0 & 99.50 \\
\hline 90.0 & 97.70 \\
\hline 75.0 & 82.27 \\
\hline 63.5 & 79.09 \\
\hline 50.8 & 61.29 \\
\hline 38.1 & 40.35 \\
\hline 25.4 & 27.95 \\
\hline 19.1 & 21.73 \\
\hline 12.7 & 15.95 \\
\hline 9.5 & 13.30 \\
\hline 6.4 & 10.09 \\
\hline 4.75 & 8.44 \\
\hline 3.35 & 6.97 \\
\hline 2.36 & 5.76 \\
\hline 1.70 & 4.82 \\
\hline 1.18 & 4.01 \\
\hline 0.850 & 3.39 \\
\hline 0.600 & 2.88 \\
\hline 0.425 & 2.52 \\
\hline 0.300 & 2.15 \\
\hline 0.212 & 1.85 \\
\hline 0.150 & 1.62 \\
\hline 0.106 & 1.41 \\
\hline 0.075 & 1.22 \\
\hline & \\
\hline
\end{tabular}

C 7

\begin{tabular}{|r|r|}
\hline size $(\mathbf{m m})$ & Cum \% Passing \\
\hline 300.0 & 100.00 \\
\hline 212.0 & 100.00 \\
\hline 175.0 & 100.00 \\
\hline 150.0 & 100.00 \\
\hline 125.0 & 100.00 \\
\hline 105.0 & 100.00 \\
\hline 90.0 & 99.28 \\
\hline 75.0 & 94.16 \\
\hline 63.5 & 86.00 \\
\hline 50.8 & 69.54 \\
\hline 38.1 & 50.15 \\
\hline 25.4 & 36.81 \\
\hline 19.1 & 29.54 \\
\hline 12.7 & 22.16 \\
\hline 9.5 & 18.86 \\
\hline 6.4 & 14.72 \\
\hline 4.75 & 12.56 \\
\hline 3.35 & 10.75 \\
\hline 2.36 & 9.20 \\
\hline 1.70 & 8.01 \\
\hline 1.18 & 6.91 \\
\hline 0.850 & 6.12 \\
\hline 0.600 & 5.42 \\
\hline 0.425 & 4.88 \\
\hline 0.300 & 4.34 \\
\hline 0.212 & 3.90 \\
\hline 0.150 & 3.55 \\
\hline 0.106 & 3.21 \\
\hline 0.075 & 2.90 \\
\hline & \\
\hline
\end{tabular}




\section{Tertiary Section - Audit 1}
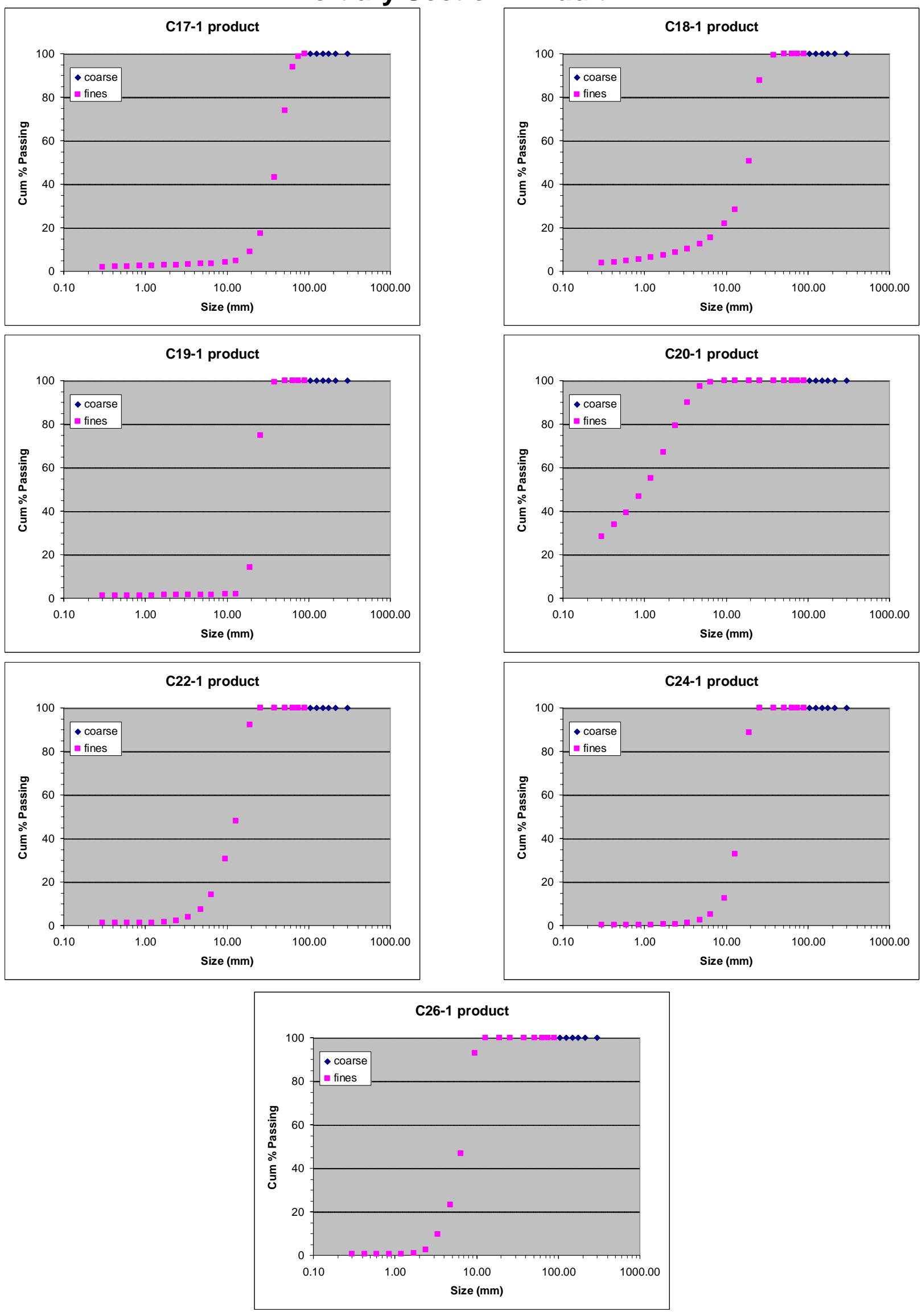
C 17-1

\begin{tabular}{|r|r|}
\hline size (mm) & Cum \% Passing \\
\hline 300.0 & 100.00 \\
\hline 212.0 & 100.00 \\
\hline 175.0 & 100.00 \\
\hline 150.0 & 100.00 \\
\hline 125.0 & 100.00 \\
\hline 105.0 & 100.00 \\
\hline 90.0 & 100.00 \\
\hline 75.0 & 98.70 \\
\hline 63.5 & 93.74 \\
\hline 50.8 & 73.95 \\
\hline 38.1 & 43.34 \\
\hline 25.4 & 17.37 \\
\hline 19.1 & 9.02 \\
\hline 12.7 & 4.99 \\
\hline 9.5 & 4.29 \\
\hline 6.4 & 3.65 \\
\hline 4.75 & 3.39 \\
\hline 3.35 & 3.19 \\
\hline 2.36 & 3.02 \\
\hline 1.70 & 2.86 \\
\hline 1.18 & 2.70 \\
\hline 0.850 & 2.55 \\
\hline 0.600 & 2.40 \\
\hline 0.425 & 2.26 \\
\hline 0.300 & 2.08 \\
\hline 0.212 & 1.90 \\
\hline 0.150 & 1.74 \\
\hline 0.106 & 1.58 \\
\hline 0.075 & 1.43 \\
\hline & \\
\hline
\end{tabular}

C 22-1

\begin{tabular}{|c|c|}
\hline size $(\mathrm{mm})$ & Cum \% Passing \\
\hline 300.0 & 100.00 \\
\hline 212.0 & 100.00 \\
\hline 175.0 & 100.00 \\
\hline 150.0 & 100.00 \\
\hline 125.0 & 100.00 \\
\hline 105.0 & 100.00 \\
\hline 90.0 & 100.00 \\
\hline 75.0 & 100.00 \\
\hline 63.5 & 100.00 \\
\hline 50.8 & 100.00 \\
\hline 38.1 & 100.00 \\
\hline 25.4 & 100.00 \\
\hline 19.1 & 92.24 \\
\hline 12.7 & 48.06 \\
\hline 9.5 & 30.50 \\
\hline 6.4 & 14.10 \\
\hline 4.75 & 7.56 \\
\hline 3.35 & 3.97 \\
\hline 2.36 & 2.10 \\
\hline 1.70 & 1.57 \\
\hline 1.18 & 1.45 \\
\hline 0.850 & 1.38 \\
\hline 0.600 & 1.32 \\
\hline 0.425 & 1.27 \\
\hline 0.300 & 1.20 \\
\hline 0.212 & 1.13 \\
\hline 0.150 & 1.06 \\
\hline 0.106 & 0.98 \\
\hline 0.075 & 0.88 \\
\hline
\end{tabular}

C 18-1

\begin{tabular}{|c|c|}
\hline size (mm) & Cum \% Passing \\
\hline 300.0 & 100.00 \\
\hline 212.0 & 100.00 \\
\hline 175.0 & 100.00 \\
\hline 150.0 & 100.00 \\
\hline 125.0 & 100.00 \\
\hline 105.0 & 100.00 \\
\hline 90.0 & 100.00 \\
\hline 75.0 & 100.00 \\
\hline 63.5 & 100.00 \\
\hline 50.8 & 100.00 \\
\hline 38.1 & 99.40 \\
\hline 25.4 & 87.61 \\
\hline 19.1 & 50.49 \\
\hline 12.7 & 28.25 \\
\hline 9.5 & 21.91 \\
\hline 6.4 & 15.51 \\
\hline 4.75 & 12.71 \\
\hline 3.35 & 10.48 \\
\hline 2.36 & 8.77 \\
\hline 1.70 & 7.46 \\
\hline 1.18 & 6.33 \\
\hline 0.850 & 5.51 \\
\hline 0.600 & 4.81 \\
\hline 0.425 & 4.31 \\
\hline 0.300 & 3.79 \\
\hline 0.212 & 3.38 \\
\hline 0.150 & 3.04 \\
\hline 0.106 & 2.72 \\
\hline 0.075 & 2.42 \\
\hline
\end{tabular}

C 24-1

\begin{tabular}{|c|c|}
\hline size $(\mathrm{mm})$ & Cum \% Passing \\
\hline 300.0 & 100.00 \\
\hline 212.0 & 100.00 \\
\hline 175.0 & 100.00 \\
\hline 150.0 & 100.00 \\
\hline 125.0 & 100.00 \\
\hline 105.0 & 100.00 \\
\hline 90.0 & 100.00 \\
\hline 75.0 & 100.00 \\
\hline 63.5 & 100.00 \\
\hline 50.8 & 100.00 \\
\hline 38.1 & 100.00 \\
\hline 25.4 & 100.00 \\
\hline 19.1 & 88.62 \\
\hline 12.7 & 32.78 \\
\hline 9.5 & 12.42 \\
\hline 6.4 & 5.17 \\
\hline 4.75 & 2.60 \\
\hline 3.35 & 1.31 \\
\hline 2.36 & 0.67 \\
\hline 1.70 & 0.51 \\
\hline 1.18 & 0.45 \\
\hline 0.850 & 0.42 \\
\hline 0.600 & 0.39 \\
\hline 0.425 & 0.37 \\
\hline 0.300 & 0.34 \\
\hline 0.212 & 0.32 \\
\hline 0.150 & 0.30 \\
\hline 0.106 & 0.28 \\
\hline 0.075 & 0.25 \\
\hline
\end{tabular}

C 19-1

\begin{tabular}{|l|l|}
\hline size (mm) & Cum \% Passing \\
\hline
\end{tabular}

\begin{tabular}{|c|c|}
\hline 300.0 & 100.00 \\
\hline 212.0 & 100.00 \\
\hline 175.0 & 100.00 \\
\hline 150.0 & 100.00 \\
\hline 125.0 & 100.00 \\
\hline 105.0 & 100.00 \\
\hline 90.0 & 100.00 \\
\hline 75.0 & 100.00 \\
\hline 63.5 & 100.00 \\
\hline 50.8 & 100.00 \\
\hline 38.1 & 99.33 \\
\hline 25.4 & 74.76 \\
\hline 19.1 & 14.26 \\
\hline 12.7 & 1.99 \\
\hline 9.5 & 1.79 \\
\hline 6.4 & 1.66 \\
\hline 4.75 & 1.61 \\
\hline 3.35 & 1.55 \\
\hline 2.36 & 1.51 \\
\hline 1.70 & 1.47 \\
\hline 1.18 & 1.43 \\
\hline 0.850 & 1.40 \\
\hline 0.600 & 1.35 \\
\hline 0.425 & 1.31 \\
\hline 0.300 & 1.25 \\
\hline 0.212 & 1.18 \\
\hline 0.150 & 1.11 \\
\hline 0.106 & 1.03 \\
\hline 0.075 & 0.94 \\
\hline
\end{tabular}

C 26-1

\begin{tabular}{|c|c|}
\hline size (mm) & Cum \% Passing \\
\hline 300.0 & 100.00 \\
\hline 212.0 & 100.00 \\
\hline 175.0 & 100.00 \\
\hline 150.0 & 100.00 \\
\hline 125.0 & 100.00 \\
\hline 105.0 & 100.00 \\
\hline 90.0 & 100.00 \\
\hline 75.0 & 100.00 \\
\hline 63.5 & 100.00 \\
\hline 50.8 & 100.00 \\
\hline 38.1 & 100.00 \\
\hline 25.4 & 100.00 \\
\hline 19.1 & 100.00 \\
\hline 12.7 & 100.00 \\
\hline 9.5 & 93.03 \\
\hline 6.4 & 46.79 \\
\hline 4.75 & 23.27 \\
\hline 3.35 & 9.52 \\
\hline 2.36 & 2.53 \\
\hline 1.70 & 1.00 \\
\hline 1.18 & 0.79 \\
\hline 0.850 & 0.73 \\
\hline 0.600 & 0.67 \\
\hline 0.425 & 0.63 \\
\hline 0.300 & 0.59 \\
\hline 0.212 & 0.55 \\
\hline 0.150 & 0.52 \\
\hline 0.106 & 0.48 \\
\hline 0.075 & 0.44 \\
\hline
\end{tabular}

C 20-1

\begin{tabular}{|l|l|}
\hline size (mm) & Cum \% Passing \\
\hline
\end{tabular}

\begin{tabular}{|r|r|}
\hline 300.0 & 100.00 \\
\hline 212.0 & 100.00 \\
\hline 175.0 & 100.00 \\
\hline 150.0 & 100.00 \\
\hline 125.0 & 100.00 \\
\hline 105.0 & 100.00 \\
\hline 90.0 & 100.00 \\
\hline 75.0 & 100.00 \\
\hline 63.5 & 100.00 \\
\hline 50.8 & 100.00 \\
\hline 38.1 & 100.00 \\
\hline 25.4 & 100.00 \\
\hline 19.1 & 100.00 \\
\hline 12.7 & 100.00 \\
\hline 9.5 & 100.00 \\
\hline 6.4 & 99.31 \\
\hline 4.75 & 97.33 \\
\hline 3.35 & 90.06 \\
\hline 2.36 & 79.29 \\
\hline 1.70 & 67.10 \\
\hline 1.18 & 55.19 \\
\hline 0.850 & 46.81 \\
\hline 0.600 & 39.51 \\
\hline 0.425 & 33.92 \\
\hline 0.300 & 28.49 \\
\hline 0.212 & 24.27 \\
\hline 0.150 & 21.03 \\
\hline 0.106 & 18.22 \\
\hline 0.075 & 15.83 \\
\hline & \\
\hline
\end{tabular}




\section{Tertiary Section - Audit 2}
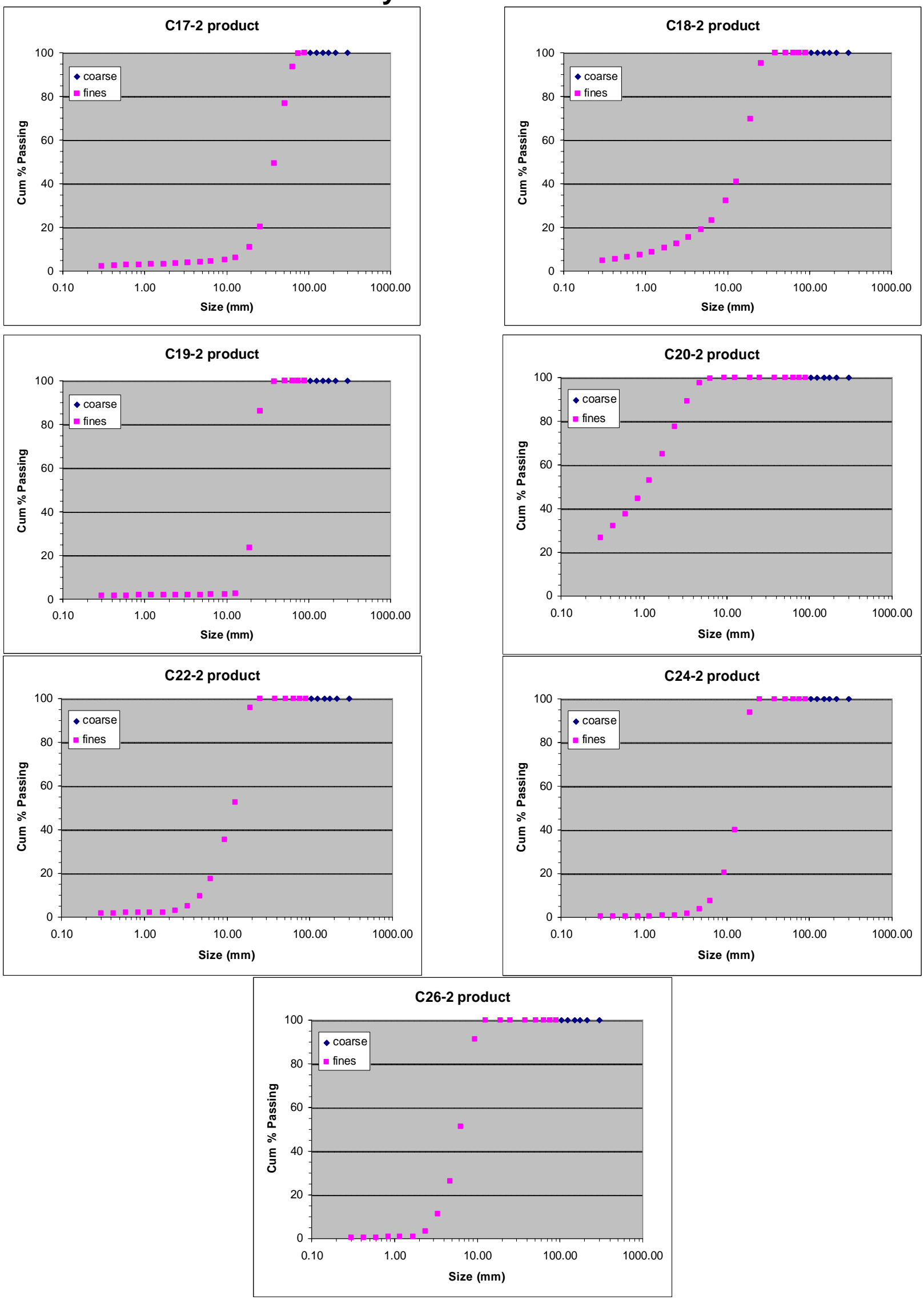
C 17-2

\begin{tabular}{|r|r|}
\hline size $\mathbf{( m m}$ ) & Cum \% Passing \\
\hline 300.0 & 100.00 \\
\hline 212.0 & 100.00 \\
\hline 175.0 & 100.00 \\
\hline 150.0 & 100.00 \\
\hline 125.0 & 100.00 \\
\hline 105.0 & 100.00 \\
\hline 90.0 & 100.00 \\
\hline 75.0 & 99.60 \\
\hline 63.5 & 93.47 \\
\hline 50.8 & 76.64 \\
\hline 38.1 & 49.29 \\
\hline 25.4 & 20.33 \\
\hline 19.1 & 10.87 \\
\hline 12.7 & 6.03 \\
\hline 9.5 & 5.19 \\
\hline 6.4 & 4.36 \\
\hline 4.75 & 4.03 \\
\hline 3.35 & 3.78 \\
\hline 2.36 & 3.55 \\
\hline 1.70 & 3.36 \\
\hline 1.18 & 3.16 \\
\hline 0.850 & 2.98 \\
\hline 0.600 & 2.78 \\
\hline 0.425 & 2.60 \\
\hline 0.300 & 2.39 \\
\hline 0.212 & 2.18 \\
\hline 0.150 & 1.99 \\
\hline 0.106 & 1.81 \\
\hline 0.075 & 1.62 \\
\hline & \\
\hline
\end{tabular}

C 22-2

\begin{tabular}{|r|r|}
\hline size (mm) & Cum \% Passing \\
\hline 300.0 & 100.00 \\
\hline 212.0 & 100.00 \\
\hline 175.0 & 100.00 \\
\hline 150.0 & 100.00 \\
\hline 125.0 & 100.00 \\
\hline 105.0 & 100.00 \\
\hline 90.0 & 100.00 \\
\hline 75.0 & 100.00 \\
\hline 63.5 & 100.00 \\
\hline 50.8 & 100.00 \\
\hline 38.1 & 100.00 \\
\hline 25.4 & 100.00 \\
\hline 19.1 & 95.64 \\
\hline 12.7 & 52.53 \\
\hline 9.5 & 35.55 \\
\hline 6.4 & 17.60 \\
\hline 4.75 & 9.72 \\
\hline 3.35 & 5.06 \\
\hline 2.36 & 2.77 \\
\hline 1.70 & 2.17 \\
\hline 1.18 & 2.02 \\
\hline 0.850 & 1.95 \\
\hline 0.600 & 1.88 \\
\hline 0.425 & 1.81 \\
\hline 0.300 & 1.73 \\
\hline 0.212 & 1.64 \\
\hline 0.150 & 1.56 \\
\hline 0.106 & 1.47 \\
\hline 0.075 & 1.36 \\
\hline & \\
\hline &
\end{tabular}

C 18-2

\begin{tabular}{|c|c|}
\hline size (mm) & Cum \% Passing \\
\hline 300.0 & 100.00 \\
\hline 212.0 & 100.00 \\
\hline 175.0 & 100.00 \\
\hline 150.0 & 100.00 \\
\hline 125.0 & 100.00 \\
\hline 105.0 & 100.00 \\
\hline 90.0 & 100.00 \\
\hline 75.0 & 100.00 \\
\hline 63.5 & 100.00 \\
\hline 50.8 & 100.00 \\
\hline 38.1 & 100.00 \\
\hline 25.4 & 95.01 \\
\hline 19.1 & 69.57 \\
\hline 12.7 & 41.04 \\
\hline 9.5 & 32.32 \\
\hline 6.4 & 23.36 \\
\hline 4.75 & 19.10 \\
\hline 3.35 & 15.43 \\
\hline 2.36 & 12.67 \\
\hline 1.70 & 10.56 \\
\hline 1.18 & 8.74 \\
\hline 0.850 & 7.43 \\
\hline 0.600 & 6.34 \\
\hline 0.425 & 5.57 \\
\hline 0.300 & 4.81 \\
\hline 0.212 & 4.21 \\
\hline 0.150 & 3.74 \\
\hline 0.106 & 3.31 \\
\hline 0.075 & 2.92 \\
\hline
\end{tabular}

C 24-2

\begin{tabular}{|l|l|}
\hline size (mm) & Cum \% Passing \\
\hline
\end{tabular}

\begin{tabular}{|r|r|}
\hline 300.0 & 100.00 \\
\hline 212.0 & 100.00 \\
\hline 175.0 & 100.00 \\
\hline 150.0 & 100.00 \\
\hline 125.0 & 100.00 \\
\hline 105.0 & 100.00 \\
\hline 90.0 & 100.00 \\
\hline 75.0 & 100.00 \\
\hline 63.5 & 100.00 \\
\hline 50.8 & 100.00 \\
\hline 38.1 & 100.00 \\
\hline 25.4 & 100.00 \\
\hline 19.1 & 93.75 \\
\hline 12.7 & 39.93 \\
\hline 9.5 & 20.27 \\
\hline 6.4 & 7.70 \\
\hline 4.75 & 3.76 \\
\hline 3.35 & 1.72 \\
\hline 2.36 & 0.88 \\
\hline 1.70 & 0.66 \\
\hline 1.18 & 0.60 \\
\hline 0.850 & 0.56 \\
\hline 0.600 & 0.52 \\
\hline 0.425 & 0.49 \\
\hline 0.300 & 0.46 \\
\hline 0.212 & 0.42 \\
\hline 0.150 & 0.39 \\
\hline 0.106 & 0.36 \\
\hline 0.075 & 0.32 \\
\hline & \\
\hline
\end{tabular}

C 19-2

\begin{tabular}{|l|l|}
\hline size (mm) & Cum \% Passing \\
\hline
\end{tabular}

\begin{tabular}{|r|r|}
\hline 300.0 & 100.00 \\
\hline 212.0 & 100.00 \\
\hline 175.0 & 100.00 \\
\hline 150.0 & 100.00 \\
\hline
\end{tabular}

\begin{tabular}{|r|r|}
\hline 150.0 & 100.00 \\
\hline 125.0 & 100.00 \\
\hline 105.0
\end{tabular}

\begin{tabular}{|r|r|}
\hline 105.0 & 100.00 \\
\hline 90.0 & 100.00 \\
\hline
\end{tabular}

\begin{tabular}{|r|r|}
\hline 90.0 & 100.00 \\
\hline 75.0 & 100.00 \\
\hline 63.5 & 100.00 \\
\hline
\end{tabular}

\begin{tabular}{|r|r|}
\hline 63.5 & 100.00 \\
\hline 50.8 & 100.00 \\
\hline 38.1
\end{tabular}

\begin{tabular}{|r|r|}
\hline 50.8 & 100.00 \\
\hline 38.1 & 99.72 \\
\hline 25.4 & 86.00 \\
\hline 19.1 & 23.55 \\
\hline 12.7 & 2.57 \\
\hline
\end{tabular}

\begin{tabular}{|r|r|}
\hline 12.7 & 2.57 \\
\hline 9.5 & 2.35 \\
\hline 6.4 & 2.17 \\
\hline
\end{tabular}

\begin{tabular}{|r|r|}
\hline 9.5 & 2.35 \\
\hline 6.4 & 2.17 \\
\hline 4.75 & 2.08 \\
\hline 3.35 & 2.01 \\
\hline
\end{tabular}

\begin{tabular}{|r|r|}
\hline 4.75 & 2.08 \\
\hline 3.35 & 2.01 \\
\hline 2.36 & 1.96 \\
\hline 1.70 & 1.91 \\
\hline
\end{tabular}

\begin{tabular}{|r|r|}
\hline 2.36 & 1.96 \\
\hline 1.70 & 1.91 \\
\hline 1.18 & 1.86 \\
\hline
\end{tabular}

\begin{tabular}{|r|r|}
\hline 1.18 & 1.86 \\
\hline 0.850 & 1.82 \\
\hline 0.600 & 1.76 \\
\hline
\end{tabular}

\begin{tabular}{|l|r|}
\hline 0.600 & 1.82 \\
\hline 0.425 & 1.76 \\
\hline 0.300 & 1.71 \\
\hline 0.212 & 1.64 \\
\hline 0.150 & 1.56 \\
\hline 0.106 & 1.49 \\
\hline 0.075 & 1.40 \\
\hline
\end{tabular}

C 26-2

\begin{tabular}{|r|r|}
\hline size (mm) & Cum \% Passing \\
\hline 300.0 & 100.00 \\
\hline 212.0 & 100.00 \\
\hline 175.0 & 100.00 \\
\hline 150.0 & 100.00 \\
\hline 125.0 & 100.00 \\
\hline 105.0 & 100.00 \\
\hline 90.0 & 100.00 \\
\hline 75.0 & 100.00 \\
\hline 63.5 & 100.00 \\
\hline 50.8 & 100.00 \\
\hline 38.1 & 100.00 \\
\hline 25.4 & 100.00 \\
\hline 19.1 & 100.00 \\
\hline 12.7 & 99.94 \\
\hline 9.5 & 91.25 \\
\hline 6.4 & 51.28 \\
\hline 4.75 & 26.07 \\
\hline 3.35 & 11.33 \\
\hline 2.36 & 3.15 \\
\hline 1.70 & 1.04 \\
\hline 1.18 & 0.74 \\
\hline 0.850 & 0.66 \\
\hline 0.600 & 0.60 \\
\hline 0.425 & 0.56 \\
\hline 0.300 & 0.52 \\
\hline 0.212 & 0.49 \\
\hline 0.150 & 0.46 \\
\hline 0.106 & 0.43 \\
\hline 0.075 & 0.41 \\
\hline & \\
\hline
\end{tabular}

C 20-2

\begin{tabular}{|r|r|}
\hline size $\mathbf{( m m}$ ) & Cum \% Passing \\
\hline 300.0 & 100.00 \\
\hline 212.0 & 100.00 \\
\hline 175.0 & 100.00 \\
\hline 150.0 & 100.00 \\
\hline 125.0 & 100.00 \\
\hline 105.0 & 100.00 \\
\hline 90.0 & 100.00 \\
\hline 75.0 & 100.00 \\
\hline 63.5 & 100.00 \\
\hline 50.8 & 100.00 \\
\hline 38.1 & 100.00 \\
\hline 25.4 & 100.00 \\
\hline 19.1 & 100.00 \\
\hline 12.7 & 100.00 \\
\hline 9.5 & 100.00 \\
\hline 6.4 & 99.58 \\
\hline 4.75 & 97.49 \\
\hline 3.35 & 89.05 \\
\hline 2.36 & 77.42 \\
\hline 1.70 & 64.83 \\
\hline 1.18 & 53.04 \\
\hline 0.850 & 44.58 \\
\hline 0.600 & 37.37 \\
\hline 0.425 & 32.00 \\
\hline 0.300 & 26.81 \\
\hline 0.212 & 22.86 \\
\hline 0.150 & 19.87 \\
\hline 0.106 & 17.32 \\
\hline 0.075 & 15.18 \\
\hline &
\end{tabular}

. 


\section{Tertiary Section - Audit 3}
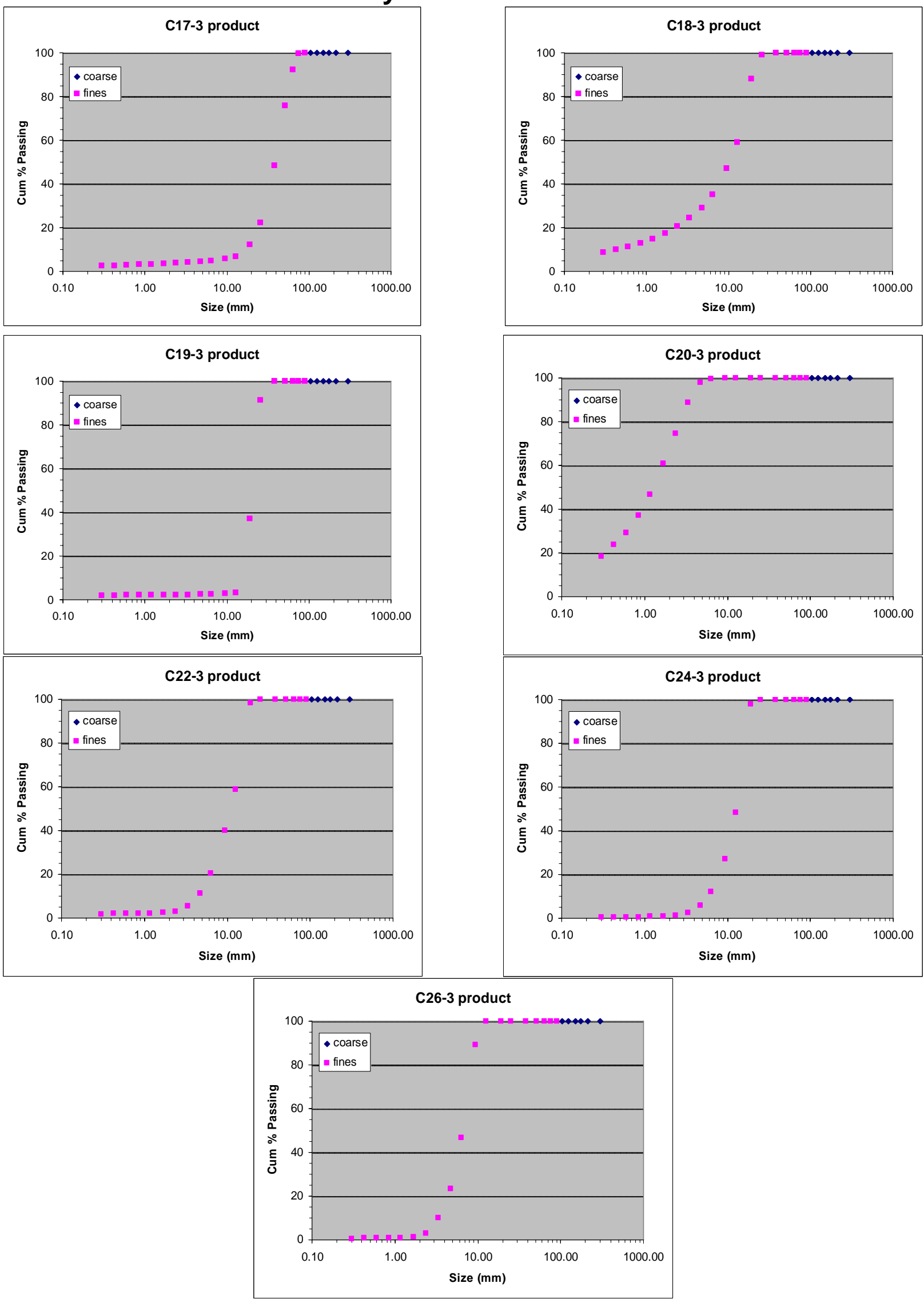
C 17-3

\begin{tabular}{|r|r|}
\hline size $\mathbf{( m m )}$ & Cum \% Passing \\
\hline 300.0 & 100.00 \\
\hline 212.0 & 100.00 \\
\hline 175.0 & 100.00 \\
\hline 150.0 & 100.00 \\
\hline 125.0 & 100.00 \\
\hline 105.0 & 100.00 \\
\hline 90.0 & 100.00 \\
\hline 75.0 & 99.70 \\
\hline 63.5 & 92.13 \\
\hline 50.8 & 75.66 \\
\hline 38.1 & 48.35 \\
\hline 25.4 & 22.20 \\
\hline 19.1 & 12.18 \\
\hline 12.7 & 6.65 \\
\hline 9.5 & 5.66 \\
\hline 6.4 & 4.77 \\
\hline 4.75 & 4.36 \\
\hline 3.35 & 4.06 \\
\hline 2.36 & 3.80 \\
\hline 1.70 & 3.58 \\
\hline 1.18 & 3.35 \\
\hline 0.850 & 3.15 \\
\hline 0.600 & 2.93 \\
\hline 0.425 & 2.74 \\
\hline 0.300 & 2.51 \\
\hline 0.212 & 2.29 \\
\hline 0.150 & 2.09 \\
\hline 0.106 & 1.89 \\
\hline 0.075 & 1.70 \\
\hline & \\
\hline
\end{tabular}

\section{22-3}

\begin{tabular}{|l|l|}
\hline size (mm) & Cum \% Passing \\
\hline
\end{tabular}

\begin{tabular}{|r|r|}
\hline 300.0 & 100.00 \\
\hline 212.0 & 100.00 \\
\hline 175.0 & 100.00 \\
\hline 150.0 & 100.00 \\
\hline 125.0 & 100.00 \\
\hline 105.0 & 100.00 \\
\hline 90.0 & 100.00 \\
\hline 75.0 & 100.00 \\
\hline 63.5 & 100.00 \\
\hline 50.8 & 100.00 \\
\hline 38.1 & 100.00 \\
\hline 25.4 & 100.00 \\
\hline 19.1 & 98.37 \\
\hline 12.7 & 58.54 \\
\hline 9.5 & 39.96 \\
\hline 6.4 & 20.35 \\
\hline 4.75 & 11.11 \\
\hline 3.35 & 5.54 \\
\hline 2.36 & 3.01 \\
\hline 1.70 & 2.33 \\
\hline 1.18 & 2.14 \\
\hline 0.850 & 2.05 \\
\hline 0.600 & 1.96 \\
\hline 0.425 & 1.88 \\
\hline 0.300 & 1.78 \\
\hline 0.212 & 1.68 \\
\hline 0.150 & 1.58 \\
\hline 0.106 & 1.46 \\
\hline 0.075 & 1.33 \\
\hline & \\
\hline
\end{tabular}

C 18-3

\begin{tabular}{|l|l|}
\hline size (mm) & Cum \% Passing \\
\hline
\end{tabular}

\begin{tabular}{|r|r|}
\hline 300.0 & 100.00 \\
\hline 212.0 & 100.00 \\
\hline 175.0 & 100.00 \\
\hline 150.0 & 100.00 \\
\hline 125.0 & 100.00 \\
\hline 105.0 & 100.00 \\
\hline 90.0 & 100.00 \\
\hline 75.0 & 100.00 \\
\hline 63.5 & 100.00 \\
\hline 50.8 & 100.00 \\
\hline 38.1 & 100.00 \\
\hline 25.4 & 99.03 \\
\hline 19.1 & 87.97 \\
\hline 12.7 & 59.16 \\
\hline 9.5 & 47.11 \\
\hline 6.4 & 35.05 \\
\hline 4.75 & 29.15 \\
\hline 3.35 & 24.59 \\
\hline 2.36 & 20.49 \\
\hline 1.70 & 17.39 \\
\hline 1.18 & 14.72 \\
\hline 0.850 & 12.80 \\
\hline 0.600 & 11.16 \\
\hline 0.425 & 9.99 \\
\hline 0.300 & 8.85 \\
\hline 0.212 & 7.98 \\
\hline 0.150 & 7.30 \\
\hline 0.106 & 6.69 \\
\hline 0.075 & 6.17 \\
\hline & \\
\hline
\end{tabular}

\section{24-3}

\begin{tabular}{|r|r|}
\hline size (mm) & Cum \% Passing \\
\hline 300.0 & 100.00 \\
\hline 212.0 & 100.00 \\
\hline 175.0 & 100.00 \\
\hline 150.0 & 100.00 \\
\hline 125.0 & 100.00 \\
\hline 105.0 & 100.00 \\
\hline 90.0 & 100.00 \\
\hline 75.0 & 100.00 \\
\hline 63.5 & 100.00 \\
\hline 50.8 & 100.00 \\
\hline 38.1 & 100.00 \\
\hline 25.4 & 100.00 \\
\hline 19.1 & 97.87 \\
\hline 12.7 & 48.19 \\
\hline 9.5 & 26.92 \\
\hline 6.4 & 11.89 \\
\hline 4.75 & 5.77 \\
\hline 3.35 & 2.54 \\
\hline 2.36 & 1.14 \\
\hline 1.70 & 0.77 \\
\hline 1.18 & 0.67 \\
\hline 0.850 & 0.62 \\
\hline 0.600 & 0.58 \\
\hline 0.425 & 0.54 \\
\hline 0.300 & 0.50 \\
\hline 0.212 & 0.46 \\
\hline 0.150 & 0.43 \\
\hline 0.106 & 0.39 \\
\hline 0.075 & 0.35 \\
\hline & \\
\hline &
\end{tabular}

C 19-3

\begin{tabular}{|l|l|}
\hline size (mm) Cum \% Passing \\
\hline
\end{tabular}

\begin{tabular}{|r|r|}
\hline 300.0 & 100.00 \\
\hline 212.0 & 100.00 \\
\hline 175.0 & 100.00 \\
\hline 150.0 & 100.00 \\
\hline 125.0 & 100.00 \\
\hline 105.0 & 100.00 \\
\hline 90.0 & 100.00 \\
\hline 75.0 & 100.00 \\
\hline 63.5 & 100.00 \\
\hline 50.8 & 100.00 \\
\hline 38.1 & 99.92 \\
\hline 25.4 & 91.37 \\
\hline 19.1 & 37.04 \\
\hline 12.7 & 3.15 \\
\hline 9.5 & 2.79 \\
\hline 6.4 & 2.55 \\
\hline 4.75 & 2.45 \\
\hline 3.35 & 2.39 \\
\hline 2.36 & 2.33 \\
\hline 1.70 & 2.28 \\
\hline 1.18 & 2.22 \\
\hline 0.850 & 2.17 \\
\hline 0.600 & 2.11 \\
\hline 0.425 & 2.04 \\
\hline 0.300 & 1.95 \\
\hline 0.212 & 1.85 \\
\hline 0.150 & 1.75 \\
\hline 0.106 & 1.64 \\
\hline 0.075 & 1.52 \\
\hline & \\
\hline
\end{tabular}

\section{26-3}

\begin{tabular}{|r|r|}
\hline size (mm) & Cum \% Passing \\
\hline 300.0 & 100.00 \\
\hline 212.0 & 100.00 \\
\hline 175.0 & 100.00 \\
\hline 150.0 & 100.00 \\
\hline 125.0 & 100.00 \\
\hline 105.0 & 100.00 \\
\hline 90.0 & 100.00 \\
\hline 75.0 & 100.00 \\
\hline 63.5 & 100.00 \\
\hline 50.8 & 100.00 \\
\hline 38.1 & 100.00 \\
\hline 25.4 & 100.00 \\
\hline 19.1 & 100.00 \\
\hline 12.7 & 99.88 \\
\hline 9.5 & 89.12 \\
\hline 6.4 & 46.61 \\
\hline 4.75 & 23.33 \\
\hline 3.35 & 9.97 \\
\hline 2.36 & 2.98 \\
\hline 1.70 & 1.11 \\
\hline 1.18 & 0.81 \\
\hline 0.850 & 0.74 \\
\hline 0.600 & 0.67 \\
\hline 0.425 & 0.63 \\
\hline 0.300 & 0.59 \\
\hline 0.212 & 0.56 \\
\hline 0.150 & 0.53 \\
\hline 0.106 & 0.51 \\
\hline 0.075 & 0.48 \\
\hline & \\
\hline
\end{tabular}

C 20-3

\begin{tabular}{|r|r|}
\hline size (mm) & Cum \% Passing \\
\hline 300.0 & 100.00 \\
\hline 212.0 & 100.00 \\
\hline 175.0 & 100.00 \\
\hline 150.0 & 100.00 \\
\hline 125.0 & 100.00 \\
\hline 105.0 & 100.00 \\
\hline 90.0 & 100.00 \\
\hline 75.0 & 100.00 \\
\hline 63.5 & 100.00 \\
\hline 50.8 & 100.00 \\
\hline 38.1 & 100.00 \\
\hline 25.4 & 100.00 \\
\hline 19.1 & 100.00 \\
\hline 12.7 & 100.00 \\
\hline 9.5 & 100.00 \\
\hline 6.4 & 99.70 \\
\hline 4.75 & 97.94 \\
\hline 3.35 & 88.79 \\
\hline 2.36 & 74.78 \\
\hline 1.70 & 60.74 \\
\hline 1.18 & 46.73 \\
\hline 0.850 & 37.07 \\
\hline 0.600 & 29.21 \\
\hline 0.425 & 23.56 \\
\hline 0.300 & 18.29 \\
\hline 0.212 & 14.28 \\
\hline 0.150 & 11.30 \\
\hline 0.106 & 8.70 \\
\hline 0.075 & 6.51 \\
\hline & \\
\hline &
\end{tabular}


Appendix IV

Blast Designs 


\section{Bealeton Blast Designs (Audit Blast and Proposed D1)}

\begin{tabular}{|c|c|c|}
\hline & $2904(14.8 \times 13.9 \mathrm{ft})$ & D1 $(10.5 \times 12.1 \mathrm{ft})$ \\
\hline Bench Height (m) & 11.6 & 11.6 \\
\hline Burden $(\mathrm{m})$ & 4.5 & 3.2 \\
\hline Spacing $(\mathrm{m})$ & 4.2 & 3.7 \\
\hline S/B Ratio (Equalateral = 1.15) & 0.93 & 1.15 \\
\hline Hole Diameter $(\mathrm{mm})$ & 165 & 165 \\
\hline Subdrill (m) & 0.9 & 0.6 \\
\hline Hole Length (m) & 12.5 & 12.2 \\
\hline Stemming Height (m) & 4.3 & 4.3 \\
\hline Staggered $(\mathrm{Y} / \mathrm{N})$ & $\mathrm{N}$ & $\mathrm{Y}$ \\
\hline Explosive (Bottom Deck) & HEET 30 & HEET 30 \\
\hline Explosive Length (m) & 6.4 & 3.0 \\
\hline Density $(\mathrm{kg} / \mathrm{m} 3)$ & 1220 & 1220 \\
\hline $\operatorname{VOD}(\mathrm{m} / \mathrm{s})$ & 4800 & 4800 \\
\hline RWS & 95 & 95 \\
\hline Explosive Weight (kg) & 167.0 & 78.3 \\
\hline Explosive (Top Deck) & ANFO & ANFO \\
\hline Explosive Length (m) & 1.8 & 4.9 \\
\hline Density $(\mathrm{kg} / \mathrm{m} 3)$ & 850 & 850 \\
\hline VOD $(\mathrm{m} / \mathrm{s})$ & 3962 & 3962 \\
\hline RWS & 100 & 100 \\
\hline Explosive Weight (kg) & 32.7 & 89.1 \\
\hline Total Explosive Weight (kg) & 199.7 & 167.3 \\
\hline Total Charge Length $(\mathrm{m})$ & 8.2 & 7.9 \\
\hline Powder Factor (kg/m3) & 0.91 & 1.22 \\
\hline Powder Factor (kg/t) & 0.31 & 0.41 \\
\hline Domain & Diabase & Diabase \\
\hline Rock Density (kg/m3) & 2970 & 2970 \\
\hline Youngs Modulus (GPa) & 67 & 67 \\
\hline UCS (MPa) & 245 & 245 \\
\hline Mean Insitu Block Size (m) & 0.4 & 0.4 \\
\hline Blast Model Size $(\mathrm{mm})$ & Cum \% Pass & Cum \% Pass \\
\hline 3000 & 100.0 & 100.0 \\
\hline 2000 & 100.0 & 100.0 \\
\hline 1500 & 100.0 & 100.0 \\
\hline 1000 & 99.5 & 100.0 \\
\hline 750 & 97.6 & 100.0 \\
\hline 500 & 89.3 & 98.5 \\
\hline 300 & 69.0 & 85.6 \\
\hline 200 & 50.4 & 65.2 \\
\hline 150 & 38.6 & 49.7 \\
\hline 100 & 28.6 & 32.9 \\
\hline 70 & 23.7 & 27.5 \\
\hline 40 & 17.5 & 20.4 \\
\hline 31.5 & 15.4 & 17.9 \\
\hline 19.0 & 11.5 & 13.5 \\
\hline 13.2 & 9.4 & 11.0 \\
\hline 9.5 & 7.7 & 9.1 \\
\hline 4.75 & 5.1 & 6.1 \\
\hline 3.35 & 4.2 & 4.9 \\
\hline 2.36 & 3.4 & 4.0 \\
\hline 1.70 & 2.8 & 3.3 \\
\hline 1.18 & 2.2 & 2.6 \\
\hline 20\% Passing Size (mm) & 50.9 & 38.4 \\
\hline $50 \%$ Passing Size $(\mathrm{mm})$ & 198.2 & 150.9 \\
\hline $80 \%$ Passing Size (mm) & 386.1 & 264.9 \\
\hline Top Size $(\mathrm{mm})$ & 1222.9 & 700.5 \\
\hline
\end{tabular}




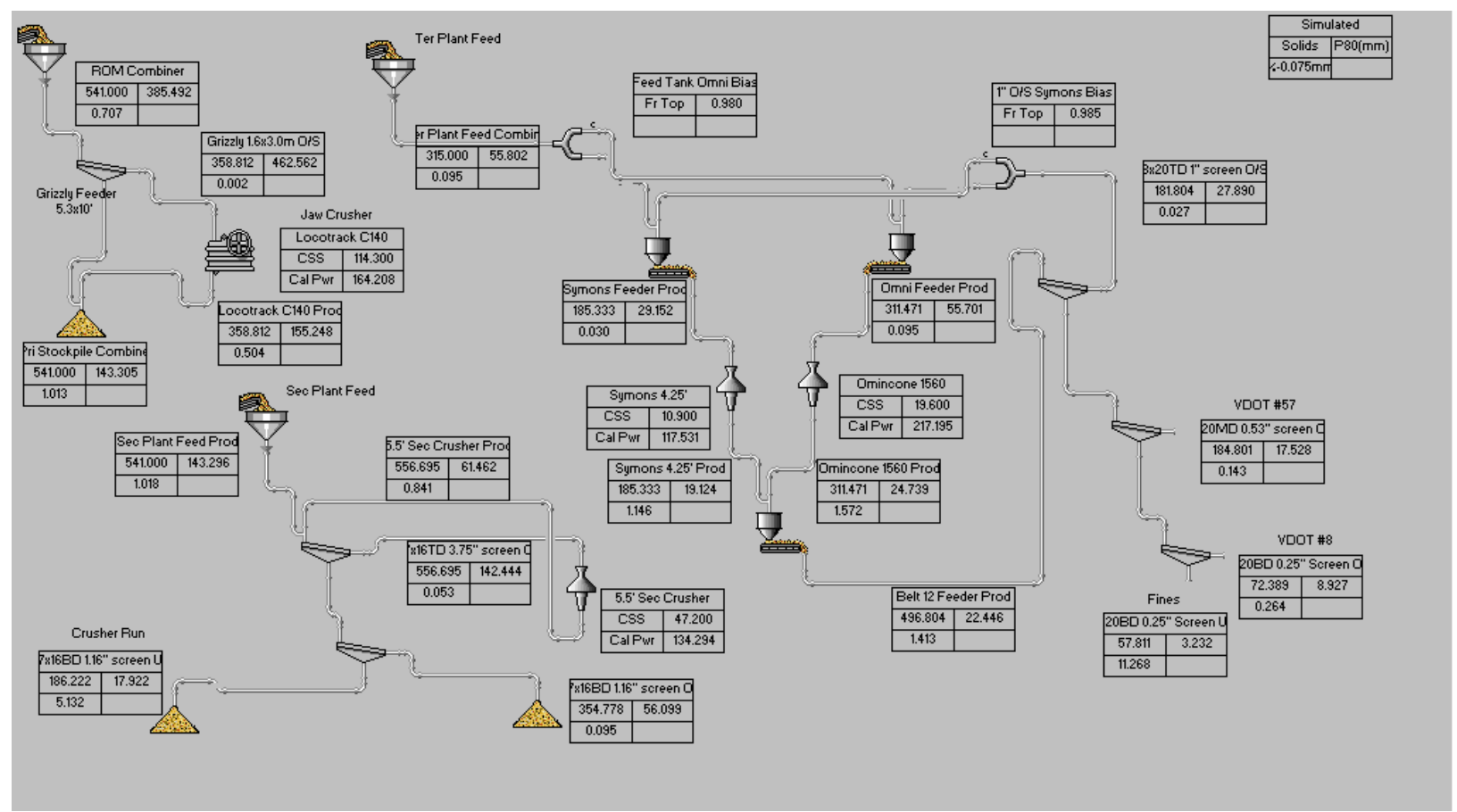

\section{Baseline Design}

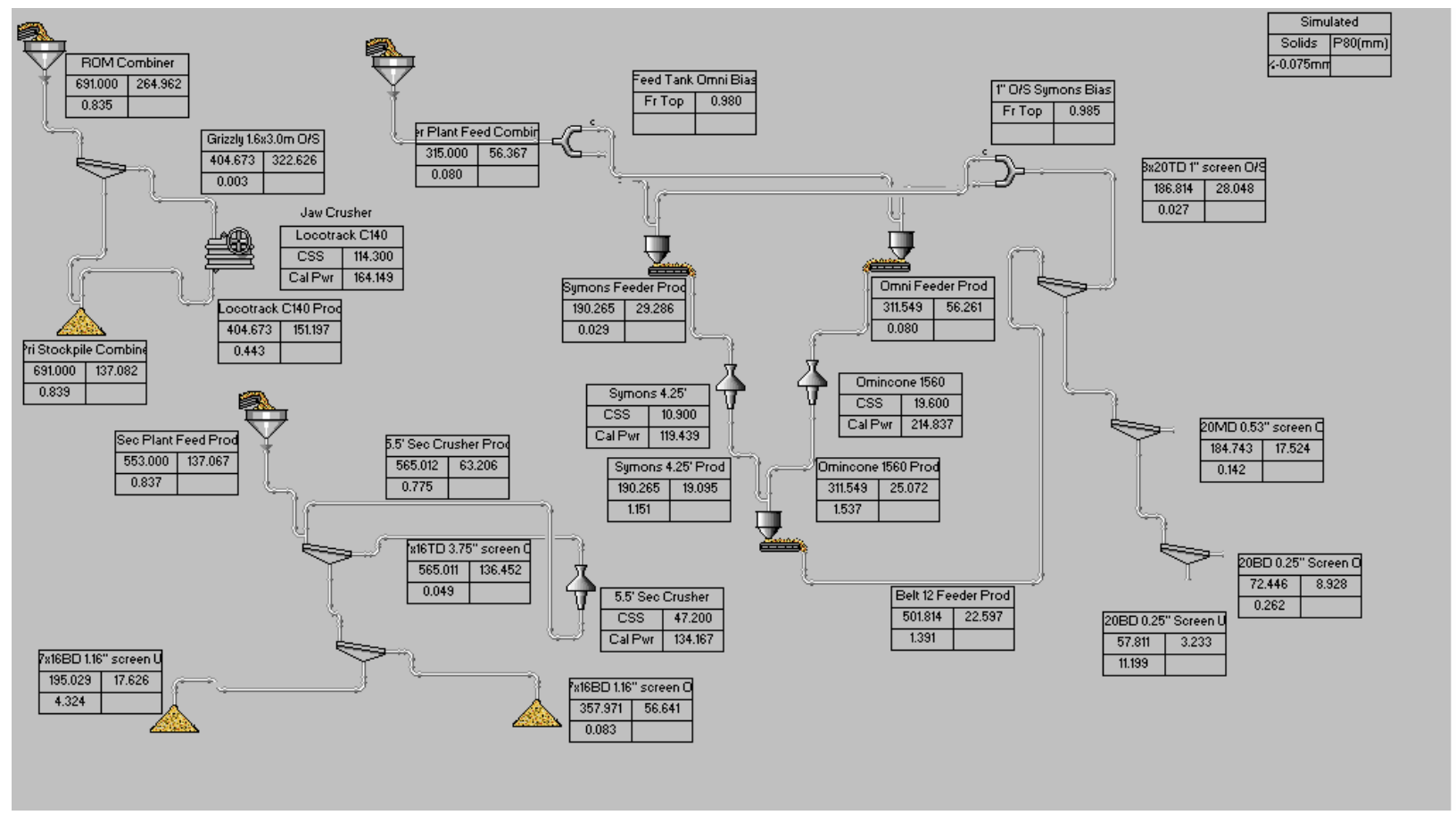

Design D1 
Bealeton Side-by-Side Blasts \{LS (0105) and MTM (0305)\}

\begin{tabular}{|c|c|c|}
\hline Blast No. & $0105(13.7 \times 13.5 \mathrm{ft})$ & $0305(10.5 \times 12.1 \mathrm{ft})$ \\
\hline Bench Height (m) & 11.0 & 11.3 \\
\hline Burden (m) & 4.2 & 3.2 \\
\hline Spacing (m) & 4.1 & 3.7 \\
\hline S/B Ratio (Equalateral = 1.15) & 0.99 & 1.15 \\
\hline Hole Diameter $(\mathrm{mm})$ & 165 & 165 \\
\hline Subdrill $(m)$ & 0.3 & 0.6 \\
\hline Hole Length (m) & 11.3 & 11.9 \\
\hline Stemming Height (m) & 4.3 & 4.3 \\
\hline Staggered $(Y / N)$ & $\mathrm{N}$ & $\mathrm{Y}$ \\
\hline Explosive (Bottom Deck) & HEET 30 & HEET 30 \\
\hline Explosive Length (m) & 2.7 & 5.8 \\
\hline Density $\left(\mathrm{kg} / \mathrm{m}^{3}\right)$ & 1220 & 1220 \\
\hline $\operatorname{VOD}(\mathrm{m} / \mathrm{s})$ & 4800 & 4800 \\
\hline RWS & 95 & 95 \\
\hline Explosive Weight (kg) & 70 & 151 \\
\hline Explosive (Top Deck) & ANFO & ANFO \\
\hline Explosive Length (m) & 4.3 & 1.8 \\
\hline Density (kg/m3) & 850 & 850 \\
\hline $\operatorname{VOD}(\mathrm{m} / \mathrm{s})$ & 3962 & 3962 \\
\hline RWS & 100 & 100 \\
\hline Explosive Weight (kg) & 78 & 33 \\
\hline Total Explosive Weight (kg) & 149 & 184 \\
\hline Total Charge Length (m) & 7.0 & 7.6 \\
\hline Powder Factor (kg/m3) & 0.78 & 1.38 \\
\hline Powder Factor (kg/t) & 0.26 & 0.47 \\
\hline Domain & Diabase & Diabase \\
\hline Rock Density (kg/m3) & 2970 & 2970 \\
\hline Young's Modulus (GPa) & 67 & 67 \\
\hline UCS (MPa) & 245 & 245 \\
\hline Mean Insitu Block Size (m) & 0.4 & 0.4 \\
\hline
\end{tabular}


Bealeton Side-by-Side Blasts (Simulated Size Distributions)

\begin{tabular}{|c|c|c|}
\hline Blast No. & $0105(13.7 \times 13.5 \mathrm{ft})$ & $0305(10.5 \times 12.1 \mathrm{ft})$ \\
\hline Blast Model Size (mm) & Cum \% Pass & Cum \% Pass \\
\hline 3000 & 100.0 & 100.0 \\
\hline 2000 & 100.0 & 100.0 \\
\hline 1500 & 99.9 & 100.0 \\
\hline 1000 & 98.6 & 100.0 \\
\hline 750 & 95.3 & 100.0 \\
\hline 500 & 85.0 & 98.9 \\
\hline 300 & 64.8 & 88.0 \\
\hline 200 & 47.8 & 68.8 \\
\hline 150 & 37.1 & 53.3 \\
\hline 100 & 26.3 & 36.1 \\
\hline 70 & 21.5 & 30.5 \\
\hline 40 & 15.5 & 23.2 \\
\hline 31.5 & 13.4 & 20.5 \\
\hline 19.0 & 9.9 & 15.7 \\
\hline 13.2 & 7.9 & 13.0 \\
\hline 9.5 & 6.4 & 10.8 \\
\hline 4.75 & 4.2 & 7.4 \\
\hline 3.35 & 3.3 & 6.1 \\
\hline 2.36 & 2.7 & 5.0 \\
\hline 1.70 & 2.2 & 4.1 \\
\hline 1.18 & 1.7 & 3.4 \\
\hline $20 \%$ Passing Size $(\mathrm{mm})$ & 61.8 & 30.0 \\
\hline $50 \%$ Passing Size $(\mathrm{mm})$ & 211.4 & 140.8 \\
\hline $80 \%$ Passing Size $(\mathrm{mm})$ & 434.3 & 248.8 \\
\hline Top Size $(\mathrm{mm})$ & 1508 & 666 \\
\hline
\end{tabular}

\section{Bealeton Side-by-Side Blasts (SPLIT Size Distributions)}

\begin{tabular}{|c|c|c|}
\hline Blast No. & $0105(13.7 \times 13.5 \mathrm{ft})$ & $0305(10.5 \times 12.1 \mathrm{ft})$ \\
\hline Blast Model Size $(\mathrm{mm})$ & Cum \% Pass & Cum \% Pass \\
\hline 3000 & 100.0 & 100.0 \\
\hline 2000 & 100.0 & 100.0 \\
\hline 1500 & 100.0 & 100.0 \\
\hline 1000 & 99.6 & 99.5 \\
\hline 750 & 93.1 & 95.8 \\
\hline 500 & 74.4 & 80.2 \\
\hline 300 & 52.1 & 58.6 \\
\hline 200 & 40.3 & 46.9 \\
\hline 150 & 34.5 & 40.6 \\
\hline 100 & 27.5 & 33.5 \\
\hline 70 & 22.3 & 28.2 \\
\hline 40 & 16.1 & 21.5 \\
\hline 31.5 & 14.1 & 19.2 \\
\hline 19.0 & 10.6 & 15.2 \\
\hline 13.2 & 8.7 & 13.0 \\
\hline 9.5 & 7.3 & 11.3 \\
\hline 4.75 & 5.2 & 8.6 \\
\hline 3.35 & 4.4 & 7.6 \\
\hline 2.36 & 3.8 & 6.7 \\
\hline 1.70 & 3.2 & 5.9 \\
\hline 1.18 & 2.7 & 5.2 \\
\hline $20 \%$ Passing Size $(\mathrm{mm})$ & 57.9 & 34.4 \\
\hline $50 \%$ Passing Size $(\mathrm{mm})$ & 280.1 & 223.6 \\
\hline $80 \%$ Passing Size $(\mathrm{mm})$ & 552.5 & 497.1 \\
\hline Top Size $(\mathrm{mm})$ & 1020 & 1350 \\
\hline
\end{tabular}




\section{Pittsboro Audit Blast Design}

\begin{tabular}{|c|c|}
\hline Blast No. & $8605(4.3 \times 3.8 \mathrm{~m})$ \\
\hline Bench Height (m) & 21.0 \\
\hline Burden (m) & 4.3 \\
\hline Spacing (m) & 3.8 \\
\hline S/B Ratio (Equilateral $=1.15$ ) & 0.89 \\
\hline Hole Diameter $(\mathrm{mm})$ & 165.1 \\
\hline Subdrill (m) & 1.0 \\
\hline Hole Length (m) & 22.1 \\
\hline Stemming Height (m) & 4.8 \\
\hline Staggered $(Y / N)$ & $\mathrm{N}$ \\
\hline Explosive (Bottom Deck) & Hydromite 4400 \\
\hline Explosive Length (m) & 17.3 \\
\hline Density $\left(\mathrm{kg} / \mathrm{m}^{3}\right)$ & 1220 \\
\hline $\operatorname{VOD}(\mathrm{m} / \mathrm{s})$ & 5500 \\
\hline RWS & 95 \\
\hline Explosive Weight (kg) & 452.2 \\
\hline Explosive (Top Deck) & ANFO \\
\hline Explosive Length (m) & 0.0 \\
\hline Density $\left(\mathrm{kg} / \mathrm{m}^{3}\right)$ & 850 \\
\hline $\operatorname{VOD}(\mathrm{m} / \mathrm{s})$ & 3962 \\
\hline RWS & 100 \\
\hline Explosive Weight (kg) & 0.0 \\
\hline Total Explosive Weight (kg) & 452.2 \\
\hline Total Charge Length (m) & 17.3 \\
\hline Powder Factor $\left(\mathrm{kg} / \mathrm{m}^{3}\right)$ & 1.31 \\
\hline Powder Factor (kg/t) & 0.45 \\
\hline Domain & Basalt \\
\hline Rock Density $\left(\mathrm{kg} / \mathrm{m}^{3}\right)$ & 2950 \\
\hline Young's Modulus (GPa) & 67 \\
\hline UCS (MPa) & 200 \\
\hline Mean Insitu Block Size (m) & 0.3 \\
\hline Blast Model Size (mm) & Cum \% Pass \\
\hline & 100.0 \\
\hline 2000 & $\frac{100.0}{090}$ \\
\hline$\frac{1500}{1000}$ & $\begin{array}{l}99.9 \\
99.6\end{array}$ \\
\hline 750 & 998.6 \\
\hline$\frac{500}{300}$ & $\begin{array}{l}95.3 \\
86.5\end{array}$ \\
\hline 200 & 76.1 \\
\hline 150 & 70.5 \\
\hline$\frac{100}{70}$ & 55.3 \\
\hline$\frac{70}{40}$ & $\frac{45.1}{33.8}$ \\
\hline 31.5 & 31.1 \\
\hline 19.0 & 24.3 \\
\hline 13.2 & 20.2 \\
\hline$\frac{9.5}{475}$ & $\frac{17.0}{110}$ \\
\hline$\frac{4.75}{3.35}$ & $\frac{11.8}{9.7}$ \\
\hline$\frac{3.35}{2.36}$ & $\frac{9.7}{8.0}$ \\
\hline 1.70 & $\frac{0.0}{6.7}$ \\
\hline 1.18 & 5.4 \\
\hline $20 \%$ Passing Size $(\mathrm{mm})$ & 12.9 \\
\hline $50 \%$ Passing Size $\mathrm{5mm}$ ) & $\frac{83.3}{230.5}$ \\
\hline $\begin{array}{l}80 \% \text { Passing Iize }(\mathrm{mm}) \\
\text { Top Size (mm) }\end{array}$ & $\frac{230.5}{1338.9}$ \\
\hline
\end{tabular}

